\title{
Generate and Repair Machine Translation
}

\author{
A THESIS \\ SUBMITTED TO THE FACULTY OF GRADUATE STUDIES AND RESEARCH \\ IN PARTIAL FULFILLMENT OF THE REQUIREMENTS \\ FOR THE DEGREE OF \\ DOCTOR OF PHILOSOPHY \\ IN \\ COMPUTER SCIENCE \\ UNIVERSITY OF REGINA
}

\begin{abstract}
By
Kanlaya Naruedomkul

Regina, Saskatchewan
\end{abstract}

April, 2000

(C) Copyright 2000: Kanlaya Naruedomkul 
National Library of Canada

Acquisitions and Bibliographic Services

395 Wellington Street OHtawa ON KIA ON4 Canada
Bibliothèque nationale du Canada

Acquisitions et services bibliographiques

395, rue Wellington

Ottawa ON K1A ON4

Canada
The author has granted a nonexclusive licence allowing the National Library of Canada to reproduce, loan, distribute or sell copies of this thesis in microform, paper or electronic formats.

The author retains ownership of the copyright in this thesis. Neither the thesis nor substantial extracts from it may be printed or otherwise reproduced without the author's permission.
L'auteur a accordé une licence non exclusive permettant à la Bibliothèque nationale du Canada de reproduire, prêter, distribuer ou vendre des copies de cette thèse sous la forme de microfiche/film, de reproduction sur papier ou sur format électronique.

L'auteur conserve la propriété du droit d'auteur qui protège cette thèse. $\mathrm{Ni}$ la thèse ni des extraits substantiels de celle-ci ne doivent être imprimés ou autrement reproduits sans son autorisation. 
To my parents, sisters, brothers, and my two lovely nephews 


\section{Abstract}

We propose Generate and Repair Machine Translation (GRMT), a constraint-based approach to machine translation (MT) that focuses on accurate translation output. The architecture of GRMT was designed to take advantage of, and have advantages over, the three classic strategies (Direct MT, Interlingual MT and Transfer MT), the nonlinguistic information strategies (Example-Based MT and Statistics-Based MT), and the hybrid strategies (Knowledge-Based MT and Shake-and-Bake MT) with respect to several translation aspects: simplicity, accuracy and multilingualism.

GRMT performs the translation by generating a Translation Candidate (TC), verifying the syntax and semantics of the TC, and repairing the TC when required. GRMT comprises three modules: Analysis Lite Machine Translation (ALMT), Translation Candidate Evaluation (TCE), and Repair and Iterate (RI).

In generating the TC, GRMT refines the scope of translation choices of each input word by taking into account the differences between languages in a unique way. In selecting an appropriate word for each input word, GRMT considers the semantic relationship between words. This semantic relationship is based on the Word Association (WordAsso) number. (WordAsso). WordAsso number is assigned to word class. Words are classified according to the meaning of words and their usage. Word classification is designed and used not only in the word selection process but also in the classifier selection process and in semantic representation.

GRMT is highly modular and extendible in the following respects: each component is separated, not only the translation process components (ALMT, TCE, RI), but also in the knowledge-bases, each component can be extended easily to a larger domain. The adding of new languages is also possible since the source language (SL) and the target language (TL) are treated separately. The SL and the TL are connected via the SL-TL dictionary which contains simple information and is manageable. 
An English-Thai translation system has been implemented to illustrate the performance of GRMT. The system has been developed and run under SWI-Prolog 3.2.8. The English and Thai grammars have been developed based on the Head-Driven Phrase Structure Grammar (HPSG) and implemented on the Attribute Logic Engine (ALE).

This English-Thai MT system was evaluated and it performs in the way we intended. ALMT generated acceptable translations (grammatically correct, correct word usage and convey the original meaning) for 47 out of the 90 sentences in the test corpus without repair. TCE and RI improved 15 sentences using our current HPSG based grammars and lexicons. Twenty-one sentences which contain logical connections are first separated into linguistic units before the repair can be performed due to a current inadequacy in HPSG's semantic representation. However, each linguistic unit was then repaired successfully. Seven sentences faced with the problems of adding linking words and classifiers in Thai also require further research in order to develop ways to repair these sentences. 


\section{Acknowledgments}

I would like to acknowledge the following people who, at different times, have helped me with this thesis. My deepest gratitude and appreciation goes to my advisor, Prof. Nick Cercone, who has given me a great deal of freedom to pursue ideas and research topics and who is always there when I need help and guidance. His unfailing support, his patience, his constructive criticism and his vast experience and invaluable advice have made the writing of this thesis possible and enjoyable.

I would like to thank Dr. Guy Lapalme, the external examiner, Dr. Brent Galloway, Dr. Howard Hamilton and Dr. Brien Maguire, the members of my thesis committee, for the remarkable feedback received during my viva. I also would like to thank Dr. Klaus $\mathrm{H}$. Burmeister for chairing the defense.

I am thankful to Dr. Booncharoen Sirinaovakul, whose thoughtful, inventive suggestions are woven into the fabric of this work, and to whom I am deeply grateful for countless conversations and generous sharing of ideas and for explaining complex HPSG ideas with clarity and enthusiasm.

I would like to thank Dr. Douglas Arnold, Dr. Gerald Gazdar, Dr. John Luis Beaven, Dr. Carl Pollard, and Dr. Fred Popowich, for providing me advice and the materials which are very helpful to my research, and Dr. Bob Carpenter and Dr. Gerald Penn for their help with my questions about ALE.

I would like to thank the Department of Computer Science, University of Waterloo for providing me with the office and computer resources, to the academic, administrative, computing and research staff in the Department of Computer Science and Graduate Studies at University of Regina for all the support they have given me, to Dr. Paitoon Tontiwachwuthikul and Dr. Christine Chan for making my first few days in Regina a very pleasant experience. 
My gratitude also goes to Assoc. Prof. Nardtida Tumrasvin and Assoc. Prof. Chinda Achariyakul, Department of Mathematics, Mahidol University, Prof. Amaret Bhumiratana, Doctor Kattaporn and Ms. Patrarawadee for supporting me to pursue my doctorate study in Computer Science in Canada. I am also thankful to Dr. Virach Sornlertlamvanich, Nisanard Tannin and Kaewchai Chancharoen for providing me with the information needed for the study.

It has been a privilege indeed to have worked with these people. Also, my stay in Canada, the beautiful country, would not have been as pleasant without these fine peopleUrsula Thoene, Chris Blair, Doreen Thiessen, Marnie Jeworski, Sel Murray, Dr. Brian Sveinson and Dr. Larry Saxton, I am grateful for their friendship and support.

I thank also my friends over the years, Weerapong Kritpiphat, Narate Lertpalangsunti, Amornvadee Veawab, Adisorn Aroonwilas, Teeradet Supap, Aijun An, Jessie Hou, Jianchao Han, Jian Jianna Zhang and Yingwei Wang.

I also would like to thank Margaret and Gordon, the Cooper family, for their kindness which will be forever remembered.

I also acknowledge the generous financial support I received while writing this dissertation, including The Royal Thai Government, Natural Sciences and Engineering Research Council (NSERC) and The Institute for Robotics and Intelligent Systems (IRIS).

I am thankful to the improvements in Computer Science and related fields which are very helpful to my research and thesis writing.

Lastly, I would like to express my thanks and appreciation to my parents Kiat and Somjit, my sisters Patcharee and Daranee, my brothers Taworn and Pornchai, and my nephews Sirawit and Potchara for their love and understanding. 


\section{Contents}

Abstract

Acknowledgements iii

Table of Contents $\quad$ v

List of Tables $\quad$ ix

List of Figures $\quad$ xi

List of Abbreviations and Acronyms xiv

Chapter 1 Introduction 1

I.1 Why Machine Translation I

1.2 Objectives 3

1.3 Outline of the thesis 4

Chapter 2 Machine Translation 6

2.1 What is Machine Translation? 6

2.2 A Brief History of Machine Translation $\quad 8$

2.3 Machine Translation Methodologies/Technologies 12

$\begin{array}{ll}\text { 2.3.1 Methodologies used to develop MT systems } & 12\end{array}$

$\begin{array}{ll}\text { 2.3.2 Techniques used to increase the performance of MT } & 14\end{array}$

2.3.2.1 Post-editing. Pre-editing and Interaction 14

2.3.2.2 Lexicon constructions and parsing techniques 17

$\begin{array}{ll}\text { 2.3.3 Discussion of some existing MT methodologies } & 18\end{array}$ 
CONTENTS

2.3.3.1 Three Classic Strategies 18

2.3.3.2 Nonlinguistic Information Strategies 23

2.3.3.3 Hybrid Strategies 25

2.4 Our approach : Generate and Repair Machine Translation 28

Chàpter 3 Generate and Repair Machine Translation 30

3.1 Why Generate and Repair, Not Analyze and Generate? 32

3.2 The Three Phases 35

3.3 Knowledge-bases Required 36

3.4 Translation Examples by GRMT 36

3.5 Key Features of GRMT 39

Chapter 4 Differences Between Languages: $\quad 41$ The English and Thai Languages

4.1 Differences between Thai and English 41

4.2 Word Classification 46

4.2.1 Word Classification Criteria $\quad 52$

4.2.2 The semantic relationship development in GRMT 56

Chapter 5 Analysis Lite Machine Translation 58

5.1 Word Treatment 59

5.1.1 SL Constraints Application $\quad 59$

$\begin{array}{ll}5.1 .2 & \text { Dictionary Look-up }\end{array}$

5.1.3 Dictionaries $\quad 62$

5.2 Word Selection $\quad 63$

$\begin{array}{lll}5.3 \text { Word Ordering } & 71\end{array}$

$\begin{array}{lll}5.3 .1 & \text { Word Addition } & 71\end{array}$

$\begin{array}{ll}\text { 5.3.2 Word Ordering } & 73\end{array}$

$\begin{array}{ll}5.4 \text { Example of ALMT } & 75\end{array}$ 
CONTENTS

Chapter 6 Translation Candidate Evaluation $\quad 80$

6.1 The Analyzer 81

6.1.1 Parsing 81

6.1.1.1 About Head-Driven Phrase Structure Grammar 81

6.1.1.2 Words and Phrases as Feature Structures 82

6.1.1.3 Lexicon 85

6.1.1.4 Some Universal Principle and Grammar Rules $\quad 87$

6.1.1.5 Attribute Logic Engine 92

6.1.1.6 English and Thai Grammars in GRMT 94

$\begin{array}{lll}6.1 .2 & \text { Semantic Extraction } & 104\end{array}$

6.1.2.1 Semantic Representation 104

6.1.2.2 Semantic Extraction Examples 106

$\begin{array}{ll}6.2 \text { Semantic Comparison } & 109\end{array}$

Chapter 7 Repair and Iteration $\quad 116$

Chapter 8 Machine Translation Evaluation $\quad 125$

8. I What needs to be evaluated? (Types of Evaluation) 126

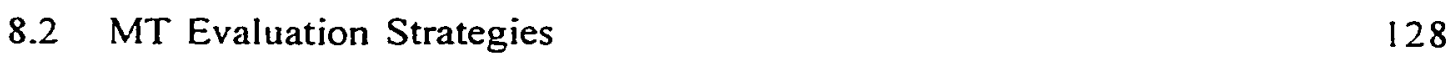

$\begin{array}{lr}\text { 8.2.1 Error Analysis } & 129\end{array}$

$\begin{array}{lll}\text { 8.2.2 Test Suite } & 129\end{array}$

8.2.3 The ARPA MT Evaluation 131

$\begin{array}{lll}\text { 8.3 GRMT Evaluation } & 132\end{array}$

Chapter 9 Discussion $\quad 142$

9.1 Contributions 142

$\begin{array}{lll}9.2 & \text { Future Research } & 145\end{array}$

$\begin{array}{ll}\text { Bibliography } & 147\end{array}$ 
CONTENTS

Appendices

$\begin{array}{ll}\text { A WordAsso hierarchy } & 161\end{array}$

B SL Dictionary $\quad 185$

$\begin{array}{ll}\text { C SL-TL Dictionary } & 190\end{array}$

D Types, their features and their value types 195

E Lexical Rules 198

$\begin{array}{ll}\text { F Grammars } & 201\end{array}$

G Intelligibility and Fidelity Evaluation 205

$\begin{array}{ll}\text { H Comprehensibility Evaluation } & 225\end{array}$ 


\section{List of Tables}

2.1 Translation examples by the commercial MT system 22

3.1 The TC and selected words generated for Example 1 34

3.2 The selected words and the TC generated for Example 2 37

3.3 Three corresponding Thai words to the word spring 38

3.4 The selected words and the TC generated for Example $3 \quad 38$

4.1 Descriptions and the English corresponding words of 42 Aน (khon), เขา (khaw) and ที่ (thîi)

4.2 The additional words that express Tense, Passive Voice and 43 Plurality in Thai

4.3 Some information on the words นายแพทย์, สุนทร, ปลอก and ปากกา 49

4.4 Semantic relationships assigned for noun-noun combination 49 in CICC MMT

4.5 The subgroup of vehicle 54

4.6 Some classified English and Thai words 55

4.7 Examples of words and their contexts 56

$\begin{array}{lll}4.8 & \text { Classes and their sample words } & 57\end{array}$

5.1 Some SL Constraints $\quad 59$

5.2 Example result of Dictionary Look-up of Example 3

$\begin{array}{lll}5.3 & \text { The possible corresponding Thai words for } & 69\end{array}$ spirit, willing, flesh and weak

$\begin{array}{lll}5.4 & \text { The possible corresponding Thai words for } & 70\end{array}$ left, duckling and marsh

5.5 A fraction of classifier classes $\quad 72$

5.6 The selected words in Thai for the words woman, cat and hen 73 
5.7 ALMT steps applied to the sentence of Example 11

$\begin{array}{lll}5.8 & \text { ALMT steps applied to the sentence of Example } 12 & 78\end{array}$

6.1 Some types, their features and their value types 84

6.2 Features and their value types of the types noun and verb 86

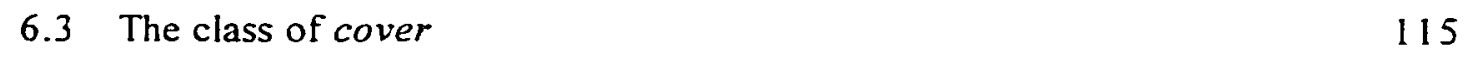

7.1 A part of Word Treatment output of Example 1 119

$\begin{array}{lll}7.2 & \text { A part of Word Treatment output of Example 2 } & 123\end{array}$

8.1 The intelligibility and fidelity evaluation result of 136 evaluating ALMT on the 90 sentences test corpus

$\begin{array}{ll}\text { 8.2 The comprehensible evaluation result } & 136\end{array}$

9.1 Advantages and disadvantages of the existing MT approaches 143 


\section{List of Figures}

2.1 Direct MT 18

2.2 Some translations of the word open 19

$\begin{array}{ll}2.3 \text { Interlingual MT } & 20\end{array}$

$\begin{array}{lll}2.4 & \text { Transfer } \mathrm{MT} & 21\end{array}$

2.5 Example based MT 24

3.1 GRMT Architecture 30

3.2 The translation between languages of two language 40 families

4.1 Examples of nิน (kin) and its subjects 43

4.2 Examples of additional words to indicate different tenses and aspects

4.3 Examples of passive voice in Thai 44

4.4 Examples of classifiers 45

4.5 Examples of Thai attributive constructions 45

4.6 Examples of Thai constructions without auxiliary verb 46

4.7 A part of Thai Concept Classification (CICC MMT) 47

4.8 A part of Indonesian Concept Classification (CICC MMT) 48

4.9 A co-occurrence of the word เพราะ (phrd') [CICC 1995i] 49

4.10 A partition type hierarchy for thing [Cercone et al. 1992] 51

4.11 A part of word classification in GRMT 53

$\begin{array}{lll}5.1 & \text { ALMT Architecture } & 58\end{array}$

$\begin{array}{lll}5.2 & \text { SL constraints applications examples } & 60\end{array}$

$\begin{array}{lll}5.3 & \text { Example of SL Dictionary } & 62\end{array}$

5.4 Example of SL-TL Dictionary $\quad 62$ 
5.5 The relationship between the proximity words -Examples 4 and $5 \quad 63$

5.6. Examples of WordAsso relations 64

$\begin{array}{lll}5.7 & \text { Example of selection steps } & 67\end{array}$

$\begin{array}{lll}5.8 & \text { Examples of WordAsso relations } & 69\end{array}$

5.9 Examples of classifier relations $\quad 72$

5.10 Word orders of จอห์น กิน ข้าว ทุก วัน 74

5.11 Word orders of ลูกเป็ด ขี้เหร่ ตัว นั้น ได้ช่อน หัว ของเขา ใด้ ปก ของเขา 75

5.12 A part of "The ugly duckling" and its translation 79

$\begin{array}{ll}6.1 \text { TCE Architecture } & \mathbf{8 0}\end{array}$

$\begin{array}{ll}6.2 & \text { The lexical entry hide } \\ 6.3 & 83\end{array}$

\begin{tabular}{lr}
6.3 & The phrase Leslie drinks milk \\
\hline
\end{tabular}

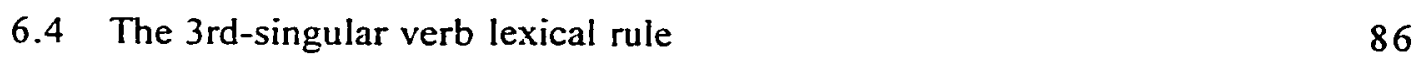

6.5 Example output, hides, of the 3rd-singular verb lexical rule 87

6.6 HFP applied to Leslie drinks milk 88

6.7 Semantic principle applied to Leslie drinks milk 90

6.8 Head_complement rule applied to likes John 91

6.9 Specifier_head rule applied to the book 92

6.10 Example of result of parsing in ALE representation 94

6.11 The lexical entry for hide 98

6.12 The representation of hide in ALE with some macros 99

6.13 The parse syntax of Example $I$ and that of its translation 100

6.14 The representation of under in ALE with some macros 101

$\begin{array}{ll}\text { 6.15 The representation of ขี้เหร (khîrèe- ugly) in ALE } & 101\end{array}$ with some macros

6.16 The representation of the classifier ตัว (tua) in ALE 102

6.17 The parse syntax of Example 2 and that of its translation 103

6.18 The partial description of the lexical entry the 104

6.19 The partial description of the lexical entry Joan 105

$\begin{array}{ll}\text { 6.20 The semantic information, in ALE's internal structure, } & 107\end{array}$ of the SL in Example 3

6.21 The semantic information of the SL in Example $3 \quad 107$ 
6.22 The semantic information, in ALE's internal structure, of the TC in Example 3

6.23 The semantic information of the TC in Example $3 \quad 108$

6.24 The semantic information of the SL in Example 1

6.25 The semantic information of the TC in Example $1 \quad 110$

6.26 The semantic information of the parse of the SL in Example 1

6.27 The semantic information of the parse of the TC in Example $1 \quad 112$

6.28 The CONT value of the SL parse of Example $4 \quad 114$

6.29 The CONT value of the TC parse of Example $4 \quad 114$

$\begin{array}{lll}7.1 & \text { RI Architecture } & 116\end{array}$

7.2 The QSTORE values of the SL and the TC parses of Example $1 \quad 118$

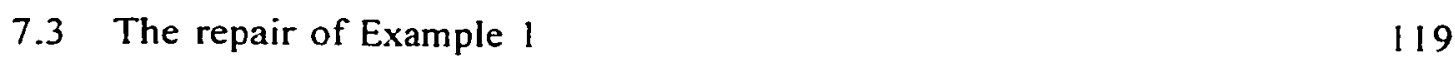

$\begin{array}{ll}7.4 & \text { The semantic information of the SL and that of } \\ & 120\end{array}$ the repaired TC in Example 1

7.5 The TC parse of Example 2

$\begin{array}{ll}7.6 \text { CONT value of the SL parse } & 122\end{array}$

$\begin{array}{lll}7.7 & \text { The repair of Example 2 } & 123\end{array}$

$\begin{array}{lll}\text { 7.8 The semantic information of the SL and that of } & 124\end{array}$ the repaired TC in Example 2

8.1 A fraction of test suites [Arnold et al. 1994] 130

$\begin{array}{ll}\text { 8.2 Examples of intelligibility and fidelity evaluation } & 135\end{array}$

$\begin{array}{ll}\text { 8.3 Examples of comprehensibility evaluation } & 137\end{array}$

8.4 Example sentences 6,10,21 and $22 \quad 138$

$\begin{array}{ll}8.5 \text { A fragment of sentence 55 } & 139\end{array}$

8.6 Example sentences 26,39 and $90 \quad 141$ 


\section{List of Abbreviations and Acronyms}

Al

ALE

ALMT

ALPAC

ALPS

ATR-ITL

AVM

BYU

CAT

CEC

CG

$\mathrm{CICC}$

CKY

CLRU

CT

DBMT

EBMT

GPSG

GRMT

HAMT

HFP

HPSG

ISI
Artificial Intelligence

Attribute Logic Engine

Analysis Lite Machine Translation

Automatic Language Processing Advisory Committee

Automated Language Processing Systems

Advanced Telecommunications Research, Interpreting Telecommunication Research Laboratories

Attribute-Value Matrices

Brigham Young University

Computer-Aided Translation

The Commission of the European Communities

Categorial Grammar

Center of the International Cooperation for Computerization

Cocke-Kasami-Younger

The Cambridge Language Research Unit

Correct Translation

Dialogue-based MT

Example-Based Machine Translation

Generalized Phrase Structure Grammar

Generate and Repair Machine Translation

Human-Aided Machine Translation

Head Feature Principle

Head-Driven Phrase Structure Grammar

University of Southern California's Information Sciences Institute 
ITS

KBMT

LFG

MAHT

MAT

MCE

MIT

MMT

MT

NLP

PAHO

RI

SAM

SL

TAUM

TC

TCE

TL

TSNLP

WordAsso
Interactive Translation System

Knowledge-Based Machine Translation

Lexical Functional Grammar

Machine-Aided Human Translation

Machine-Aided Translation

Multinational Customised English

The Massachusetts Institute of Technology

Multilingual Machine Translation

Machine Translation

Natural Language Processing

Pan American Health Organization

Repair and Iterate

Script Applying Mechanism

Source Language

Traduction Automatique de l'Université de Montréal

Translation Candidate

Translation Candidate Evaluation

Target Language

Test Suites for Natural Language Processing

Word Association (Number) 


\section{Chapter 1}

\section{Introduction}

Translation, from one language into another, presents subtle, important, ancient, and difficult problems.

- Warren Weaver (1955)

A primary objective of this research is to uncover and deploy new solutions that apply when developing an efficient machine translation (MT) system. We propose an alternative constraint-based approach to machine translation that focuses on accurate translation output. We call this approach Generate and Repair Machine Translation (GRMT) and we have implemented an advanced GRMT prototype for demonstration and evaluation purposes to translate English into Thai.

Successful results from this research should prove beneficial to machine translation studies currently underway around the world. GRMT's application should minimize the language barrier and simplify communication between peoples who speak different languages.

\subsection{Why Machine Translation?}

Country to country exchanges in trade, technologies, politics, telecommunications, culture, etc., continue to grow rapidly. Language plays a significant role in the communication processes between nations. To understand what is communicated, it is necessary to understand the language used in the communications process, its nuances and subtleties, hence, accurate machine translation assumes importance in order to facilitate this communications process from one language into another. When exchanges become more 
globalized, the requirement for accurate machine translation increases. In multilingual countries like Canada (French-English), Switzerland (German, Italian, French, Swiss), India (32 official languages), the need for translation exists apart from increasingly globalized communications.

In countries where multiple official languages are used, translation is necessary to communicate with others who speak different languages. Translation enables people to express themselves in the way in which they wish to express themselves and to obtain the type of information they desire. Choice of language for communicative and other aspects is important in order for people to retain and enhance distinctive cultures and distinctive ways of thinking; language loss should matter to everyone.

The advance in computer technologies and the explosive growth of the World Wide Web has brought people closer together. Multilingual text has reached nearly to everyone with a computer. Information is readily accessible in growing numbers of languages. Machine translation has been integrated into man-machine communication systems which include electronic mail, information retrieval and the internet. The demand for machine translation systems has, therefore, not surprisingly, increased.

It would appear that successful machine translation efforts become a social and political necessity for modern societies (intelligent communities) that do not wish to impose a common language on their constituents. Past efforts at standardization, e.g., Esperanto, have not been successful.

For over a half century, MT research has drawn attention from people in different fields: cognitive psychology, linguistics, philosophy, cultural studies, computer science, computational linguistics. Several paradigms have developed. However, they still need improvement. No current operational MT systems can produce good quality output without either placing restrictions on input texts or involving human assistance before, during or after the translation processes. MT Research continues unabated, focused primarily on producing translations of greater accuracy.

It was for these reasons that we decided to discover a new approach to develop a machine translation system, an approach that can generate a reliable and accurate translation. 


\subsection{Objectives}

Our goal is to find a new approach to MT which generates accurate translations. simplifies the design and the implementation of MT systems, and encourages others to adopt our approach as a usable tool.

In this thesis we describe the design of the approach we propose, GRMT. GRMT performs the translation process as follows: generate Translation Candidate (TC), verify the syntax and semantics of the TC and repair the TC when required. The tasks involved in generating the TC for the source language (SL) include:

- developing a set of constraints which are specific to resolve the syntactic differences between the source and the target languages.

- developing a SL dictionary to be used together with a set of constraints to refine the scope of the translation choices.

- developing the SL-target language (TL) dictionary to be used in relating SL and TL.

- classifying words into appropriate categories.

- developing a semantic relationship between words based on word classification to be used in selecting an appropriate translation for each input word.

- developing a set of constraints which are specific enough to resolve the syntactic differences between the target and the source languages to be used in completing the structure of the TC.

- developing the ordering rule. This rule is based on the syntactic structure differences between the SL and TL.

Tasks involved in verifying the TC requires development of the SL and TL grammars and lexicons. The grammars are used to analyze the SL and the TC to determine the accuracy of the TC. The grammars are developed based on a well-known grammar formalism, HeadDriven Phrase Structure Grammar (HPSG), since it is an integrated theory of natural language syntax and semantics. Implementation on the Attribute Logic Engine version 3.2 Beta (ALE) provides a mechanism which was designed to facilitate the use of HPSG grammar. The repair process is called upon when necessary to improve the quality of the TC.

Our English-Thai translation system is developed and implemented based on GRMT, in order to investigate the feasibility of GRMT. 
GRMT is evaluated using our English-Thai translation system to examine whether the system performs in the way intended, whether the translation is acceptable and whether the system is extendable.

\subsection{Outline of the thesis}

In chapter 2, an introduction to MT including a brief history of MT and a discussion of the methodologies used in developing MT system is provided. Following this introduction we present the idea behind Generate and Repair Machine Translation.

Chapter 3 begins with a description of the architectural design of the GRMT system, the motivation of the design, similarities and dissimilarities between GRMT and other approaches, the knowledge-bases required in GRMT, advantages of GRMT, GRMT and multilingual $\mathrm{MT}$.

We examine, in chapter 4 , the difference between source language and target language, which are English and Thai respectively in this study, and in particular, on the aspects which will concern us in this work. The rest of this chapter addresses the word classification criteria. Of course, the notion of word classes is as old as the study of language itself. However, word classification has not been, in general, exploited fully in MT applications when the criteria used in classifying words includes both the meaning of the words and their usage. In addition, words in different languages are classified under the "same umbrella" even though there are differences at some levels between different languages. Finally the word association number, which plays a crucial role in GRMT, is introduced; the development of semantic relationship between words based on word classification and its usage are discussed.

Analysis Lite Machine Translation, the first phase of GRMT which generates the translation candidate for GRMT, is presented in chapter 5. Each component of ALMT is described in detail. The chapter includes some TC examples generated by ALMT.

Chapter 6 depicts the architecture of Translation Candidate Evaluation (TCE), the second phase of GRMT. After a brief description of HPSG and ALE we proceed to describe the English and Thai grammars we developed based on HPSG. The idea of how TCE extracts the semantic information from the source language input and the TC and how TCE determines the similarity between them are discussed.

Chapter 7 examines how Repair and Iteration, the last phase of GRMT, improves the quality of the translation candidate. 
In Chapter 8, we describe the evaluations carried out on intelligibility, fidelity and comprehensibility of the translations for the English-Thai MT system.

Chapter 9 summarizes our contribution and concludes with some remarks about some efficiency considerations and possible improvements to GRMT.

Appendices are provided to illustrate SL Dictionary, SL-TL Dictionary, WordAsso hierarchy, Types, their features and their value types, Lexical Rules, Grammars, Intelligibility and Fidelity Evaluation and Comprehensibility Evaluation. 


\title{
Chapter 2
}

\section{Machine Translation}

\author{
When I look at an article in Russian, I say \\ "This is really written in English. \\ but it has been coded in some strange symbols. \\ I will now proceed to decode it." \\ - Warren Weaver (1949)
}

\subsection{What is Machine Translation?}

Machine translation can be categorized under the more general heading of automatic natural language processing. MT is described in several ways as follows:

- MT is the application of computers to the translation of texts from one natural language into another [Hutchins 1986].

- MT is the transfer of meaning from one natural (human) language to another with the aid of a computer [Goshawke et al. 1987].

- Systems which perform a syntactic analysis of a source text and then generate a target language rendering thereof which seeks to preserve and reconstitute its semantic and stylistic elements are described as machine translation systems [Newton 1992].

- MT is the name for computerized systems responsible for the production of translations from one natural language into another, with or without human assistance [Hutchins and Somers 1992].

- MT is the translation of texts by means of computer [Rosetta 1994]. 
- $\mathrm{MT}$ is to automate all, or part of the process of translating from one human language to another [Amold et al. 1994].

All descriptions, however, promote machine translation as an attempt to translate from one language into another (or others in the case of multilingual systems) with the aid of a computer.

The term MT usually refers to fully automatic machine translation. In the case where a computer "collaborates" with a human translator to some degree during the translation process, the system is then referred to as Machine-Aided Translation (MAT) or ComputerAided Translation (CAT). We can further classify MAT into two categories as follows:

- Machine-Aided Human Translation (MAHT): The human performs the translation process with the assistance of a machine, e.g., consulting an on-line/automatic dictionary or terminological database, using multilingual word processors.

- Human-Aided Machine Translation (HAMT): The machine performs the translation process and consults a human user at many stages to complete the process, e.g., asking a user to make a choice in case of lexical ambiguity.

The major task of any MT system is to map the source language text onto an appropriate target language text that conveys the meaning of the original text. Therefore, the MT task includes language understanding and language generation tasks. In order to perform these tasks, MT efforts require linguistic and non-linguistic knowledge.

Required linguistic knowledge includes:

- Morphological knowledge- To provide the properties and meaning of an individual word.

- Syntactic knowledge- To recognize and form the structural relationship between words.

- Semantic and world knowledge- To understand and form the relations between the entities and events designated by words.

- Pragmatic and stylistic knowledge- To understand and form relations between the structure of texts and their communicative functions and also the idiomatic usage of the languages. 
Required non-linguistic knowledge includes:

- Real world knowledge- Knowledge about the subject matter of a text, including general knowledge and common sense knowledge.

- Culture/social knowledge- The cultural and social context of a given text.

\subsection{A Brief History of Machine Translation}

The idea of using a machine in translation began in 1933, before the invention of the computer, and it remains a primary motivating problem for computational linguistics. Details of the MT history can be found in many books e.g., [Locke and Booth. 1955], [Hutchins 1986], [Slocum 1988], [Nirenburg et al. 1992], [Hutchins and Somers 1992], [Arnolds 1994]. Some pivotal earlier events are summarized as follows:

1933

1946

1948
George Artsruni (a French engineer, Armenian by birth) was issued a certificate patent for a translation machine which was called a Mechanical Brain by its inventor. [Henisz-Dostert et al. 1979].

P. P. Trojanskij ${ }^{\prime}$, in the USSR, envisaged the three stages (see section 2.3.1) of mechanical translation [Henisz-Dostert et al. 1979]. He was issued a patent for a Machine for selection and printing of words while translating from one language into another or into several others simultaneously [Hutchins 1986].

Warren Weaver (Vice-President for the Natural and Medical Sciences, Rockefeller Foundation) and Andrew D. Booth (a British Crystallographer) discussed the possibility of using computers for translation. This is the first discussion on MT [Henisz-Dostert et al. 1979].

Weaver brought the idea of MT to general notice and suggested some techniques to be used in developing MT systems. [Henisz-Dostert et al. 1979].

Andrew D. Booth and R. H. Ritchens implemented a word-by-word Frenchto-Spanish dictionary translation program.

'The name is spelled Petr Petrovich Smirnov-Troyanskii according to Hutchins 1986 and P. P. (Smirnov-) Troyansky according to Bar-Hillel, 1964. 

reprinted].

This memorandum drew the interest of researchers all over the United States. It is considered the starting point for research in MT.

$1949-1952$

1952

$1955-1960$

The studies on MT started at a number of research institutions, universities and industries in the United States, e.g., University of Washington in Seattle, University of California at Los Angeles, The Massachusetts Institute of Technology (MIT) and The RAND Corporation in Santa Monica.

Yehoshua Bar-Hillel organized the first MT conference at the Research Laboratory of Electronics- MIT, outlining future research in MT.

Leon Dostert at Georgetown University collaborated with IBM on the Russian-English MT project and demonstrated their MT system to public. It is regarded as "the first generation of MT".

The journal of Mechanical Translation was founded. It was edited and published by William N. Locke and Victor Yngve at MIT.

MT projects initiated elsewhere in the world, e.g., Cambridge Language Research Unit in the United Kingdom, University of Milan in Italy, Charles University in Czechoslovakia, Institute of Precision Mechanics and Computer Technology in the Soviet Unions and Kyoto University in Japan [Hutchins 1986].

1959

Yehoshua Bar-Hillel published his critique of contemporary MT research. He concluded [Bar-Hillel 1964]:

- The fully automatic, high quality translation was not really attainable in the near future so that a less ambitious aim is definitely indicated.

- The empirical approach ${ }^{2}$ seemed somewhat wasteful in practice and not sufficiently justified in theory.

\footnotetext{
${ }^{2}$ The empirical approach emphasized the need to base procedures on actual linguistic data. It was distrustful of existing grammars and dictionaries. The approach stressed statistical and distributional analyzes of texts [Hutchins 1986].
} 
The government sponsors of MT in the United States formed the Automatic Language Processing Advisory Committee (ALPAC) to provide directed technical assistance as well as to contribute independent observations in mechanical translation. [ALPAC 1966].

The ALPAC report concluded that MT was slower, less accurate and twice as expensive as human translation. The report also stated that "There is no immediate or predictable prospect of useful MT". This report brought a virtual end to MT research in the USA and damaged the public perception of MT for many years afterward [Hutchin and Somers 1992].

MT research initiated in Canada.

In Middletown, New York, Charles Byme and Bernard Scott found Logos to develop MT systems [Demos and Frauenfelder 2000].

A renaissance of MT research projects in the United States after ALPAC report [Hutchins, 1986].

The beginnings of Al-oriented research on MT [Wilks 1972].

The Commission of the European Communities (CEC) purchased the "Systran" system for the development of translating systems for languages of the community [Hutchins 1988].

The first multilingual MT "Eurotra project" had been developed. This system's goal was to translate back and forth between nine languages; Danish, Dutch, English, French, German, Greek, Italian, Portuguese, and Spanish.

The first public MT system "METEO", developed by the Université de Montreal, for translating weather reports from English to French had been used. It is one of the most successful MT systems.

The first commercial system, "Automated Language Processing Systems (ALPS)", was developed.

Speech translation had begun at British Telecom Research Laboratories in Great Britain and Advanced Telecommunications Research Laboratories in Japan.

A number of commercial MT systems had begun development, e.g., Globalink, PC-Translator. 
Japan launched the Advanced Telecommunications Research, Interpreting Telecommunication Research Laboratories (ATR-ITL), to study multilingual speech translation.

Researchers at IBM's Thomas J. Watson Research Center revived statistical MT methods [see section 2.3.3.2]

The first translator dedicated workstations appear, including STAR's Transit, IBM's TranslationManager, Canadian Translation Services' PTT, and Eurolang's Optimizer [Demos and Frauenfelder 2000], [Hutchins, 1997].

ATR-ITL founds the Consortium for Speech Translation Advanced Research (C-STAR) which demonstrated the phone translation between English, German, and Japanese to the public.

The German-funded Verbmobil project gets under way. Researchers focus on portable systems for face-to-face English-language business negotiations in German and Japanese.

BBN Technologies demonstrates the first off-the-shelf MT workstation for realtime, large-vocabulary $(20,000$ words), speaker-independent, continuousspeech-recognition software [Demos and Frauenfelder 2000].

Free Systran machine translation was available in selected CompuServe chat forums.

AltaVista's Babel Fish offers real-time Systran translation on the Web.

Logos released e.Sense Enterprise Translation, the first Web-enabled multiple translator operating from a single server.

Kevin Knight, of the University of Southem California's Information Sciences Institute (ISI), led a multi-university team that developed Egypt, a software toolkit for building statistical MT systems. Egypt examines bilingual texts for statistical relationships, analyzes those patterns, and applies what it has "learned" to its translation functions.

At MIT's Lincoln Laboratory, Young-Suk Lee and Clifford Weinstein demonstrate an advanced Korean-English speech-to-speech translationsystem prototype. 


\subsection{Machine Translation Methodologies/Technologies}

\subsubsection{Methodologies used to develop MT systems}

The translation process with the aid of a machine was proposed by $\mathrm{P}$. P. Trojanskij in 1933 [Henisz-Dostert et al. 1979]. Trojanskij's translation process begins by analyzing the input words in the source language to obtain their base forms and syntactic functions. Next, the process transforms sequences of those base forms and syntactic functions into equivalent sequences in the target language. Only transformation step is performed by machine. Then the process converts the output of the transformation step into TL.

In 1946, Warren Weaver suggested that war-time cryptography techniques could be used to detect the basic elements which might be contained in all languages and A. D. Booth suggested that any digital computing machine having the necessary storage capacity could make a bilingual dictionary. Weaver also suggested some other techniques used in a translation process, e.g., statistical analysis, Shannon's communication theory, and exploration of the underlying logic and universal features of language.

A Brute-force approach was used to develop a Russian-English system [Garvin 1972]. The Brute-force approach is based on the assumption that, given a sufficiently large memory, MT can be accomplished without a complex algorithm, i.e., that MT can be accomplished with a dictionary containing not only words but also phrases, or a dictionary and a table of grammar rules. The negative opinion of ALPAC regarding the achievements of machine translation is based largely on a study of these systems, and is, of course, justified to the extent to which it concerns them [Garvin 1972].

The approach employed in nearly all MT systems until the late 1960's was the Direct translation approach. The Direct translation approach is a word-to-word replacement approach (see section 2.3.3.1). The morphology and syntax of the SL text need not be analyzed any more than is strictly necessary for the resolution of ambiguities and the specification of the TL word order. Erwin Reifler, at University of Washington in Seattle, recognized the problem of multiple meanings of word as an obstacle to successful direct translation. He began to attack the central problem of semantic ambiguity in 1950 [BarHillel 1964]. Ten years later, the requirements of MT gave impetus to significant theoretical developments in linguistics and what would later become known as the disciplines of computational linguistics and artificial intelligence [Nirenburg et al. 1992]. It had been 
recognized by 1960 , that the achievement of acceptable MT requires a very detailed and extensive knowledge of the languages concerned, particularly with respect to the fundamental semantic problems of translation. Therefore, research on the Indirect Translation approach was begun. The treatment of linguistic structure became more sophisticated. The source language text analysis and target language text generation were treated separately and conversion was achieved via an "interlingual" representation or a "transfer" component operating on abstract representations of the SL and TL. These approaches are now known as the interlingual and transfer approaches respectively (see section 2.3.3.1).

Statistical methods were first suggested by Weaver to resolve problems of multiple meanings of words. A detailed study of statistical techniques was conducted at RAND Corporation by Abraham Kaplan in 1950. This study encouraged the belief that problems of ambiguity in MT could be overcome, however, the approach was quickly abandoned due to machine limitations and the critique of Bar-Hillel [Bar-Hillel 1964]. A decade later, the statistical approach had proven successful in speech recognition and parsing which drew the interest of the MT researchers at IBM's T. J. Watson Research Center [Brown et al. 1988]. In 1988, a statistical approach to MT was implemented at IBM. The basic idea of the statistical approach is to carry out a translation based on complex cooccurrence and distribution probability calculations over very large aligned bilingual text corpora (see section 2.3.3.2).

An artificial intelligence approach to MT was developed by Yorick Wilks at Stanford University in 1972 [Wilks 1972]. Wilks' system is based on an interlingual approach with a semantic grammar and inference rules (see section 2.3.3.3). A conceptually similar approach was carried on by J. Carbonell, R. E. Cullingford and A. V. Gershman in 1981 under the name of Knowledge-Based Machine Translation (KBMT) [Carbonell, Cullingford and Gershman 1981]. Other experiments were conducted at Yale University during 1978-1982, and by S. Nirenburg, V. Raskin and A. Tucker in 1985 [Nirenburg, Raskin and Tucker, 1986]. KBMT is different from the interlingual approach in terms of the expected depth of SL analysis, the building of semantic representations of the meanings of the $\mathrm{SL}$, and the reliance of KBMT systems on the explicit representation of world knowledge [Hutchins 1986; Nirenburg et al. 1992; Whitelock and Kilby 1995].

A framework for MT by the analogy principle or by example-guided inference was first proposed by M. Nagao in 1984 [Nagao 1984]. His idea is that translation is achieved by imitating the translation of a similar example in a database. The task becomes one of 
matching new input to the appropriate stored translation. In 1990 Sumita, Iida and Kohyama proposed a similar approach called Example-Based Machine Translation (EBMT) [Sumita, lida and Kohyama 1990]. The basic idea of EBMT is to search for the closest match of the input text in a bilingual text archive, where text in the SL are stored and aligned with their translations into a TL. The translation of the closest match is accepted as the translation (see section 2.3.3.2).

Lexically-driven machine translation develops the translation upwards from the lexicon without translation rules or interlingual operations. Each lexical entry contains information such as orthography, syntax and semantics. Shake-and-Bake MT developed by Pete Whitelock and Mike Reape [Beaven 1992] is one sample system of a Lexically-driven MT (see section 2.3.3.3).

\subsubsection{Techniques used to increase the performance of MT}

Two techniques can be explored to enhance the performance of MT systems. The first technique is to accommodate the translation process by forming a collaboration between human and machine in post-editing, pre-editing and interaction. The other technique is to study the nature of the linguistic knowledge required and the approach used in acquiring it e.g., building the lexicon, parsing the SL, generation of TL text.

\subsubsection{Post-editing, Pre-editing and Interaction}

The concepts of post-editing and pre-editing were introduced by Erwin Reifler in 1950 [Locke and Booth, 1955]. Both post-editing and pre-editing are performed by a human who need not be bilingual. A post-editor reduces the translation output to a reasonable literary form while a pre-editor prepares the original text for the machine by removing ambiguities. Interaction involves human collaboration during translation processes.

Post-editing The task of the post-editor is to resolve residual problems (e.g., to select the appropriate choice from the alternative translations) appearing in the raw MT output and to tidy the style of the translation up. The post-editing technique was used at RAND Corporation in the late 1950's with a MT system that translates from French to English [Hutchins 1986]. This idea has continued to be used in a number of MT systems, e.g., AMPAR (English to Russian) developed at the USSR Centre [Marchuk 1989]), SPANAM

(Spanish to English) developed by the Pan American Health Organization (PAHO) [Pan 
American Health Organization 1999], and Systran (e.g., English to Chinese, French to German, English to Italian) developed by Systran [Systran 1999].

The difficulty of post-editing and the time required for it correlates well with the quality of the raw MT output: the better the output, the less the post-edit effort. The post-editing task time and cost increases as translation quality gets poorer.

Within the past few years there have been dramatic improvements in hardware (e.g.. storage capabilities, processor speed, memory), software (e.g., programming languages. database management) and also developments in linguistic theory. These advances lead MT researchers to believe that good quality MT output is achievable: therefore, current research is searching for theories and methods to accomplish perfect translation and thus reduce the need for post-editing.

Pre-editing The SL text is adjusted before it is entered into the system by someone who knows the input restrictions. The text is written in a "controlled language" or "sublanguage" [Rosetta 1994]. A controlled language is a form of language usage restricted by grammar and vocabulary rules [Arnold 1994]. A sublanguage is the language used by a particular community of speakers concerned with a particular subject matter [Sager 1986]. By restriction to a controlled language or sublanguage, the problems of lexical homography and syntactic ambiguity can be reduced and, at the same time, higher levels of comprehensiveness and completeness in dictionaries are enabled. As an added benefit, the original text becomes clearer as well. The pre-edited text can sometimes be translated without the need for postediting. The pre-editing technique is particularly cost-effective when there is a need to translate one document into many languages. The first really successful use of this technique was made by Xerox Corp. Xerox developed "Multinational Customized English" (MCE) for writing unambiguous English. The Systran system with MCE was installed to translate from English into French, Spanish and Italian [Hutchins 1986]. In 1976, Météo was developed by the researchers at Traduction Automatique de l'Université de Montréal (TAUM) for translating weather reports from English to French, and is now in daily use. In Météo, the sublanguage grammar was written for analyzing English texts and for generating the corresponding French texts. However, the practice of "sublangauge" is now rarely adopted

\footnotetext{
3 MCE was developed based on a general and technical vocabulary of 3000 words and rules [Hutchins 1986].
} 
since few texts are limited to single subject fields and also for economic reasons, since output inevitably requires revision as well.

Interaction Interactive MT systems involve human intervention for resolving doubts and uncertainties about the structure of the SL text or about the correct choice of the translation word in the TL texts during the translation processes. The final (raw) output does not require post-editing because ambiguities and other problems are solved. The philosophy of interactive systems was that unaided computer analysis can never be satisfactory and that difficult problems of linguistic analysis can be circumvented by calling upon human expertise at appropriate moments [Hutchins 1989a].

In the mid-1960s, the Cambridge Language Research Unit (CLRU) investigated the possibilities of an interactive English-French MT system [Hutchins 1986]. The Management of Information through Natural Discourse ${ }^{4}$ (MND) was developed at The RAND Corporation in early 1970 [Bisley and Kay 1972]. MND relies on a monolingual user to resolve ambiguities in the translation process. The Interactive Translation System ${ }^{5}$ (ITS) was developed at the Translation Sciences Institute of Brigham Young University (BYU) in 1970 [Hutchins 1986]. An Interactive Japanese Parser for MT, proposed in 1990, was developed at IBM Research, Tokyo Research Laboratory. This system allows a user to intervene during parsing to help the system to produce a correct parse [Maruyama and Watanabe 1990]. The Dialogue-based MT (DBMT) conducted at Grenoble allows a monolingual user (with limited ability in TL) to interact with the translation system [Boitet 1990]. InterTran, a free web translation service provided by Translation Experts $\operatorname{Ltd}^{6}$, allows a user to select an appropriate TL word for each SL if there are choices.

The efficiency of an interactive MT system depends on the number of questions asked during the translation process. More questions means less efficiency since a user needs to go through the entire SL text to accurately answer the questions. In addition. the time used during the interaction corresponding between a user and a system should be taken into account.

\footnotetext{
${ }^{4}$ The chief designers of MND were Martin Kay and Ronald Kaplan. Matin Kay was a member of the CLRU.

5 The leadership of ITS development was Eldon G. Lytle at BYU. He and other members of the ITS project left BYU and continued the development of their interactive approach to MT . the first commercial MT system Automated Language Processing System (ALPS), in 1980.

${ }^{6}$ InterTran is available at "http://www.tranexp.com:2000/InterTran" as of December. 1999
} 


\subsubsection{Lexicon constructions and parsing techniques}

Lexicons and parsers are vital components of any MT system. An accurate lexicon and good syntactic and semantic analyses are required to ensure a good translation. Therefore, the lexicon construction method and the parsing technique must be considered not only in the translation process, but also to improve the efficiency of a MT system. Much current research is directed at improving existing $M T$ approaches by developing a better linguistic analysis for the analysis-based MT approach (e.g., Direct MT, Interlingual MT, Transfer MT, Knowledge-Based MT and Shake-and-Bake MT) or by developing better tools to construct and modify an accurate lexicon. Some interesting parsing techniques and lexicon construction tools are summarized below.

PARSEC, the connectionist parsing system, is one of the parsers used in JANUS [Woszczyna et al. 1995]. JANUS is a speech-to-speech translation system developed at Carnegie Mellon University. PARSEC is used as a fall-back module if the symbolic high precision parser fails to analyze the input. The important aspect of the PARSEC system is that it learns to parse sentences from a corpus of training examples.

Steven Abney proposed the idea of parsing by chunks ${ }^{7}$ in 1994 [Abney 1994]. In Abney's chunking parser, the syntactic analyzer comprises the chunker and the attacher. The chunker converts a stream of words into a stream of chunks, and the attacher converts the stream of chunks into a stream of sentences. Abney also compared his parser and chart parsing [Covington, 1994]. In 1996, Michael John Collins at University of Pennsylvania proposed a statistical parser which employs a simple statistical model based on dependencies between words [Collins 1996].

I. Dan Melamed, at the University of Pennsylvania, proposed a new method used in constructing a lexicon [Melamed 1998]. Melamed's method was designed to generate a wordto-word translation lexicon, and each lexical entry is tagged with its relative frequency of cooccurence. Davide Turcato, at Simon Fraser University, proposed a method to build a bilingual lexicon [Turcato 1998]. This lexicon contains not only word equivalence but also the syntactic and semantic descriptions.

\footnotetext{
${ }^{7}$ Chunks correspond to prosodic patterns. It appears, for instance. that the strongest stresses in the sentence fall one to a chunk, and pauses are most likely to fall between chunks. Chunks also represent a grammatical watershed of sorts. The typical chunk consists of a single content word surrounded by a constellation of function words, matching a fixed template [Abney 1994].
} 


\subsubsection{Discussion of some existing MT methodologies}

The methodologies used for developing MT systems can be classified into three different categories: the three classic strategies (Direct MT, Interlingual MT and Transfer MT), the nonlinguistic information strategies (Example-Based MT and Statistics-Based MT), and the hybrid strategies (Knowledge-Based MT and Shake-and-Bake MT).

\subsubsection{Three Classic Strategies}

Three widely articulated strategies for developing MT systems include Direct $M T$, Interlingual MT and Transfer MT. Direct MT (Figure 2.1) is a "word-to-word" replacement approach that replaces the SL word with the TL word. Therefore, the accuracy of the translation depends primarily on the bilingual dictionary. Accuracy is rather limited because the Direct MT system takes into account only morphological information. The following examples, using the word open with English as the SL and Thai as the TL, illustrate this limitation (Figure 2.2).

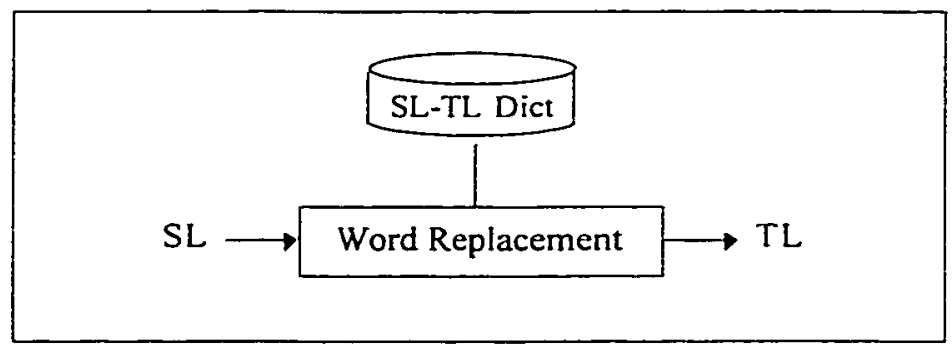

Figure 2.1: Direct MT

The meaning of each open is different because of the circumstances of usage. Therefore, the translations of the word open into the Thai language which are shown underlined in Figure 2.2 depend on which Thai word will cover each circumstance. In phrase (1), the word open is translated as เปด $\left(\mathrm{p}^{\circ}{ }^{\circ} \mathrm{d}\right)^{8}$ in Thai because it means not shut. However, the word open in phrase (2) is translated as เ ริ่ม $\left(\mathrm{r}^{\wedge} \ni \mathrm{m}\right)$ since open fire means to start shooting. Nevertheless,

\footnotetext{
${ }^{8}$ The parenthesizing item is the phonetic transcription of the Thai word. Thai phonetic transcription is provided from the Thai-English Student's Dictionary compiled by Mary R. Haas [Haas 1964].
} 


\begin{tabular}{|c|c|c|}
\hline & SL & TL \\
\hline 1. & open door & เปดประตู \\
\hline 2. & open fire & $\begin{array}{l}\text { (рэัวd-open) (pratuu door) } \\
1 \text { ริมยิง }\end{array}$ \\
\hline 3. & open arms & 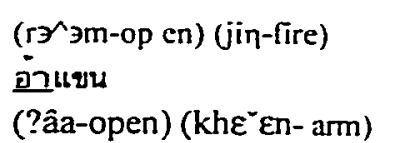 \\
\hline 4. & open eyes & $\begin{array}{l}\text { ลูมดา } \\
\text { (Iyym-open) (taa-cye) }\end{array}$ \\
\hline 5. & เป็ดไฟ & turm on the light \\
\hline 6. & ลิมบอก & $\begin{array}{l}\text { ( } p \ni^{*} \ni \text { d-turn on) (faj'-light) } \\
\text { forget to tell } \\
\text { (lyym-forget) (bo } \partial^{\prime} \partial g^{\prime} \text {-tell) }\end{array}$ \\
\hline
\end{tabular}

Figure 2.2: Some translations of the word open

the translation of the word เปิด ( $\left.\mathrm{p}^{\circ}{ }^{\circ} \mathrm{d}\right)$, phrase (5), into English is turn on, not open. The word ลิม (lyym), in phrase (6), cannot be translated as open either because it has a complete different meaning from the word ลม (lyym) in phrase (4). The translation of the word ลม (lyym), phrase (6), must be forget. The meaning of a word or phrase depends, in part, on the situation in which it is used. The relationship between the basic meaning of a word and its circumstances of usage is very complex. This complexity is one reason why the mapping from one language to another is far from direct.

The direct approach was adopted by most MT systems in the first generation of MT, e.g., the Georgetown system of Garvin 1967 [Goshawke et al. 1987]. The translation accuracy of this approach is limited because the linguistic analysis of the SL is inadequate. In addition, the design of Georgetown system was orientated towards a specific language pair, and emphasis on a bilingual dictionary as knowledge source. The addition of a new language pair means that entire new modules have to be written. The number of rules tend to be very large, and rule interaction difficult to monitor, so that the whole system is difficult to extend and maintain. However, the Direct MT is still appealing in certain circumstances. Traces of the direct approach are found in an indirect approaches such as Météo and Systran [Hutchins and Somers 1992]. 
To generate more accurate translations, a second approach, Interlingual MT (IL MT) was developed. The treatment of linguistic information became more sophisticated in this approach. IL MT analyzes and represents the SL in an intermediate language-independent conceptual representation called interlingua (Figure 2.3). IL MT then generates the TLs (in any language) from the interlingua. The accuracy of the IL approach is based on the ability to generate an accurate interlingua. Since interlingua is a language-independent representation of the meaning of the text, the analysis and generation modules are independent from each other. The advantage is that the addition of a new language involves only the creation of two new modules: the analyzer and the generator of the new language. The all-ways translation between $n$ languages requires $n$ analysis and $n$ generation modules whereas the direct approach requires $n(n-I)$ translation modules.

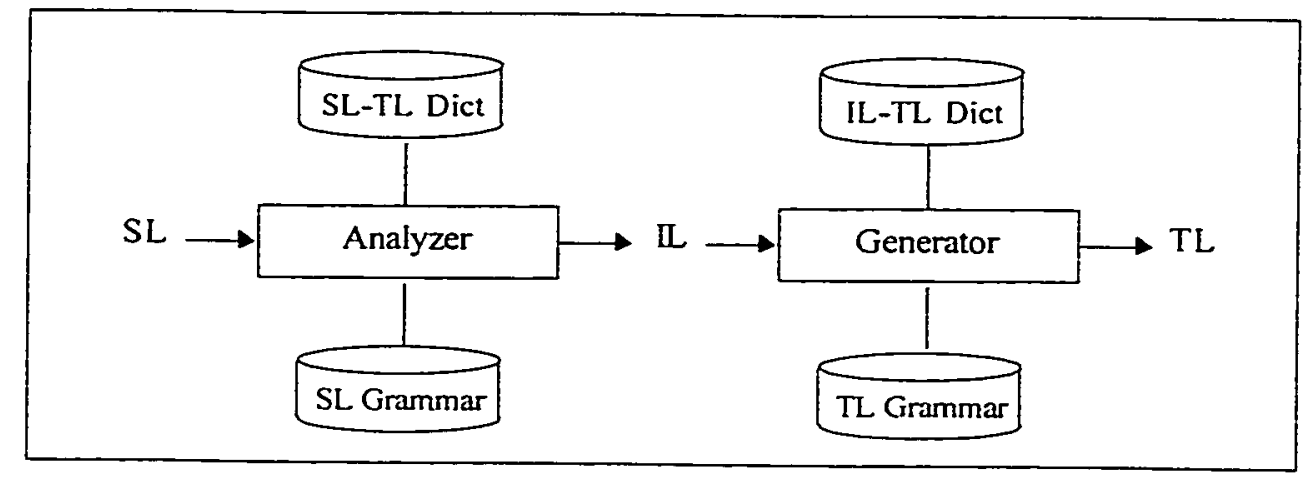

Figure 2.3: Interlingual MT

The IL approach is the most attractive to multilingual machine translation (MMT) systems. However, to define neutral concepts for different languages is rather a chimera. Interlingua must capture all necessary information of the analyzed SL so that the generator can generate an accurate translation in all languages. A number of interlingual systems were developed e.g., ATLAS of Fujitsu [Uchida 1989], PIVOT of NEC [Muraki 1989], Rosetta of Phillips [Landsbergen 1987a], KANT [Mitamura, Nyberg and Carbonell 1991], UNITRAN [Dorr 1991] and CICC Interlingual [CICC 1995e]. The CICC interlingual system was developed and implemented in the project "The research and development cooperation 
project on a machine translation system for Japan and its neighboring countries ${ }^{9 " *}$ (CICC MMT 1987-1994) [CICC 1995g]. The CICC MMT project was aimed at developing MMT, an all-ways translation between five languages: Japanese, Chinese, Malaysian, Indonesian and Thai. Some limitations and problems were encountered in developing the interlingual system for this project. For example, interlingua theory assumes that sentences in different languages which carry the same meaning must be represented by the same interlingua. However, in the CICC MMT project, the interlingual representations of these sentences are different [CICC 1995d] for several reasons [Cercone 1975; CICC 1995c; CICC 1995g; CICC [995h; CICC 1995i]:

- The scopes and concept classification of each language are different (e.g., the concept of culture, the concept of the supernatural world, and the concept of unit).

- A single concept in one language can be mapped into many concepts in another language.

- More than one concept can be mapped into only one single concept in another language.

- Some concepts do not exist in some languages.

Different languages and different cultures result in different circumstances of language usage. Thus, it is very difficult to define a neutral concept. Interlingual then, is still an ideal despite being considered one of the best approaches.

Because of these difficulties, the compromise between the direct approach and the interlingual approach led to the idea of the third approach, Transfer MT (Figure 2.4). The

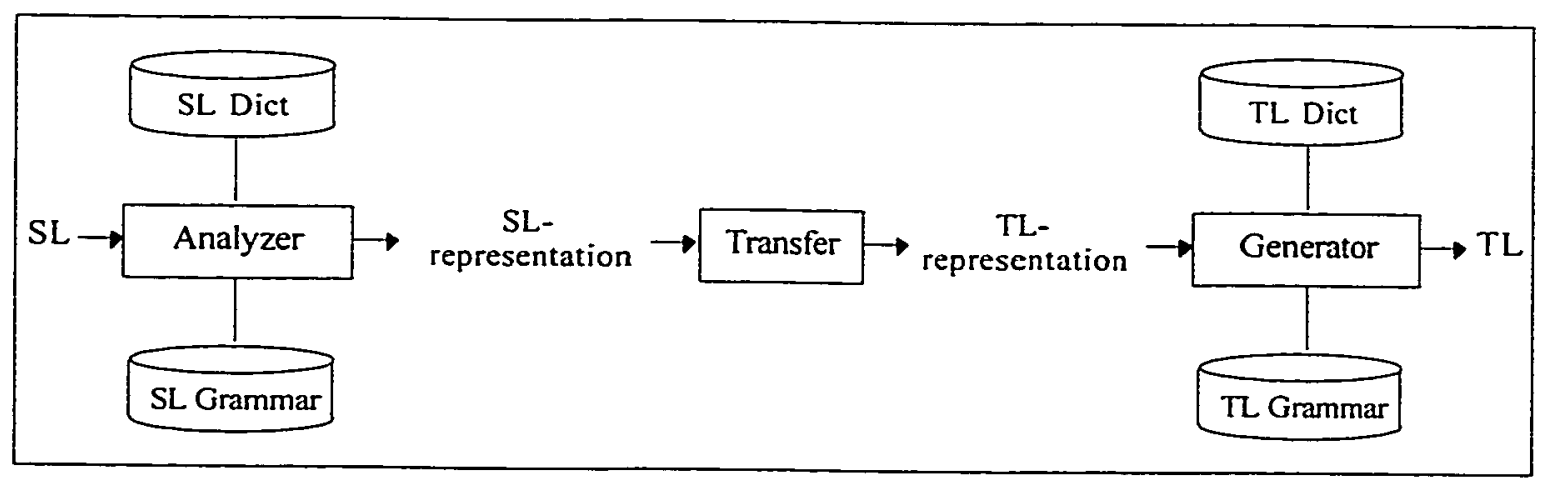

Figure 2.4: Transfer MT

\footnotetext{
${ }^{9}$ China, Indonesia. Malaysia and Thailand.
} 
transfer approach involves "transferring" the linguistic information of SL to TL. The transfer approach analyzes and represents the SL with a machine-readable form and maps this form into a machine-readable form of $\mathrm{TL}$, then generating the $\mathrm{TL}$ from that representation. The accuracy of transfer approach depends primarily on the transfer module.

Unlike the intermediate representation in the interlingual approach, the intermediate representation in the transfer approach strongly depends on language pairs. Therefore, the all-ways translation of $n$ languages requires $n$ analysis, $n$ generation and $n(n-I)$ transfer modules. The transfer approach is not attractive to MMT systems. However, it is still preferred to the interlingual approach among MT researchers for two reasons. There are difficulties in defining neutral concepts as mentioned earlier. Furthermore the intermediate representation of the transfer approach depends on language pairs so the analysis and generation processes are less complicated when compared to the interlingual approach (the relative complexity of the analysis and generation modules in a transfer system is much reduced because the intermediate representations involved are still language dependent). The

Table 2.I: Translation examples by the commercial MT system

\begin{tabular}{|c|c|c|}
\hline English & Translation to French & Translation back to English \\
\hline $\begin{array}{l}\text { 1. Hatchery officials are having } \\
\text { to teach the fish to like } \\
\text { worms. }\end{array}$ & $\begin{array}{l}\text { I. Les fonctionnaires de } \\
\text { l'incubateur doivent } \\
\text { apprendre le poisson pour } \\
\text { aimer des vers. }\end{array}$ & $\begin{array}{l}\text { 1. Civil servants of the } \\
\text { incubator must learn fish for } \\
\text { aimerdes }{ }^{10} \text { toward. }\end{array}$ \\
\hline $\begin{array}{l}\text { 2. It does not matter if you are } \\
\text { born in a duck yard. }\end{array}$ & $\begin{array}{l}\text { 2. Il n'importe pas si vous } \\
\text { naissez dans un jardin du } \\
\text { canard }\end{array}$ & $\begin{array}{l}\text { esn't import if you } \\
\text { in a garden of the }\end{array}$ \\
\hline $\begin{array}{l}\text { 3. Only a life lived for others is } \\
\text { a life worth while. } \\
\text { 4. I never think of the future. }\end{array}$ & $\begin{array}{l}\text { 3. Seulement une vie pour les } \\
\text { autres vaut pendant que. } \\
\text { 4. Je ne pense jamais du futur. }\end{array}$ & $\begin{array}{l}\text { 3. Only a life for other is worth } \\
\text { while. } \\
\text { 4. I never think the future. }\end{array}$ \\
\hline $\begin{array}{l}\text { 5. You can take a fish to } \\
\text { school, but you can not } \\
\text { make them think. }\end{array}$ & $\begin{array}{l}\text { 5. Vous poivez prendre un } \\
\text { poisson pour scolariser. } \\
\text { mais vous ne pouvez pas les } \\
\text { faire penser. }\end{array}$ & $\begin{array}{l}\text { 5. You can take a fish to } \\
\text { school, but you don't can } \\
\text { pasles to make think. }\end{array}$ \\
\hline $\begin{array}{l}\text { 6. BOISE, Idaho (AP)- Trout } \\
\text { in Idaho are not just } \\
\text { swimming in schools- they } \\
\text { are going to school. }\end{array}$ & $\begin{array}{l}\text { 6. BOISE, Idaho (AP) - Truite } \\
\text { dans Idaho ne nage pas dans } \\
\text { les écoles juste - theyare } \\
\text { aller scolariser. }\end{array}$ & $\begin{array}{l}\text { 6. BOISE, Idaho (AP) - Trout } \\
\text { in Idaho doesn't swim rightly } \\
\text { in schools-theyare to be } \\
\text { going to school. }\end{array}$ \\
\hline
\end{tabular}

\footnotetext{
${ }^{10}$ This is how the translation actually appeared. This type of error appears through aout these examples.
} 
interlingual approach necessarily requires complete resolution of all ambiguities and anomalies of SL texts so that the translation into any other language is possible whereas in the transfer approach, only those ambiguities inherent in the language pair are tackled.Some examples of MMT systems which were developed based on the transfer approach include: Eurotra which has been developed by European Community ${ }^{11}$ since 1978; Susy which was developed at the Universität des Saarlandes in Saarbrücken during 1972-1986; and METAL which has been developed at the Linguistic Research Center at the University of Texas (Austin, Texas) since 1961. Details of these MT systems can be found in Hutchins and Somers, 1992.

The transfer of structure information in the transfer approach may cause inaccuracies because of the different structures between languages and thus the transfer approach may lose some information during processing. Table 2.1 illustrates this problem. The second column in French represents the translation of the first column from English ${ }^{12}$. Each translation fails to maintain close fidelity to the meaning of the original sentence. The translations are incorrect in both words selected and in grammar. The third column shows the translation back into English of the French translation in the second column ${ }^{13}$. The third and the first columns should convey the same meaning but they do not because accumulative errors occurred during the translation processes.

\subsubsection{Nonlinguistic Information Strategies}

There is a possibility that different languages require different amounts of information to be expressed. For example, the Spanish word llego means either he arrived or she arrived, but in order to translate it into English, we have to choose "he" or "she" on the basis of context and background knowledge. Japanese and Thai have "polite" markers. To translate from English to these languages, the "polite" markers need to be added according to the knowledge of culture. This observation led to nonlinguistic information strategies. Nonlinguistic information strategies are currently popular, e.g., Example-based MT [Jones 1996], Statistical strategies [Brown et al. 1992].

\footnotetext{
$"$ Eurotra project involves research groups in all member states in Europe e.g.. GETA in Grenoble, IAI in Saarbrücken, and ISSCO in Geneva [Hutchins and Somers 1992].

${ }^{12,13}$ These translations were provided by the commercial MT system.
} 


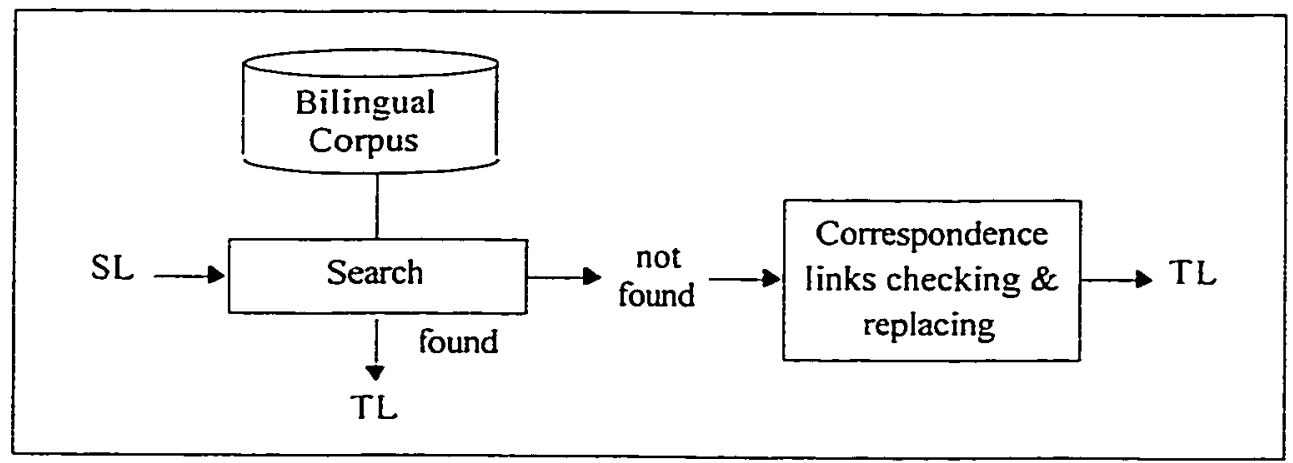

Figure 2.5: Example based MT

Example-Based machine translation (Figure 2.5) attempts to achieve translations by using examples of translation in the translation process. EBMT performs a translation by mapping the input text to an example in the bilingual corpus: a collection of translation pairs. If the entire input phrase can be matched, then it will be translated to the translation pair of that matched example. If the entire input phrase cannot be matched then EBMT takes two approaches to translate such a sentence: the closest mapping and recombining the matched segments.

The first approach, closest mapping, looks for the closest example for the input text. If it is found, the system will use its translation pair as a template and replace the SL words with the corresponding words in TL. In case the closest example is not found, there is a possibility that its segments can be found in a number of examples. Therefore, the second approach, recombining the matched segments, is applied. All matched segments will be translated and recombined to be the translation of the input text. The measurement of similarity between an input text (segments) and a set of examples can be considered according to both surface and content. The similarity measurement can be performed by using a thesaurus. One advantage of EBMT is that translations come with scores which are measurements of similarities to known examples. These scores could be useful to a post- editor. Further details of the EBMT can be found in Nagao 1984], [Sato and Nagao 1990], [Sumita, Iida and Kohyama 1990] and [Jones 1996].

The feasibility of EBMT depends crucially on the availability (suitability) of the translation examples. EBMT requires a large collection of translation examples (pairs) to 
produce an accurate output. The coverage of EBMT system depends on the size and diversity of the collection of the translation pairs.

Statistics-Based $M T$ tries to do away with formulating linguistic knowledge, but applies statistical techniques instead. Statistics-based MT views every sentence in one language as a possible translation of any sentence in other languages [Brown et al. 1990]. This approach attempts to search for a sentence $S$ in the source language that maximizes $\operatorname{Pr}(S) \operatorname{Pr}(T \mid S)$. whereas $\operatorname{Pr}(\mathrm{T} \mid \mathrm{S})$ is the translation model probability and $\operatorname{Pr}(\mathrm{S})$ is the language model probability.

The translation model probability, $\operatorname{Pr}(T \mid S)$, is assigned to every pair of sentences $(S, T)$. It is the probability that a translator will produce $T$ in the target language given $S$ in the source language. The translation model probability is calculated from the probability of word alignment. The word alignment corpus, contained the aligned translated text, is used to predict which elements of one language of the corpus are most likely to be equivalent to elements in the other. The languarge model probability, $\operatorname{Pr}(\mathrm{S})$, is the probability of words occuring in a particular order. Further details of the computation and searching method can be found in [Brown et al. 1988], [Brown et al. 1990], [Arnold 1994], and [Jones 1996].

One sample system of the statistics-based approach has been carried out by a research group at IBM. The researchers had access to three million sentence pairs from the Canadian (English-French) Hansard which contains the Proceedings of the Canadian Parliament.

This approach, while interesting, requires a very large and reliable aligned bilingual corpus to produce an accurate translation. As with EBMT, the statistics-based approach relies heavily on the availability of a large and diverse quality corpus; currently such corpora for most languages are underdeveloped.

\subsubsection{Hybrid Strategies}

Knowledge-Based Machine Translation is based on the interlingual approach using AI techniques. Reasoning-induction and abduction are used in interpreting the SL text by reference to world knowledge, not only a knowledge of language. The meaning representation should be sufficient for translation two a number of languages, rather than sufficient for total understanding [Nirenburg et al. 1992].

Basic Components of KBMT systems include: a parser, a reasoning system, and a generator. The parser (Semantic-based) recognizes semantic features of lexical items in SL text rather 
than grammatical categories. Wilks' Preference Semantics (MT) system ${ }^{\text {i4 }}$ represents the meaning of the SL text (interlingual representation) with "binary decomposition trees" while KBMT, developed at Yale University, adopted an IL representation based on the "conceptual dependency theory"- developed by Roger Schank ${ }^{15}$. The reasoning system (inference mechanism) applys contextual world knowledge which augments the representation, to solve ambiguities and uncertainties in the SL text. The generator maps the representation of the $\mathrm{SL}$ into the TL.

J. Carbonell, R. E. Cullingford and A. V. Gershman combined their system with a Script Applying Mechanism (SAM) to understand and represent the meaning of the SL. SAM is the script-based story understander developed by R. Schank and R. E. Cullingford in 1978. Carbonell, Cullingford and Gershman remarked that their system did not perform strict translation, but rather retold or summarized the SL text in the TL [quoting Carbonell, Cullingford and Gershman 1981; Carbonell and Tomita 1987]. The domain of the translation is English newspaper articles.

KBMT-89 is a larger-scale KBMT developed by researchers at the Center for Machine Translation at Carnegie Mellon University and the researchers from IBM's Tokyo Research Laboratory in 1987 [Goodman and Nirenburg 1991]. Its interlingual representation is a frame notation and can be viewed as a kind of a semantic network. The world knowledge is organized as a multiply interconnected, hierarchical network of frames. The domain of the translation is limited to personal computer manuals.

Other KBMT systems have been implemented, e.g., ATLAS-II [Uchida 1989]. PIVOT [Muraki 1989], ATR [Kudo 1990] and ULTRA [Farwell and Wilks 1991].

One advantage of the KBMT approach is solving some ambiguity problems. However, the disadvantage of this approach is the expense of either abductive or inductive reasoning, even on small domains. Building the knowledge representation is also time consuming and expensive.

${ }^{13}$ Details discussion on Wilk's system can be found in [Wilks 1972] and [Whitelock and Kilby 1995].

it Schank's conceptual dependency theory. developed in 1972, is rich in semantic representation. It is designed to provide a representation of meaning of natural language in terms of which paraphrase. inference, and MT could be carried out There are some similarities between Wilks' formulas and Schank's conceptual dependency representations (Wilks and Schank were both at Stanford in the early 1970). Wilks formulas bear much similarity to the (binary) decomposition trees developed by Lakoff. Further discussion on Wilks formulas and Schank's conceptual dependency theory can be found in [Cercone 1975] and [Hutchins 1986]. 
We doubt that a pure interlingua (semantic representation) is appropriate for $\mathrm{MT}$ systems since the pure IL does not contain syntactic information. The abstractness of "content" representations results in information loss about "surface" structures of text; it seems that a pure interlingua is more suitable for the paraphrase task than for the translation task.

Shake-and-Bake MT developed by Pete Whitelock and Mike Reape is Lexically-driven machine translation. In Shake-and-Bake MT, the SL is analyzed by using a SL monolingual grammar, then each SL word is replaced with its equivalent in the TL using the bilingual dictionary, and finally the translation is generated from a set of TL words by shift-reduce parsing algorithms according to the TL grammar [Whitelock 1992].

One advantage of Shake-and-Bake MT is that it relates the SL and the TL via the bilingual lexicon alone, without a transfer module or an IL representation. The semantic information of the SL is copied across by the coindexation specified in the bilingual lexicon (the variables in the semantic indices are copied from the SL word as prescribed by the bilingual lexicon.).

Shake-and-Bake MT is not efficient since it generates the translation by trying all possible permutations of the TL words. The system parses an arbitrary permutation to determine its grammatical well-formedness. If that permutation is well-formed, the system indicates success. If not, another permutation is tried. The system might have to verify all possibilities to find the appropriate translation or find none at all. A number of techniques were proposed to improve the efficiency of the generation process in Shake-and-Bake MT e.g., Brew uses a heuristic method to constrain the solution space [Brew 1992]. Beaven employs a Cocke-Kasami-Younger (CKY) baking ${ }^{16}$ to avoid recalculating the same combinations of words more than once during the generation process [Beaven 1992]. Popowich's generation process is also based on a chart parsing algorithm with a variety of different search strategies [Popowich 1996]. Poznanski, Beaven and Whitelock proposed the idea of considering the information from the previous stages, analysis and dictionary look-up, in the generation process [Poznanski, Beaven and Whitelock 1995]. However, none of these algorithms is guaranteed to avoid protracted search times in order to achieve an accurate translation result.

\footnotetext{
${ }^{16}$ Beaven calls his algorithm the "CKY baking" because of the great similarity between his algorithm and the CKY chart parsing algorithm.
} 
The approaches to MT discussed thus far do not explicitly recognize the notion of incremental repair of a mistranslating and subsequent iteration through an evaluation phase to further repair and iteration.

The notion of "repair and iterate" is a well accepted methodology in computer science. It seems to us that this notion should prove useful in a MT system as we iterate to a better and better translation. we note that this concept is not unlike Verbmobil's notion of "negotiations" [Kay, Gawron and Norvig 1994] for their speech to speech system.

We discuss Generate and Repair Machine Translation in the next section. GRMT is a novel MT paradigm that takes advantage of the best features of the more traditional MT approaches (see Table 9.1) and combines them in a Repair and Iterate architecture.

\subsection{Our approach : Generate and Repair Machine Translation}

There are advantages and disadvantages in each approach. The efficiency inherent in the direct MT approach is limited because linguistic elements of the languages are considered only at the morphology level. The transfer of structure information in the transfer MT approach may cause inaccuracy because of the different structures between languages and thus may lose some information during processing. In addition, the transfer approach does not appear appropriate for multilingual systems. Of the three approaches, although the interlingual MT approach appears to be the most attractive, the interlingual representation is still an ideal. Example-Based MT and Statistics-Based MT approaches requires a very large and reliable bilingual corpus to produce an accurate translation; these corpus are not available for most languages. To build the knowledge for KBMT is time consuming and expensive. The Shakeand-Bake MT approach lacks efficiency due to its generation process.

Our goal is to overcome shortcomings of earlier approaches and to increase the accuracy of the overall translation. Generate and Repair Machine Translation is a proposed solution.

The GRMT approach is designed to increase the accuracy and efficiency of MT. The architecture of GRMT was designed to take advantage of, and have advantages over, the Direct, Transfer, Interlingual, Non-linguistic and the existing hybrid approaches to MT with respect to several translation aspects: simplicity, accuracy and multilingualism. The GRMT integrates the best features of each approach. The GRMT process is relatively simple and straightforward, not unlike the Direct method. However, the GRMT is more concerned with preserving linguistic information to produce an accurate translation result, like the Transfer 
approach. GRMT also treats the SL and TL separately for easy management in multilingual MT systems, like the Interlingual approach. GRMT uses simple statistical information, in part, in the word selection process like the statistic-based approach. GRMT builds the semantic relationship between words based on world knowledge, like the KBMT approach. GRMT associates the SL and TL via the bilingual lexicon, like the Shake-and-bake MT approach.

Unlike the transfer or interlingual approaches, GRMT generates a translation candidate (TC) directly from the SL input to avoid information loss during the transfer process of the transfer approach and to avoid difficulties in defining neutral concepts for different languages in the interlingual approach. GRMT does not require any bilingual corpus in the translation process, unlike EBMT or the statistical based MT approach. Unlike the Shake-and-bake MT approach, GRMT verifies the generated TC and revises it if required to achieve an accurate translation without trying all possibilities.

GRMT takes into account the differences between languages in a unique way, hence a further advantage. If languages can be grouped according to various characteristics which they share, then the translation between groups can be performed more simply by GRMT. For example: Group 1 consists of English, French and Spanish, Group 2 consists of Chinese, Japanese and Thai. To perform the translation between these two groups, the transfer approach requires six SL analyzers, six TL generations and eighteen sets of transfer rules while GRMT requires six analyzers and two sets of constraints.

The English-Thai translation system has been developed based on the GRMT approach. The initial experiments of ALMT [Naruedomkul and Cercone 1997] indicate that the translation candidates can be generated quickly with relatively high accuracy. We have greatly expanded the dictionaries used in the earlier experiment, five fold [Naruedomkul, Cercone and Sirinoavakul 1999]. All necessary knowledge bases required were updated. ALMT has been improved to increase the performance of GRMT. The English-Thai translation system we developed has been used to translate a number of phrases. These sample phrases were collected from different sources: newspapers, text books, articles, bedtime stories and fortune cookies. This dissertation presents the design and some experiments of GRMT.

As far as we are are aware two commercial products were claimed to translate English to Thai, Tapestry (http://knowledge.krdl.org.sg/MT/) and Language Force (www.wforce.com), however, 


\title{
Chapter 3
}

\section{Generate and Repair Machine Translation}

\author{
'When I use a word,' Humpty Dumpty said in rather a scornful tone, \\ 'it means just what I choose it to mean - neither more or less.' \\ - Through the Looking Glass \\ by Lewis Carroll
}

Generate and Repair Machine Translation is an efficient approach to machine translation distinct from the direct, transfer, interlingual, statistical, example-based, knowledge-based approaches. The architecture of GRMT (Figure 3.1) is designed to serve two purposes: first, to generate an accurate translation and second, to be amenable to multilingual translation. An accurate translation corresponds to a translation which retains the linguistic meaning of the source language. To achieve an accurate translation, GRMT performs the translation in

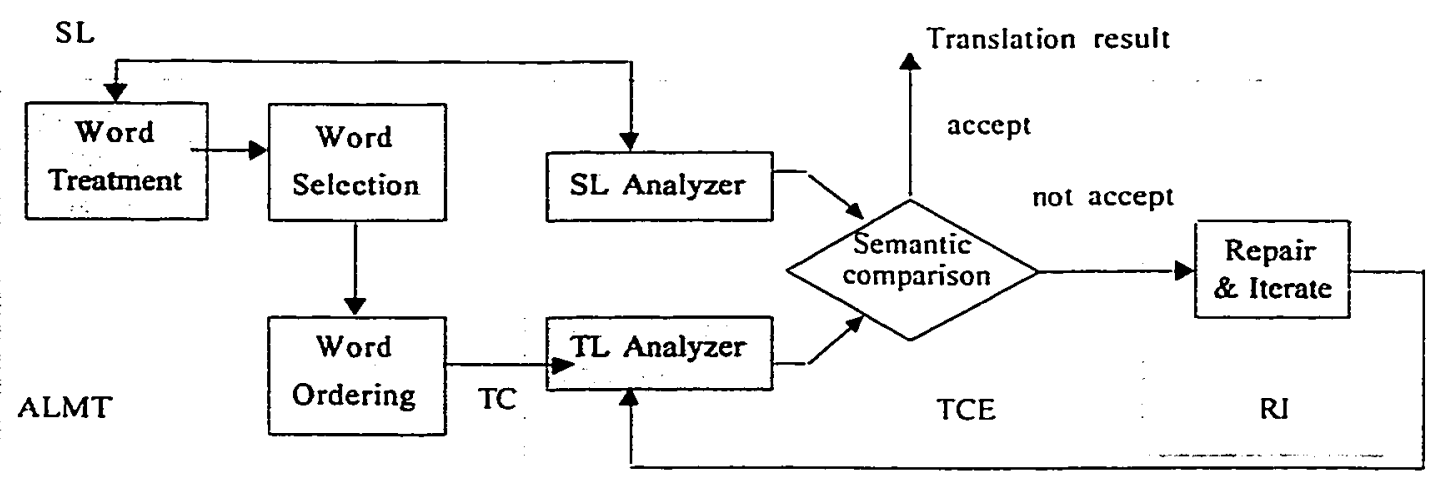

Figure 3.1 GRMT Architecture 
three phases: The first phase, Analysis Lite Machine Translation (ALMT) generates a translation candidate for the SL. The accuracy of the generated TC is evaluated by analyzing both the TC and the SL in the second phase, Translation Candidate Evaluation (TCE). TCE compares the semantic information of the TC with that of the SL. If there is any dissimilarity then the TC will be "repaired" in the third phase, Repair and Iterate (RI). The repaired TC will again be analyzed and again be compared until there is no appreciable dissimilarity between the meaning of the SL and the TC. By performing the TCE and RI processes, GRMT ensures an accurate translation.

To make GRMT attractive to a multilingual MT system, we pay attention to simplicity in accommodating new languages and the associated systems knowledge required. System maintenance also adds further complications. Therefore, GRMT treats SLs and TLs separately and relates them by using information provided in a SL-TL lexicon. The SL-TL lexicon contains simple but necessary information for the translation process, and this SLTL lexicon is simple to construct (see section 5.1.3). GRMT organizes knowledge required for the translation process into separate modules e.g., SL constraints, TL constraints, grammar and analysis lexicon for each language so that they can be developed easily and maintained simply. SL and TL constraints represent the syntactic differences between SL and TL which GRMT considers, in part, in generating a TC. The translation between languages in different families of languages that share some characteristics should be able to take good advantage of GRMT architecture (see section 3.5).

To illustrate the performance of GRMT, translation from English to Thai has been implemented. The English-Thai MT system translates isolated sentences (sentence by sentence). This English-Thai translation system has been developed and run under SWIProlog 3.2.8. The English and Thai grammars (see section 6.1.1.6) have been developed based on Head-Driven Phrase Structure Grammar formalism [Pollard and Sag 1987; Pollard and Sag 1994] and implemented on the Attribute Logic Engine version 3.2 Beta [Carpenter and Penn 1999].

GRMT was tested to generate the translations for a number of sentences/phrases by using a dictionary which contains 314 English words and their translations into 731 Thai words. The sample sentences/phrases were collected from different sources: newspapers, textbooks, articles, bedtime stories and fortune cookies. 


\subsection{Why Generate and Repair, Not Analyze and Generate?}

GRMT (Figure 3.1) generates a TC directly from the SL input, analyzes and repairs (if necessary) the TC to verify its accuracy. The generate and repair methodology draws inspiration from the following sources:

- "...and since word-for-word translations are surprisingly good, it seems reasonable to accept a word-for-word translation as a first approximation and then see what can be done to improve it." quoting Victor $H$. Yngve [Yngve 1955].

- "If someone asks me how I translate, ....I can describe the physical process: I make a very rapid first draft, put it aside for a while, then go over it at a painfully slow pace, pencil- and eraser-in hand ..." quoting William Weaver [Weaver 1989].

Based on Victor H Yngve's' investigation on the direct MT approach and William Weaver's ${ }^{2}$ (human) translation procedure, the GRMT approach begins by generating an initial translation which we called the iranslation candidate and then revises the TC, if necessary, to ensure its accuracy.

The TC, the initial translation, must be generated simply, quickly and efficiently. Therefore, we generate the TC directly from the SL. Our TC generation process is different from the old fashioned Direct MT in several important aspects. The differences between languages have been used as constraints to limit the choices of the corresponding words in the TL. We select the most appropriate choice of TL word for each SL word by considering the relationship between the close proximity words (see section 5.2). All selected words are arranged into grammatical order according to the similarities and the dissimilarities between the structure of the SL and that of the TL. Once the TC generation is completed, the revision process begins by analyzing the TC to determine whether it is grammatically correct and conveys the linguistic meaning of the SL. To verify the meaning of the TC, we compare its parse with the parse of SL in terms of semantics only since there are differences in the syntactic level between languages. Any dissimilarity appearing in the TC parse will be repaired according to the semantic information of the SL parse.

\footnotetext{
I Victor H. Yngve investigated a word-to-word translation and this quote is a part of his conclusion.

2 William Weaver is the author of several books about opera and a translator of modern ltalian literature [Weaver 1989].
} 
Example 1, one of the most popular examples during the first generation of MT, was translated into Russian and then back from Russian into English by the direct MT approach. The three different translations are shown below. None of these translations conveys the linguistic meaning of the original sentence.

\section{Example 1}

SL: The spirit is willing but the flesh is weak ${ }^{3}$.

Translated back from Russian into English :

- The whisky is all right but the meat has gone bad.

- The vodka is good but the meat is rotten.

- The liquor is holding out all right, but the meat has spoiled.

Table 3.1 illustrates the selected words (shown in the third column) and the TC generated by our generation process for the Example 1. If we translate back from this TC into English we will achieve the following translation: "The soull is ready but the body is weak". This result is because the corresponding Thai word, วิญาน (winjaan), selected for the word spiril means "thought of as remaining alive without appearing in physical form." (the descriptions of each word and its corresponding translations are provided in section 5.2).

The TC is verified and repaired in the revision process. The appropriate sense of spirit in the Example 1 is "mental or moral strength to resist." which corresponds to Thai จตใจcidcaj. Therefore, the word วิญา (winjaan) is replaced with the word จิตจ-cidcaj in the repair process. The repaired $\mathrm{TC}$ is shown in Table 3.1. If we translate back from the repaired TC into English, we will achieve "The mind is ready but the body is weak".

Our TC generation process is distinct from the direct MT approach, not only the process of translation but also its modularity and extendibility (see section 3.5). Our TC generation process is a modular system in that each component can be modified and changed independently of each other and is intended to be easily extendible to any other language.

A good translation must be generated from a precise source. To generate a good translation from the SL parse, the SL parse should contain consistent information (in terms

3 In theory of 3D semantics [Galloway 1989], both "spirit" and "flesh" have allosemes in the domain of FOOD and in the domain of ANATOMY [Galloway 1993]. The reason FOOD is wrong for "flesh" is that the alloseme "meat" is archaic and rarely used; the alloseme in ANATOMY is thus the most likely one and this makes a domain match in ANATOMY for the alloseme of "spirit" also most likely. Thus "mind" and "body" are good alloseme choices. 
of both syntax and semantics) required in the generation process. Unfortunately, there is no parser which can provide such parses available in all languages. Therefore, there is a possibility that a generation process generates the translation from the input, the SL parse. and the SL parse may contain errors. The errors accumulate during the generation process, depending on how the translation is generated. For example; in the transfer MT paradigm, to generate the translation from a SL parse, the structure and lexicon of the SL is transferred to those of the TL. This transfer process results in the information-loss problem we discussed in section 2.3.3.1.

Table 3.1: The TC and selected words generated for Example 1

SL: The spirit is willing but the flesh is weak.

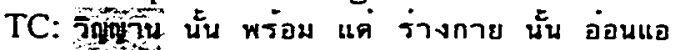

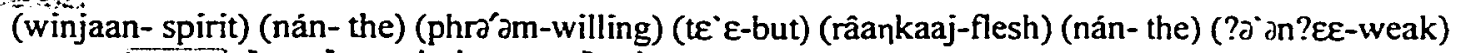
Repaired TC จดใจ น้น พร่อม แต่ ร่างกาย นั้ อ่อนแอ

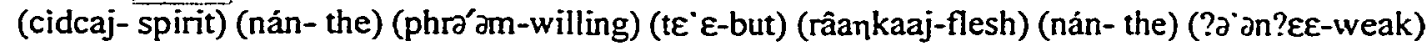

\begin{tabular}{|c|c|c|c|}
\hline Input & $\begin{array}{l}\text { Possible corresponding words } \\
\text { in Thai }\end{array}$ & $\begin{array}{l}\text { Selected } \\
\text { Word }\end{array}$ & Description $^{4}$ \\
\hline $\begin{array}{l}\text { The } \\
\text { spirit }\end{array}$ & 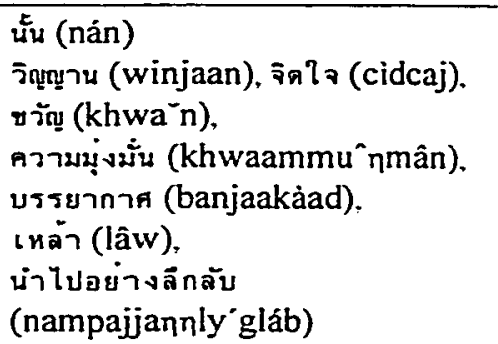 & $\begin{array}{l}\text { นั้น (nản) } \\
\text { รัญญาน } \\
\text { (winjaan) }\end{array}$ & $\begin{array}{l}\text { determiner } \\
\text { thought of as remaining alive without } \\
\text { appearing in physical form. }\end{array}$ \\
\hline is & - & - & - \\
\hline willing & พร้อม (phrว’วm), เต็มใจ (temcaj) & $\begin{array}{l}\text { พร้อม } \\
\text { (phra'วm) }\end{array}$ & $\begin{array}{l}\text { regarding favorably the possibility of } \\
\text { doing something, ready }\end{array}$ \\
\hline & 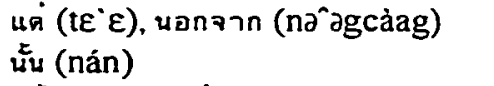 & $\begin{array}{l}\text { แต่ }\left(t \varepsilon^{\prime} \varepsilon\right) \\
\text { น้น (nán) }\end{array}$ & $\begin{array}{l}\text { in spite of this } \\
\text { determiner }\end{array}$ \\
\hline flesh & เนื้อ (nyª), ร่างกาย (râankaaj) & $\begin{array}{l}\text { ร่างกาย } \\
\text { (râankaaj) }\end{array}$ & $\begin{array}{l}\text { the physical human body as opposed } \\
\text { to the mind or soul }\end{array}$ \\
\hline is & $\because$ & & - \\
\hline weak & 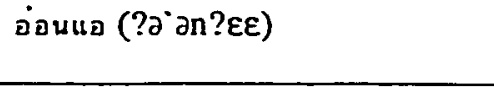 & $\begin{array}{l}\text { อ่อนแอ } \\
\left(? \partial^{\circ} \partial n ? \varepsilon \varepsilon\right)\end{array}$ & \\
\hline
\end{tabular}

4 The descriptions are provided in Longman Dictionary of Contemporary English [Longman 1992]. WordNet [Cognitive Science Laboratory 1998] and Merriam-Webster [Franklin 1987-1998]. 
In shake-and-bake MT, the generation process replaces the SL words in the parse with their corresponding TL words. A number of algorithms were proposed to combine these TL words according to the TL grammar (see section 2.3.3.3). However, none of these algorithms is guaranteed to avoid protracted search times during the generation process.

In interlingual MT, the analysis produces a pure interlingua which does not contain any syntactic information. Generating the TL from this parse could result in a paraphrase, not a translation (see section 2.3.3.3).

In our approach, we generate the translation candidate directly from the SL to avoid these problems: an inaccurate input of the generation process (the SL parse), the information lost during the transfer process, protracted search times during the generation process, the doubt about paraphrase/translation. The TC is revised to ensure that the translation is grammatically correct and preserves the meaning of the SL

\subsection{The Three Phases}

Analysis Lite Machine Translation generates a TC by considering the differences between language pairs in terms of syntax and semantics without performing any sophisticated analysis. ALMT first simplifies the structure of SL and then considers TL words which correspond to all possible meanings of each SL word. The most appropriate TL word is selected by applying a semantic relationship between words. To make the TC grammatically correct in the TL and to retain the meaning of the SL, some words in the TL may be added and then all words are rearranged according to the grammar of the TL. ALMT comprises three modules: word treatment, word selection, and word ordering.

Translation Candidate Evaluation analyzes the generated TC, which is an output of the previous step, ALMT, to determine whether the TC retains the meaning of the SL. TCE performs the evaluation by analyzing both the TC and the SL in terms of syntax and semantics in parallel. Then only the semantic results are compared (there are syntactic level differences between languages). If the semantic results are the same, that $\mathrm{TC}$ will be deemed an acceptable translation. If not, any part of the TC which causes its semantics to differ from that of SL will be repaired in the next phase, RI.

Repair and Iterate will replace inappropriate words or rearrange words in the TC depending on the analysis results of the previous step, TCE. The analysis results will identify 
the incorrect (inappropriate) parts and RI will use the analysis result of the SL as a pattern for repairing the TC.

\subsection{Knowledge-bases Required}

The essential knowledge-bases required for GRMT include: Constraints, Dictionaries, and Grammar and Lexicon. The SL and TL knowledge-bases are developed separately for easy modification, extendibility and management. The details of each knowledge-base will be discussed in later sections where appropriate.

Constraints, the different characteristics between languages, are required in ALMT. There are two sets of constraints: SL constraints and TL constraints. The $S L$ constraints are the characteristics of the SL which are different from those of the TL. They are used to simplify the structure of the SL and to narrow the scope of possible TL words which correspond to each SL word (see section 5.1.1). The TL constraints are the characteristics of the TL which are different from those of the SL. They are required, not only to retain the meaning of SL but also to make them grammatically correct (see section 5.3.1).

The $S L$ dictionary is required in ALMT. It is used in the constraint application and inflectional analysis steps. Each entry contains its syntactic categories. The SL and the TL are put into correspondence via the $S L-T L$ dictionary. The SL-TL dictionary contains the SL entry and its all possible corresponding words in the TL. Each corresponding TL word is related to its Word Association (WordAsso) number (see section 4.2). All TL words are ordered according to the frequency of usage.

Grammars and lexicons of both SL and TL are required in the analysis process of TCE. Grammars and lexicons of SL and TL are developed principally based on the linguistic theories applied to GRMT, Head-Driven Phrase Structure Grammar [Pollard and Sag 1987; Pollard and Sag 1994]. Each lexical entry contains morphological, syntactic and semantic information (see section 6.1.1.3).

\subsection{Translation Examples by GRMT}

In this section we present the results of applying GRMT to the translation of some English example sentences into Thai. The input symbols of Example 2 are shown in the first column labeled input (Table 3.2). The second column illustrates the output after applying 
the constraints. In this example, no constraint is applied. Each word in this column is used as a keyword to search for the corresponding words in Thai. All possible translations in Thai of each input word are shown in the third column. The most appropriate words are selected by ALMT (see section 5.2) and the choices are shown in the fourth column. The classifier ${ }^{5}$ ตัว (tua, in shaded box) is added to complete the TC (details are described in section 5.3.1).

This generated TC and the SL were analyzed in the TCE, the second phase of GRMT. The parses show that the TC requires no repair (see section 6.1.1.6). Thus, the generated TC is a complete translation of Example 2. Table 3.3 presents four different senses of the word spring in the classification system (see section 4.2) and their corresponding words in Thai: ทดูใบไม้ผลิ (ry'duubajmáajphli), สปริง (sapring), กระโดด (kradòod) and น้ำพุ (námphú). Each word is classified into different classes according to its meaning as illustrated in the fourth column of Table 3.3 (see section 4.2). Consider the case that the word ถุดใบไม้ผลิ (ry'duubajmáajphli) is chosen for the word spring ${ }^{6}$ in Example 3 by ALMT as shown in Table 3.4. The TCE indicated the inappropriate selection by comparing

Table 3.2: The selected words and the TC generated for Example 2

Example 2

SL: The ugly duckling hides his head under his wing.

TC: ลูกเป็ด ชี้เหร่ ตัว นั้น ซ่อน หัว ของเขา ใด้ ปีก ชองเขา (lûugpèd- duckling) (khîirèe- ugly) (tua- clas) (nán-the) (sð^ən- hide) (hu־a- head) (khə־ðnkhaw- his) (tâaj- under) (piig- wing) (khð־ ’nkhaw- his)

\begin{tabular}{|c|c|c|c|}
\hline Input & $\begin{array}{l}\text { Constraint } \\
\text { Application }\end{array}$ & Dic. Lookup \& Inflec. Analysis & Selected Word \\
\hline $\begin{array}{l}\text { The } \\
\text { ugly } \\
\text { duckling } \\
\text { hides } \\
\text { his } \\
\text { head } \\
\text { under }\end{array}$ & $\begin{array}{l}\text { The } \\
\text { ugly } \\
\text { duckling } \\
\text { hides } \\
\text { his } \\
\text { head } \\
\text { under }\end{array}$ & 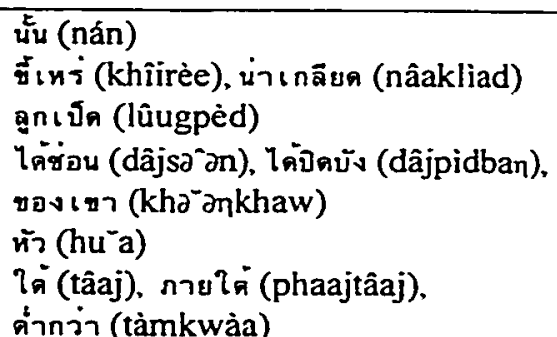 & 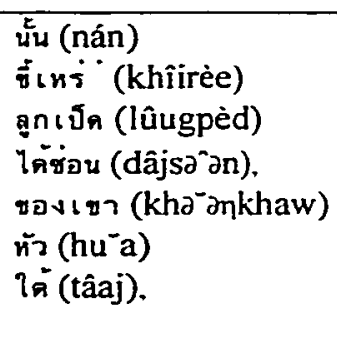 \\
\hline $\begin{array}{l}\text { his } \\
\text { wing }\end{array}$ & $\begin{array}{l}\text { his } \\
\text { wing }\end{array}$ & 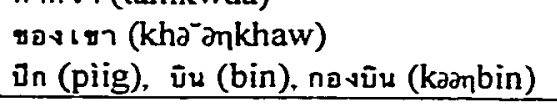 & 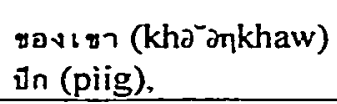 \\
\hline
\end{tabular}

5 In Thai, classifiers are used to express not only a quantity but aiso to modify a noun (see section 4.1 )

${ }^{6}$ In our experiment. ALMT selected the correct corresponding Thai word for the word spring in this expression. This inappropriate selection is to illustrate the repair process (see section 6.1.2.2). 
Table 3.3: Three corresponding Thai words to the word spring

\begin{tabular}{|c|c|c|c|}
\hline English & Thai & Description & Word Class \\
\hline \multirow[t]{4}{*}{ spring } & $\begin{array}{l}\text { ๆดใบไม่ผลิ } \\
\text { (ry'duubajmáajphli) }\end{array}$ & $\begin{array}{l}\text { The season between winter and } \\
\text { summer }\end{array}$ & Season \\
\hline & สปริง (sapring) & An elastic device & Elastic device \\
\hline & nระโคด (kradòod) & To move suddenly upward or forward & $\begin{array}{l}\text { Move forward as } \\
\text { if by jumping }\end{array}$ \\
\hline & น้ำพุ (námphú) & $\begin{array}{l}\text { A place where water comes up } \\
\text { naturally from the ground }\end{array}$ & Geology \\
\hline
\end{tabular}

the SL and the TC parses. The SL parse determined the appropriate meaning of the word spring in this expression is "An elastic device" (see section 6.1.2.2). But in the TC parse, the word ฤดูใบไมผผลิ (ry'duubajmáajphli) means "The season between winter and summer". According to the analysis of analyzing the SL, the RI module replaced the incorrect selection ฤดูในไมผลล (ry'duubajmáajphli) with the word สปริง (sapring) to generate the new TC for Example 3: จอห์น พูด เกี่ยวกับสปริง ที่ หัก อัน ${ }^{7}$ น้น. This new TC was analyzed and compared to

Table 3.4: The selected words and the TC generated for Example 3

Example 3

SL: John talks about the broken spring.

TC: จอห์น พูด เกี่ยวกับ ทดุใบไมผล ที่ ทั่ น้น (cวan- John) (phûud- talk) (kiàwkàb- about) (ry'duubajmáajphli- spring, the season) (thîimodifying) (hàg- broken) (nán- the)

\begin{tabular}{|c|c|c|c|}
\hline Input & $\begin{array}{l}\text { Constraint } \\
\text { Application }\end{array}$ & Dic. Lookup \& Inflec. Analysis & Selected Word \\
\hline $\begin{array}{l}\text { John } \\
\text { talks } \\
\text { about }\end{array}$ & $\begin{array}{l}\text { John } \\
\text { talks } \\
\text { about }\end{array}$ & $\begin{array}{l}\text { จอห์น (çan) } \\
\text { พูด (phûud), บรรยาย (banjaaj), ตุย } \\
\text { (khuj) } \\
\text { เ เี่ยวกับ (kiảwkàb) , ประมาณ (pramaan), }\end{array}$ & $\begin{array}{l}\text { จอห์น (caan) } \\
\text { พูด (phûud) }\end{array}$ \\
\hline & the & ไปทั่ว (pajthûa), เกีอบจ $=(\mathrm{ky}$ abca) & เกยวกบ (KiaWkaO) \\
\hline $\begin{array}{l}\text { the } \\
\text { broken }\end{array}$ & $\begin{array}{l}\text { the } \\
\text { broken }\end{array}$ & $\begin{array}{l}\text { น̌ (nán) } \\
\text { ทัn (hàg) }\end{array}$ & $\begin{array}{l}\text { นัน (nán) } \\
\text { หัn (hảg) }\end{array}$ \\
\hline spring & spring & $\begin{array}{l}\text { ๆดใบไม่นล (ry'duubajmáajphli), } \\
\text { สปริง (sapring), กร=โคด (kradòod), } \\
\text { น้ำพุ (námphú) }\end{array}$ & $\begin{array}{l}\text { ฤดใบไมผผล } \\
\text { (ry'duubajmáajphli) }\end{array}$ \\
\hline
\end{tabular}

${ }^{7}$ The classifier $\mathrm{d}$ (?an) is added during the repair process (see chapter 7). 
the SL parse again and the TCE found no semantic difference between them. Therefore, this new TC is an appropriate translation for Example 3.

\subsection{Key Features of GRMT}

The key features of GRMT are: simplicity, modularity, extendibility and multilinguality, by which we mean the following:

Simplicity Each step performed by GRMT is straightforward and simple to carry out.

Modularity GRMT's translation process is separated into three modules: ALMT, TCE and RI. Each module is comprised of sub-modules for easy modification and maintenance. ALMT is comprised o.f word treatment, word selection and word ordering. Word treatment deals with the syntax of the SL while the word ordering is concerned with the a syntax of the TL. The SL and TL are treated separately and related via the SL-TL dictionary. The SL and the TC analysis modulies in the TCE are separated. The repair process in the RI module does not depend on languages, it can be applied to any languages pair. The knowledge-bases: constraints, dictionarie s, grammars and lexicons required in GRMT are developed separately.

Extendibility GRMT is intended to be easily extendible to any other language. Since each component is separated not only in the translation process components but also in the knowledge-bases, each component can be extended easily to a larger domain. The constraints of the SL and those of the TL are developed separately. The SL-dictionary contains only the word form and its syntactic categories information. The SL-TL dictionary contains the SL word form and its corresponding words in the TL with its WordAsso numbers. The grammars we developed are based on the HPSG formalism which provides for adequate coverage of the language with few grammar rules. HPSG theory is a lexically oriented theory and lexical entries are complex. The lexicons are very rich in information and well organized. The lexical rules reduce the number of lexical entries (see section 6.1.1.3). Therefore, the knowledge-bases of ne:w languages can easily be integrated into GRMT which is suitable for multilingual machine translation.

Multilinguality GRMT is designed to be amenable to a multilingual MT system. The multilinguality feature depends on the modularity and extendibility features of the system. GRMT is highly modular and extendible in two major respects. The first respect is the treatment of the SL and TL are independent of each other which means the same output of the SL constraints application module can be an input to more than one TL Word selection 
module, provided that those TLs share common characteristics. The second respect is the knowledge-bases of the SL and TL required are developed separately, hence it is easy to add the new languages to the system. For example, the SL-constraints (e.g., Plurality, Continuous tense, Adjective and so on; see section 5.1.1) required in translating from English into Thai can be applied to the translation from English into Chinese and Japanese since Chinese. Japanese and Thai share those characteristics. Where French and Spanish share the same syntactic features with English, features which differ from those of Thai, Chinese and Japanese, then GRMT requires six analyzers and two sets of constraints to perform the translation between the two language families (Figure 3.2) while the transfer MT approach requires six SL analyzers, six TL generations and eighteen sets of transfer rules.
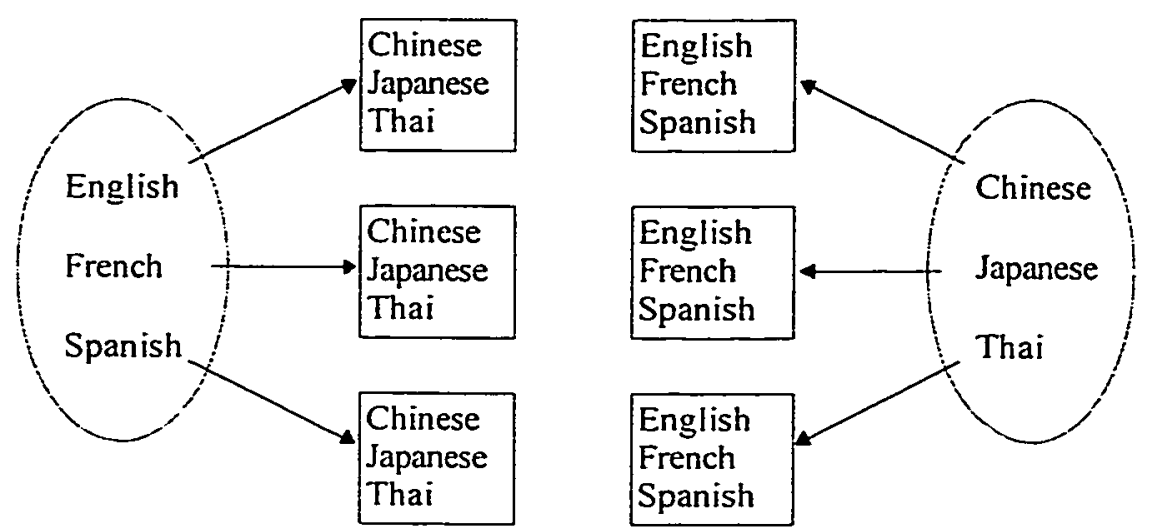

Figure 3.2: The translation between languages of two language families ${ }^{8}$

We now go onto considerable detail of how GRMT works, first considering the English and Thai languages used to illustrate GRMT.

\footnotetext{
${ }^{8}$ While Chinese is a member of the Sino-Tibetan language family and Thai and Japanese are not: Japanese is not proven to be related to any language family, but the most discussed possibility is that it could be a distant relative of the Altaic language family. Thai is a member of the unrelated Tai family [Crystal 1987]. However, Chinese, Japanese, and Thai are typologically similar in a number of ways (share certain features of phonology and syntax), which is why they have been grouped here. English, French, and Spanish, in contrast are all members of the same language family. Indo-European (This information provided by Dr. Brent D. Galloway).
} 


\section{Chapter 4}

\section{Differences Between Languages: The English and Thai Languages}

An advantage employed by GRMT is its treatment of the differences between languages. Some significant characteristics of the source language and the target language, English and Thai in this experiment, are described in this chapter and exploited by GRMT. We conclude this chapter with the word classification and their usage in GRMT.

\subsection{Differences between Thai and English}

Thai is the standard spoken and literary language of Thailand. Thai is basically monosyllabic in word form. In addition to consonants and vowels ${ }^{\prime}$, each syllable has one of five phonemically differentiated tones (middle, low, falling, high and rising). The Thai language is written as a string of words with no explicit boundary marker between words. Different segmentations result in different meanings or no meaning. In this dissertation, a space is used to specify the word boundary in order to make interpretation simple and clear to the reader.

In Thai, morphology is restricted to derivation ${ }^{2}$ since the language makes no use of inflection ${ }^{3}$. The word form does not change according to its parts of speech. In other words, the same word form can be a noun, verb, adjective and so on (some examples are shown in

\footnotetext{
Thai has 44 consonants. 21 vowel forms and 32 vowel sounds.

2. Inflection provides the various forms of any single word while Derivation creates new words from the old ones [Covington 1994].
} 
Table 4.1: Descriptions and the English corresponding words of คน (khon), เขา (khaw) and ที่ (thii)

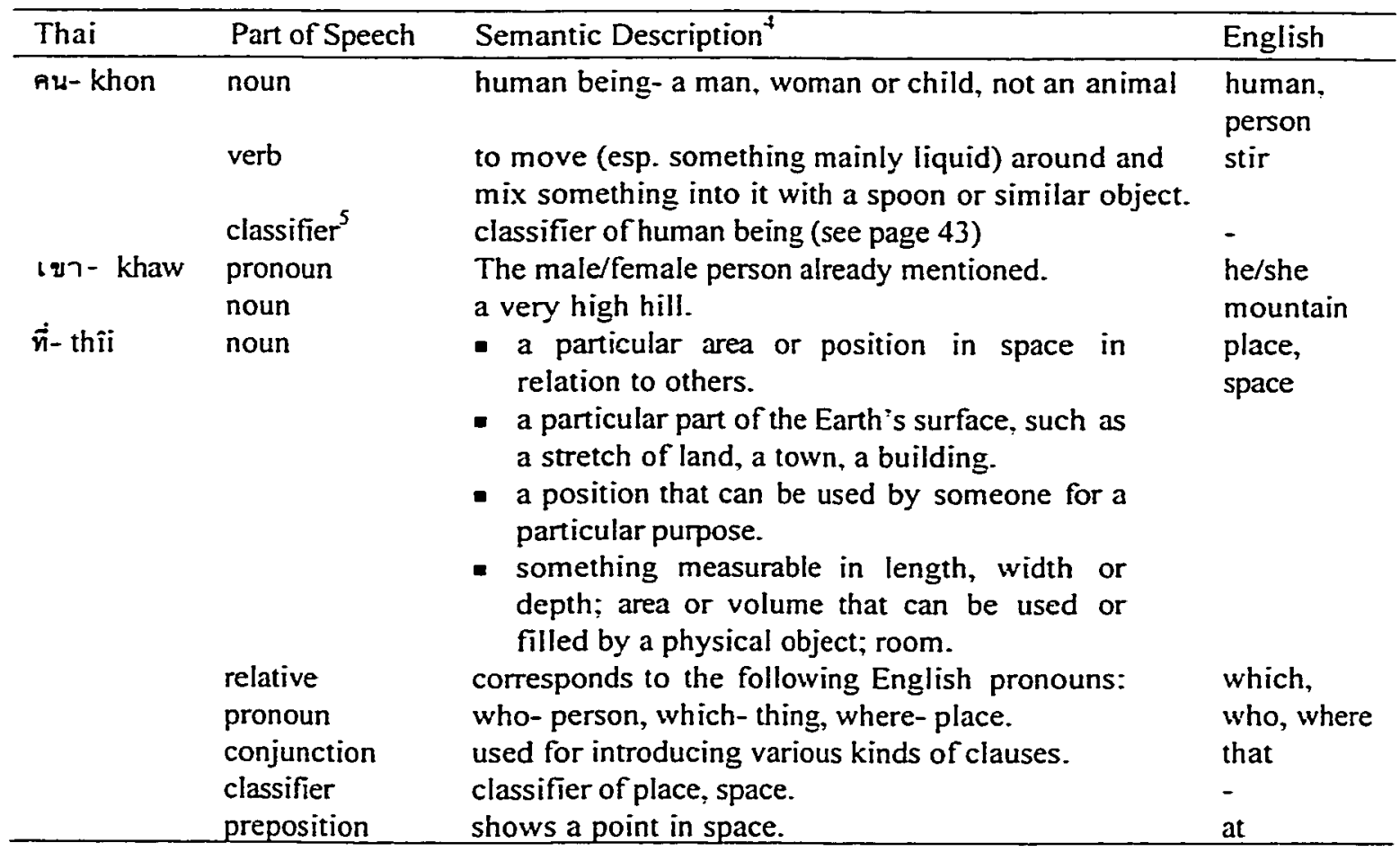

Table 4.1). There is no inflection due to "verb agreement", "tense", "passive voice" and "number". The non-inflection feature leads to the number of constraints which are used in the first phase, ALMT, of GRMT (see section 5.1.1).

The Thai verb does not have an inflection resulting from verb agreement. In Figure 4.1, it does not matter what the subject is, the word eat is translated as nิน- kin. Tense, passive voice and number can be indicated by additional words as shown in Table 4.2. The words กำลัง

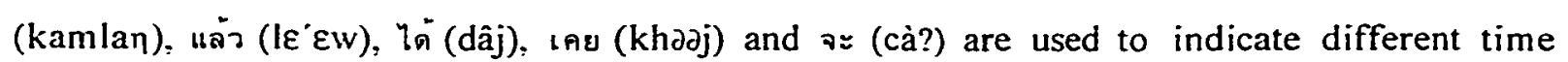
aspects.

${ }^{4}$ Semantic descriptions are provided from Longman Dictionary of Contemporary English [Longman 1992] and Thai-English Student's Dictionary [Haas 1964]

5 Classifiers indicate the unit of a countable noun (see page 43 ).

6 Gerunds (e.g., parking, fishing.) and present participles as adjectives (e.g., boring, terrifying) are exceptions. 
I eat rice every day.

He eats rice every day.

They eat rice every day.

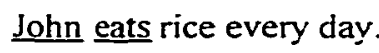

อัน กิน ร่าว ทุก วัน (chân- I) (kin- eat) (khâaw- rice) (thúg- every) (wan- day) เขา กิน ข้าว ทุก วัน (khaw- he) (kin- eat) (khâaw- rice) (thúg- every) (wan- day) พวกเทา กิน ข้าว ทุก วัน (phûagkhaw- they) (kin- eat) (khâaw- rice) (thúg- every) (wan- day) จอห์น กิน ข้าว ทุก วัน (cəən- John) (kin- eat) (khâaw- rice) (thúg- every) (wan- day)

Figure 4.1: Examples of กิน (kin) and its subjects

- กำลัง (kamlan) is used before the verb ${ }^{6}$ to mark an on-going or progressive action.

- แล่ว ( $\left(\varepsilon^{\prime} \varepsilon w\right)$ shows past tense and denotes a completed action. แล่ว ( $\left.\mid \varepsilon^{\prime} \varepsilon w\right)$ appears immediately after the verb and its object or right after the verb if there is no object.

- ได้ (dâj) also shows past tense. It immediately precedes the verb. It is often used in conjunction with แล่ว ( $\left(\varepsilon^{\prime} \varepsilon w\right)$.

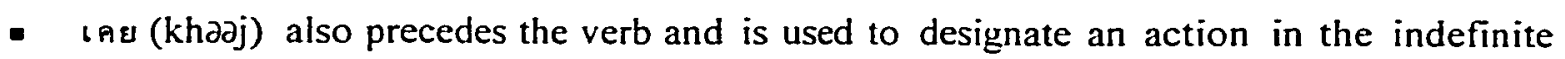
past.

- จะ (cà?) is used to mark an action to be completed in the future. It always appears directly before the verb.

Some examples are illustrated in Figure 4.2. Tenses can also be conveyed by context, or by means of adding time indicators e.g., today, tomorrow, last year, yesterday. A phrase can refer to an action at any time, without a time reference.

Table 4.2: Additional words to express Tense, Passive Voice and Plurality in Thai

\begin{tabular}{lll}
\hline Thai & English & Description \\
\hline กำลัง (kamlan) $+\mathrm{V}$ & $\mathrm{V}$ to be $+\mathrm{V}$-ing & aspect \\
$\mathrm{V}+(\mathrm{obj})+$ แล้ว $\left(\mathrm{I}^{\prime} \varepsilon w\right)$ & $\mathrm{V} 2$ & past tense \\
ได้ (dâj) $+\mathrm{V}+$ แล่ว $\left(l \varepsilon^{\prime} \varepsilon w\right)$ & $\mathrm{V} 2$ & past tense \\
จะ (cà?) $+\mathrm{V}$ & will $+\mathrm{V}$ & future tense \\
ถูก (thủug) $+\mathrm{V}$ & $\mathrm{V}$ to be $+\mathrm{V} 3$ & passive voice \\
$\mathrm{N}+$ หลาย (la`aj) & $\mathrm{N}-\mathrm{s}, \mathrm{N}$-es & plurality \\
\hline
\end{tabular}


In Thai, passive voice is rarely used. It is used mainly when discussing an unpleasant situation; Figure 4.3 illustrates some examples. The word ถูก (thùg) denotes the passive voice in Thai. In the third example, the first of the two Thai sentences, which is passive, is not generally used in Thai even though it is grammatically correct. The second sentence carries the same meaning but it is in active voice.
I am swimming.
จัน กำดัง ว่ายน้า
He bought a book.
(chân- I) (kamlan- ing) ('wâaj-nảam'- swim)
The duckling hid in the farmyard.
เขา ซื้อ หนังสือ แลว

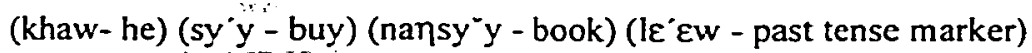 ลูกเป็ด ตัว น้น ได้ ชืน ใน ลานติดโรงนา แห่ง นั้น (lûugpèd -duckling) (tua-classifier') (nán-the) (dâj-past tense marker)

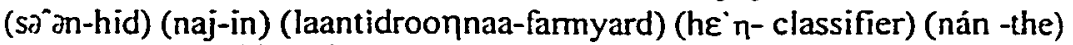
The wedding will take place in December. การแต่งงาน น้น จะ มีที้น ใน เดือนธันวาคม (kaantعं nnaan- wedding) (nán-the) (cà?- will) (miikhy"-take place) (naj-in) (dyanthanwaakhom- December)

Figure 4.2: Examples of additional words to indicate different ttenses and aspects.

He was killed.

He was arrested.

The book was taken by him.

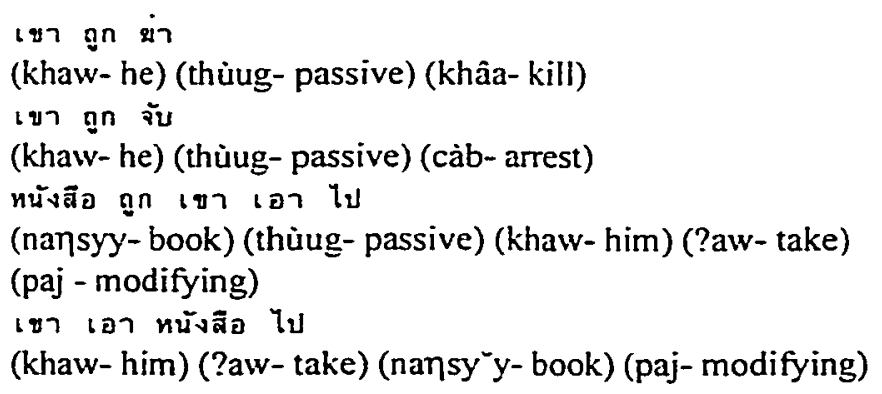

Figure 4.3: Examples of passive voice in Thai.

In Thai, to express a quantity of countable nouns, either by quantifiers e.g., หลาย ${ }^{7}$ (la ${ }^{\circ} a j$ ), บาง ${ }^{8}$ (baan) or numbers, classifiers are required. A classifier indicates the unit of a noun, each countable noun is compatible with a specific classifier (see Figure 4.4).

\footnotetext{
${ }_{8}^{7}$ หลาข- la aj corresponds to the word many in English.

8 บาง- baan corresponds to some in English.
} 
The structure of a Thai phrase is similar to that of English in that the typical sentence contains subject, verb and object, in that order. However, some structures are different e.g., in Thai the head (noun) must precede its attributes, possessive pronouns and determiners. The negative of "can", and "could" is formed in the reverse order of the order in English. Some examples are shown in Figure 4.5. These differences must be considered in the ordering process (see section 5.3).

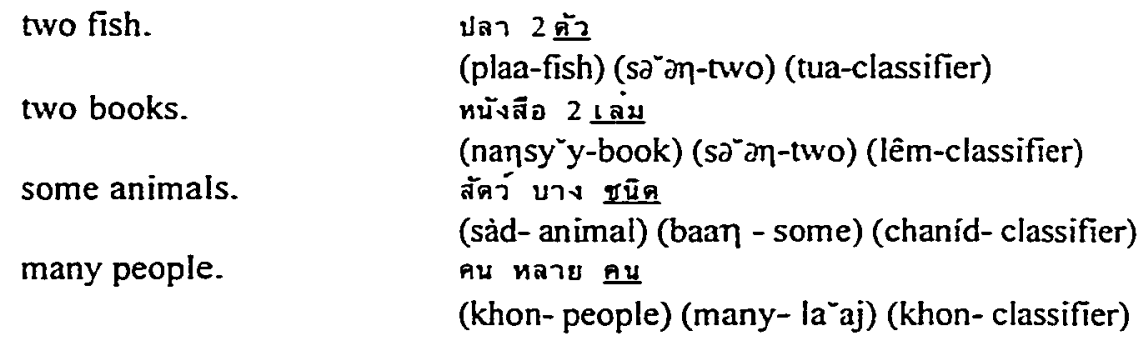

Figure 4.4: Examples of classifiers

In addition, auxiliary verbs in English are needed in many cases, e.g., in front of an adjective or negative "not", but they are not used in Thai for the same expression as shown in Figure 4.6. The English pronoun "there" followed by auxiliary "to be" shows that something or someone exists or happens (see Figure 4.6). "There" plus auxiliary "to be" corresponds to the word $\tilde{ม}$ (mii) in Thai. These differences are considered in the constraint application process.

\begin{tabular}{|c|c|}
\hline gray ugly duckling & ลูกเป็ด ชี้เหร่ สีเทา \\
\hline her brown hen & (lûugpèd- duckling) (khîirèe- ugly) \\
\hline the old lady & 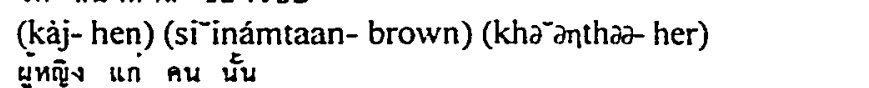 \\
\hline should not & $\begin{array}{l}\text { (phûuji }{ }^{\prime} \text { - woman) }\left(k \varepsilon^{\circ} \varepsilon \text { - old) (khon -classifier)(nán -the) }\right. \\
\text { ไม่ ควร } \\
\text { (mâj-not) (khuan -should) }\end{array}$ \\
\hline
\end{tabular}

Figure 4.5: Examples of Thai attributive constructions 
Of course there are additional significant differences between Thai and English. The differences illustrated in this section are to provide the reader with some insight of differences GRMT takes advantage of in generating accurate translations.

\subsection{Word Classification}

In chapter 3, we sketched the overall architecture of GRMT in which the relationship between words was employed in several modules e.g., TL word selection and classifier selection in ALMT (the classifier selection is applied to some languages which require classifiers e.g., Thai, Chinese, Japanese), analysis in TCE, comparison and repair in RI. The semantic relationship between words was built based on the words' classes. In this section, we discuss our word classification technique and criteria by which we created the semantic relationship between words and word classes.

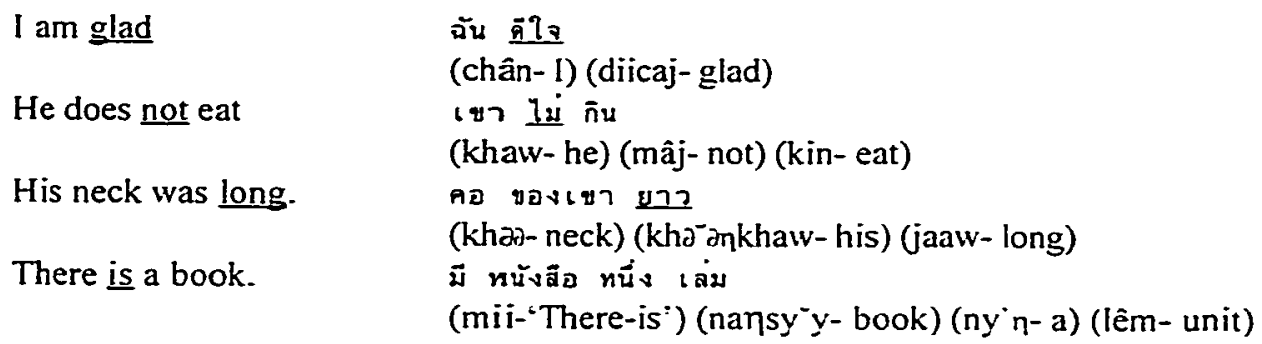

Figure 4.6: Examples of Thai constructions without auxiliary verb

In designing our word classification, we have considered the $A$ Kind Of (AKO) relation which was designed to be used in the CICC MMT project (see section 2.3.3.1), the topic hierarchy for physical objects [Cercone et al. 1992] and Hypernym in WordNet 1.6 for English [Cognitive Science Laboratory 1998] with significant introspection?.

\footnotetext{
${ }^{9}$ Different point of view will result in different epistemologies (word classification). What important is that independent of epistemologies, the same classification be usc across languages to whatever extent possible. Our word classification is the first attempt based on the CICC AKO. topic hierarchy for physical objects. and Hypernym in WordNet 1.6. as GRMT evolves so will the word classification.
} 
In the CICC MMT project; $\mathrm{AKO}$, co-occurrence information and concept identifier (concept-id) were developed. $\boldsymbol{A K} \boldsymbol{O}$ is basically a relationship between a word and its concept class (or semantic domain). Each participating country developed the concept classification for its language based on its own criteria; therefore, the resulting AKO systems are different. For example, the Thai concept classification was developed by grouping words with a specific definitions into the same class [CICC 1995f]. A part of Thai concept classification is shown in Figure 4.7. Each class was assigned a number. The digit which comes after a hyphen "-" is the subclass number, the digit which comes before a hyphen is the superclass number. For example, Animal with AKO number $1-1-2$ is a second subclass of the superclass $1-1$ which is an AKO number of a class Living Thing. The Indonesian concept classification (Figure 4.8) was developed based on syntactic categories, e.g., nouns are classified into two main classes: concrete thing and abstract thing; verbs are classified into class event with three subclasses state, process and action. Adjective and adverb are classified into classes properties and manner respectively [CICC 1995b]. The numbering system of the Indonesian AKO is the same as that of Thai AKO. However, AKO specifications for Thai, Indonesian and Chinese have the same problems regarding consistency and coverage [CICC 1995a; CICC 1995g; CICC 1995h].

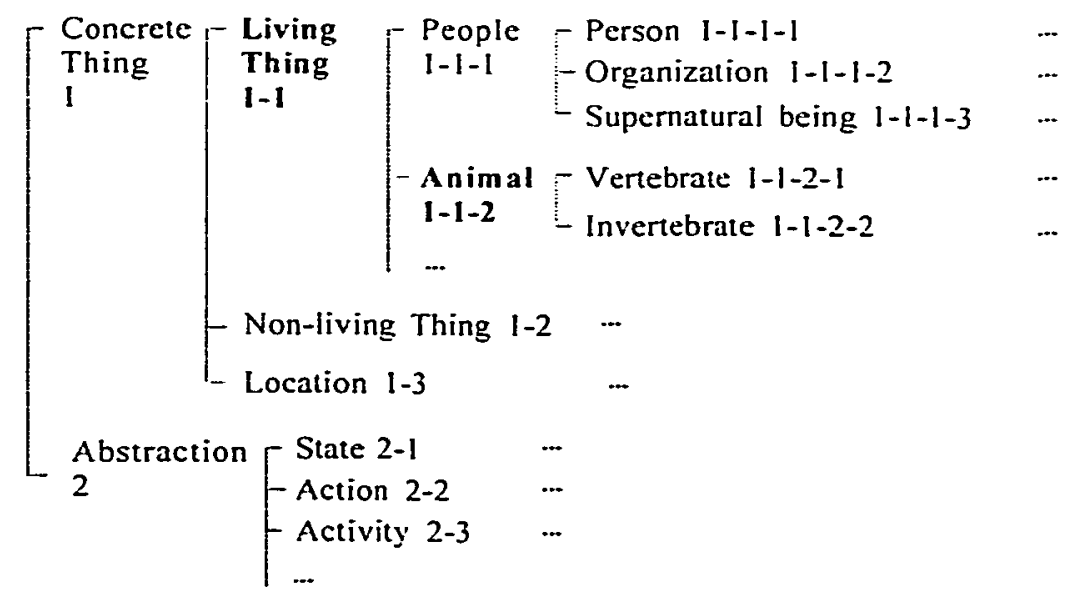

Figure 4.7: A part of Thai Concept Classification (CICC MMT)

Co-occurrence information indicates the syntactic relationship between words e.g., subject and verb relation, verb and second complement relation [CICC 1995j]. Thai co- 
occurrence information was designed from the co-occurrence of two to five adjacent words. The Indonesian version only considered co-occurrence from two adjacent words [CICC $1995 c]$.

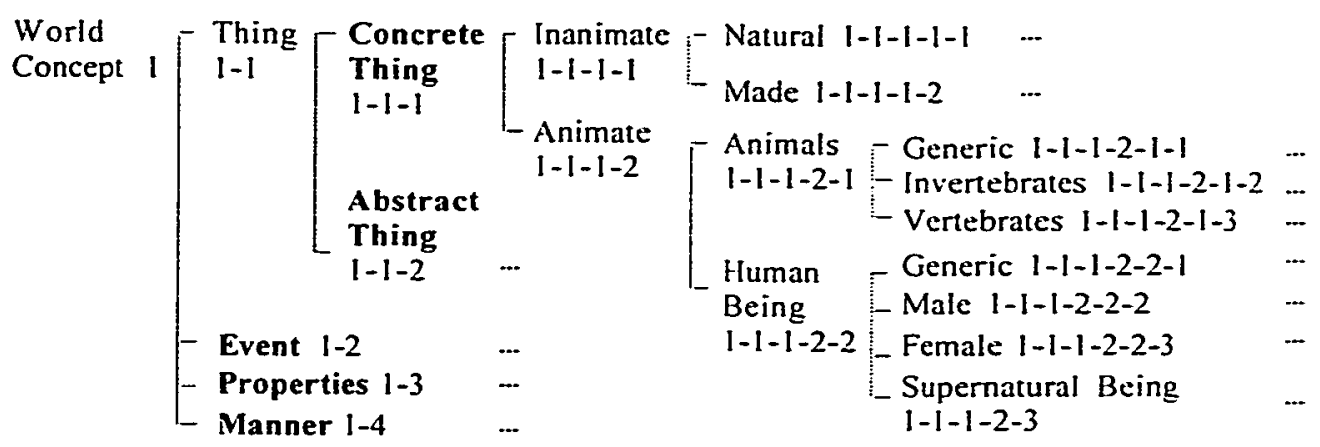

Figure 4.8: A part of Indonesian Concept Classification (CICC MMT)

Concepts (variant meanings or allosemes) of words in each language were assigned a concept-id. For example, the concept-id $3 b e 7 d 8$ is assigned to the Thai word เครื่องกรอง

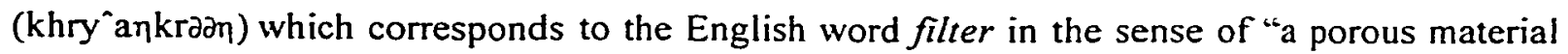
through which a fluid is passed to separate out matter in suspension." [CICC 1995g]. Each country designed its own concept-id system. Therefore, a concept-id linking table was needed to link the concepts of each language to IL.

In the Thai analysis process, AKO and syntactic information were used to determine the semantic relationship between two nouns [CICC 1995f]. For example, the syntactic categories of นายแพทย์ (naajph $\varepsilon^{\wedge} \varepsilon d$ ) and สุนทร (su־nthəวn), Example 1, are title noun and proper noun (Table 4.3); therefore, the semantic relationship between นายแพทย (naajph $\varepsilon^{\wedge} \varepsilon d$ ) and สุนทร (su"nthəan) is "name" according to the information available in Table 4.4. The semantic relationship between ปลan (plàg) and ปาnกา (pàagkaa), Example 2, is "part-of" since their syntactic categories are common nouns with the AKO numbers 1-2-6 and 1-2-5-1-2 respectively.

Co-occurrence information was used to solve lexical ambiguity problems [CICC 1995j]. In the Thai generation process, co-occurrence was used in selecting the surface form of verbs and adjectives. For example: the word beautiful in "beautiful lady" corresponds to the 
wordสวย (su`aj) which means "having beauty". However, the word beautiful in "beautiful song" corresponds to the word เพราะ (phra') in the sense of "very good" according to the cooccurrence information available in Figure 4.9 [CICC 1995i].

\section{Example 1: นายแพทย์ สนทร}

(naajph $\left.\varepsilon^{\wedge} \varepsilon d-D r.\right)$ (su`nthəən- Sunthorn)

Example 2: ปลอก ปากกา

(plə⿳亠口冋- cap) (pàagkaa- pen)

Table 4.3: Some information of the words นายแพทย์, สุนทร, ปลอก and ปากกา

\begin{tabular}{|c|c|c|c|c|}
\hline Thai & $\begin{array}{l}\text { Corresponding } \\
\text { Word in English }\end{array}$ & $\begin{array}{l}\text { Syntactic } \\
\text { Categories }\end{array}$ & AKO & Description \\
\hline 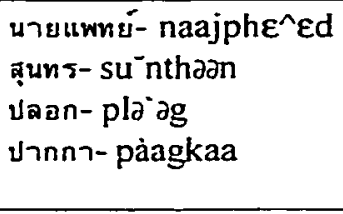 & $\begin{array}{l}\text { Dr. } \\
\text { Sunthorn } \\
\text { cap } \\
\text { pen }\end{array}$ & $\begin{array}{l}\text { title noun } \\
\text { proper noun } \\
\text { common noun } \\
\text { common noun }\end{array}$ & $\begin{array}{l}- \\
1-2-6 \\
1-2-5-1 \\
-2\end{array}$ & $\begin{array}{l}\text { Abbreviation of doctor. } \\
\text { person's given name. } \\
\text { a movable cover } \\
\text { an instrument for writing or } \\
\text { drawing with ink. }\end{array}$ \\
\hline
\end{tabular}

Table 4.4: Semantic relationships assigned for noun-noun combination in CICC MMT

\begin{tabular}{lll}
\hline $\begin{array}{l}\text { Semantic } \\
\text { relationship }\end{array}$ & $\begin{array}{l}\text { Syntactic category and } \\
\text { AKO number }\end{array}$ & $\begin{array}{l}\text { Syntactic category and } \\
\text { AKO number }\end{array}$ \\
\hline modifier & collective noun & common noun \\
& AKO $=2-3-4$ & \\
part of & common noun & common noun \\
& AKO $=1-3-1-1-2,1-3-1-1-4$, & AKO $=1-1-1,1-3-1-1,1-3-1-1-3$, \\
& \multicolumn{1}{c}{$1-3-2-3,1-2-6$} & proper noun \\
name & title noun &
\end{tabular}

เwsา:
/phr@/
c\#beautiful
BEAUTIFUL
ECAT. $\{\mathrm{V}\}$
ESUBCAT.\{VATT\}
EMAPS. $\{$ SUB=ATT\}
ATT.\{c\#song

Figure 4.9: A co-occurrence of the word เพราะ (phrd') [CICC 1995i] 
AKO was used in the analysis process of Indonesian and Chinese also but no public document was produced to show how AKO was used. In the Indonesian generation process, co-occurrence was used to determine whether the occurrence of two adjacent words in a sentence was correct [CICC 1995d].

Developing an AKO system required great effort; however, AKO application was not fully utilized in the CICC MMT system. Our explorations revealed that suitably constructed AKO information is useful in selecting the surface form of TL words in a translation process and it helps to determine the occurrence of adjacent words in the expression. In addition, if AKO information for each language was designed using the same criteria, the AKO information might also be used in linking concept-id.

The topic hierarchy for physical objects was designed to be used in the English Conversation System (ECO) family formalism of semantic network [Cercone et al. 1992]. ECO was developed at University of Alberta during 1974-1978 by Len Schubert, Nick Cercone, Randy Goebel and Al Covington. ECO represents an extended semantic network formalism which is used for representing troublesome natural language constructions, e.g., logical connectives, quantifiers, descriptions, modalities. ECO classifies propositions according to their topic e.g., color proposition, location proposition, size proposition and so on. ECO structures propositions associated with each concept according to a topic hierarchy. A topic is defined as a predicate over proposition-concept pairs. For example, for the proposition $A$ zebra has black and white stripes, a topic predicate coloring is instantiated in relation to the concept zebra. Topic predicates which are linked by subtopic and supertopic form a topic hierarchy. Topic hierarchies provide a basis for organizing the propositions attached to a node of a particular kind. Topic hierarchies are useful in organizing the retrieval of information relevant to the implications of concepts. To accelerate a deductive inference for Types in the ECO family, the partitioning hierarchies of type predicates are used as a logical representation of the relationships among the predicates that appear in the hierarchy. Figure 4.10 illustrates a partitioning type hierarchy for thing. The numbers following the predicates are assigned when the hierarchy is created or changed. This number is used to determine the 


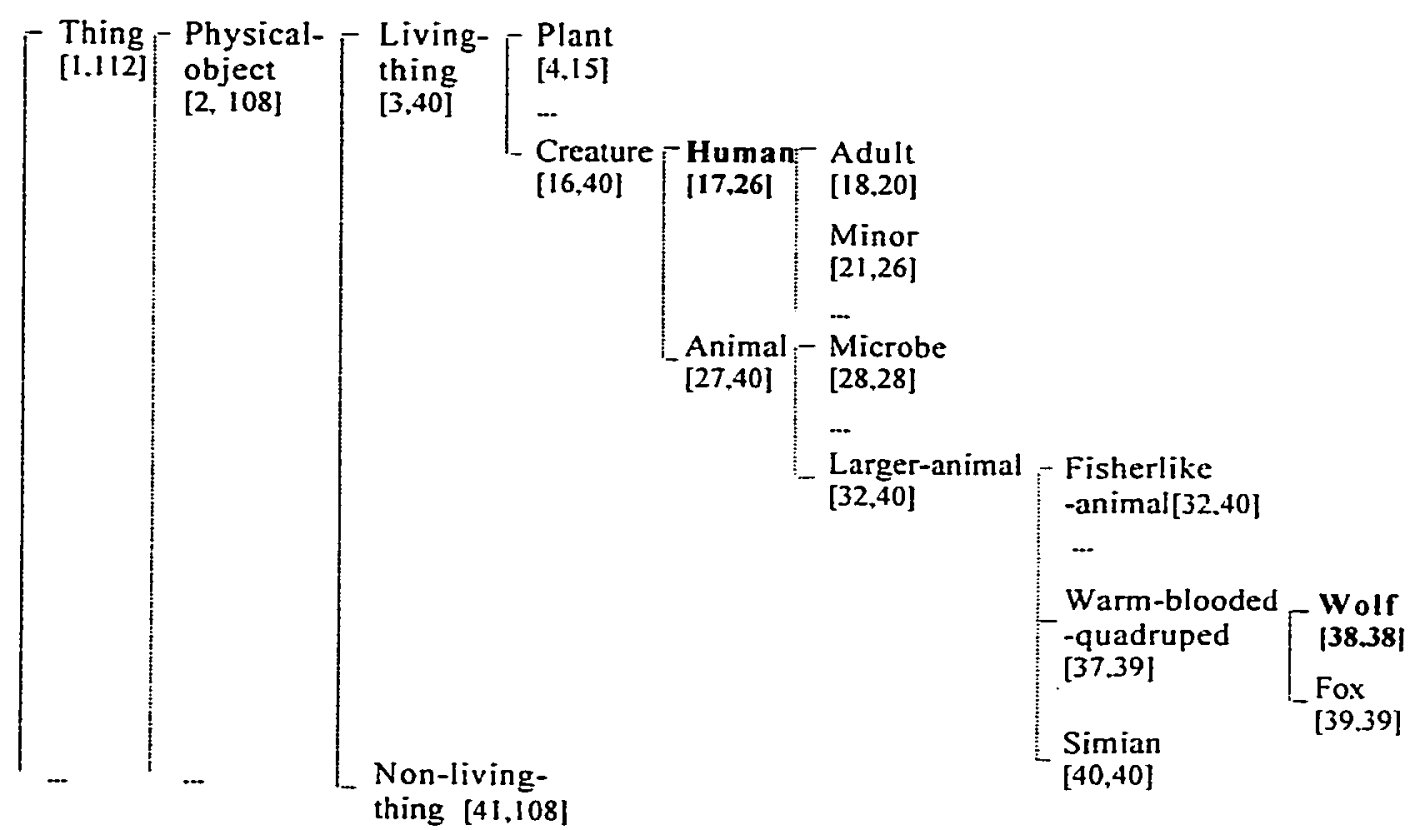

Figure 4.10: A partition type hierarchy for thing [Cercone et al. 1992]

subsumption or disjointness relationships. For example: wolf and human are disjoint because there is no overlap between the numbering range associated with wolf $[38,38]$ and human $[17,26]$. Wolf is subsumed by creature because wolf $[38,38]$ is ranged within creature $[16,40]$. The same predicate can appear in several hierarchies, all connected at that predicate. Overlap hierarchies are also possible.

WordNet $\mathbf{1 . 6}$ is a program that allows users to explore an on-line dictionary on the basis of semantic, rather than alphabetic, similarities [Cognitive Science Laboratory 1998]. WordNet does not contain syntagmatic relations linking words from different syntactic categories because the syntactic categories noun, verb, adverb and adjective are treated separately due to the semantic differences between the relations that link words and concepts from those syntactic categories [Fellbaum 1998]. For example, the relation that links nouns differs from the relation that links verbs. The semantic relation that is most important in organizing nouns is a relation between lexicalized concepts. This relation is called Hypernym. Hypernym is the generic term used to designate a whole class of specific instances. $Y$ is a hypernym of $\mathrm{X}$ if $\mathrm{X}$ is a (kind of) $\mathrm{Y}$. For example: bird is a hypernym of robin. This semantic relation organizes nouns into a lexical hierarchy. A lexical hierarchy can be reconstructed by following the trail of hypernymically related synonym sets. The semantic relation between sets is is-a or is-a-kind-of. This hierarchy goes from many specific terms at the lower levels to a few generic terms at the top. The nouns in WordNet form a lexical 
inheritance system where by all of the properties of the superordinate are assumed to be properties of the subordinate as well. For example: according to the WordNet; robin is-a thrush, a thrush is-an oscine, an oscine is-a passerine, a passerine is-a bird. Therefore, robin inherited perching from passerine, singing from oscine, and flying and migration from thrush (This example is taken from [Miller, 1998]). In WordNet, verbs are grouped together as sets of synonyms, like nouns. However, the semantic relation between set of verbs is expressed by is one way to. For example: see is-one-way-to perceive, drink is-one-way-to consume or ingest.

We further developed our notion of word classification by classifying words into categories based on shared characteristics. From ECO we borrow the notion that subclasses are subsumed by their superclasses, cf., the topic hierarchy for physical objects. Words in our classification form a lexical inheritance system like nouns in WordNet. Since we were concerned with consistency as well and we wanted to apply this classification in MT, we needed to classify words in any language under the "same umbrella" even though there were differences at some levels between different languages. Our solution is to classify words into categories according to the same criteria, regardless of language as discussed in the next section.

\subsubsection{Word Classification Criteria}

In GRMT, word classification information is applied to be used in word selection, classifier selection, TCE analysis, comparison and repair processes.

To select the most appropriate word for each input word in ALMT, we consider the relationship between the close proximity words. We must know which word can occur with which word in the same expression. To obtain that information, semantic information of each word should be considered and also the semantic relationship between proximity words. Thus, the criteria used in classifying words considers the definition or meaning of words and their usage. Words which share significant features are classified into the same group. With these criteria, words in GRMT dictionaries are classified into thirteen categories: Thing, Abstraction, Phenomenon, Event, State, Be, Reference term for thing, Group/Grouping, Be able to, Get/Acquire, Have, Accumulate/Collect, and Attribute value. New categories can be added in future if it is necessary to do so. A classification fragment is shown in Figure 4.11 (see also appendix A). 
Since we classified words not only according to their meaning but also their usage, words in the same class will automatically be in the same syntactic category, e.g., words in the class thing are nouns, words in the class act (a subclass of abstraction) are verbs, words in the class attribute value are adjectives and adverbs. The semantic relation between classes and their superclass is is-a. For example: turkey is-a fowl, fowl is-a bird, bird is-a vertebrate, vertebrate is-an animal, animal is-a living thing, living thing is-a concrete thing, concrete thing is-a thing; say is-a way to utter, utter is-a way to communicate, communicate is-a way to interact, way to interact is-a way to act, act is-an abstraction. The semantic relation forms a lexical inheritance hierarchy which generally means all properties of the superclass are assumed to be

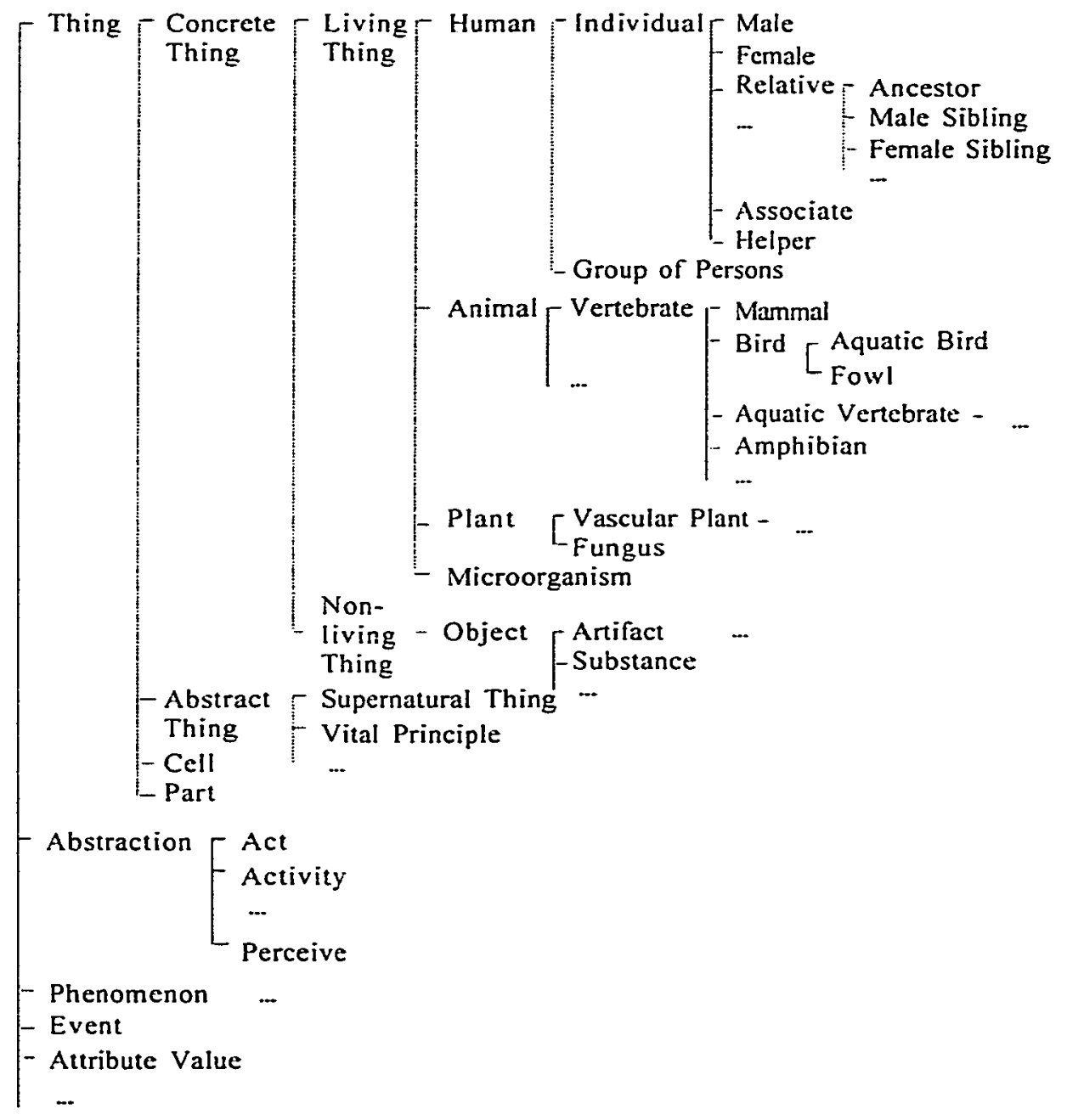

Figure 4.11: A part of word classification in GRMT. 
properties of the subclasses as well. This property is useful in the comparison step of TCE, the second phase of GRMT.

A word can be classified into more than one class depending on context and usage. For example: turkey is also classified into the class of poultry, poultry is-a meat, meat is-a foodstuff, foodstuff is-a food, food is-a substance, substance is-an object, object is-a nonliving thing, non-living thing is-a concrete thing, concrete thing is-a thing.

Words which are used to link phrases with clauses or connect clauses together or provide the basis for a descriptive phrase e.g., prepositions, conjunctions, definite determiner are classified as well. A separate classification is built for those words, see appendix D for examples.

The scope of any class can be narrowed, if necessary, by subdividing a class into subclasses. For example, consider the class "vehicle". If we classify "vehicle" into two subgroups by mode of transportation as shown in Table 4.5: by land, and by sea or by air. Then the classifiers คัน-khan and ขบวน (khabuan) are compatible with the first subgroup, by land, while the classifier ลำ- lam is compatible with the second subgroup, by sea or by air. The group "by land" can be classified further into "Train" and "Road/Rails vehicle (but not train)". The classifiers ขบวน (khabuan) and คัน (khan) are compatible with the group "train" and "Road/Rails vehicle" respectively. This classification is used to select an appropriate classifier for a noun if it is required, in the word addition step of ALMT and the analysis process of TCE.

Table 4.5. The subgroup of vehicle.

\begin{tabular}{|c|c|c|c|}
\hline Class & Subclass & Examples & Classifier \\
\hline Land & $\begin{array}{l}\text { Train } \\
\text { Road/ } \\
\text { Rail } \\
\text { vehicle }\end{array}$ & $\begin{array}{l}\text { รถ ไฟ (ródfaj-train) } \\
\text { รถยนต์ (ródjon-automobile) } \\
\text { รถพ่วง (ródphûan-trailer) } \\
\text { รถลาก (ródlâag-rickshaw) } \\
\text { รถม่า (ródmáa-horse carriage) } \\
\text { รถจักรยาน (ródcàgkajaan-bicycle) } \\
\text { รถราง (ródraan-streetcar, tram) }\end{array}$ & $\begin{array}{l}\text { ขบวน (khabuan) } \\
\text { คัน (khan) }\end{array}$ \\
\hline $\begin{array}{l}\text { Air or } \\
\text { Sea }\end{array}$ & & $\begin{array}{l}\text { เรือใบ (ryabaj-sailboat) } \\
\text { เรือหางยาว (ryaha"anjaaw-"Iong-tailed boat") } \\
\text { เครื่องบิน (khry^ąbin-"airplane") }\end{array}$ & ลำ (lam) \\
\hline
\end{tabular}


For efficient MMT, words in different languages must be classified into the same classification system, some examples are shown in Table 4.6. For example, we can use the classification information of each word as a part of the semantic information of any phrase which contains that word. The last issue that we must be concerned with in classifying words is "consistency".

Each class is assigned a number which is called Word Association (WordAsso) number. WordAsso number represents a relation between a word and its class. Words which belong to the same class are assigned the same WordAsso number. We number classes using the convention that was used in CICC AKO for Thai. The digit which comes after a hyphen "_" is the subclass number, the digit which comes before a hyphen is the superclass number. For example, in Table 4.6, Imaginary creature with WordAsso number 1-2-1-2-2 is a second subclass of the superclass 1-2-1-2 which is a WordAsso number of a class Imaginary being. The class Imaginary being is the second subclass of a class Supernatural thing with WordAsso number 1-2-1. This numbering system is used for easy modification.

Table 4.6: Some classified English and Thai words

\begin{tabular}{|c|c|}
\hline Class & Sample Word \\
\hline \multicolumn{2}{|l|}{1 Thing } \\
\hline \multicolumn{2}{|l|}{ I-2 Abstract thing } \\
\hline \multicolumn{2}{|l|}{ 1-2-1 Supernatural thing } \\
\hline $1-2-1-1$ Supernatural being & 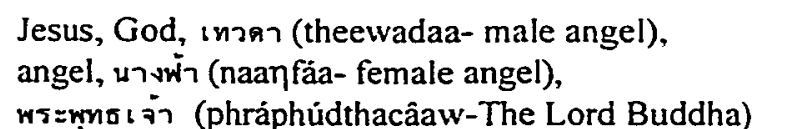 \\
\hline I-2-1-1-I Spirit & ghost, $\bar{a}$ (phi'i-ghost) ร̄ญญาณ (winjaan- spirit, soul) \\
\hline \multicolumn{2}{|l|}{ |-2-1-1-1-1 Good spirit } \\
\hline 1-2-1-1-1-2 Evil spirit & $\begin{array}{l}\text { satan, devil, demon, ผีปอป (phi`ipə`ab- ghoul) } \\
\text { ปศาจ (piisàad- devil, demon) }\end{array}$ \\
\hline \multicolumn{2}{|l|}{ 1-2-1-2 Imaginary being } \\
\hline 1-2-1-2-1 Imaginary person & $\begin{array}{l}\text { Santa Claus, tooth-fairy, mermaid, } \\
\text { นางเ จือก (naanny^ag-mermaid) }\end{array}$ \\
\hline $1-2-1-2-2$ Imaginary creature & $\begin{array}{l}\text { Pegasus, unicom, } \\
\text { uาn (nâag-Naga }{ }^{11} \text { ) }\end{array}$ \\
\hline
\end{tabular}

\footnotetext{
${ }^{10}$ Garuda is a supernatural half-man and half-bird vehicle or bearer of Vishnu. It is a state symbol of Thailand.

"Naga is a legendary serpent (Longman Dictionary).
} 


\subsubsection{The semantic relationship development in GRMT}

Since the word classification is based on semantic information of words and their usage, a link between WordAsso numbers indicates a relationship between words. This relationship indicates which word can occur with which word in the same expression. Based on this observation, we have built a relationship between words in the form of WordAsso numbers according to the contexts in which the words occur.

The possible contexts in which a given word can occur are part of a word's meaning. Therefore, we make use of the contextual knowledge to disambiguate polysemous words. For example, we interpret the meaning of quack in the first and the second sentences in Table 4.7 (the first column) differently. In the first sentence, the relationship between duck (in the sense of "a common swimming bird with short legs and a wide beak, either wild or kept

Table 4.7: Examples of words and their contexts

\begin{tabular}{lll}
\hline $\begin{array}{l}\text { Sample sentences in } \\
\text { English/Thai }\end{array}$ & Description of a given word & WordAsso relation \\
\hline "quack, guack", said the mother & to make the sound that ducks make. & $1-1-1-2-1-2-1,4-1-1-2$ \\
duck. & $\begin{array}{l}\text { a person dishonestly claiming to } \\
\text { A quack is an untrained }\end{array}$ & $\begin{array}{l}\text { have medical knowledge or skills. } \\
\text { having a top that is some distance, - } \\
\text { physician. }\end{array}$ \\
How high is the mountain? & $\begin{array}{l}\text { especially a large distance, above the } \\
\text { ground. } \\
\text { having a greater than average height, }\end{array}$ \\
She likes that tall man. &
\end{tabular}

for meat, eggs and soft feathers.") and quack indicates the meaning of quack as "to make the sound that ducks make" shown in the second column. However, the relationship between quack and physician in the second sentence determine the meaning of quack as "a person dishonestly claiming to have medical knowledge or skills". Based on this observation, the WordAsso relation between the classes animal and animal made sound, human's occupation and human's occupation are established as shown in the third column of Table 4.7. The class animal and animal made sound are related since duck belongs to the class aquatic bird with the WordAsso number 1-1-1-2-1-2-1 and quack belongs to the class Animal made sound 
Table 4.8: Classes and their sample words

\begin{tabular}{|c|c|c|}
\hline $\begin{array}{l}\text { WordAsso } \\
\text { Number }\end{array}$ & Class & Sample words \\
\hline $1-1-1-2-1-2-1$ & Aquatic Bird & $\begin{array}{l}\text { duck, เป็ด (pèd- duck), duckling, aูกเป็ต (lûugpèd- } \\
\text { duckling), swan, หงส์ (ho-n- swan), stork, } \\
\text { นกnระสา (nógkrasa-a-stork) }\end{array}$ \\
\hline $4-1-1-2$ & Animal made sound & quack, แควก (khwยE'g- quack), peep, ป̄u (pîp- peep) \\
\hline $13-5-1$ & Human's occupation & 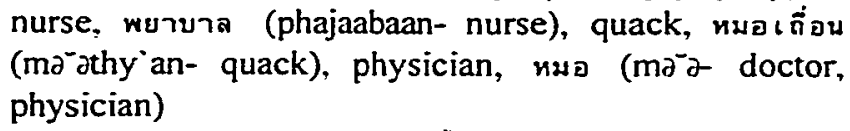 \\
\hline $13-8-9-2$ & $\begin{array}{l}\text { Attribute value of } \\
\text { height used for people }\end{array}$ & tall, สูง (suัuท- tall), short, เตี้ย (tîa- short) \\
\hline $1-1-1-1-1-1$ & Male $^{12}$ & $\begin{array}{l}\text { boy, เด็กนัชาย (dègphûuchaaj-boy), man, } \\
\text { ผัชาย (phûuchaaj-man) }\end{array}$ \\
\hline
\end{tabular}

with the WordAsso number 4-1-1-2 (Table 4.8). Both quack and physician belong to the same class Human's occupation with the WordAsso number 13-5-I.

In Table 4.7, the attribute values (of height) high and tall in the third and the fourth sentences are selective about the nouns they modify. High is used for measurements of distance above ground while tall is used for height measurements, e.g., for people [Longman 1992]. According to their usage and implied reference set, the relationship between the classes Attribute value of height used for people and Male (the third column of Table 4.7) is developed. tall belongs to the class Attribute value of height used generally for people with the WordAsso number 13-8-9-2 and man belongs to the class Male with the WordAsso number $1-1-1-1-1-1$.

In addition to consider the possible contexts in which a given word can occur, the associations between words that are interchangeable in a context and the associations between words that frequency occur together are considered in developing the WordAsso relations for GRMT (see section 5.2).

The construction of WordAsso relation and its use will be presented in chapter 5 , some examples will be provided.

12 The classes Male (1-1-1-1-I-1) and Female (1-1-1-1-1-2) are subclasses of Individual ( $1-1-1-1-1)$. This classification is for associaing words in Male and Female with the particles ครับ-khráb คะ- khâ in Thai. Particles are sentence-ending words. ครัป-khráb and $\dot{A} z-$ khâ are used to show politeness, courtesy and respect to another person. ครับ-khráb is used by men and $\dot{A}=-$ khâ is used by women. 


\section{Chapter 5}

\section{Analysis Lite Machine Translation}

... and since word-for-word translations are surprisingly good. it seems reasonable to accept a word-for-word translation

as a first approximation

and then see what can be done to improve it.

- Victor H. Yngve (1955)

Analysis Lite Machine Translation, the first phase of GRMT, generates an appropriate translation candidate for an input text. ALMT was designed around two simple notions: the more accurately ALMT generates a TC, the less work is required in the latter phases; and generating the TC must be done quickly. Therefore, ALMT generates a TC by considering the differences between language pairs in terms of syntax and semantics without performing any sophisticated analysis. ALMT performs its task by judiciously selecting a few efficient heuristics, constraints, and semantic principles to apply when appropriate. ALMT first applies

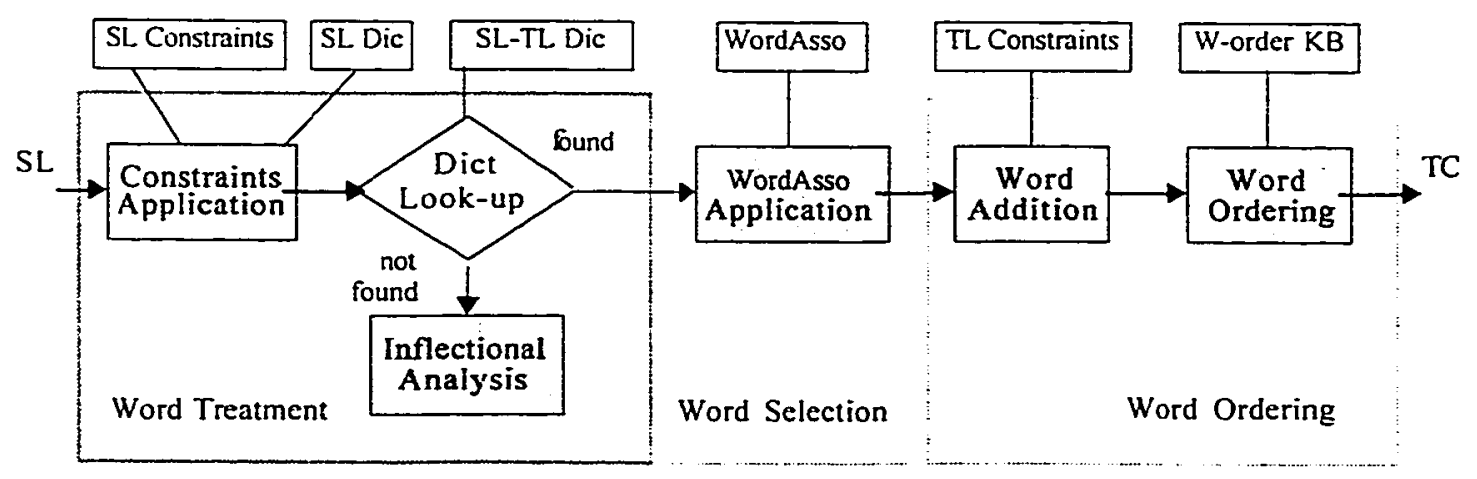

Figure 5.1: ALMT Architecture 
the SL constraints to simplify the structure of the SL, maps each SL word into all possible meanings in the TL. The most appropriate TL word is selected by applying a semantic relationship between words and then rearranging the selected words according to the grammar of the TL. ALMT comprises three modules as shown in Figure 5.1, word treatment, word selection, and word ordering.

\subsection{Word Treatment}

There are two steps performed by word treatment module: SL-Constraints Application and Dictionary look-up (Figure 5.1). The SL constraints are used to simplify the structure of the SL. After simplification, the word treatment maps each SL word to all possible corresponding words in TL by consulting the SL-TL dictionary. An inflectional analysis might be needed in the dictionary look-up stage. This analysis is quite simple but useful as it saves dictionary space and reduces search time. The knowledge-bases required in the word treatment module are: the SL constraints, the inflectional rules, the SL dictionary and the SLTL Dictionary.

\subsubsection{SL Constraints Application}

The SL constraints, the morphological and syntactic characteristics of the SL which differ from those of the TL, are incorporated in this step to narrow the scope of possible TL words which correspond to each SL word. Table 5.1 illustrates some SL constraints we considered according to the differences between English and Thai as discussed in section 4.1 .

Table 5.1: Some SL Constraints

\begin{tabular}{lll}
\hline SL-Constraints & Descriptions & Examples \\
\hline Plurality' & noun_(e)s $\rightarrow$ noun + plural & The books ... $\rightarrow$ The book + plural \\
Continuous tense & $\mathrm{V}$ to be $+\mathrm{V}$-ing $\rightarrow \mathrm{V}+$ ing & I am swimming. $\rightarrow \mathrm{I}+$ ing + swim \\
Passive voice & be $+\mathrm{V} 3 \rightarrow$ passive $+\mathrm{V}$ & He was arrested. $\rightarrow$ He passive + arrest \\
Adjective & $\mathrm{V}$ to be + adj $\rightarrow$ adj & I am glad. $\rightarrow$ I glad \\
Negative & do + not $\rightarrow$ not & He does not eat $\rightarrow$ He not eat \\
\hline
\end{tabular}

'This constraint does not apply in the case of the irregular plural forms. e.g., children. feet men, women. and so on. The irregular plural forms are entries in the dictionaries. 
Since Thai word form does not have an inflection resulting from plurality or tense, the inflections of plural noun and present participle forms in English are removed in this step. Once the inflections are removed, the features plural and ing are added to preserve the meaning of the original sentence. The structure of a passive voice is examined as well; the verb inflection and auxiliary to be are removed. The feature passive is added to indicate the passive voice. The features plural, ing and passive will be replaced with the appropriate corresponding TL words in the ordering step of ALMT.

The auxiliaries $t o$ be which precedes an adjective and to do which precedes a negative "not" are discarded since they are not required in the same expression in Thai. Figure 5.2 illustrates the outputs of SL constraints applications of Example 1 and Example 2. The auxiliary is is removed from Example 1 according to the adjective constraint. The inflection $-s$ of the word symbol in Example 2 is removed and the feature plural is added, the passive voice form are used is replaced with passive use, the auxiliary do is discarded and the continuous tense form is replaced with ing lalk.

\section{Example 1:}

SL: The spirit is willing but the flesh is weak.

SL Constraints- output: The spirit _ willing but the flesh _ weak.

Example 2:

SL: Algebraic symbols are used when you do not know what you are talking about.

SL Cons- output: Algebraic plural symbol passive use when you not know what you ing talk about.

Figure 5.2: SL constraints applications examples

\subsubsection{Dictionary Look-up}

After the SL constraints are applied, each SL word will be used as a keyword to search for its corresponding words in the TL. If the keyword used is found in the SL-TL dictionary, all possible corresponding TL words will be attached to that SL word. If the keyword is not found, inflectional analysis is performed and the search is restarted. The inflections of each entry are not entries in the dictionaries, therefore the size of the SL dictionary and the search times are reduced.

In our case in which English is regarded as SL, the following inflectional forms are considered: past simple tense (-d, -ed), gerund (-ing), subject-verb agreement (-s, -es) and 
comparatives (-er, -est); plurality and present participle are treated in the SL Constraints Application. An output of this step is a list of all possible corresponding words of SL words in the TL with their WordAsso numbers. The second column (Table 5.2) shows the dictionary look-up result for Example 3 based on the information available in SL-TL dictionary. The descriptions of the words are provided in the third column.

Table 5.2: Example result of Dictionary Look-up of Example 3

\section{Example 3:}

SL: The spirit is willing but the flesh is weak.

SL Constraints- output: The spirit willing but the flesh weak.

Dictionary Look-up-output:

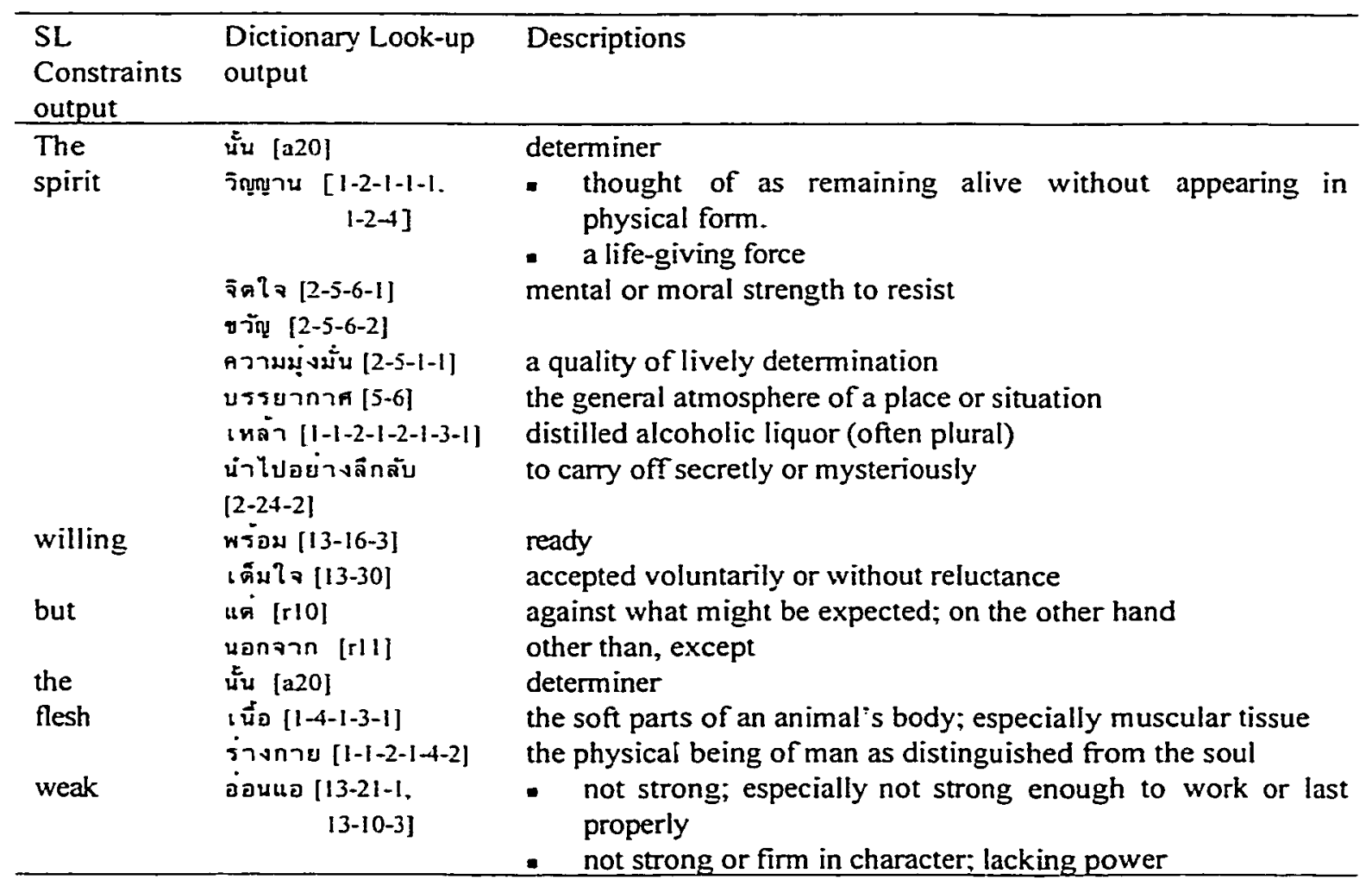




\subsubsection{Dictionaries}

The $S L$ dictionary provides the information required in the constraint application and the inflectional analysis steps. Each lexical entry contains its syntactic categories. The inflections of each entry are not included. Figure 5.3 illustrates a fragment of SL dictionary which is in a Prolog representation: the categories of the word all are adjective, adverb, pronoun, noun and determiner. Hid is an adjective and a past simple tense form of hide, therefore one of its categories is vpast. Vpast is a category of the verbs which are in a past simple tense form (see also appendix B).

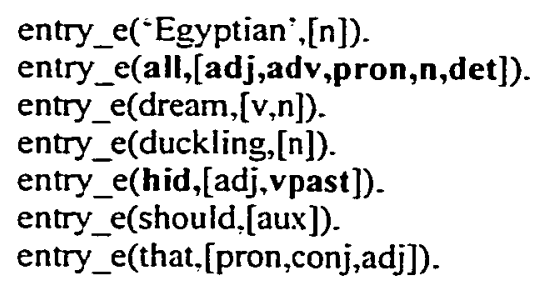

Figure 5.3: Example of SL Dictionary

The SL-TL dictionary is required in the dictionary look-up step. It is used to map the SL word to all possible corresponding words in the TL. The SL-TL dictionary contains the SL entry and all of its possible corresponding words in the TL. The TL words are ordered according to the frequency of their usage. Each TL word is related to its WordAsso numbers. Figure 5.4 illustrates a part of SL-TL dictionary which is in a Prolog representation: the word

entry('Egyptian', [wordasso('คนอียิปต', [['13-6-l']), wordasso('ภาษาอียิปต์',['2-15-1-3-l'])]).

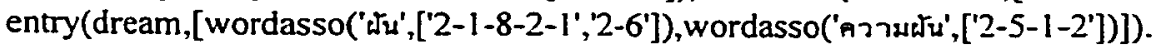

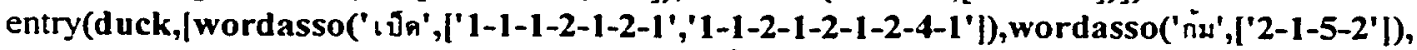

wordasso('จับกคลง',|'2-1-5-4-1'|), wordasso('ผ่าลินินขาว',|'1-1-2-1-1-1'|)|).

entry(hidden, [wordasso('ซ่อน',['2-10-l']), wordasso('บีดบัง ', ['2-10-2'])]).

entry(old,[wordasso('un',['13-7-1']), wordasso('เก'่', ['13-7-2'])]).

entry(should,[wordasso('ควร',['al2'])]).

entry(that, [wordasso('ว่า',['rl2']).wordasso('น้น',['rl 3']), wordasso('ที่,,['rl4'])]).

Figure 5.4: Example of SL-TL Dictionary 
duck corresponds to four Thai words; เป็ด (pèd) with WordAsso 1-1-1-2-1-2-1 (Aquatic Bird) and 1-1-2-1-2-1-2-4-1 (Poultry), ñม (kôm) with WordAsso 2-1-5-2 (A way to move so as of a body part), จับกดลง (càbkòdlon) with the WordAsso 2-1-5-4-1 (a way to move thing with force) and ผ่าลินินขาว (phâalininkha`aw) with the WordAsso 1-1-2-1-1-1 (Fabric), see also appendix $\mathrm{C}$.

\subsection{Word Selection}

One difficult task in the MT process is to select the most appropriate word in the TL which preserves the meaning of the corresponding word in the SL if there are more than one possibility. To select the most appropriate word in TL for each SL input word, we need to know the meaning of the input word. The meaning of the input word can be determined by the context in which the input word occurs as we discussed in section 4.2.2. In Example 4 (Figure 5.5), the semantic relationship between the word เปด ( $\left.7^{\circ} \ni d\right)$ and ตู (tûu) indicates that the word เจด ( $\left.\ni^{\circ} \ni \mathrm{d}\right)$ means "not shut". Therefore, its corresponding word in English is open; this expression means "He opens the closet." The word เจด ( $\left.\mathrm{p} \ni^{\circ}{ }^{\prime} \mathrm{d}\right)$ in Example 5, Figure 5.5 , cannot be translated as "open" since the semantic relationship between เปด ( $\ni \ni$ " $\ni d)$ and

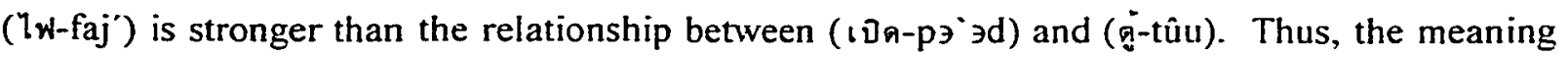
of the sentence in Example 5 corresponds to "He turns on the light in the closet". This example and others like it lead to the notion that physical proximity implies a stronger connection. Therefore, the word selection process in ALMT is carried out by considering the relationship between the close proximity words.

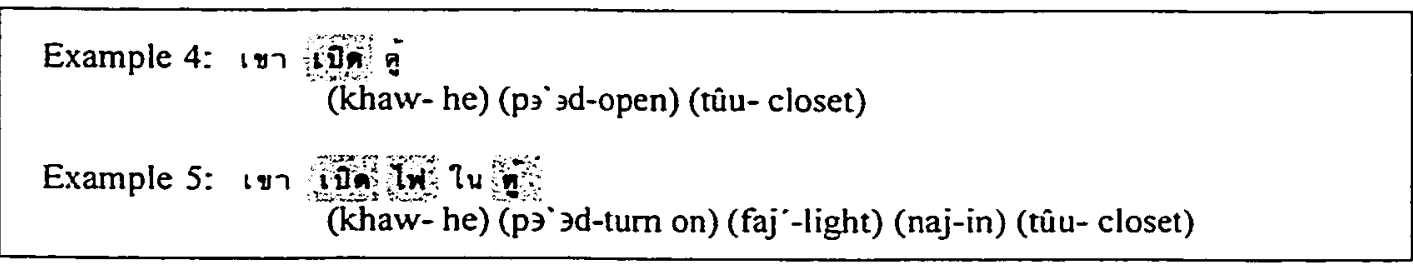

Figure 5.5. The relationship between the proximity words-Examples 4 and 5 .

Figure 5.6 illustrates some Wordasso relations we developed for ALMT (see section 4.2.2), the word with WordAsso number in the first argument can occur with the word which has a WordAsso number shown in the second argument. For example: words with the 
WordAsso number 1-1-1-2-1-1 can occur with any word which has WordAsso number 13-8-2 or 13-8-5-2.

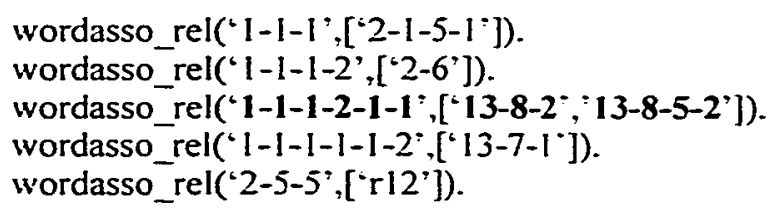

Figure 5.6. Examples of WordAsso relations

As well as applying the semantic relationship between words in the form of the WordAsso relation, the selection step continues. According to a linguistic theory, a collocation $^{2}$ consists of basically two or three lexical words [Newmark 1981] and our investigation of a number of sample sentences; we consider the relationship between words in the range of four consecutive words in our selection step. Words in close proximity are considered to have stronger connections. Our selection steps are designed as follows:

Program word_selection;

$X$ and newX are arrays of $x_{i}$;

$x_{i}$ is a list of the TL words which corresponds to the ith word of the SL input sentence;

$\mathrm{n}$ is the number of words in the SL input sentence;

$i, j, m$ and $n$ are integers;

$x_{i}$ is null if $i<1$;

$x_{i}$ is null if $i>n$;

$\%$ Use $x_{i}$ to determine the most appropriate word for $x_{i-j}$ and $x_{i-j}$.

Procedure select ( $\mathrm{j}$, newX);

begin

for $\mathrm{i}=1$ to $\mathrm{n}$ do

2 collocation is a group of words in a sentence in which a word with particular meaning is supplanted by another word because of other words in the environment. For example: the word pay in to pay attention means to use: the word commit in commit a crime means to do. 
begin

if $x_{i}$ contains only one word

then begin

use the word in $x_{i}$ to select the appropriate TL word(s) in $x_{i-j}$;

if wordasso_rel $\left(x_{i}, x_{i-j}\right)=$ true

then begin

$x_{i-j}=$ new $x_{i-j}$

end;

else begin

new $X=X$;

use the word in $x_{i}$ to select the appropriate TL word(s) in $x_{i+j}$;

if wordasso_re $\left(x_{i}, x_{i+j}\right)=$ true

then begin

end;

$x_{i+j}=$ new $x_{i+j}$;

else new $X=X$;

end;

end;

end;

$\mathrm{i}=\mathrm{i}+\mathrm{i}$;

$\%$

Procedure word_check $(\mathrm{j}, \mathrm{X})$;

begin

do while $(j \leq 3)$

begin

select (j,newX);

if $X \neq$ new $X$

then begin

$\mathrm{X}=$ new $\mathrm{X}$;

$\mathrm{j}=1$;

word check $(j, X)$;

end;

else begin

if $j<3$

then begin

$\mathrm{j}=\mathrm{j}+\mathrm{l}$;

word_check $(\mathrm{j}, \mathrm{X})$;

end;

else begin

select final $(j, X)$;

$\mathrm{j}=\mathrm{I}$;

word_check $(j, X)$;

end;

$$
\text { end; }
$$

end;

end; 
$\%$ Select the first meaning appearing on the list of meanings of each word

Procedure select_final (j, newX);

begin

for $i=1$ to $n$ do

begin

if $x_{i}$ contains only one word

then $i=i+1$

else select the first word in $x_{i+j}$ as the most appropriate word;

end; end;

$\%$ main

begin

$\mathrm{X}=$ input sentence;

new $X=X$;

if each $x_{i}$ contains only one word

then return $X$ as an output

stop.

else begin

$\mathrm{j}=\mathrm{I}$ :

word_check $(\mathrm{j}, \mathrm{X})$;

end. end; 


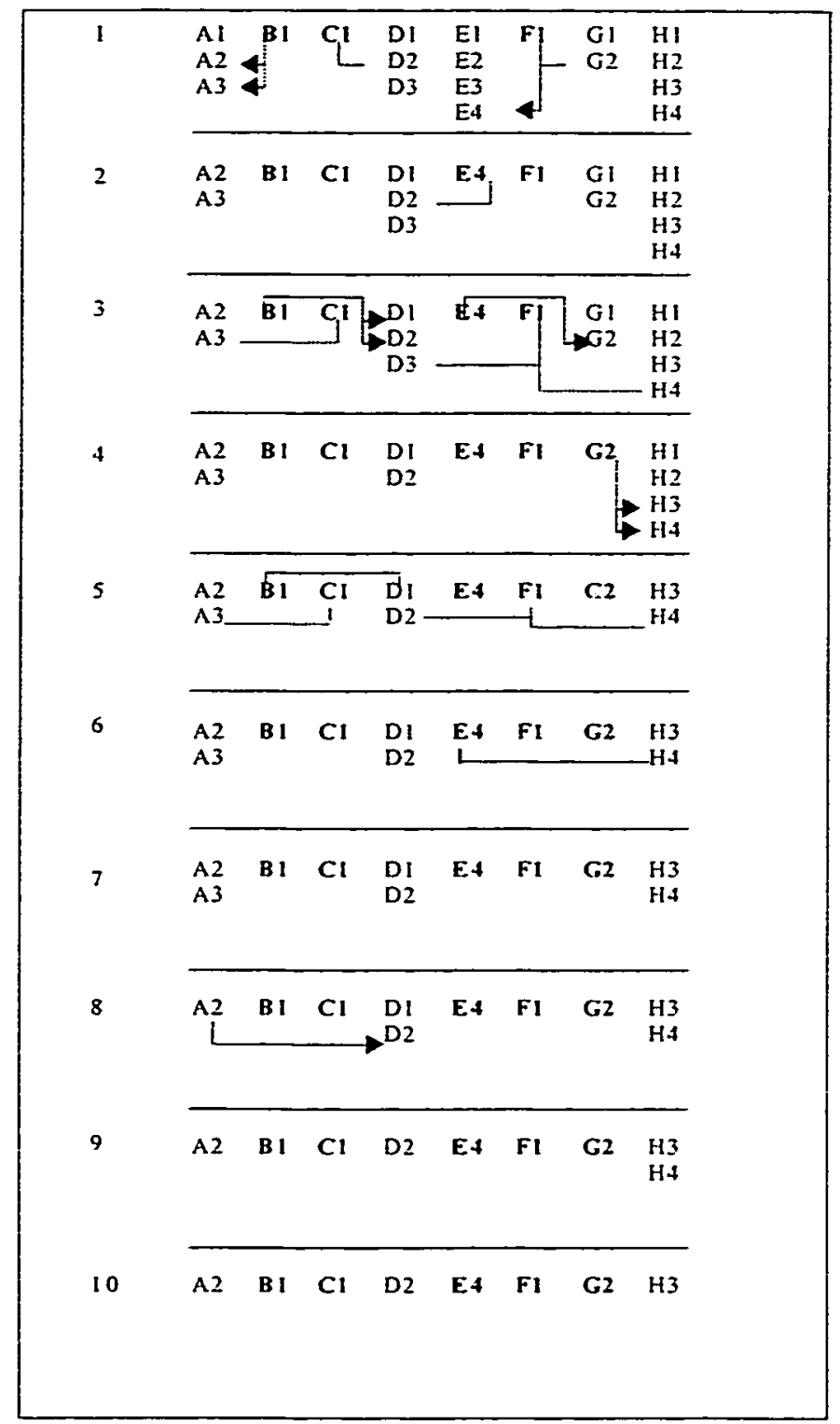

Figure 5.7: Example of selection steps

Figure 5.7 illustrates an example of the selection step process. In this illustration an eight (input) words sentence is examined with words A, B, C, ...H. Some words correspond to more than one TL word e.g., $A$ corresponds to three TL words, $A_{1}, A_{2}$ and $A_{3}$. Some words correspond to one TL word e.g., $\mathrm{B}, \mathrm{C}$ and $\mathrm{F}$ correspond to $\mathrm{Bl}, \mathrm{Cl}$ and $\mathrm{Fl}$ respectively. Based on our selection step and the WordAsso relation template, the appropriate meaning of each word is selected in ten steps as follows: 
I. $\mathrm{Bl}$ is used to determine the meanings of $\mathrm{A}$ and $\mathrm{C}$ which are adjacent to $\mathrm{B}$ on the left and right. $\mathrm{A}$ has three different meanings, $A 1, A 2$ and $A 3$ while $C$ has one meaning. Therefore, we select only the meaning of the first word by considering the WordAsso relation between $\mathrm{BI}$ and $\mathrm{Al}, \mathrm{BI}$ and $A 2$, and $B 1$ and $A 3$ respectively. Suppose $A 2$ and $A 3$ have meaningful relations with $B 1$, then keep both of them. Next, we use $\mathrm{Cl}$ to determine the meanings of $\mathrm{B}$ and $\mathrm{D}$ in a similar manner. In the case that there is no relationship between $\mathrm{Cl}$ and the corresponding words of D (DI, D2 and D3), the three meanings (D1, D2 and D3) remains the same. $F 1$ is used to determine the meaning of $E$ and $G$, in the case that $F 1$ has a relationship with $E 4 ; E 4$ is selected.

2. E4 is used to determine its adjacent words ( $D$ and F). There is no relationship between $E 4$ and $D$, therefore the string remains the same.

3. $\mathrm{Bl}$ is used to determine the meaning of $\mathrm{D}$ (one word apart); $\mathrm{DI}$ and $\mathrm{D} 2$ are selected. $\mathrm{Cl}$ is used to determine the meanings of $A$ and $E$ (which corresponds to $E 4$ alone at this step), there is no relationship between $C$ and $A . G 2$ is selected according to its relationship with $E 4$.

4. G2 is used to determine its adjacent words (F and H). G2 has a relationship with $\mathrm{H} 3$ and $\mathrm{H} 4$. then $\mathrm{H} 3$ and $\mathrm{H} 4$ are selected.

5. $\mathrm{Bl}, \mathrm{Cl}, \mathrm{E} 4, \mathrm{Fl}$ and $\mathrm{G} 2$ are used to determine the words which are one word apart from each of them. There is no relationship between any of them, the string remains unchanged.

6. E4 is used to determine B and $\mathrm{H}$ (two words apart form E4), B already has one meaning and there is no relationship between $E 4$ and $H$, the string remains the same.

7. A2 is selected for A since A2 is the first meaning appearing at this step according to the SL-TL dictionary.

8. A2 is used to determine the meanings of D, D2 is selected.

9. $\mathrm{H} 3$ is selected for $\mathrm{H}$ since $\mathrm{H} 3$ is the first meaning (most common of those remaining) appearing at this step according to the SL-TL dictionary.

10. $\mathrm{A} 2, \mathrm{~B} 1, \mathrm{Cl}, \mathrm{D} 2, \mathrm{E} 4, \mathrm{~F} 1, \mathrm{G} 2$ and $\mathrm{H} 3$ are selected.

The first column of Table 5.3 illustrates the constraint application result of Example 6 . The dictionary look-up result is shown in the second column. Each word spirit, willing, but and flesh has more than one meaning (the descriptions of each meaning are shown in Table 5.2). To select the appropriate words for spirit, willing, but and flesh, ALMT first considers the relationship between the and its adjacent words since the has a unique meaning. However, there is no relationship between any of them. ALMT then considers the relationship between weak and its adjacent word, flesh. The word ร่างnาย (râankaaj) is selected for flesh (the fourth column) according to the WordAsso relation, 13-21-1 and $1-1-2-1-4-2$, see Figure 5.8. The first meaning left on the list of the words spirit, willing and but; วิญาน 
(winjaan), พร้อม (phro' $\mathrm{m}$ ) and แต่ $\left(\mathrm{t} \varepsilon^{\prime} \varepsilon\right)$ are selected since there is no relationship between spirit, willing, but and their proximity words according to our WordAsso relation template. The selected words for example 6 are shown in the fourth column of Table 5.3.

To associate the input words so, ugly and left in Example 7 (Table 5.4) with the most appropriate words in Thai, ALMT considers the relationship between those words with words

Table 5.3 The possible corresponding Thai words for spirit, willing, flesh and weak

Example 6: The spirit is willing but the flesh is weak.

\begin{tabular}{|c|c|c|c|}
\hline $\begin{array}{l}\text { SL Constraints } \\
\text { output }\end{array}$ & $\begin{array}{l}\text { Dictionary } \\
\text { look-up output }\end{array}$ & WordAsso number & $\begin{array}{l}\text { Word Selection } \\
\text { Output }\end{array}$ \\
\hline $\begin{array}{l}\text { The } \\
\text { spirit }\end{array}$ & 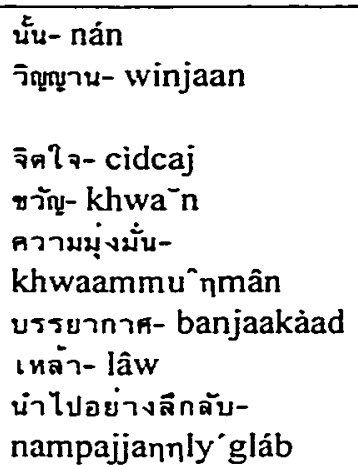 & $\begin{array}{l}220 \\
1-2-1-1-1 \\
1-2-4 \\
2-5-6-1 \\
2-5-6-2 \\
2-5-1-1 \\
5-6 \\
1-1-2-1-2-1-3-1 \\
2-24-2\end{array}$ & $\begin{array}{l}\text { นั้น- nán } \\
\text { วิญญาน- winjaan }\end{array}$ \\
\hline willing & $\begin{array}{l}\text { พร่อม- phrว'วm } \\
\text { เต็มใจ- temcaj }\end{array}$ & $\begin{array}{l}13-16-3 \\
13-30\end{array}$ & พร้อม- phrฮ’วm \\
\hline but & 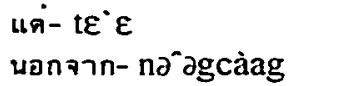 & $\begin{array}{l}\mathrm{rl0} \\
\mathrm{rll}\end{array}$ & แต่- $t \varepsilon^{\circ} \varepsilon$ \\
\hline $\begin{array}{l}\text { the } \\
\text { flesh }\end{array}$ & $\begin{array}{l}\text { นั้น- nán } \\
\text { เนื้อ- ny'a }\end{array}$ & $\begin{array}{l}\text { a20 } \\
1-4-1-3-1\end{array}$ & นั้น- nán \\
\hline weak & 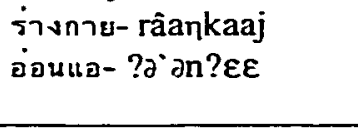 & $\begin{array}{l}1-1-2-1-4-2 \\
13-21-1 \\
13-10-3\end{array}$ & 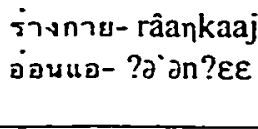 \\
\hline
\end{tabular}

wordasso_rel( $\left.1-1-1-2-1-2-1^{\prime},\left[{ }^{\circ} 2-1-1-6^{\prime},{ }^{2}-13^{\prime},{ }^{\prime} 2-1-25^{\prime}\right]\right)$.

wordasso_rel(' $\left.1-1-2-1-5-1^{\prime},\left[{ }^{\prime} 2-13^{\prime}\right]\right)$.

wordasso_rel('13-21-1', ['1-1-2-1-4-2']).

wordasso_rel(' $\left.1-1-2-1-1-2^{\prime},\left[{ }^{\prime} 2-2-8^{\prime}\right]\right)$.

wordasso_rel( $\left({ }^{\prime} 1-2-1-2-1^{\prime},\left[{ }^{2} 2-8-3^{\prime},{ }^{\prime} 2-9-1^{\prime}\right]\right)$.

Figure 5.8: Examples of WordAsso relations 
in their proximity. There is a relationship between the words duckling (ลูกเป็ด (lûugpèd), 1 $1-1-2-1-2-1$ ) and left as indicated in the WordAsso relation template (Figure 5.8). The WordAsso number $1-1-1-2-1-2-1$ can occur with any word with WordAsso number 2-1-1-6 or

Table 5.4. The possible corresponding Thai words for left, duckling and marsh.

Example 7: So the ugly duckling left the marsh.

\begin{tabular}{|c|c|c|c|c|}
\hline $\begin{array}{l}\text { SL Constraints } \\
\text { output }\end{array}$ & $\begin{array}{l}\text { Word } \\
\text { Treatment } \\
\text { Output }\end{array}$ & Description & $\begin{array}{l}\text { WordAsso } \\
\text { number }\end{array}$ & Selected word \\
\hline \multirow[t]{2}{*}{ So } & ดังน้น- dąnán & with the result that & $r 30$ & \multirow[t]{2}{*}{ ดังนั้น-dannán } \\
\hline & $\begin{array}{l}\text { อย่างนั้น- } \\
\text { jànกán }\end{array}$ & to such a (great) degree & $2-4-8$ & \\
\hline the & นั้น- nán & determiner & a20 & \multirow{3}{*}{$\begin{array}{l}\text { นั้น- nán } \\
\text { ชี่เหร่-khîilèe }\end{array}$} \\
\hline \multirow[t]{2}{*}{ ugly } & $\begin{array}{l}\text { ปี้เหร่- } \\
\text { khîilièe }\end{array}$ & $\begin{array}{l}\text { unpleasant to look at } \\
\text { (use with living thing) }\end{array}$ & $13-8-4-1$ & \\
\hline & $\begin{array}{l}\text { นำเกลียด- } \\
\text { nàakliad }\end{array}$ & $\begin{array}{l}\text { unpleasant to look at } \\
\text { (use with non-living } \\
\text { thing, abstract thing) }\end{array}$ & $13-8-4-2$ & \\
\hline duckling & $\begin{array}{l}\text { ån เป็ด- } \\
\text { lûugpèd }\end{array}$ & A young duck. & $1-1-1-2-1-2-1$ & $\begin{array}{l}\text { ลูกเป็ด- } \\
\text { lûugpèd }\end{array}$ \\
\hline \multirow[t]{4}{*}{ left } & ช้าย - sáaj & The left side or direction & $2-35-18$ & \\
\hline & จาก ${ }^{3}$ - càag & To stop being in or with. & $2-1-1-6$ & \\
\hline & ทิ้ง $v^{4}$ thin & To go without taking. & $2-19$ & \\
\hline & $\begin{array}{l}\text { ออกจาก์ - } \\
\partial \dot{\partial} \text { g càag }\end{array}$ & To go away (from) & $2-13$ & \multirow{3}{*}{$\begin{array}{l}\text { ออกจาก- } \partial^{\circ} \partial g \\
\text { càag } \\
\text { น้น- nán } \\
\text { หนอง-nวัวฤ }\end{array}$} \\
\hline the & น้น- nán & determiner & $a_{20}$ & \\
\hline marsh & หนอง-nว־ว & $\begin{array}{l}\text { low land that is soft and } \\
\text { wet. }\end{array}$ & $1-1-2-1-5-1$ & \\
\hline
\end{tabular}

2-13. Therefore, the words จาก (càag, 2-1-1-6) and ออกจาก (ว’ggàag, 2-13) are selected.

Next, to select the most appropriate word from these two possibilities; จาn (càag) and ออกจาก ( $\partial^{\circ}$ ggcàag), the relationship between the words marsh and left is considered. There is no relationship between ugly and left, or the and left according to the WordAsso relationship template. Therefore, marsh which is one word apart from left and has only one meaning, หนอง (nว॰ $\eta$ ), with the WordAsso 1-1-2-1-5-1 is considered. According to the WordAsso

\footnotetext{
3. 4.5 The meanings of left which is a past tense and a participle of leave [Longman 1992].
} 
WordAsso number 2-13. Then, the word ออกจาก (ว่agcàa) is selected for left.

The word ขิ้เหร่ (khîlèe) is selected for ugly according to the relationship between ugly and duckling as indicated in the WordAsso relationship template (Figure 5.8). There is no relationship between the word so and other words, therefore the first meaning on the list, ดังนั้น (dannán), is selected. The selected words for example 7 are shown in the fifth column of Table 5.4.

\subsection{Word Ordering}

The syntactic level differences between SL and TL are reconsidered at this point to complete the TC. Some words which are necessary in the TL, not only to retain the meaning of the SL but also to make the TL grammatically correct, are added to the string before the ordering can be performed. For example, the words แล่ว (l $\left.\varepsilon^{\prime} \varepsilon w\right)$ and $l e^{6}$ are required to indicate the past tense in Thai and Chinese respectively (see section 4.1). After all necessary words are added, ALMT rearranges the selected words without performing any analysis in a TL grammatical order according to the ordering rule. Therefore, two steps are performed by word ordering module: word addition and word ordering (Figure 5.1).

\subsubsection{Word Addition}

The morphological and syntactic characteristics of the SL which are removed in the SL constraints application step will be replaced with the appropriate corresponding words in the TL in the word addition step. In the case that English is the SL and Thai is the TL, the features plural, ing, and passive which are used to indicate the plurality, continuous tense and passive voice features of the SL are replaced with the words หลาย (la aaj), กำลัง (kamlan) and ถูก (thùug) respectively (see section 5.1.1).

In case of pluralities, classifiers are required (see section 4.1 ) to express the quantity. Each noun relates to a specific classifier; therefore, the classifier relation was designed in the form of WordAsso numbers to be used to select the appropriate classifier for each noun.

\footnotetext{
${ }^{6}$ Phonetic transcription of Chinese.
} 
In Thai, a noun and its classifier were stipulated by the Thai Royal Institute. To date, there are approximately 3000 different classifiers [The Thai Royal Institute 1995]. From our studies, we classified the classifiers into classes as shown in Table 5.5. With this classification together with the specification of the Thai Royal Institute, we then developed the relation between nouns and their classifiers, some examples are illustrated in Figure 5.9. The noun with the WordAsso number in the first argument is compatible with a classifier with a WordAsso number shown in the second argument.

Table 5.5 A small fraction of classifier classes

\begin{tabular}{|c|c|}
\hline Class & Sample Word \\
\hline 2-4-2 Classifier & \\
\hline 2-4-2-1 Classifier of object & - \\
\hline \multicolumn{2}{|l|}{$2-4-2-1-1$ Classifier of living thing } \\
\hline $2-4-2-1-1-1$ Classifier of human & คน \\
\hline 2-4-2-1-1-2 Classifier of animal & ตัว \\
\hline $2-4-2-1-1-3$ Classifier of plant & ตัน \\
\hline \multicolumn{2}{|l|}{$2-4-2-1-2$ Classifier of non-living thing } \\
\hline $2-4-2-1-2-1$ Classifier of tool & อัน \\
\hline $2-4-2-1-2-2$ Classifier of room & ห่อง \\
\hline 2-4-2-I-2-3 Classifier of external body part & ขา ทัว มือ \\
\hline 2-4-2-1-2-5 Classifier of root vegie & ทัว \\
\hline 2-4-2-2 Classifier of collection & ชนิด ประเภท \\
\hline 2-4-2-2-1 Classifier of human & กล่ม \\
\hline $2-4-2-2-2$ Classifier of animal & \\
\hline 2-4-2-3 Classifier of time period & day วัน hour ชั่วโมง \\
\hline 2-4-2-5 Classifier of frequency & 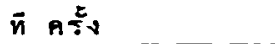 \\
\hline
\end{tabular}

clf_rel('1-1-1-1',[[wasso('ตน',['2-4-2-1-1-1'])]]).

clf_rel('1-1-1-2', [[wasso('ตัว', ['2-4-2-1-1-2'])]]).

clf_rel(' $1-1-2-1-6-1$ ', $[[$ wasso('แห่ง', ['2-4-2-1-2-2'])]]).

clf_rel('2-4-3-1-2',[[wasso(' วัน', ['2-4-2-3'])]]).

clf_rel('1-1-2-1-1-2-2', [[wasso('หลัง', ['2-4-2-1-2-10'])]]).

Figure 5.9. Examples of classifier relations.

Example 8 illustrates how to select the appropriate classifiers for the words woman, cat and hen. The selected words in Thai corresponding to the words woman, cat and hen in Example 8 are shown in the second column of Table 5.6. The indefinite determiners $a$ and 
an in this expression, corresponding to the word หนึ่ง (ny $\eta$ ) in Thai, indicate the need for classifiers for the words ผู้หญิง (phûuji $\eta$ ), แมว (mعEw) and ไn (kàj) respectively. The word ผู้หญิง (phûuji $\eta \eta$ ) belongs to the class Female $(1-1-1-1-1-2)$, a subclass of Human $(1-1-1-1)$. A noun which belongs to the class $1-1-1-1$ is compatible with a classifier with the WordAsso number 2-4-2-1-1-1 based on the classifier relation illustrated in Figure 5.9. Therefore, the classifier คน (khon) with 2-4-2-1-1-1 in Table 5.5 is selected for the word ผู่หิิง (phûuji $\eta$-woman).

Table 5.6. The selected words in Thai for the words woman, cat and hen

Example 8: An old woman lived in the cottage; with a fat black cat and a plump brown hen:

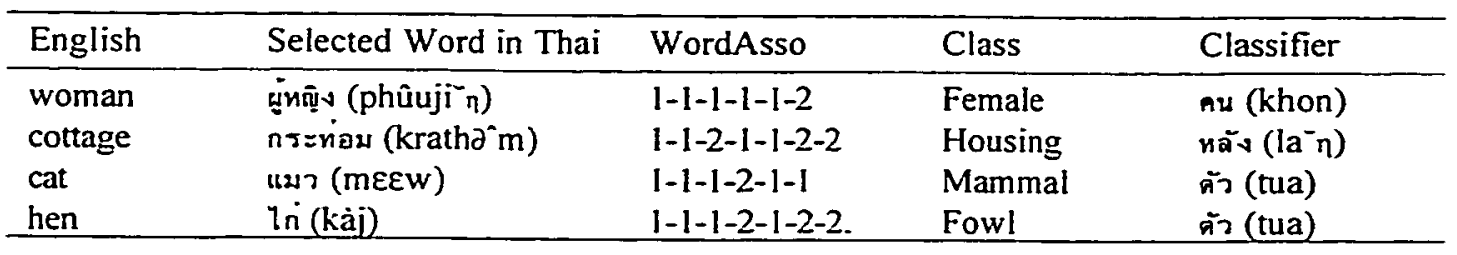

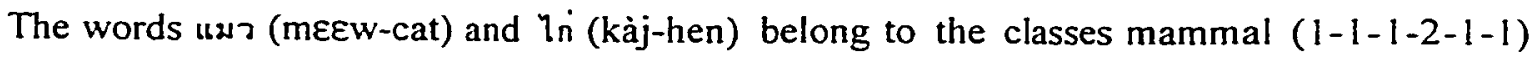
and fowl (1-1-1-2-1-2-2) respectively. Both classes are subclasses of animal $(1-1-1-2)$. Since a noun with the WordAsso number 1-1-1-2 relates to a classifier with 2-4-2-1-1-2 according to the classifier relation shown in Figure 5.9, the classifier ตัว (tua) with $2-4-2-1-1-2$ is

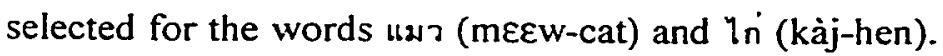

The definite determiner the corresponding to the word นั้น (nán) in Thai indicates the need for a classifier for the word กระพ่อม ( $\left.k r a t h \partial^{\wedge} \mathrm{m}\right)$. The word กระท่อม ( $k$ rath $\partial^{\wedge} \mathrm{m}$ ) belongs to the class Housing (1-1-2-1-1-2-2) which is compatible with a classifier with the WordAsso number 2-4-2-1-2-10 based on the classifier relation illustrated in Figure 5.9. Therefore, the classifier หลัง $\left(1 a^{-} \eta\right.$ ) with the WordAsso 2-4-2-1-2-10 is selected for the word กระท่อม (krathə^m).

\subsubsection{Word Ordering}

In some MT systems, e.g., Shake-and-Bake MT, the ordering process has been performed by generating valid combinations of words and analyzing (parsing) to see whether the combination is grammatically correct. If the combination is correct then it will be selected as an output; if not, another combination is tried until the grammatically correct sentence is 
found. The disadvantage is that the generator has to consider a number of possibilities which is factorial in the number of signs in the TL sentence. In GRMT, the selected words are ordered according to rules without performing any analysis. These ordering rules account for syntactic level differences between languages. The structure of the SL which is similar to that of the TL remains the same, only the sentence fragments that are different will be rearranged into the grammatical order of the TL.

The structure of the English sentence which contains subject, verb and object in that order is similar to that of the Thai sentence. Therefore, when English is translated into Thai, its structure remains the same as illustrated in Example 9 (Figure 5.10). However, in the case that the English phrase contains attributes, possessive pronouns or determiners, the word order must be rearranged to make translation of the phrase grammatically correct since the structure of such a phrase is different between English and Thai (see section 4.1). The first row of Figure 5.11 illustrates the corresponding words in Thai of Example 10 selected by ALMT. The classifier ตัว (tua) is added in the word addition step. The translations of the noun phrase The ugly duckling, his head and his wing are formed in reverse order of the order in English according to the ordering rules (the third row of Figure 5.11).

Some other structures which are different between English and Thai are examined as well. For example, the negative of can and could (cannot, could not); the adverb very which modifies an adjective (very good, very warm) and their translations are formed in the reverse order of the order in English.

\begin{tabular}{|c|c|c|c|c|}
\hline \multicolumn{5}{|c|}{$\begin{array}{l}\text { Example 9: John eats rice every day. } \\
\text { จอห์น กิน ท่าว ทุก วัน } \\
\text { (cวəก- John) (kin- eat) (khâ }\end{array}$} \\
\hline $\begin{array}{l}\text { John } \\
\text { จอห์u (cวən) }\end{array}$ & $\begin{array}{l}\text { eats } \\
\text { กิน (kin) }\end{array}$ & $\begin{array}{l}\text { rice } \\
\text { ข้าว (khâaw) }\end{array}$ & $\begin{array}{l}\text { every } \\
\text { nn (thúg) }\end{array}$ & $\begin{array}{l}\text { day } \\
\text { ju (wan) }\end{array}$ \\
\hline \multicolumn{5}{|c|}{ Word ordering output } \\
\hline $\begin{array}{l}\text { จอห์น (cวən) } \\
\text { John }\end{array}$ & $\begin{array}{l}\text { กิน (kin) } \\
\text { eats }\end{array}$ & $\begin{array}{l}\text { ข้าว (khâaw) } \\
\text { rice }\end{array}$ & $\begin{array}{l}\text { ṇn (thúg) } \\
\text { every }\end{array}$ & $\begin{array}{l}\text { วัu (wan) } \\
\text { day }\end{array}$ \\
\hline
\end{tabular}

Figure 5.10: Word orders of จอห์น กิน ข้าว ทุก วัน 
Example 10: The ugly duckling hid his head under his wing. ลูกเป็ด ขี้เหร ตัว นั้น ได่ซอน หัว ของเขา ใด้ ปีก ของเขา (lûugpèd- duckling) (khîrèe- ugly) (tua- clas) (nán- the) (sว”วn-hide) (hu“a-head) (khə־ðnkhaw- his) (tâaj- under) (piig- wing) (kha־ ankhaw- his)

\begin{tabular}{|c|c|c|c|c|c|c|c|c|c|c|c|c|c|}
\hline \multicolumn{14}{|c|}{ Selected ivords } \\
\hline \multicolumn{3}{|c|}{ 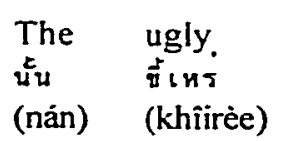 } & $\begin{array}{l}\text { duckling } \\
\text { aูกเป็ด } \\
\text { (lûugpèd) }\end{array}$ & \multicolumn{2}{|c|}{ 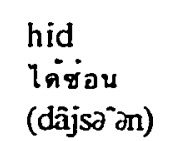 } & \multicolumn{3}{|c|}{$\begin{array}{l}\text { his } \\
\text { ของเขา } \\
\text { (khว"วnkhaw) }\end{array}$} & $\begin{array}{l}\text { head } \\
\check{\text { x̆ }} \\
\text { (hu'a) }\end{array}$ & $\begin{array}{l}\text { under } \\
\text { ใตं } \\
\text { (tâaj) }\end{array}$ & \multicolumn{2}{|c|}{$\begin{array}{l}\text { his } \\
\text { ของเขา } \\
\text { (khว־ๆkhaw) }\end{array}$} & $\begin{array}{l}\text { wing } \\
\text { In } \\
\text { (piig) }\end{array}$ \\
\hline \multicolumn{14}{|c|}{ Word addition output } \\
\hline $\begin{array}{l}\text { นั้น } \\
\text { (nán) }\end{array}$ & $\begin{array}{l}\text { ตัว } \\
\text { (tua) }\end{array}$ & $\begin{array}{l}\vec{v} \text { ( } 1 x \\
(k h\end{array}$ & $\begin{array}{l}\text { иं } \\
\text { ทีirèe) }\end{array}$ & $\begin{array}{l}\text { n เป็ด } \\
\text { ûugpèd) }\end{array}$ & $\begin{array}{l}\text { ได้ช่อ } \\
\text { (dâjss }\end{array}$ & & 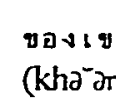 & khaw) & $\begin{array}{l}\text { หัว } \\
\text { (hu־a) }\end{array}$ & $\begin{array}{l}\text { ใต๋ } \\
\text { (tâaj) }\end{array}$ & $\begin{array}{l}\text { ของ เข } \\
\text { (khว" }\end{array}$ & h & $\begin{array}{l}\text { In } \\
\text { (piig) }\end{array}$ \\
\hline \multicolumn{14}{|c|}{ Word ordering output } \\
\hline \multicolumn{2}{|c|}{$\begin{array}{l}\text { ลูกเป็ด } \\
\text { (lûugpèd) } \\
\text { duckling }\end{array}$} & \multicolumn{2}{|c|}{$\begin{array}{ll}\text { ปี่เหร่ } & \text { ตัว } \\
\text { (khîirèe) } & \text { (tua) } \\
\text { ugly } & \text { clas } \\
\end{array}$} & $\begin{array}{l}\text { นั้น } \\
\text { (nán) } \\
\text { The }\end{array}$ & \multicolumn{2}{|c|}{ 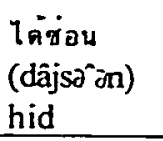 } & $\begin{array}{l}\text { หัว } \\
\text { (hüa) } \\
\text { head }\end{array}$ & \multicolumn{2}{|c|}{$\begin{array}{l}\text { ของเขา } \\
\text { (khว"วnkhaw) } \\
\text { his }\end{array}$} & $\begin{array}{l}\text { ใต่ } \\
\text { (tâaj) } \\
\text { under }\end{array}$ & $\begin{array}{l}\text { In } \\
\text { (piig) } \\
\text { wing }\end{array}$ & \multicolumn{2}{|c|}{$\begin{array}{l}\text { ของเขา } \\
\text { (khว־วkhaw) } \\
\text { his }\end{array}$} \\
\hline
\end{tabular}

Figure 5.11: Word orders of ลูกเป็ด ขี้เหร่ตัวน้น ได้ซ่อน หัว ของเขา ใต้ ปีก ของเขา

\subsection{Example of ALMT}

In this section we present the results of applying ALMT to some example sentences. The SL of Example 11 is shown in the first column of Table 5.7. The second column illustrates the output after applying the constraints e.g., the inflection $-s$ triggers the "plurality constraint", are used triggers the "passive voice" constraint, do not triggers the "negative" constraint and are talking triggers "present continuous" constraint as discussed in section 5.1.1. Each word in the second column is used as a keyword to search for the corresponding words in Thai. All possible meanings of each SL word are shown in the third column. Some of the words have more than one meaning e.g., symbol, when, know, etc. The appropriate meaning of use, know and about can be selected by considering the semantic relationship between words and the choice for each of these is shown in the fourth column. However, the appropriate words for symbol and when cannot be selected in the same manner because all possible meanings of each word have the same WordAsso number. Therefore, the first meaning appearing on the list of meaning of each word is selected. All selected words are shown in the fourth column. Before performing the ordering step, the features plural, passive and ing are replaced with the appropriate words; หลาย (la“aj), ถูก (thùg) and กำลัง (kamlan) respectively (the fifth column). The classifier ตัว (tua) is added to express the 
Table 5.7: ALMT steps applied to the sentence of Example 11

Example II: Algebraic symbols are used when you do not know what you are talking about.

TC: ลักูญูลักษณ์ ทางพืชคณิต ถูก ใช่ เมื่อ คุณ ไม่ รุ่ ว่า คุณ กำลัง พุด เกี่ยวกับ อะไร

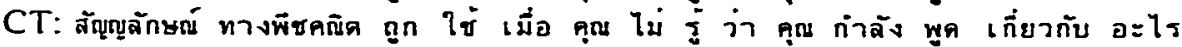

(sanjalág- symbol) (thaanphichakhanid-algebraic) (thủug- passive) (cháj- use) (my^a- when) (khunyou) (mâj- not) (ruiu- know) (wâa- connective) (khun- you) (kamlan- ing) (phûud- talk) (kiảwkàbabout) (araj- what)

\begin{tabular}{|c|c|c|c|c|c|}
\hline English & $\begin{array}{l}\text { SL } \\
\text { Constraints } \\
\text { output }\end{array}$ & $\begin{array}{l}\text { Dictionary } \\
\text { look-up output }\end{array}$ & $\begin{array}{l}\text { Selected words } \\
\text { in Thai }\end{array}$ & $\begin{array}{l}\text { Word } \\
\text { Addition }\end{array}$ & $\begin{array}{l}\text { Word } \\
\text { ordering }\end{array}$ \\
\hline Algebraic & $\begin{array}{l}\text { Algebraic } \\
\text { plural }\end{array}$ & $\begin{array}{l}\text { ทางพิชคณิต } \\
\text { (thaanphichakhanid) }\end{array}$ & $\begin{array}{l}\text { ทางพัชคณิต } \\
\text { (thaanphichakhanid) }\end{array}$ & $\begin{array}{l}\text { หลาย } \\
\text { (la־aj) } \\
\text { ดัว (tua) }\end{array}$ & $\begin{array}{l}\text { สัญญฉักษณ์ } \\
\text { (sanjalág) } \\
\text { ทางพืชคณิศ } \\
\text { (thaanphichak } \\
\text { haníd) } \\
\text { หลาย (la־aj) }\end{array}$ \\
\hline symbols & symbol & $\begin{array}{l}\text { ลัญญลักษณ์ (sanjalág), } \\
\text { เครื่องหมาย } \\
\text { (khry"anmāaj) }\end{array}$ & สัญญุลักษณ์ (sanjalág) & & ต้ว (tua) \\
\hline are & passive & & & $\begin{array}{l}\text { gan } \\
\text { (thủug) }\end{array}$ & ถูก (thùug) \\
\hline used & use & $\begin{array}{l}\text { ใช้ (cháj), } \\
\text { ปร=โยชน์ (prajòod) }\end{array}$ & ใชั (cháj) & & ใชं (cháj) \\
\hline when & when & $\begin{array}{l}\text { เมื่อ (mya), } \\
\text { เมื่อไหร (myaräj), } \\
\text { ขณะที่ (khanathii) }\end{array}$ & เมื่อ (my^a) & & เมื่อ (my`a) \\
\hline you & you & คุณ (khun) & คุณ (khun) & & คุณ (khun) \\
\hline do & - & - & - & - & - \\
\hline $\begin{array}{l}\text { not } \\
\text { know }\end{array}$ & $\begin{array}{l}\text { not } \\
\text { know }\end{array}$ & 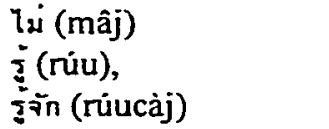 & $\begin{array}{l}\text { ไม่ (mâj) } \\
\grave{3} \text { (rúu) }\end{array}$ & & $\begin{array}{l}\text { ไม่ (mâj) } \\
\vdots \text { (núu) }\end{array}$ \\
\hline & & & & ว่า (wâa) & ว่า (wâa) \\
\hline what & what & อะไร (araj) & อะไร (araj) & & คุณ (khun) \\
\hline you & you & คุณ (khun) & คุณ (khun) & & $\begin{array}{l}\text { กำลัง } \\
\text { (kamlan) }\end{array}$ \\
\hline are & ing & & & $\begin{array}{l}\text { กำลัง } \\
\text { (kamlan) }\end{array}$ & พุด (phûud) \\
\hline talking & talk & พูด (phûud) & พูด (phûud) & & $\begin{array}{l}\text { เกี่ยวกับ } \\
\text { (kiàwkàb) }\end{array}$ \\
\hline about & about & $\begin{array}{l}\text { ประมาณ (pramaan), } \\
\text { เที่ยวกับ (kiàwkàb), } \\
\text { รอบๆ (ra`วb) }\end{array}$ & เกี่ยวกับ (kiàwkàb) & & อะ ls (araj) \\
\hline
\end{tabular}


quantity of symbol. The word ว่า (wâa) is added to combine clauses. The word ว่า (wâa) is a translation of the word that which is omitted in this sentence, however, it cannot be omitted in Thai otherwise the translation in Thai will be grammatically incorrect. The selected words are put into the correct order according to the Thai grammar as shown in the last column (The shaded area). In Example 10, the generated TC formed the Correct translation (CT) for the input sentence without the necessity of performing any correction.

In generating the TC for Example 12, once all words are selected (the fourth column, Table 5.8), the word ได (dâj) is added to clarify the past tense (lived). The classifiers aน (khon), หลัง ( $\left(\mathrm{a}^{-} \eta\right)$ and ตัว (tua) are also added as we discussed in section 5.3.1. The selected words in each noun phrase; an old woman, the cottage, a fat black cat and a plump brown hen are rearranged into the Thai grammatical order. The generated TC is exactly the same as the CT.

Figure 5.12 illustrates the translation of a fraction of The ugly duckling (version written by Ronne Randall, 1987) by ALMT. In the fourth sentence, ALMT selected the first translation word in the list, $\dot{ท}$ ไหน (thîina $\mathrm{j}$ ), for the word where since there is no significant relationship between where and its proximity words. This selection is inappropriate for this expression and it will be repaired in the later phases, TCE and RI. The word ได่ (dâj) was added to clarify the past tense (lived). It retains the meaning of the original sentence and is grammatically correct, however, ได้ (dâj) is usually omitted in such expression in Thai. In the eighth and fifteenth sentences, the translations of the phrases You are certainly not one and One evening (the shaded areas) are misordered and will be rearranged in the TCE and RI phrases. The word nับ (kàb) is an inappropriate translation for the word to in the fifteenth sentence since it means "for the attention or possession of/ intended to be given to". This selection will be replaced with the more appropriate word $\boldsymbol{n}_{\mathrm{v}}$ (thy $\eta$ ) which is a translation of the word to in the sense of "reaching as far as" in the TCE and RI phrases.

Example 12: An old woman lived in the cottage, with a fat black cat and a plump brown hen.

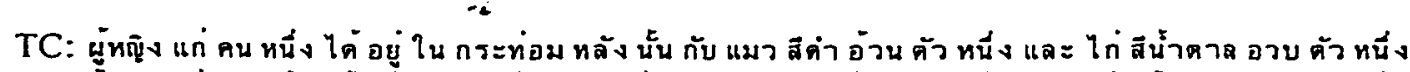

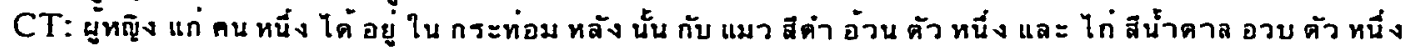

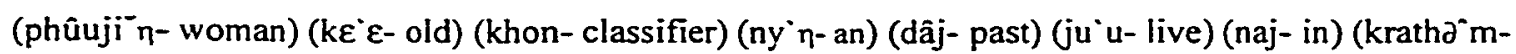

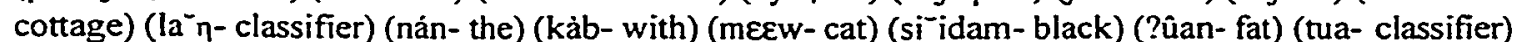

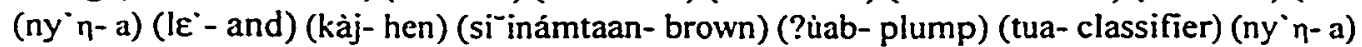


Table 5.8: ALMT steps applied to the sentence of Example 12

\begin{tabular}{|c|c|c|c|c|c|}
\hline English & $\begin{array}{l}\text { Constraint } \\
\text { Application } \\
\text { output }\end{array}$ & $\begin{array}{l}\text { Dictionary } \\
\text { look-up output }\end{array}$ & $\begin{array}{l}\text { Selected Word } \\
\text { in Thai }\end{array}$ & $\begin{array}{l}\text { Word } \\
\text { Addition }\end{array}$ & $\begin{array}{l}\text { Word } \\
\text { ordering }\end{array}$ \\
\hline An & An & หนึ่ง (ny'n) & หนึ่ง (ny'n) & คน (khon) & $\begin{array}{l}\text { ผู่หญ̄ง } \\
\text { (phûujīn) } \\
\text { แก่ }\left(k \varepsilon^{\prime} \varepsilon\right)\end{array}$ \\
\hline $\begin{array}{l}\text { old } \\
\text { woman }\end{array}$ & $\begin{array}{l}\text { old } \\
\text { woman }\end{array}$ & 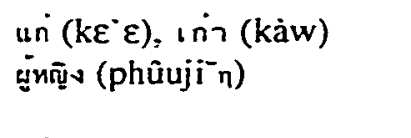 & $\begin{array}{l}\text { แก่ }\left(k \varepsilon^{\circ} \varepsilon\right) \\
\text { ผู่หญิง (phûuji־̄) }\end{array}$ & ได้ (dâj) & $\begin{array}{l}\text { คน (khon) } \\
\text { หนึ่ง (ny" }) \\
\text { ได่ (dâj) }\end{array}$ \\
\hline lived & lived & $\begin{array}{l}\text { อยู่ (ju'u), } \\
\text { มีชิวิต (miíchiiwid), } \\
\text { ด่ารงชิวิต (damronchiiwid) }\end{array}$ & อยู่ (jưu) & & อยู่ (ju u) \\
\hline in & in & $\begin{array}{l}\text { ใน (naj), } \\
\text { เข่ามา (khâwmaa), } \\
\text { เข่าไป (khâwpaj), } \\
\text { อย่าง (jàan) }\end{array}$ & ใน (naj) & & ใน (naj) \\
\hline the & the & นั้น- nán & น้น- nán & & $\begin{array}{l}\text { กระท่อม } \\
\left.\text { (krath } \partial^{\prime} \mathrm{m}\right)\end{array}$ \\
\hline cottage & cottage & กระท่อม (kratha”m) & $\begin{array}{l}\text { กระท่อม } \\
\text { (krathวัm) }\end{array}$ & หลัง (lāท) & $\begin{array}{l}\text { หลัง (la-n) } \\
\text { น้น- nán }\end{array}$ \\
\hline with & with & $\begin{array}{l}\text { กับ (kàb), ค่วย (dûaj), } \\
\text { ซิ่งมี (sȳn) }\end{array}$ & กับ (kàb) & & กับ (kảb) \\
\hline a & a & หนี่ง (ny'n) & หนึ่ง (ny'n) & ตัว (tua) & 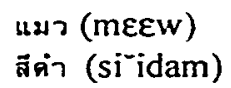 \\
\hline fat & fat & $\begin{array}{l}\text { อ่วน (?ûan) } \\
\text { ไขมัน (kha-jman) }\end{array}$ & อัวน (?ûan) & & อ้วน (?ûan) \\
\hline $\begin{array}{l}\text { black } \\
\text { cat }\end{array}$ & $\begin{array}{l}\text { black } \\
\text { cat }\end{array}$ & 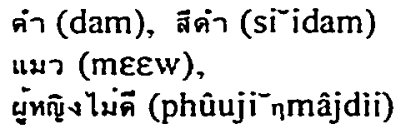 & 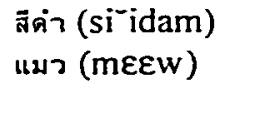 & & $\begin{array}{l}\text { ตัว (tua) } \\
\text { หนึ่ง (ny'n) }\end{array}$ \\
\hline $\begin{array}{l}\text { and } \\
\text { a }\end{array}$ & $\begin{array}{l}\text { and } \\
\text { a }\end{array}$ & $\begin{array}{l}\text { และ }\left(I \varepsilon^{\circ}\right) \\
\text { หนึ่ง (ny' } \eta)\end{array}$ & $\begin{array}{l}\text { และ }\left(I \varepsilon^{*}\right) \\
\text { หนึ่ง (ny" } \eta)\end{array}$ & & $\begin{array}{l}\text { และ }\left(l \varepsilon^{*}\right) \\
\text { ไn่ (kàj) }\end{array}$ \\
\hline & & & & ตัว (tua) & $\begin{array}{l}\text { ลื้นำตาด } \\
\text { (sĩ inámtaan) }\end{array}$ \\
\hline $\begin{array}{l}\text { plump } \\
\text { brown }\end{array}$ & $\begin{array}{l}\text { plump } \\
\text { brown }\end{array}$ & $\begin{array}{l}\text { อวบ (?ủab) } \\
\text { สี่น่าตาล (si inámtaan), } \\
\text { เกริยม (kriam), } \\
\text { คล่ำ (khlám) }\end{array}$ & $\begin{array}{l}\text { อวท (?ủab) } \\
\text { สีน์ำตาล } \\
\text { (sั̄inámtaan) }\end{array}$ & & $\begin{array}{l}\text { อวบ (?ủab) } \\
\text { ตัว (tua) }\end{array}$ \\
\hline hen & hen & 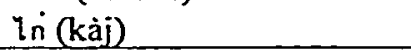 & In (kàj) & & nนُ่ง (ny'n) \\
\hline
\end{tabular}


The ugly duckling. Written by Ronne Randall.

... . The ugly duckling hid in a corner of the farmyard and cried. 2. The next moming, the ugly duckling decided to run away. 3. "I will find a place where no_one will make_fun_of me," he said to himself. 4. He left the farmyard and ran to the great marsh, where the wild ducks lived. 5. "Perhaps they will be kind to me," he said sadly. 6. But the wild ducks were not kind. 7. "You are very ugly," they said. 8. "You are certainly not one of us." 9. And the wild ducks laughed_at the duckling. 10. So the ugly duckling left the marsh. 11. The wind was blowing, and it was cold. 12. Winter was coming. 13. The ugly duckling was very tired. 14. He had_to find a place to stay where he could_be warm and safe. 15. One evening, he came to a little cottage. 16. The door was open and he went inside. 17. An old woman lived in the cottage, with a fat black cat and a plump brown hen....

ลุกเป็ดขี้เหรดัวนั้น เขียนโดย รอนนี่_แรนเดิล

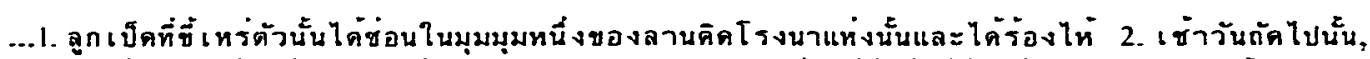

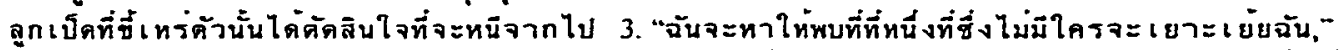
เขาได่พูดกับตัวเขาเอง 4 . เขาได่จากลานติดโรงนาแห่งนั้นและได้วิงไปที่หนองน้ำใหญ่มากหนองนั้นที่ไหน เป็ดป่าหลายตัวนัน ได้ อาศัยอยู่ 5. "บางทีพวกเขาจะใจดีกับฉัน" เขาได้ผูดอย่างเศร้าสร่อย 6. แต่เป็ดป่าหลายด้วนันไม่ใจดี 7."คุณบี้เหร่มากา," พวกเขาได่พูด 8. "คุณเป็นอย่างแน่นอนไม่หนี่ง ของพวกเรา." 9. และเป็ดป่าหลายด้วนั้นได้หัวเราะเยาะล กเป็ดตัวนัน 10 ดังนั้นลูกเป็ดขี้เหรดัวน้นได้จากหนองน้ำหนองนั้น 11. ลมนั้นกำลังพัดและมันหนาว 12 .ฤดูหนาว

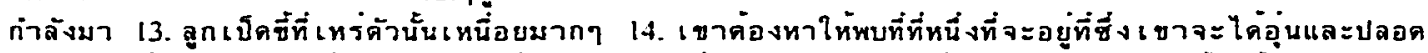
กัย 15. หน์่งเย็น เขาได่มา กับ กระท่อมเล็กหลังหนึ่ง 16. ประตูประดูนั้ถูกเจดและเขาได้ไปข่างใน 17.

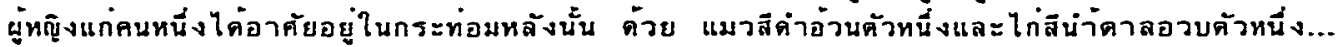

Figure 5.12: A part of "The ugly duckling" and its translation 


\section{Chapter 6}

\section{Translation Candidate Evaluation}

The second phase of GRMT, Translation Candidate Evaluation, determines whether the generated translation candidate retains the meaning conveyed by the source language. TCE analyzes both the SL and the TC in parallel, then compares the results of the parses in terms of semantics alone since there are syntactic level differences between languages (Figure 6.1). If the semantic information in each of the SL and the TC parses are acceptably similar, the TC will be deemed an appropriate translation. If their semantic information is different, the TC and their semantic differences will be reconciled in the third phase, Repair and Iterate. TCE comprises two modules as illustrated in Figure 6.1 , the analyzer and semantic comparison.

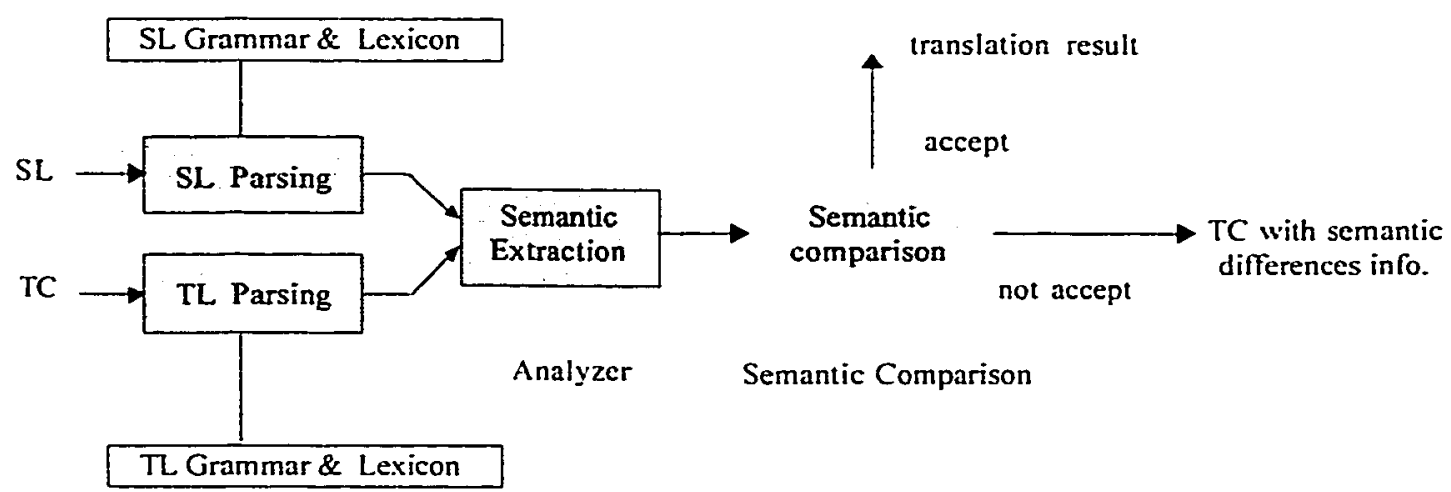

Figure 6.1: TCE Architecture 


\subsection{The Analyzer}

The analysis module analyzes the TC to examine its syntax and semantics: whether the TC is grammatically correct according to the TL grammar and whether the TC retains the meaning of the source language. Therefore, two steps are performed by the analyzer: Parsing and Semantic Extraction.

\subsubsection{Parsing}

Parsing is applied to both the SL and the TC. We have developed English and Thai grammars within the Head-Driven Phrase Structure Grammar formalism [Pollard and Sag; 1987; Pollard and Sag. 1994]. Our grammar is a modification to the grammars which were provided by Gerald Penn [Penn 1993] and Colin Matheson [Matheson 1996]. The grammars we developed have been implemented using the Attribute Logic Engine version 3.2 Beta. ALE is an integrated phrase structure parsing and definite clause logic programming system in which the terms are typed feature structures [Carpenter and Penn 1999].

In the next section, a very brief overview of HPSG and some notation are introduced. Further details on HPSG can be found in [Pollard and Sag 1987], [Pollard and Sag 1994], [Sag and Wasow 1999], HPSG homepage at http://hpsg.stanford.edu/ [Center for the Study of Language and Information 1999] and the typed feature formalism is described in [Carpenter 1992].

\subsubsection{About Head-Driven Phrase Structure Grammar}

Head-Driven Phrase Structure Grammar, the grammatical theory developed by Carl Pollard and Ivan Sag during the mid 1980s [Pollard and Sag 1987; Pollard and Sag 1994], was developed by synthesizing several contemporary linguistic theories, including Categorial Grammar (CG), Generalized Phrase Structure Grammar (GPSG) [Gazdar et al. 1985], and Lexical Functional Grammar (LFG) [Bresnan and Kaplan 1982], from which it borrows some interesting ideas. The HPSG architecture has been largely pursued by an increasing number of linguists, since the formally well-defined framework allows for an explicit formalization of a linguistic theory.

HPSG, an integrated theory of natural language syntax and semantics, is a feature-based grammatical framework which is characterized by a modular specification of linguistic 
generalizations through extensive use of principles and lexicalization of grammatical information.

HPSG is formulated in terms of order-independent constraints. In other words, the grammar is formulated as a declarative system of constraints. These constraints provide partial grammatical information that can be flexible, consulted in a variety of language processing models based on the notion of incremental, on-line integration of heterogeneous types of information. Key advant ages of HPSG which are appropriate for use in MT are as follows:

- Small number of rules and rich-information lexicon

Based on the assumption of a universal syntax. a small number of highly schematic syntactic rules are assumed to apply universally; the task of explaining the variations between languages must be carried out in the lexicon [Carpenter 1991]. The detailed lexical entries of HPSG are concisely expressed within a multiple inheritance hierarchy and lexical rules. Such hierarchical lexicons allow cross-cutting generalizations about words to be expressed in a highly efficient and compact organization.

- Unification-based constraints

Recent work in the unification framework [Shieber 1986] has shown that a formalism based on unification is particularly well-suited for declarative modes of problem solving. In addition, a declarative mode allows the construction of grammars which can be neutral as to the processes applying to them, whether parser or generator [Estival 1994].

- Language-independent principles

The modular design of HPSG offers a large degree of flexibility for applying the framework to new languages and changing individual components of a grammar.

\subsubsection{Words and Phrases as Feature Structures}

Utterances in HPSG are modeled in terms of feature structures of type sign, with its two immediate subtypes word and phrase [Ginzburg and Sag 1998]. The lexical entries are descriptions of feature structures of type word while phrase structure rules are partial descriptions of feature structures of type phrase.

A feature structure is a description of an object; it specifies some or all of the information that is asserted to be true of the object. The features CATEGORY (CAT) and CONTENT (CONT) (Figure 6.2) specify the syntactic and semantic information of an object 
respectively. Figure 6.2 represents a partial description of the lexical entry hide in an attribute-value matrix (AVM) diagram' (the detailed explanation of this representation can be found in section 6.3.1). Each feature takes a value of a particular and appropriate type. The grammar must include a specification of what types are included, which features are appropriate for which type, and what type of value is appropriate for each feature. Some types, their features and their value types are shown in Table 6.1 (see also appendix D).

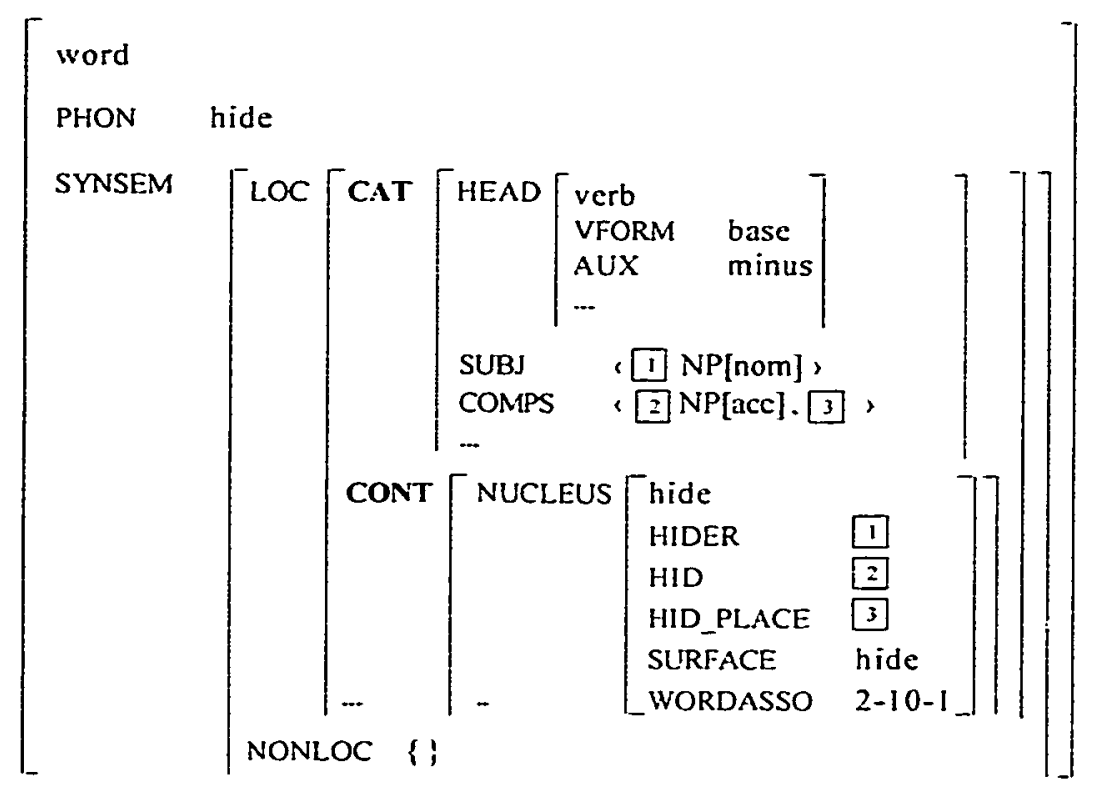

Figure 6.2: The lexical entry hide

Figure 6.3 presents a (simplified) partial description of the phrase Leslie drinks milk (this example is taken from Ginzburg and Sag, 1998) in terms of typed feature structures. This representation indicates that Leslie drinks milk is the type of head-subject phrase ${ }^{2}$ (hd-subjph). The hd-subj-ph is a subtype of the type headed-phrase (hd-ph). The hd-ph is the type of

\footnotetext{
'The AVM diagram is the standard method of representing grammatical information in modern computation grammar theories.

2 There are two types of phrases in English: headed phrase (c.g.. head- subject phrase. head-complementphrase, head-modifier-phrase) and nonheaded phrase (e.g.. imperative-phrase, coordinate-phrase). Further details can be found in [Ginzburg and Sag 1998] and [Sag and Wasow 1999].
} 
the phrase in which one daughter is assigned special status as the HEAD DAUGHTER (HD-DTR). Other subtypes of hd-ph are head-specifier-phrase (hd-spr-ph), head-complement-phrase (hd-comp-ph), head-adjunct-phrase (hd-adjunct-ph). Inst-ances of the hd-ph are governed by the feature declarations shown in the last row of Table 6.1. The indices $\square, 2,3$ specified in the feature PHONOLOGY (PHON) called tags indicate the structure sharing between feature values: two or more different features within the featu re structure may have their values specified by one and the same feature structure. The effect of structure sharing is to force two (or more) distinct nodes in a tree admitted by a rule to have identical values for a given feature. In Figure 6.3, the first phonology (phonology here means phonological shape) of the hd-subj-ph is the same as the phonology of its NON-HD-DTRS which, in this case, is Leslie, the second and the third phonologies are the same as those of its HD-DTR which are drinks and milk respectively. The syntactic category of Leslie drinks milk is a sentence (synsem: $s$ ). The syntactic category of the NON-HD-DTRS (Leslie) of the given phrase is a noun phrase (NONHD-DTRS:SYNSEM: np). The syntactic category of its HD-DTR (drinks milk) is a verb phrase (HD-DTR:SYNSEM: vp). The type of this verb phrase drinks milk is a hd-comp-ph with the HD-DTR, drinks, and the NON-HD-DTRS, milk.

Table 6.1: Some types, their features and their value types

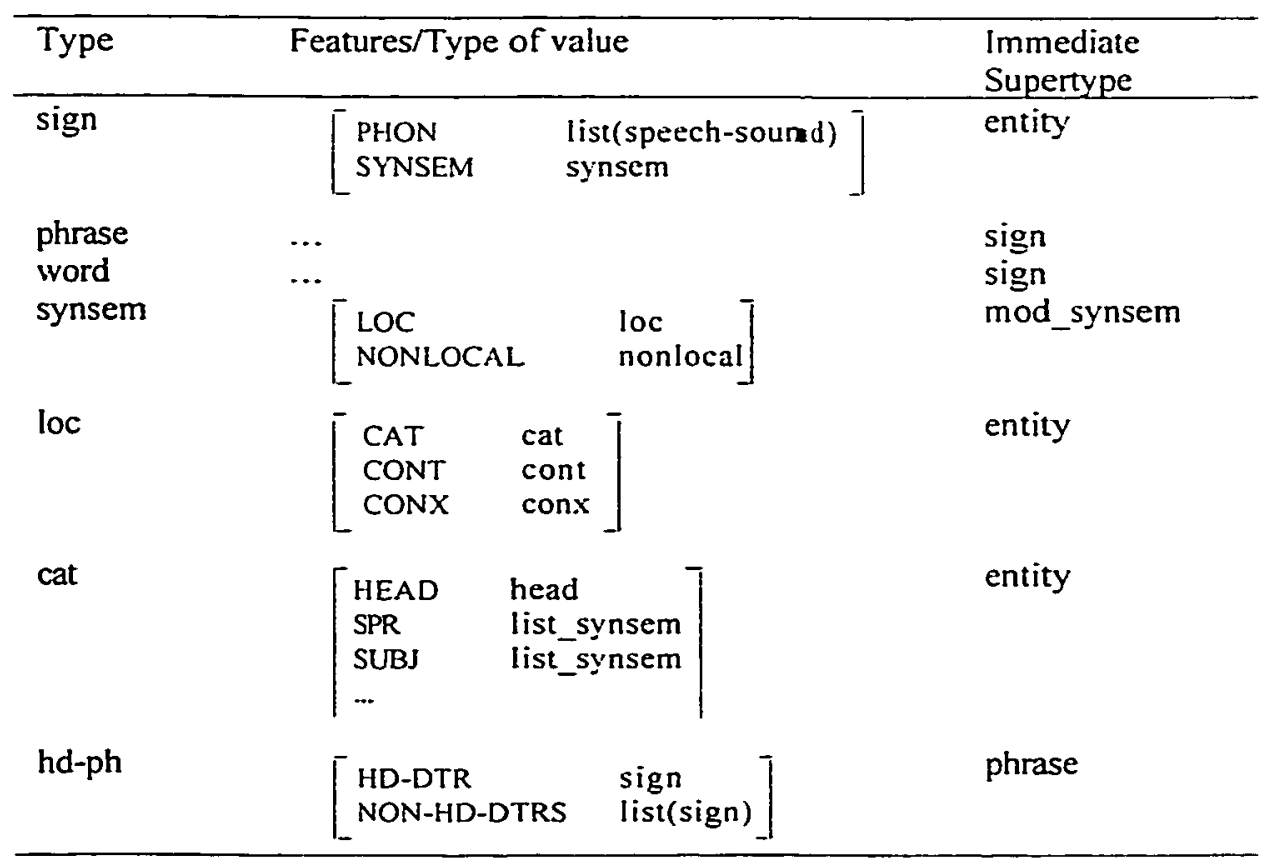




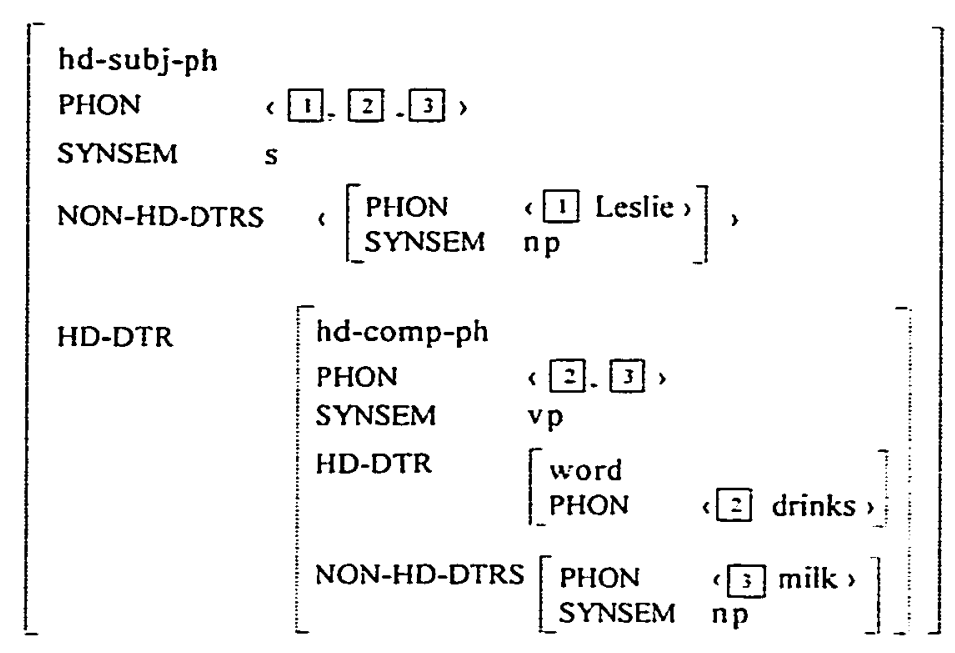

Figure 6.3: The phrase Leslie drinks milk

\subsubsection{Lexicon}

The lexical types (e.g., noun, verb, adj), a type inheritance and the lexical rules allow complex lexical information (as shown in Figure 6.2) to be derived via the logic of the lexicon, rather than simply stipulated.

The lexical types were introduced to define feature appropriateness, to avoid having to specify values for features that are irrelevant to particular classes. Table 6.2 illustrates the type constraints that state general properties (in terms of particular feature-value specifications) of particular lexemic types, noun and verb. Noun and verb are subtypes of substantive $^{3}$ (subst). The feature CASE is appropriate only for nouns (in English) and its value is either nominative (nom) or accusative (acc). The features VERB-FORM (VFORM), INVERTED (INV) and AUXILIARY (AUX) are specifiable only for verbs. The forms of verbs can be classified as base, finite, gerund, infinite, passive participle, present participle and past participle form [Pollard and Sag 1987]. The feature INV and AUX are used to distinguish auxiliary (helping) verbs from all others. The values of INV and AUX are the type of boolean. In interrogatives, a finite auxiliary verb precedes the subject, therefore, the INV and AUX values of a finite auxiliary verb are plus while the INV and AUX values of other kinds of verb

\footnotetext{
${ }^{3}$ According to Pollard and Sag, noun, verb, adjective, preposition. relativizer are subtypes of substantive. whereas marker (e.g., complementizers) and determiner are subtypes of functional [Pollard and Sag 1994].
} 
are minus.

Each type in the lexical hierarchy has constraints associated with it - some inviolable, and others that are default in nature. The inheritance of constraints in this type hierarchy is default. The default inheritance allows contradictory information associated with a subtype to take precedence over (or override) constraints that would otherwise be inherited from a supertype. In other words, lexical items have many properties in common but may differ from one another in terms of particular constraints that override the general constraints governing their supertypes. By organizing the lexicon in terms of a type hierarchy and the use of default inheritance of constraints, the stipulations associated with particular lexical entries can be minimized and the shared properties of different word classes can be expressed.

Table 6.2: Features and their value types of the types noun and verb

\begin{tabular}{|c|c|c|}
\hline Type & Features/Type of value & $\begin{array}{l}\text { Immediate } \\
\text { Supertype }\end{array}$ \\
\hline noun & [ CASE case] & subst \\
\hline verb & {$\left[\begin{array}{ll}\text { VFORM } & \text { vform } \\
\text { INV } & \text { boolean } \\
\text { AUX } & \text { boolean }\end{array}\right]$} & subst \\
\hline
\end{tabular}

The lexical rule is a mechanism for further reducing redundancy and stipulation in the lexicon by using information in one lexical entry as the basis for generating another lexical entry. The lexical rules are used for deriving predictably related lexical entries, e.g., inflected forms of verbs and nouns. A lexical rule applies to a lexical entry (of type word) and produces as output a new lexical entry whose (morphological) form, syntactic category and semantics are systematically related to the input [Sag and Wasow, 1999]. Figure 6.4 illust rates the (simplified) rule that applies tö verb bases in English, giving their $3 \mathrm{rd}$-singular

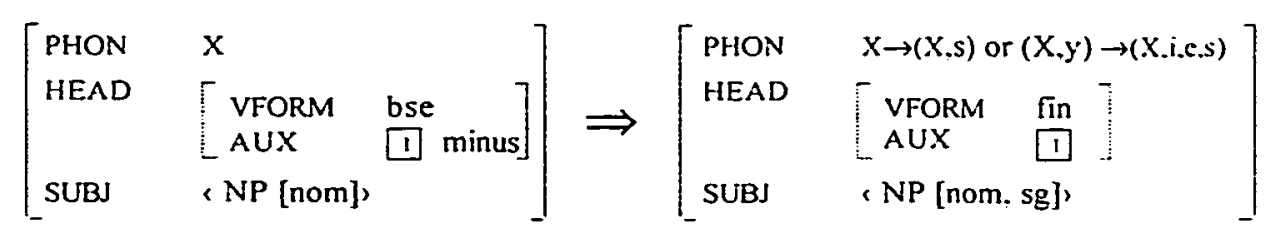

Figure 6.4: The 3rd-singular verb lexical rule 
verb form. This 3rd-singular verb lexical rule is taken from hpsg.pl written by Gerald Penn [Penn 1993]. The rule suffixes an -s or -ies (in case the verb ended with y), thus it generates hides for hide and flies for fly. The rule says that for every verb whose form is uninflected (VFORM: bse), not an auxiliary verb (AUX: minus) and it takes a nominative as its subject (SUBJ: NP (nom)), there is a corresponding lexical entry for a 3rd-singular verb whose form is dictated by the 3rd-singular verb lexical rule: finite (VFORM: fin) and it takes a subject which is nominative and singular (SUBJ: NP (nom, sg)). Figure 6.5 illustrates hides, the output of the 3rd-singular verb lexical rule applied to the lexical entry hide shown in Figure 6.2. See appendix E for additional lexical rules.

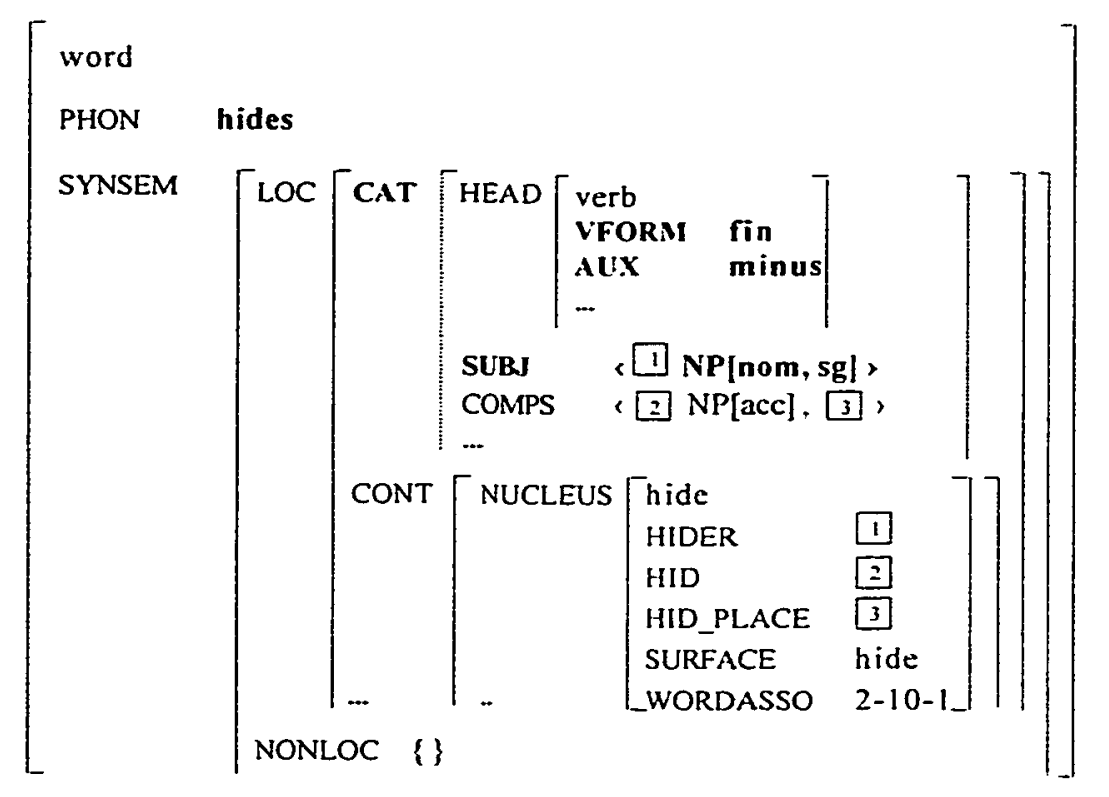

Figure 6.5: Example output, hides, of the 3rd-singular verb lexical rule

\subsubsection{Some Universal Principles and Grammar rules}

In this section, we explain some of the universal principles proposed in HPSG and consider some phrasal constructions with HPSG grammar rules.

The Head Feature Principle (HFP) can be formulated as a constraint on phrases of the type hd-ph. This principle restricts the sharing of the HEAD feature between a mother sign and its head daughter as shown in (1). HEAD always takes as its value a feature structure appropriated to each category as discussed in the last section (see the values of the HEAD 
features of drinks and milk in Figure 6.6). The effect of the sharing restriction is to guarantee that headed phrases really are a projection of their head daughters. In Figure 6.6, the HD-DTR, drinks, of the hd-comp-ph, drinks milk, passes its HEAD feature's value to the HEAD feature of its mother (marked by the dotted ellipse). The HD-DTR, drinks milk, of the hd-subj-ph. Leslie drinks milk, passes its HEAD feature's value to the HEAD feature of its mother. HFP also indicates that the category of verb phrases are verb because they have verbal heads and that of noun phrases are nominal because they have noun heads. This principle is applied to all grammar rules.

$$
\text { hd-ph } \Rightarrow\left[\begin{array}{lll}
\text { SYNSEM ILOCICAT IHEAD } & 0 \\
\text { HD-DTR } & \text { [SYNSEM|LOCICATIHEAD } & \text { b }
\end{array}\right]
$$

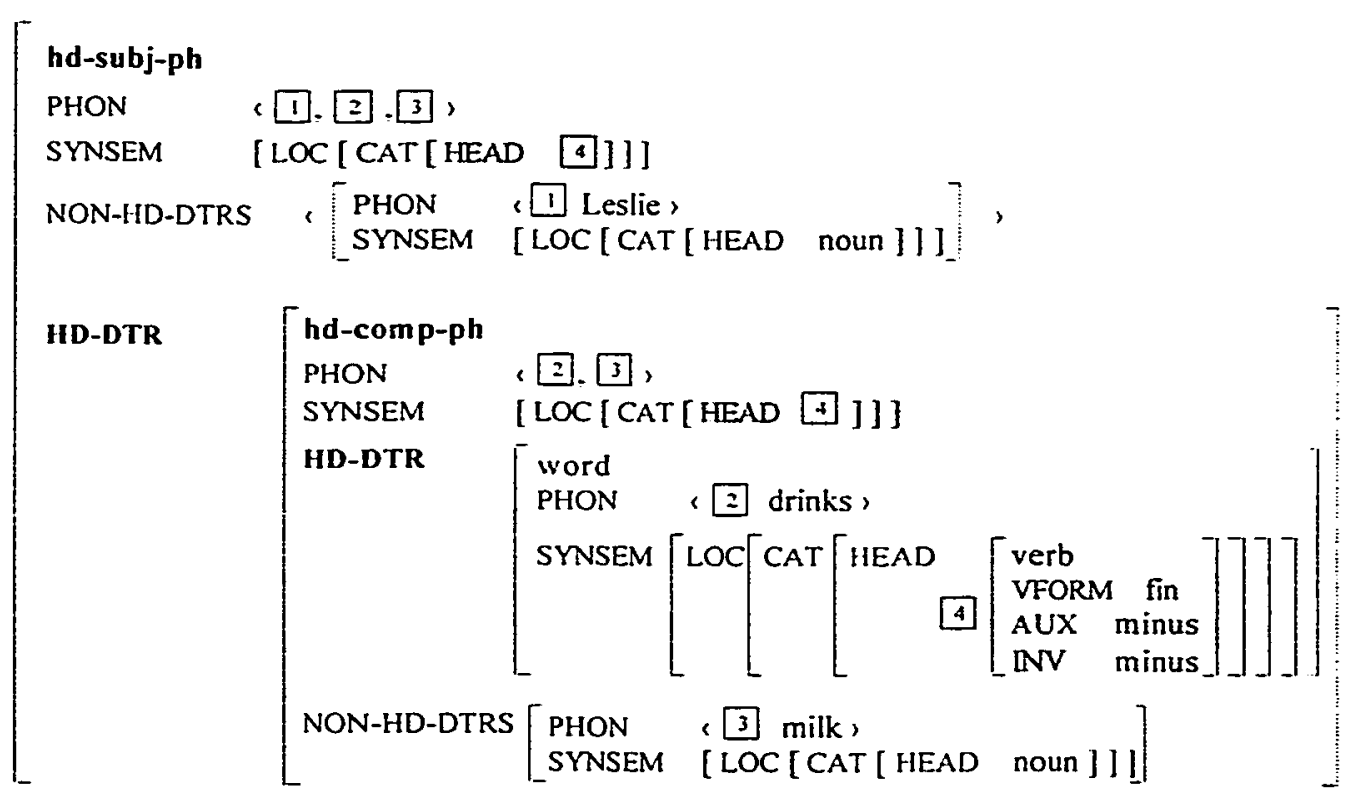

Figure 6.6: HFP applied to Leslie drinks milk

The Semantics Principle (second version) [Pollard and Sag 1994] guarantees that the semantics of a mother sign constrained by the feature CONT are identified with that of the adjunct daughter (ADJUNCT-DTR) if the phrase is the type of head-adjunct-phrase (hd-adjunctph). However, if the phrase is not the type of hd-adjunct-ph then the semantics of a mother sign are identified with that of the HD-DTR as in (2). The features CONT is concerned 
principally with linguistic information that bears directly on semantic interpretation. The CONT value of nominals (e.g., lexical nouns and their phrasal projections) is the feature structure of INDEX and restriction (RESTR).

$$
\text { hd-ph } \Rightarrow\left[\begin{array}{ll}
\text { SYNSEM|LOCICONT } & \square \\
\text { HD-DTR } & \text { [SYNSEM|LOCICONT }
\end{array}\right]
$$

with the exception of the hd-adjunct-ph

$$
\text { hd-ph } \Rightarrow\left[\begin{array}{lll}
\text { SYNSEMILOCICONT } & \square \\
\text { ADJUNCT-DTR } & \text { [SYNSEM!LOCICONT } & \square]
\end{array}\right]
$$

The type INDEX is classified into three subtypes: referential (ref), there and it [Pollard and Sag 1994]. The types there and it are used only for the expletive pronouns there and it while the type ref are used for nouns. INDEX introduces the three agreement features: PERSON (PER), NUMBER (NUM) and GENDER (GEN). The INDEX values of Leslie and milk are shown in Figure 6.7. According to the AVM diagram representation illustrated in Figure 6.7, the linguistic meaning of Leslie is that the object is refered to as Leslie, its quantity is one and its gender is masculine. The PERSON feature is unspecified for Leslie. Milk is a 3rd person, singular and neutral. The INDEX feature ${ }^{4}$ plays an important role in HPSG account of binding theory. For example: the indices for John and himself, in the sentence John shaved himself, should be shared [Matheson 1996].

The value of the feature RESTR is a set of parametrized states-of-affairs (psoas). Statesof-affairs (soa, the term used in situation semantics, it is what philosophers call propositions) are possible ways the world might be construed [Pollard and Sag 1987]. Psoa is like a soa except that certain of its argument roles (its parameter) have not yet been anchored to determinate objects. The idea behind the feature RESTR is that it contains the basic semantic information on a referent [Matheson 1996], e.g., the RESTR value of the lexical entry milk contains the basic semantic information that the object concerned is milk. In addition, the values of the INSTANCE and INDEX features are unified (the restriction imposed by the common noun is associated with the marker in the discourse as discussed in Footnote 3 ) [Matheson 1996].

\footnotetext{
${ }^{4}$ The INDEX feature is used in the HPSG analysis of discourse structure. For example, in the sentences: " the man likes books. he often reads them", the two markers representing the man and books in the first sentence should be identified with the markers for he and them, in the second sentence. respectively [Matheson 1996].
} 


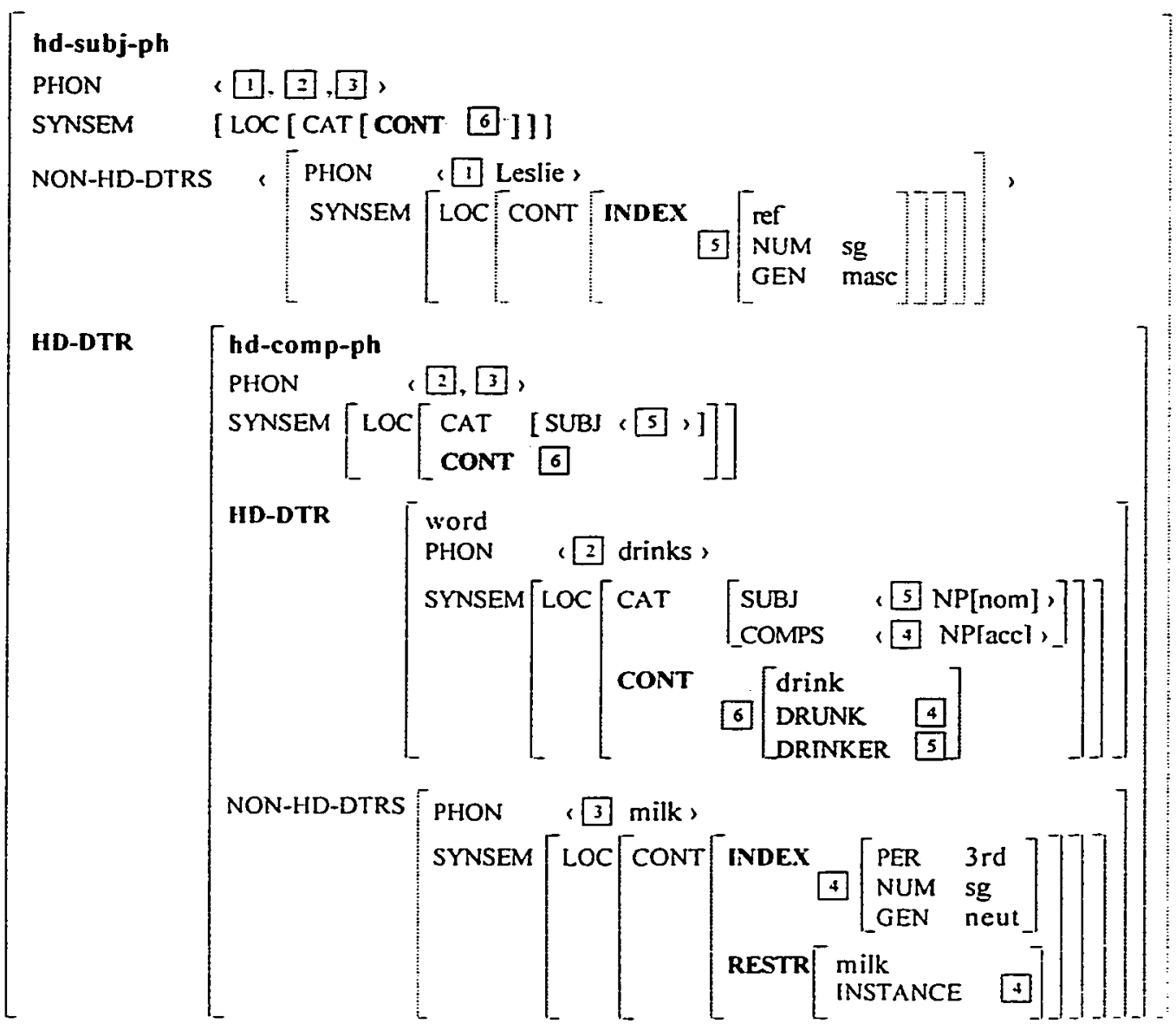

Figure 6.7: Semantic principle applied to Leslie drinks milk

The CONT value of verb is the feature structure of predication specified: what kind of relation is involved and who (or what) is participating in the relation. The CONT value of the lexical entry drinks is illustrated in Figure 6.7 , it corresponds to the condition that $\square$ drinks 4.

The effect of the semantic principle is illustrated in Figure 6.7 (marked by the shaded ellipse). The CONT value of the hd-comp-ph drinks milk is passed from its HD-DTR drinks (indicated by the tag 6 ) and the CONT value of drinks milk is passed to that of hd-subj-ph (indicated by the tag [6) since drinks milk is the HD-DTR of Leslie drinks milk. The semantic representation in Figure 6.7 means Leslie drinks milk depicts a proposition which satisfies the conditions that 5 is a masculine referred to as Leslie, $\rightarrow$ is milk, and Leslie drinks milk. This 
principle is applied to all grammar rules. For more principles e.g., Spec Principle, Marking Principle, Nonlocal Feature Principle and Relative Uniqueness Principle, consult [Pollard and Sag 1987], [Pollard and Sag 1994], and [Matheson 1996].

The Head_complement rule allows a lexical head to combine with the zero or more complements that it selects to form a phrase of type hd-comp-ph. This kind of phrase is subject to the constraint as in (3). The COMPLEMENTS (COMPS) value of the head must match a sequence of SYNSEM values of NON-HD-DTRS. The COMPS value is a list of feature structures. The list specifies a sequence of categories corresponding to the complements that the word combines with. For example: a verb likes (Figure 6.8), a HD-DTR, combines with its (only one) complement John in a hd-comp-ph. This means that the SYNSEM value of the NON-HD-DTRS of the phrase likes John is identified with 2$]$.

(3)

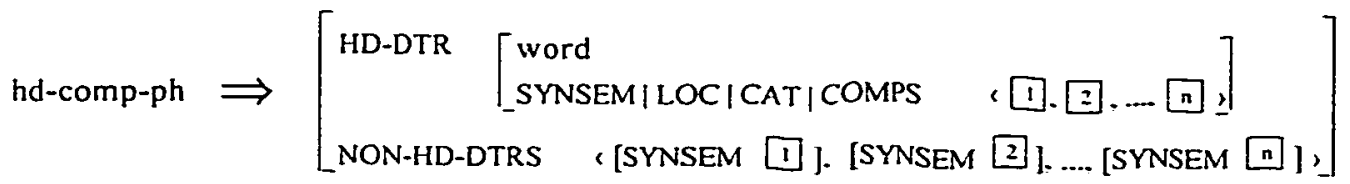

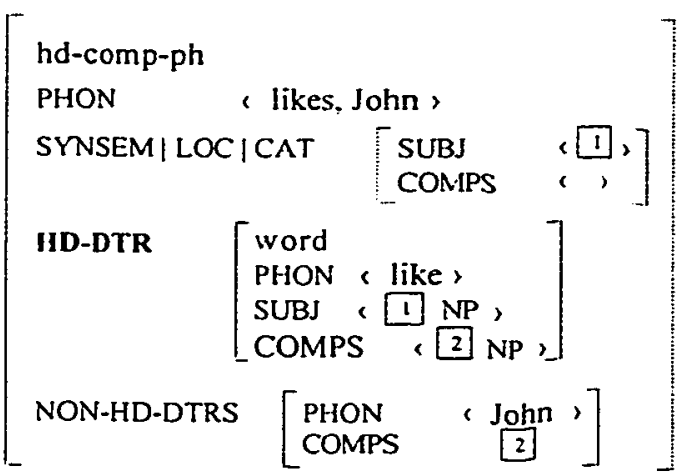

Figure 6.8: Head_complement rule applied to likes John

The Specifier_head rule (spr_hd) allows a lexical head to combine with its specifier that it selects to form a phrase of type spr-hd-ph as in (4). The spr_hd rule requires a two-way restriction: specifiers restrict their heads and heads restrict their specifiers [Matheson 1996]. For example, a specifier this selects singular nouns while common nouns select determiners as their specifiers. Therefore, the features SPECIFIER, SPR and SPEC, are introduced. SPR restricts the co-occurrence for heads and the specifiers they select. SPEC restricts the heads, 
the kinds of things they specify. A noun book (Figure 6.9), a HD-DTR of a spr-hd-ph the book, combines with its determiner $a$, SPEC-DTR, which instead selects singular nouns to be specified.

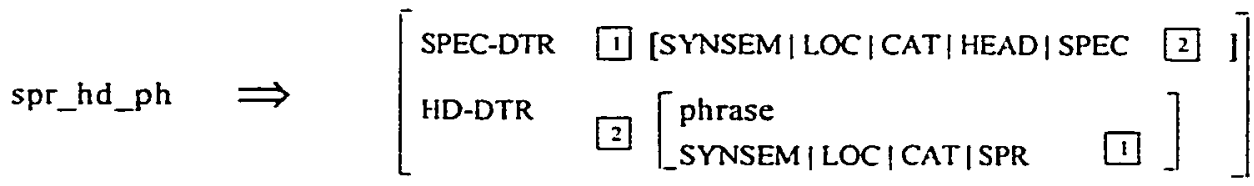

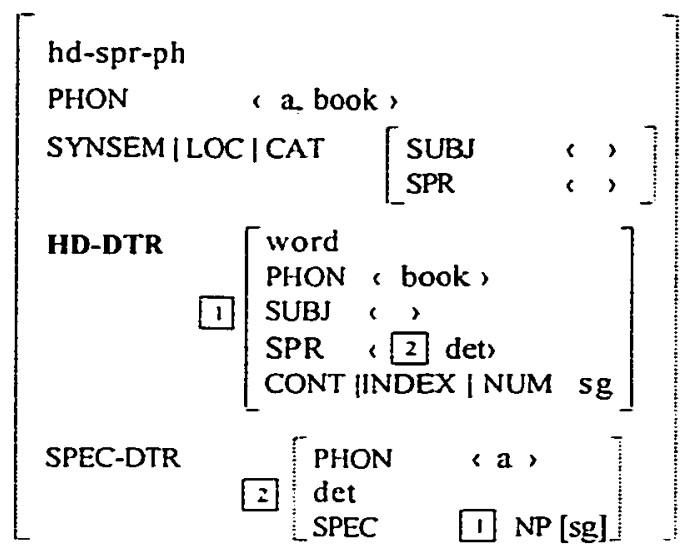

Figure 6.9: Specifier_head rule applied to the book

\subsubsection{Attribute Logic Engine}

The Attribute Logic Engine 3.2 Beta $^{5}$, was written in SICStus Prolog and developed by Bob Carpenter and Gerald Penn. ALE is a grammar parsing system which was developed to facilitate the use of HPSG and any typed feature structure grammar. Every structure used in ALE comes with a type. These types are arranged in an inheritance hierarchy whereby type constraints on more general types are inherited by their more specific subtypes [Carpenter and Penn 1999]. ALE differs from other approaches to feature structures in at least three notions. First, there is a strong type discipline enforced on feature struct ures. This means each type must specify which features it can be defined for and which types of values such features can take. The second notion is the type inference whereby types for structures which are underspecified can be automatically inferred. The third notion is that types in ALE are semant ic which means that types are used at run-time. Even though ALE employs

\footnotetext{
${ }^{5}$ ALE 3.2 Beta also contains a generator.
} 
semantic typing, a type system is employed to detect type errors in grammars.

ALE also offers macros, to be used in description. Macros allow the user to define a description once and then use a shorthand for it in other descriptions. Macros can also contain other macros. The advantages of macros is not only to make the grammars more readable (especially to organize lexical information) but also to reduce the number of simple typing errors that lead to inconsistencies. Some sample macros and their usage are illustrated in section 6.1.1.6.

The format ALE provides for stating lexical rules is similar to that found in HPSG. However, the lexical rule system of ALE is productive in that it allows lexical rules to apply sequentially to their own output or the output of other lexical rules. Thus, it is possible to derive the nominal runner from the lexical entry run by the nominal lexical rule, and then derive the plural nominal runners from runner by the plural_noun lexical rule.

The ALE system employs a bottom-up active chart parser [Carpenter and Penn 1999]. The rules are evaluated from left to right, with the mother description coming last. The chart is filled in using a combination of depth-first and breadth-first control. The parser proceeds breadth-first in the sense that it incrementally moves through the string from right to left, one word at a time, recording all of the inactive edges that can be created beginning from the current left-hand position in the string.

ALE provides a number of routines for displaying and debugging grammar specifications as well. In executing ALE, the input string must be entered as a Prolog list of atoms. In particular, it must have an opening and closing bracket, with words separated by commas. No variable should occur in the query, nor anything other than an atom. The first part of the parsing output repeats the input string, separated by numbers (nodes in the chart) which indicates positions in the string for using in inspecting the chart directly (Figure 6.10). The second part of the output is a category which is derived for the input string. If there are multiple parses, these can be iterated through by providing positive answers (yes) to the query "Another?". The parsing stops when no more parses are found. Further details on ALE can be found at ALE homepage "http://www.sfs.nphil.uni-tuebingen.de/ gpenn/ale.html \#Obtain", available as of May, 1999. 


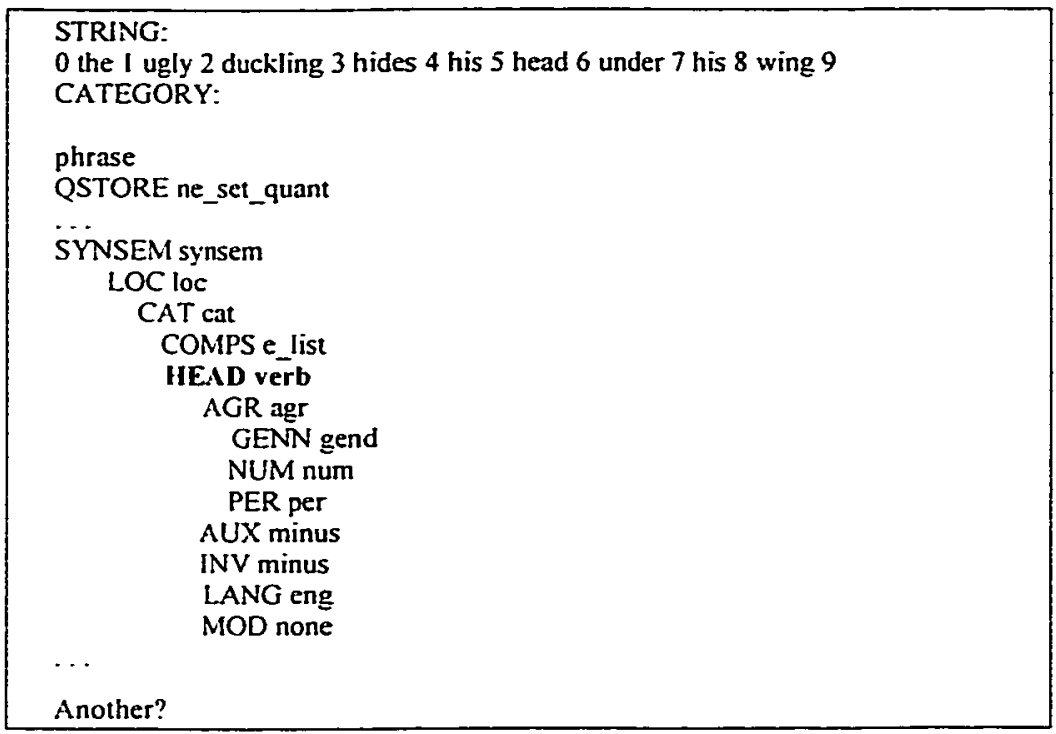

Figure 6.10: Example of result of parsing in ALE representation

\subsubsection{English and Thai Grammars in GRMT}

In HPSG, the grammatical categories are broken down into features and the feature values are broken down into features as well. In this process, more and more syntactic information is moved out of the grammar rules and into the lexicon. This philosophy results in rules with very general patterns that cut across grammatical categories. The following seven grammar rules we developed cover a wide range of cases in both English and Thai (see also appendix F).

The subject_head rule (subj_hd), the head_complement rule (hd_comp), and the coordination rule cover the phrasal structures not only in English but also in Thai (the similarity between the typical phrasal structures of English and those of Thai was discussed in section 4.1). The head_subject_complement rule (hd_subj_comp) is used to license an English inverted sentence. The hd_subj_comp can also be used to analyze the phrasal structures which have verb-subj-object order in any language. The specifier_head rule (spr_hd) combines a lexical head with its selected specifier in English. The adjunct_head and head_adjunct rules allow a phrase to consist of a phrasal head and its modifier. The head_specifier (hd_spr) rule combines a lexical head with its specifier in Thai .

(5)

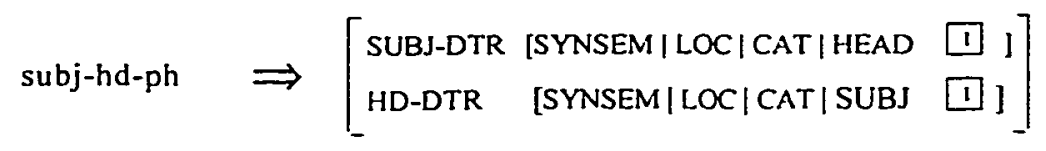


The subj_hd rule allows a lexical head to combine with its selected head according to the constraint as in (5). The HEAD value of the SUBJ-DTR must match the SUBJECT value of the HD-DTR.

(6)

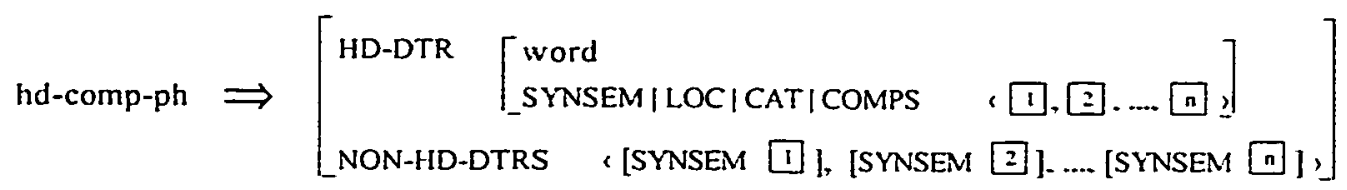

The hd_comp rule, combines a head with its complements, according to the constraint as in (6), was discussed in section 6.1.1.4.

$$
\text { coordination-ph } \Rightarrow\left[\begin{array}{ll}
\text { CONJUNCT-DTRI } & {\left[\begin{array}{l}
\text { phrase } \\
\text { SYNSEM|LOCICAT } \square]
\end{array}\right.} \\
\text { COORDINATE-DTR } & \text { [SYNSEM|LOCICAT|HEAD } \\
\text { CONJUNCT-DTR2 } & {\left[\begin{array}{l}
\text { phrase } \\
\text { SYNSEM|LOCICAT } \square
\end{array}\right]}
\end{array}\right]
$$

This coordination ${ }^{6}$ rule says that the two occurrences ${ }^{7}$ of elements of the same syntactic category can be conjoined to make a coordinate element of that category (7). This rule requires that all conjuncts of a coordinate structure have identical values for HEAD, SPR and COMPS.

The hd_subj_comp rule allows a lexical head to combine with its subject and complements that it selects to form a phrase of verb-subj-object, in that order, as in (8). The HD-DTR must be an invert ed verb and its HEAD value must match the SUBJ value of the SUBJ-DTR. The COMPS values of the HD-DTR must match a sequence of SYNSEM values of NON-HD-DTRS.

\footnotetext{
${ }^{6}$ The coordinate conjunctions are words connecting elements that are, intuitively. of equal status. In English, the paradigmatic coordinate conjunctions are and or or [Sag and Wasow 1999].

7 The number of the conjuncts of a coordinate structure in the coordination rule proposed by Sag and Wasow [Sag and Wasow 1999] is not limited at two: it could be any number of occurrences of conjuncts. However. the semantics transfer from the conjuncts to the mother is not yet finalized at this time: therefore. our corrdination rule considers only two conjuncts for simplicity.
} 
(8)

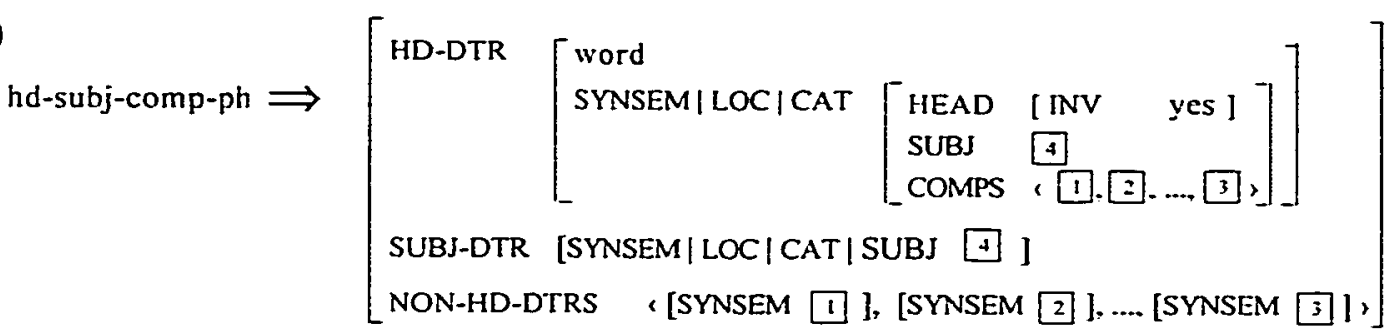

(9)

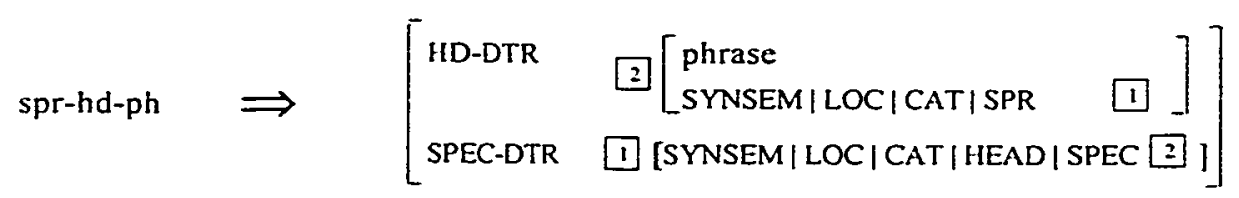

The spr_hd rule (9) says that the a phrase can consist of a phrasal head preceded by its specifier, as we discussed extensively in section 6.1.1.4.

$$
\begin{aligned}
& \text { adjunct-hd-ph } \Rightarrow\left[\begin{array}{ccc}
\text { ADJUNCT-DTR } & {[\text { SYNSEM } \mid \text { LOC ICAT } \mid \text { HEAD } \mid \text { MOD } 2,} \\
\text { HD-DTR } & 2] \text { i phrase ] }
\end{array}\right]
\end{aligned}
$$

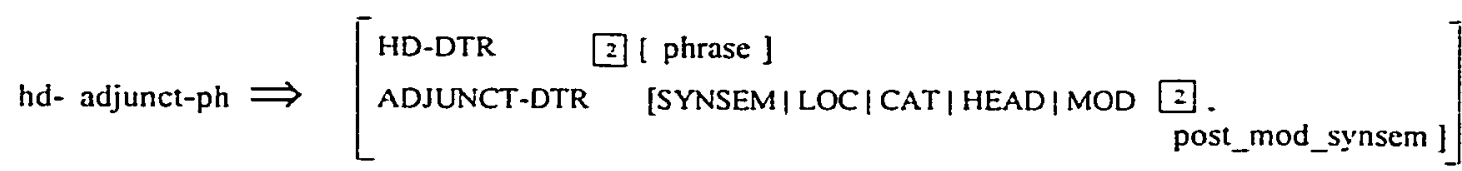

In English, adjuncts (modifiers) appear both before and after the objects they modify (HD-DTR), e.g., the ugly duckling, the duckling in the farmyard. Therefore, two rules: adjunct_hd rule and hd_adjunct rule are required to combine the HD-DTR with its modifier as in (10). In Thai, the modifiers must follow the HD-DTR (see section 4.1): thus only the hd_adjunct rule is required. The MODIFIER (MOD) values of the ADJUNCT-DTRs indicate the types of the object that the adjunct modifies. The subtypes pre_mod_synsem and post_mod_synsem specified in the ADJUNCT-DTR restrict which rule will be applied.

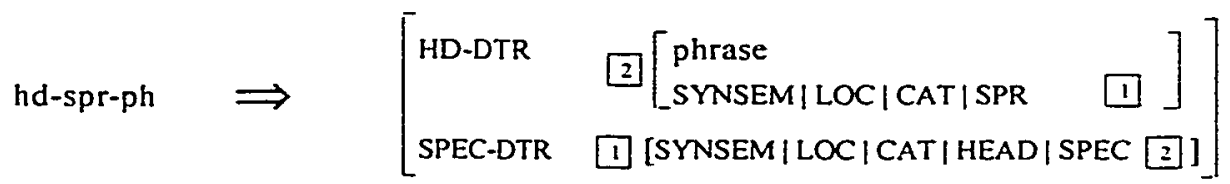




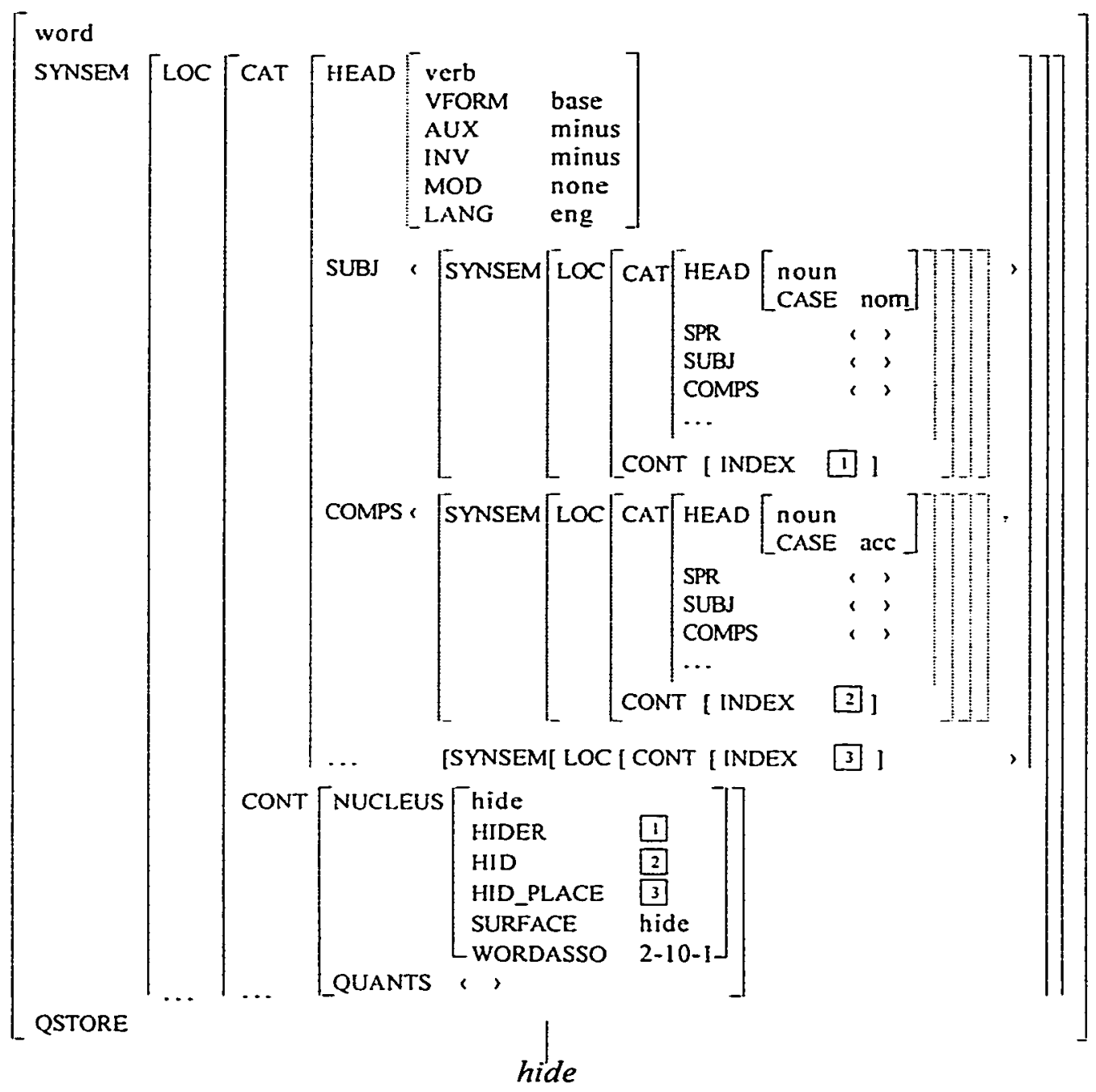

Figure 6.11: The lexical entry for hide

The grammars we developed have been implemented using the Attribute Logic Engine. Figure 6.12 illustrates the representation of the lexical entry hide (its AVM diagram is shown in Figure 6.11) in ALE with some macros. The use of the macro is specified by the @ sign followed with the macro name e.g., @np, @case. 


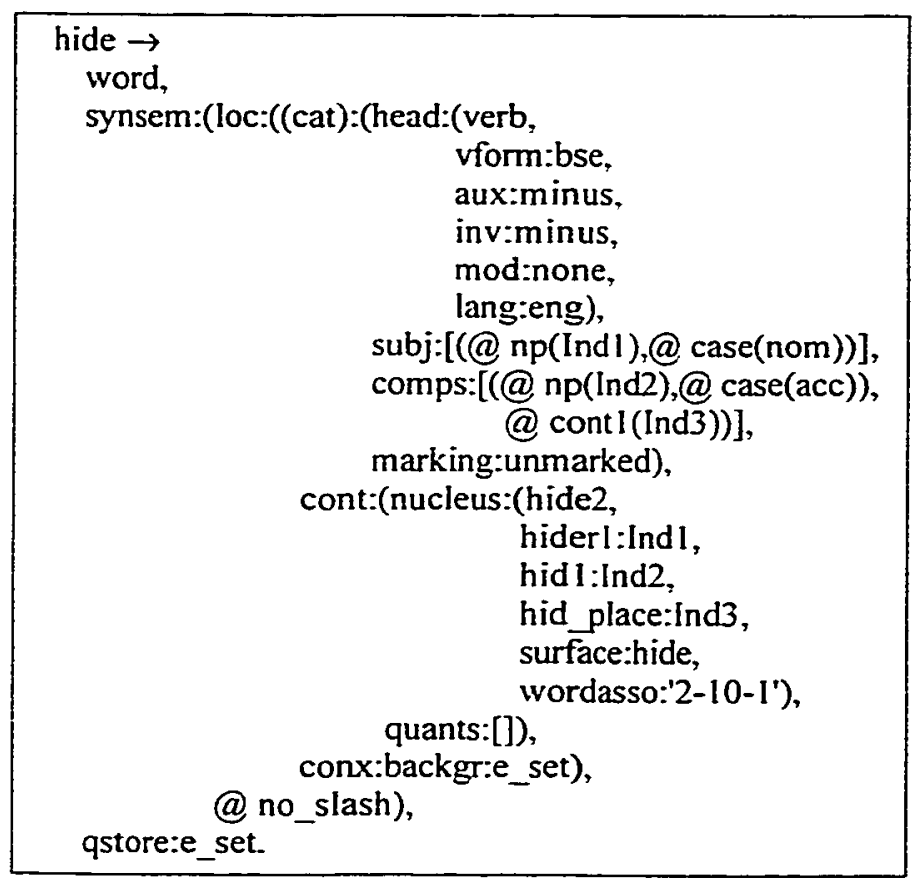

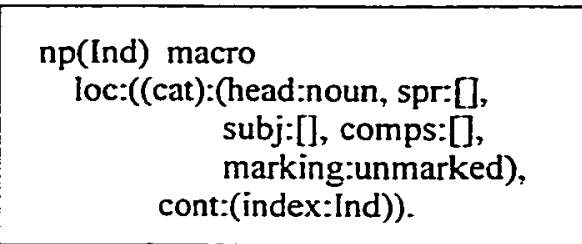

case(Case) macro loc:(cat):head:case:Case.

$$
\begin{aligned}
& \text { contl(Ind) macro } \\
& \text { loc:cont:(index:Ind). }
\end{aligned}
$$

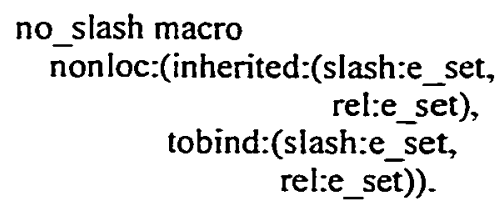

Figure 6.12: The representation of hide in ALE with some macros

Figure 6.13 illustrates the parse (in ALE representation) of the SL in Example 1 and the parse of its TC. The TC is generated by ALMT. The parses are in ALE representations. Both the SL and TC are licensed by our grammars. Their syntax is shown in the dotted boxes. The SL analysis begins by analyzing the word wing and combines it with his by the spr_hd rule. The phrase his head under his wing are licensed by hd_comp and the subj_hd rules since the lexical entry under requires subject and complement as specified lexically in Figure 6.14. Ugly and duckling are combined by the adjunct_hd rule, then the spr_hd rule combines ugly duckling with the. The phrase The ugly duckling hides his head under his wing results from combining The ugly duckling and his head under his wing via the hd_comp and the subj_hd rules. Again, everything is specified lexically; hides requires a subject and two complements. The lexical entry hides is generated by the 3 rd-singular verb lexical rule (Figure 6.5 ). The

Example 1:

SL: The ugly duckling hides his head under his wing.

TC: ลูกเป็ด จี่เหร่ ต้ว น้น ช่อน หัว ของเขา ใด้ ปี ของเขา

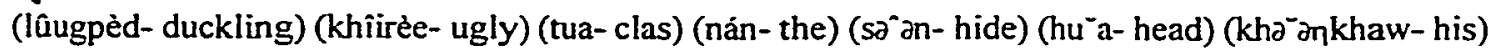
(tâaj- under) (piig- wing) (khə־ Jnkhaw- his) 


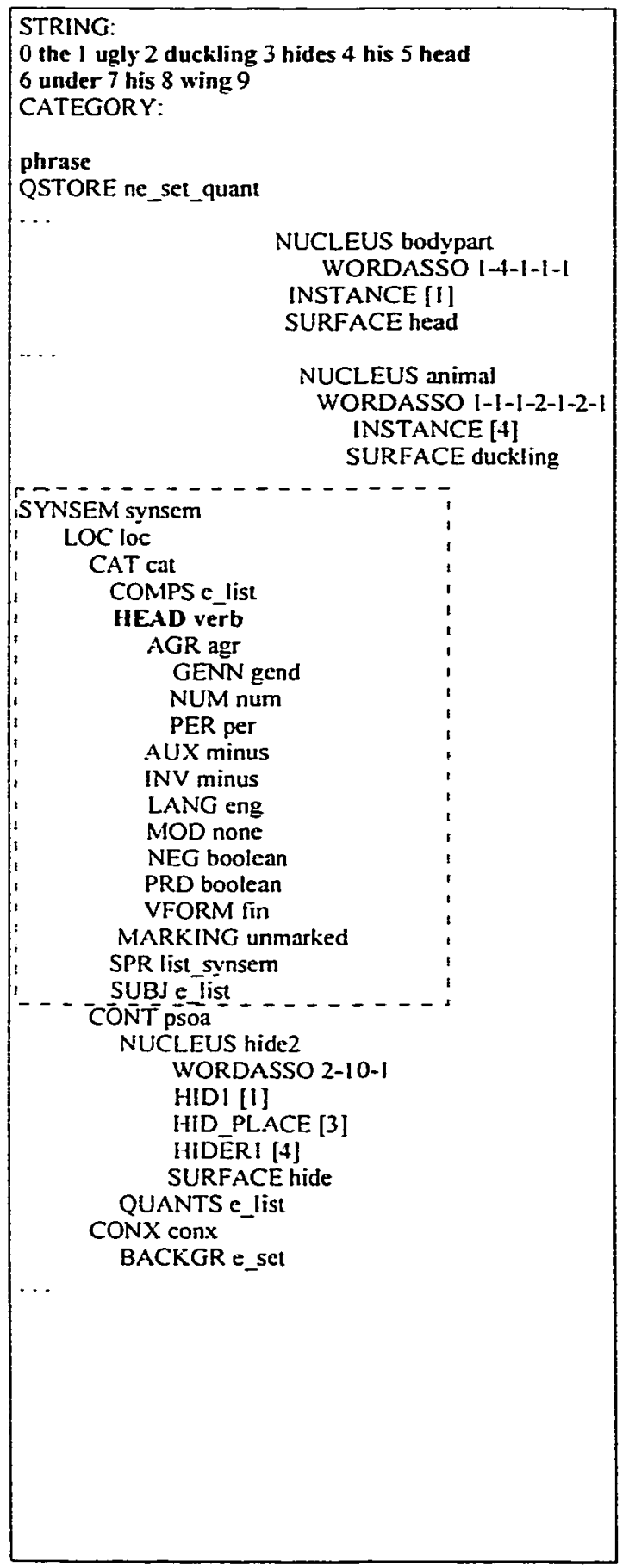

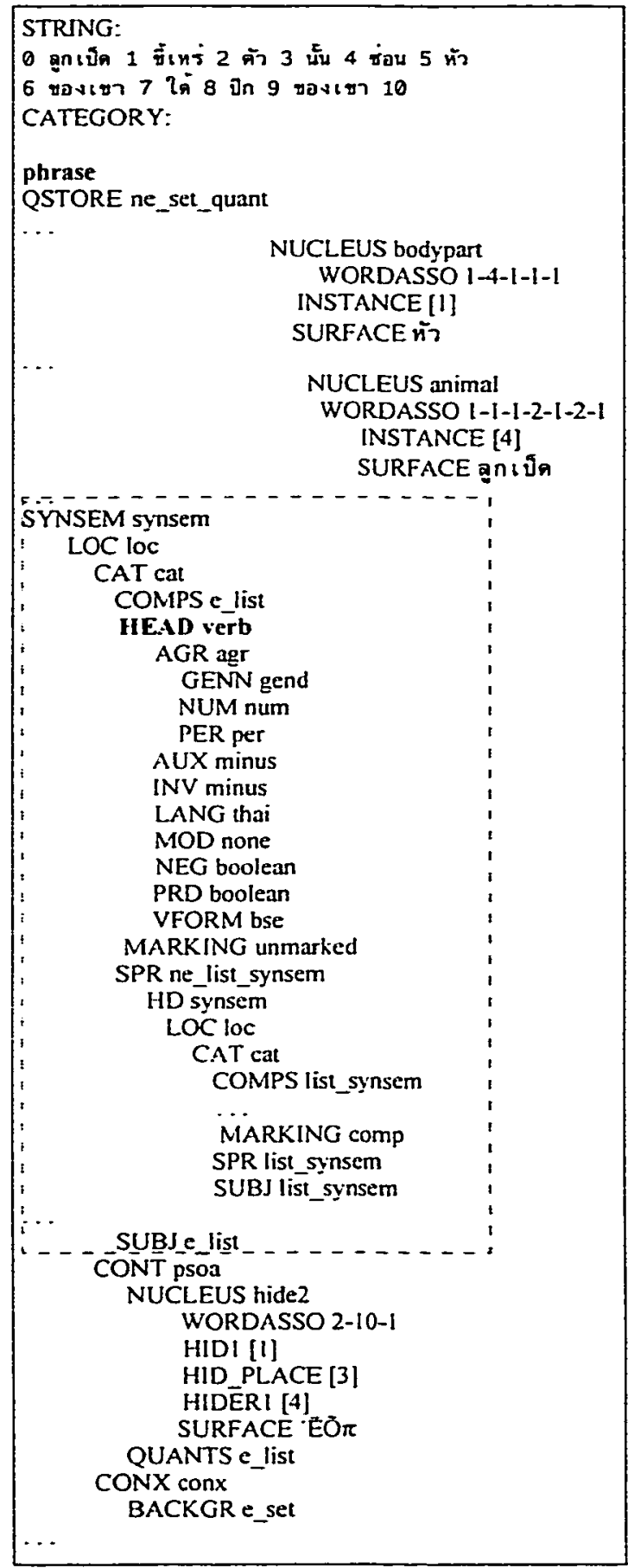

Figure 6.13: The parse syntax of Example 1 and that of its translation 


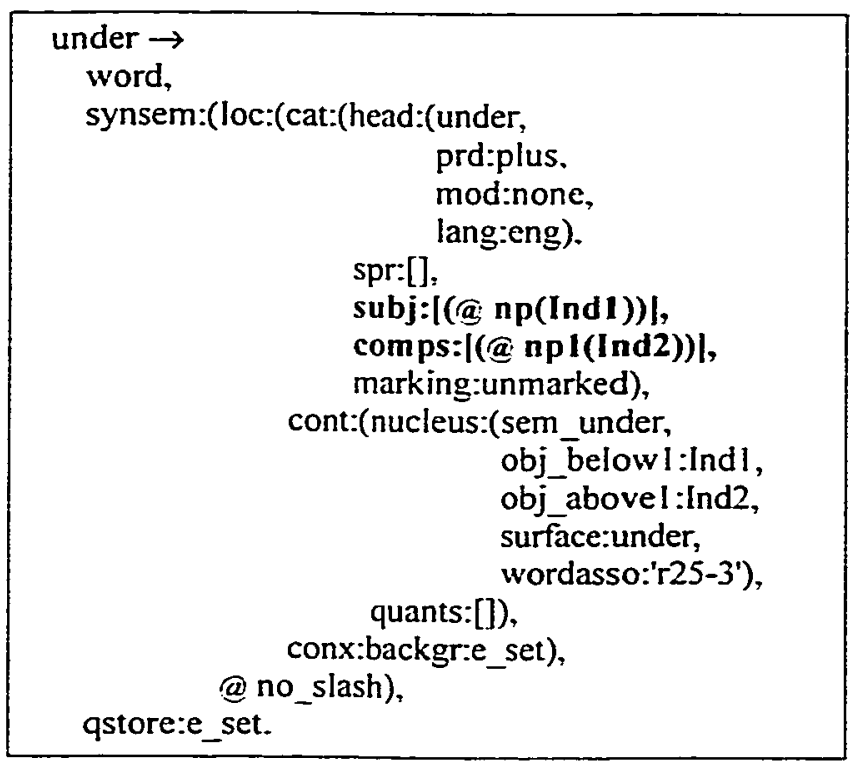

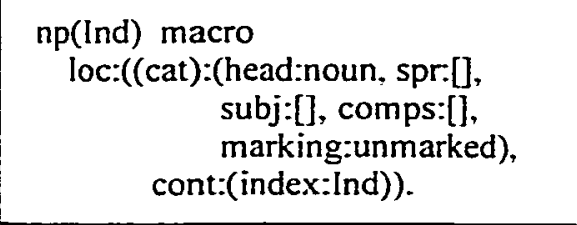
npl(Ind) macro
loc:((cat):(spr:[], subj:[], comps:[], marking:unmarked), cont:(index:Ind)).

Figure 6.14: The representation of under in ALE with some macros

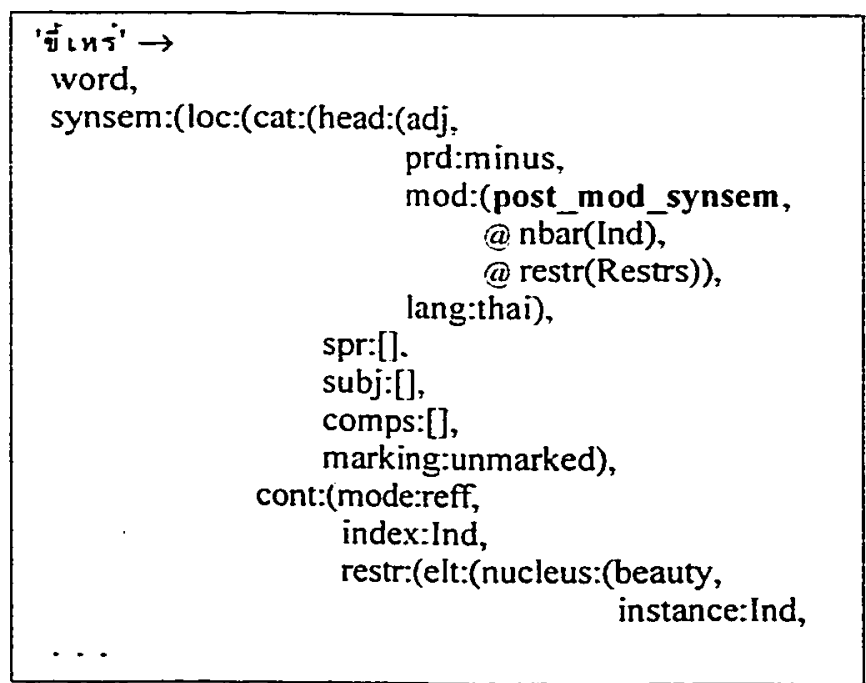

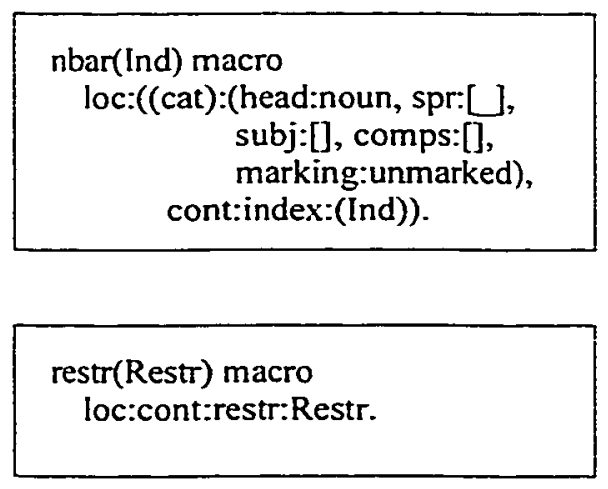

Figure 6.15: The representation of ชี่เหร (khîirèe- ugly) in ALE with some macros 
phrase The ugly duckling and his head under his wing also obeys the Head Feature Principle in which the HEAD value of the mother (HEAD: verb, Figure 6.13) is identified with that of the HD-DTR. The effect of the semantic principle (CONT) will be discussed in section 6.2. The TC is analyzed in an analogous fashion, however, different rules are applied due to the syntax differences between languages. For example, ของเขา (khวðれkhaw- his) and ปีก (piigwing) are combined with hd_spr rule to be ปีก ของเขา (corresponding to his wing). The phrase ลูกเบ็ด ขี้เหร่ (corresponding to ugly duckling) results from combining ลูกเป็ด (lûupèdduckling) and ขี้เหร (khîrèe- ugly) via the hd_adjunct rule since ขี้เหร่ (khïirèe- ugly) is the type of post_mod_synsem as indicated in the lexcial entry shown in Figure 6.15. The phrase ลูกเป็ด ชี้เหร่ัว นั้น (corresponding to The ugly duckling) are formed by the hd_spr rule. The WORDASSOI value of the classifier ตัว (tua), Figure 6.16, indicates the WordAsso number of the object that compatible with the classifier ตัว (tua).

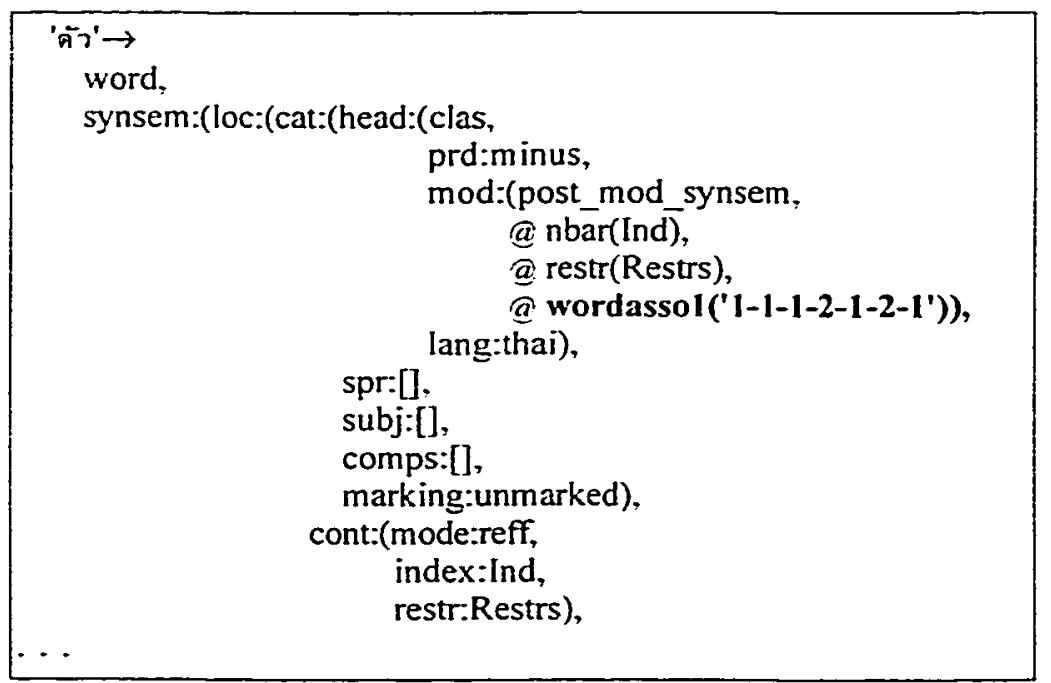

Figure 6.16: The representation of the classifier ตัว (tua) in ALE

Figure 6.17 illustrates the parse of the SL in Example 2 and the parse of its TC. The SL is licensed by our English grammar, however, there is no parse for the TC since จอй (сдวnJohn) and ค่าเช่า (khâachâw- rent, rental fee) cannot be combined according to our Thai grammar; it is syntactically incorrect. Use of the semantic information of the parse is discussed in the next section. 


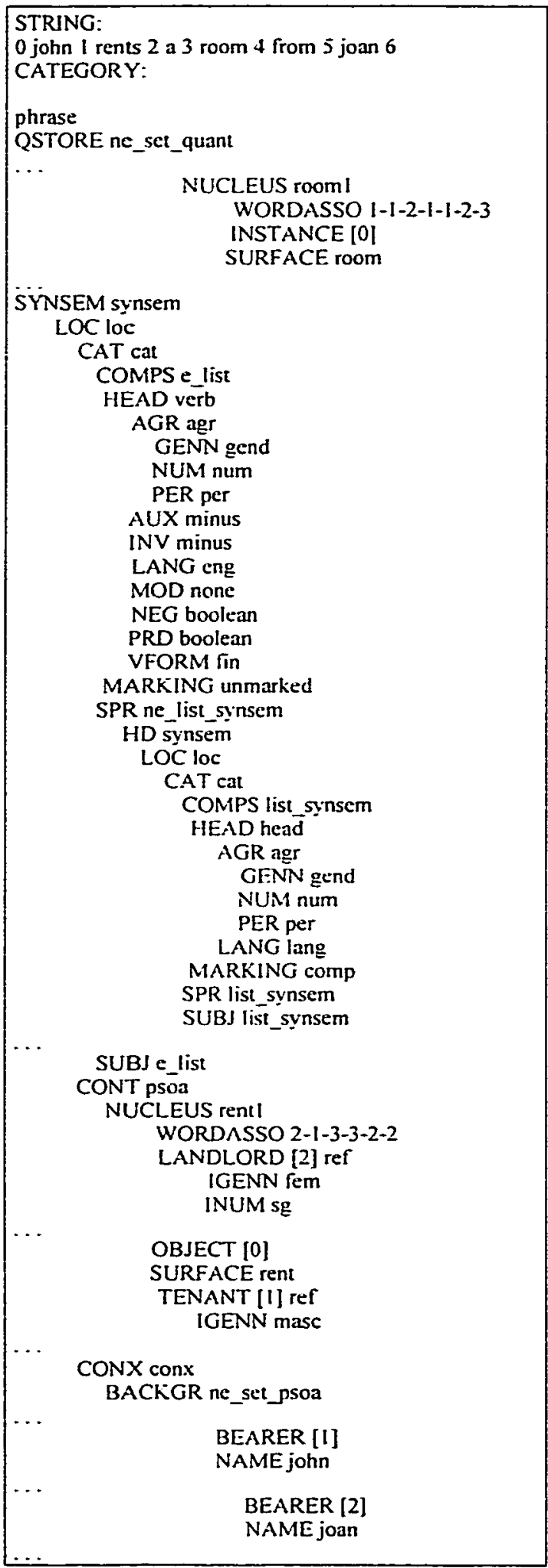

\section{Example 2:}

SL: John rents a room from Joan.

TC: จอห์น ค่าเช่า ห่อง หอง หนึ่ง จาก โจแอน (çan- John) (khâachâw- rent, rental fee) (hə̀ ทroom) (ha"n-clas) (nyn-a) (càag-from) (joo?enJoan)

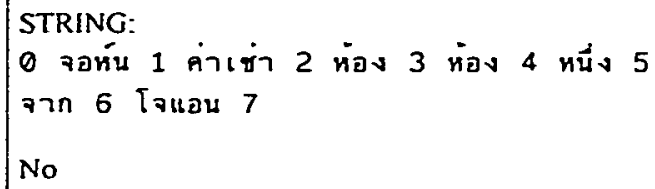

Figure 6.17: The parse syntax of Example 2 and that of its translation 


\subsubsection{Semantic Extraction}

Once the SL and the TC are parsed successfully, their semantic information will be extracted so that we can cross-examine the meaning of the TC with that of the SL. We first discuss how the semantic information is represented in our grammar. The semantic representation of an expression in GRMT is generally based on the representation in HPSG provided by Pollard and Sag, 1994 and Sag and Wasow, 1999 which will be presented in the next section.

\subsubsection{Semantic Representation}

The features CONT, CONTEXT (CONX) and QUANTIFIER-STORE (QSTORE) hold the semantics of the words. The semantic representation described in CONT (Figure 6.11) corresponds to the situation in which $\square$ (the hider) hides $\square$ (the hid) in (or under, from, etc.) 3 (the hid place). The features SURFACE and WORDASSO indicate the word form and WordAsso number of the lexical entry. These features, SURFACE and WORDASSO, are used in the Repair and Iterate phrase. The feature QSTORE is storage for the quantifiers. The QSTORE value of the in Figure 6.18 is token-identical to the CONT value. The QSTORE value of the mother is passed from its constituents according to the Quantifier Inheritance Principle (QIP) [Pollard and Sag 1994]. QIP says that the RETRIE VED-QUANTI FIERs (RETRIE VED, its

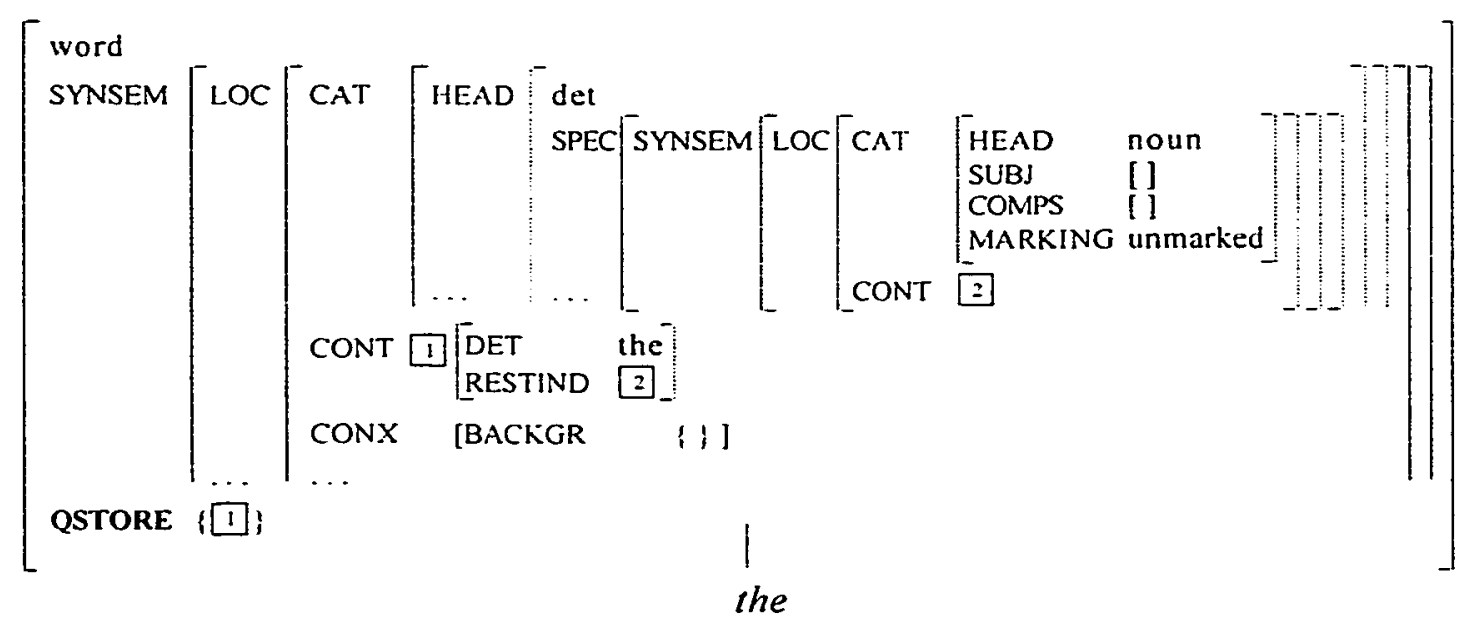

Figure 6.18: The partial description of the lexical entry the 
value is a list of quantifiers) value of the mother is a list whose set of elements forms a subset of the union of the QSTOREs of the daughters, and is nonempty only if the CONTENT of the semantic head is of type psoa, and the QSTORE value is the relative complement of the RETRIEVED value.

The CONX feature contains linguistic information that bears on certain contextdependent aspects of semantic interpretation [Pollard and Sag 1994]. The CONX value is a feature BACKGROUND (BACKGR) whose value is a set of psoas. Each background psoa restricts the possible anchors of indices that correspond to presuppositions or conventional implicature. The BACKGR value of Joan is illustrated in Figure 6.19. The atomic value Joan refers to the name Joan, not to an individual named Joan. Therefore, its psoa corresponds to the presupposition that the referent be identifiable in the utterance context by means of the name Joan. The BACKGR value of the mother obeys the Contextual Consistency Principle in which the BACKGR value of the mother is the union of the BACKGR values of the daughters as in (12).

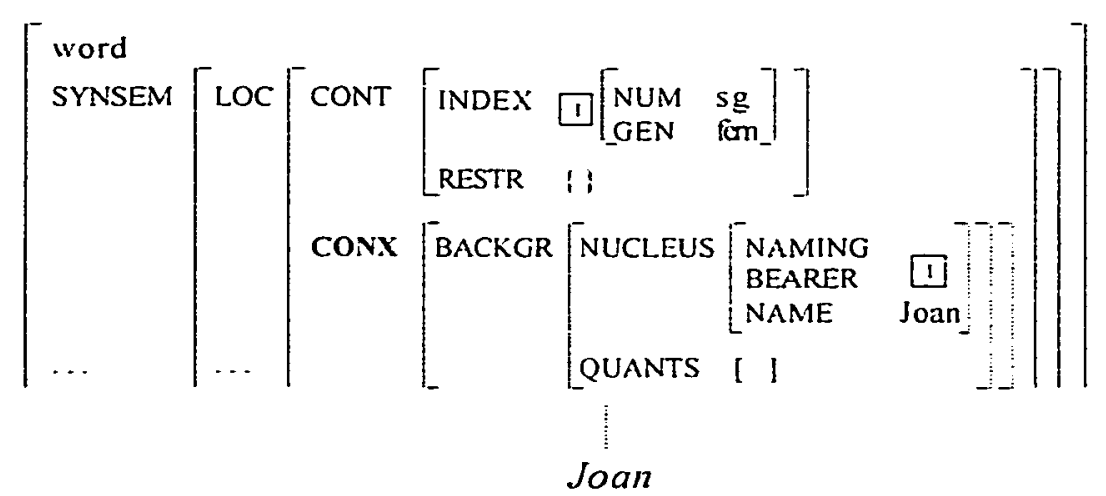

Figure 6.19: The partial description of the lexical entry Joan

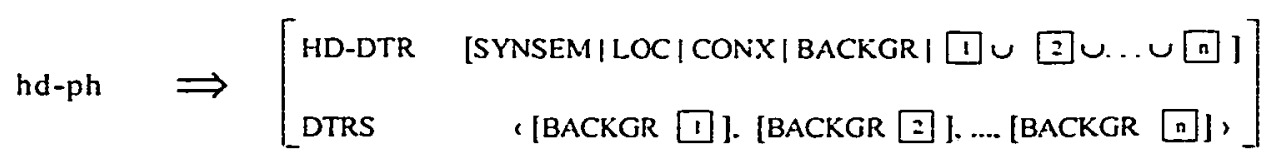




\subsubsection{Semantic Extraction Examples}

To extract the semantic information, CONT, QSTORE and CONX from the parse, we use a predicate rec/5 provided in ALE as shown in Figure 6.20. However, this predicate rec/5 binds the result (the feature values) to variables in the internal representation of feature structures of ALE. This result will be converted into a Prolog list for use in further procedure. Semantic Comparison.

Figure 6.20 illustrates the extracted internal representation of the semantic information of the SL parse of Example 3. This representation corresponds to the display in Figure 6.21 which illustrates QSTORE, CONT and CONX, the three semantics indicates used in HPSG and explained as follows. This semantic representation corresponds to the situation in which the talker is masculine and his name is John (CONT: TALKERI 1 : IGENN: masc, CONX: BACKGR: (BEARER 1 , NAME: john); the TALKERI and BEARER are unified as indicated by $\square$ ). The lalked is about the device (spring) which is broken (CONT: TALKED 0 , QSTORE: RESTIND: RESTR: (INSTANCE: 0 , \{brokenl, device\}); the TALKED and INSTANCES are unified via $\square$ ).

Figure 6.22 and Figure 6.23 illustrate the extracted (as above for 6.20 and 6.21) semantic information, in ALE's internal structure and its corresponding display respectively, of the TC parse of Example 3. This semantic representation corresponds to the situation in which the talker is masculine and his name is จอห์ (cวan- John) (CONT: TALKERI $\square$ : IGENN: masc, CONX: BACKGR: (BEARER 1 , NAME: จอห́น); the TALKERI and BEARER are unified as indicated by 1 ). The talked is about the season (ดดูใบไม้ผล - spring, in the sense of the season between winter and summer) which is broken (CONT: TALKED $\square$ QSTORE: RESTIND: RESTR: (INSTANCE: $\square$, \{broken, season\}); the TALKED and INSTANCES are unified via 0 ). According to this analysis, the TC carries no meaning since season cannot be "broken" either physically and forcibly separated into pieces or cracked or split.

Note that Example 3 is intended to demonstrate the situation in which the SL and the TC convey different meanings. In this example, we forced ALMT to disregard the relationship between the words broken and spring during the word selection process. Therefore, the word ๆดูใบไม่ผลี (ry'duubajmáajphli- the season) is selected as a translation for spring. As a result, the TC obtained is incorrect. Other possible translations of spring are สปริs (sapring- an elastic device), กระโดด (kradòod- to move suddenly upward or forward) and น้ำพุ (námphúplace where water comes up naturally from the ground).

In the next section, the semantic representations of the SL and the TC are compared to 
determine whether they convey acceptably similar meaning.

Example 3:

SL: John talks about the broken spring.

TC: จอห์น พูด เกี่ยวกับ ทดใใบไม่ผลิ ที่ ทั่ นั้ (cəan-John) (phûud- talk) (kiàw kàb- about) (ry'duubajmáajphli- spring, the season) (thî̀- modifying) (hàg-broken) (nán- the)

rec([john,talks,about.the,broken_spring]-_:_.lqs. (qstore:Q,synsem:loc:(cont:Cont. conx:(Conx))).

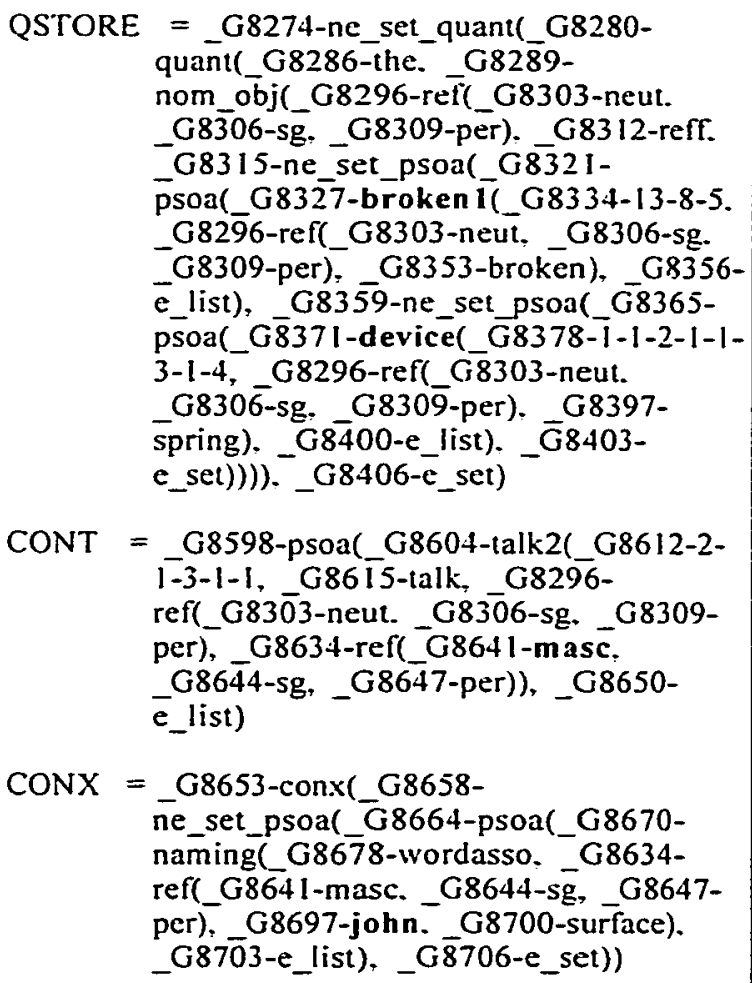

CONT = _G8598-psoa(_G8604-talk2(_G8612-21-3-1-1, G86 T5-talk, _G8296ref(_G830̄3-neut._G8306-sg._G8309per), _G8634-ref(_G8641-masc. _G8644-sg, _G8647-per)), _G8650$\bar{e}$ list)

CONX = G8653-conx(_G8658ne_set_psoa(_G8664-psoa(_G8670naming(G8678-wordasso, _G8634ref(_G8641-masc._G8644-sg, _G8647per), G8697-john. G8700-surface). _G870̄3-e_(ist)._G $\overline{\left.\left.8706-e \_s e t\right)\right) ~}$

Figure 6.20: The semantic information, in ALE's internal structure, of the SL in Example 3

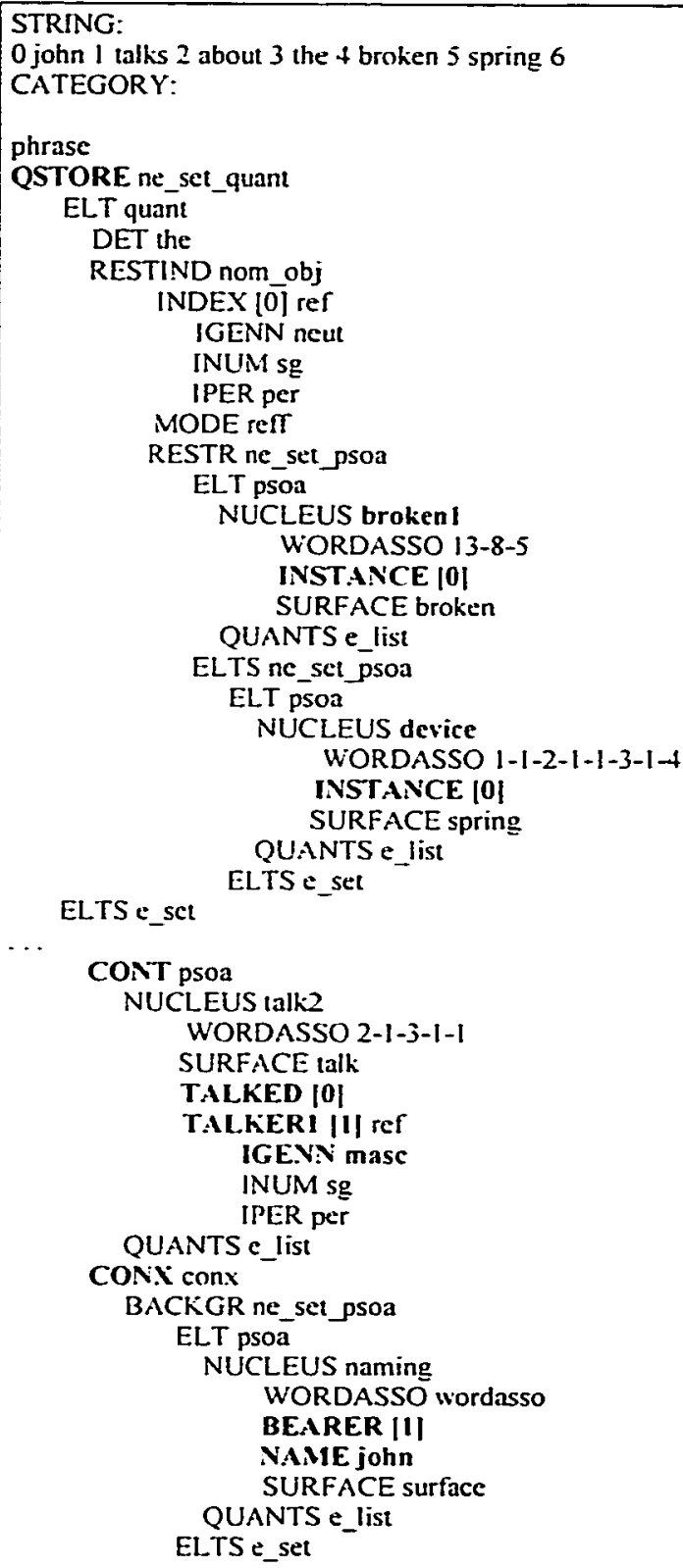

Figure 6.21: The semantic information of the SL in Example 3 


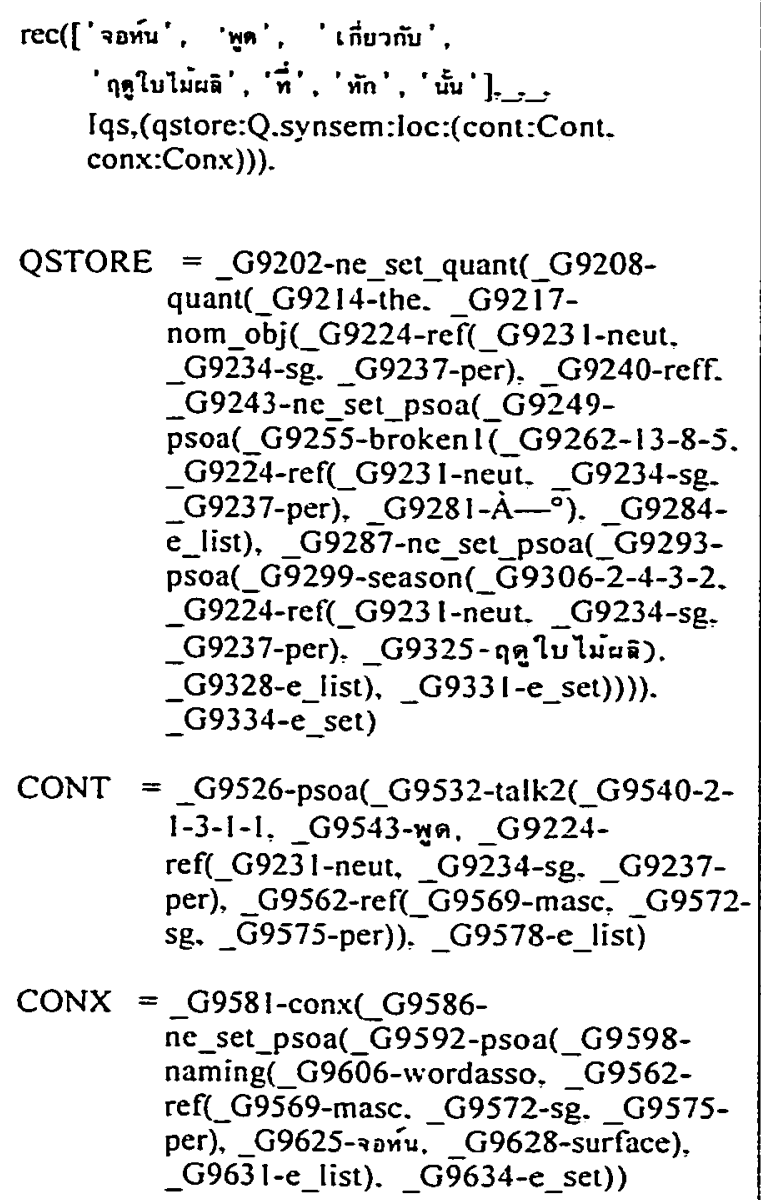

Figure 6.22: The semantic information, in ALE's internal structure, of the TC in Example 3

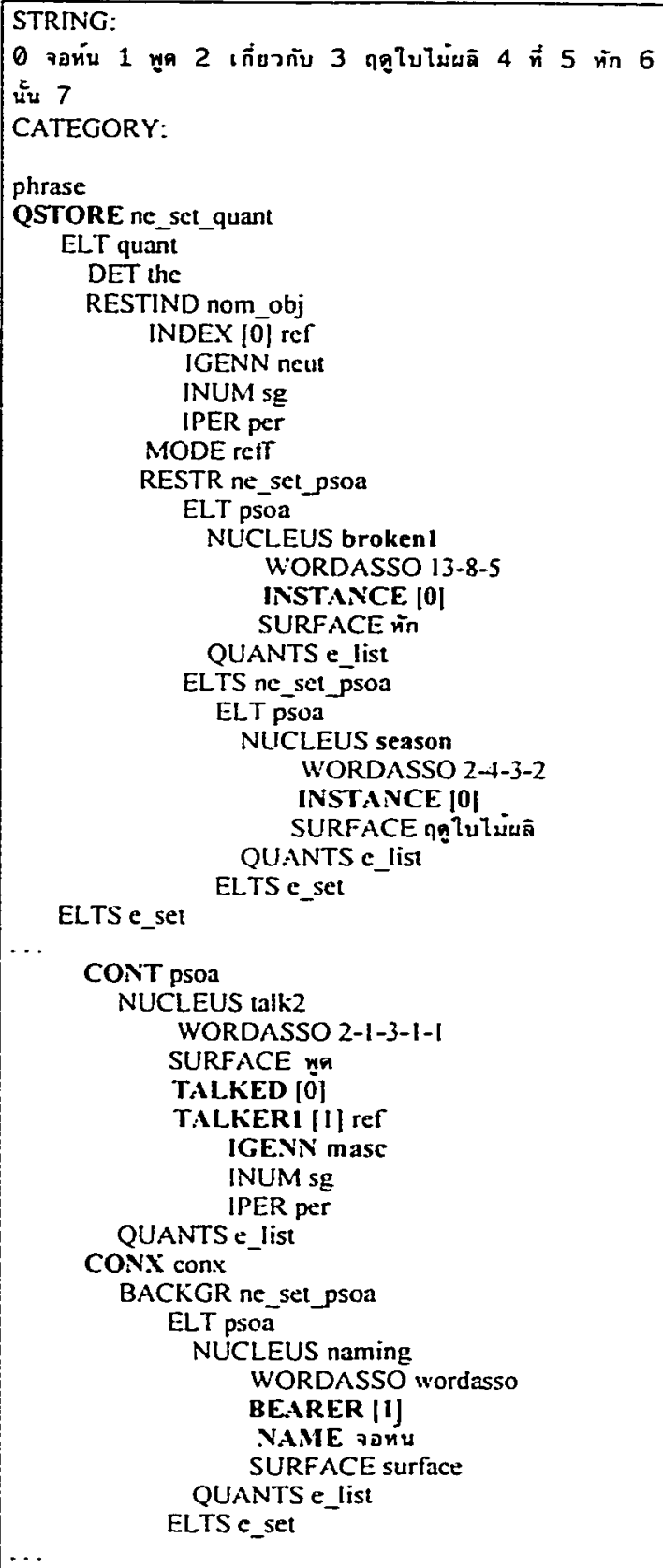

Figure 6.23: The semantic information of the TC in Example 3 


\subsection{Semantic Comparison}

In comparing the meaning between the SL and its TC, the values of the features CONT, QSTORE and CONX are considered. If the values of these features of the SL parse are the same as those of the TC parse, TCE concludes that the TC does not require repair. If any of these features are different, TCE will provide information of the SL parse which differs from that of the TC parse. This information will be used in the repair process phrase, Repair and Iterate.

The comparison process begins by investigating the CONT value of both SL and TC parses. Figure 6.24 and Figure 6.25 illustrate the semantic information of the SL and that of the TC in Example 1 (section 6.1.1.6). Their simplified displays are illustrated in Figure 6.26 and 6.27. The CONT values of both parses represent the same kind of relation involved, hide2,

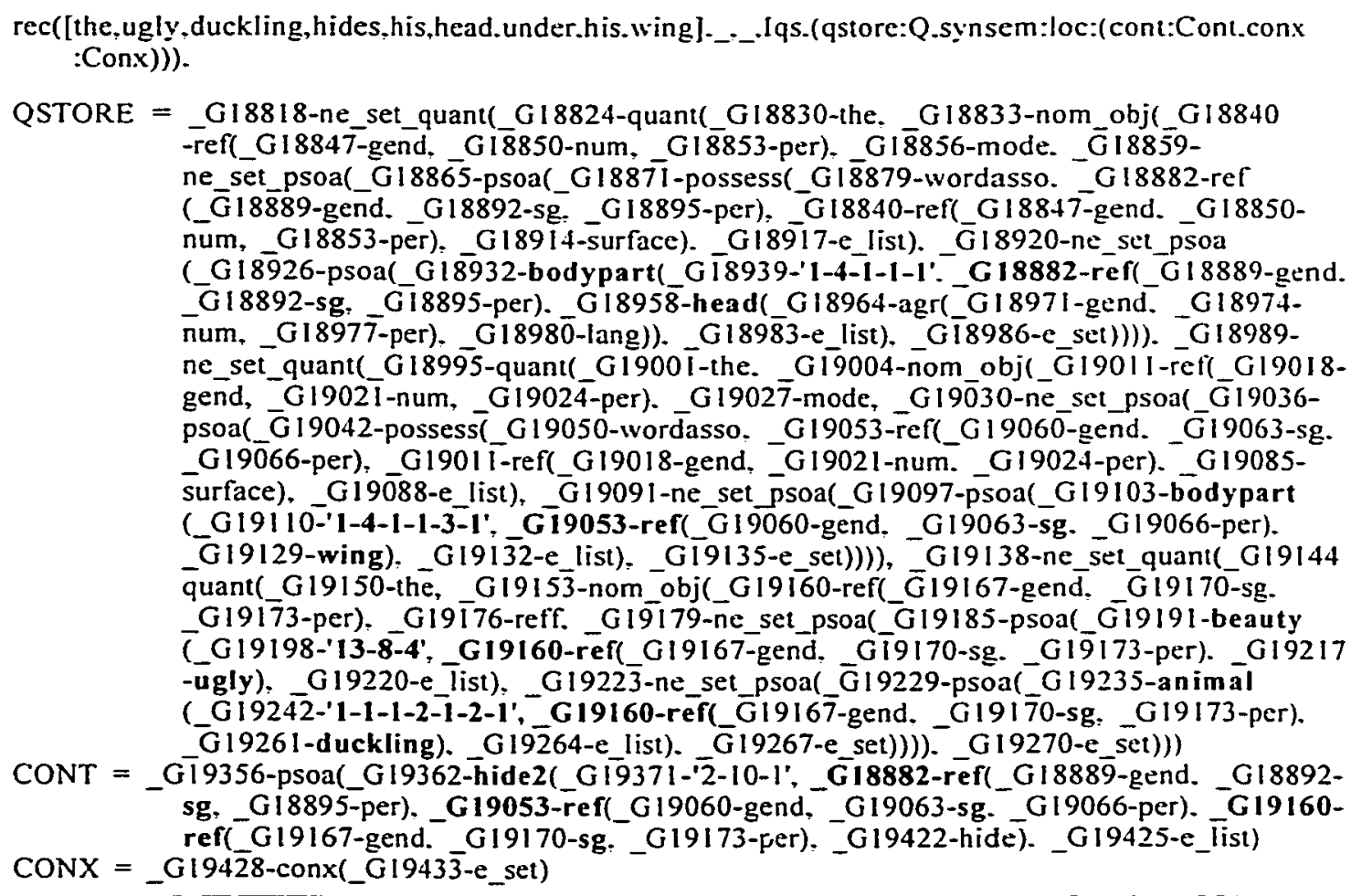

Figure 6.24: The semantic information of the SL in Example 1 


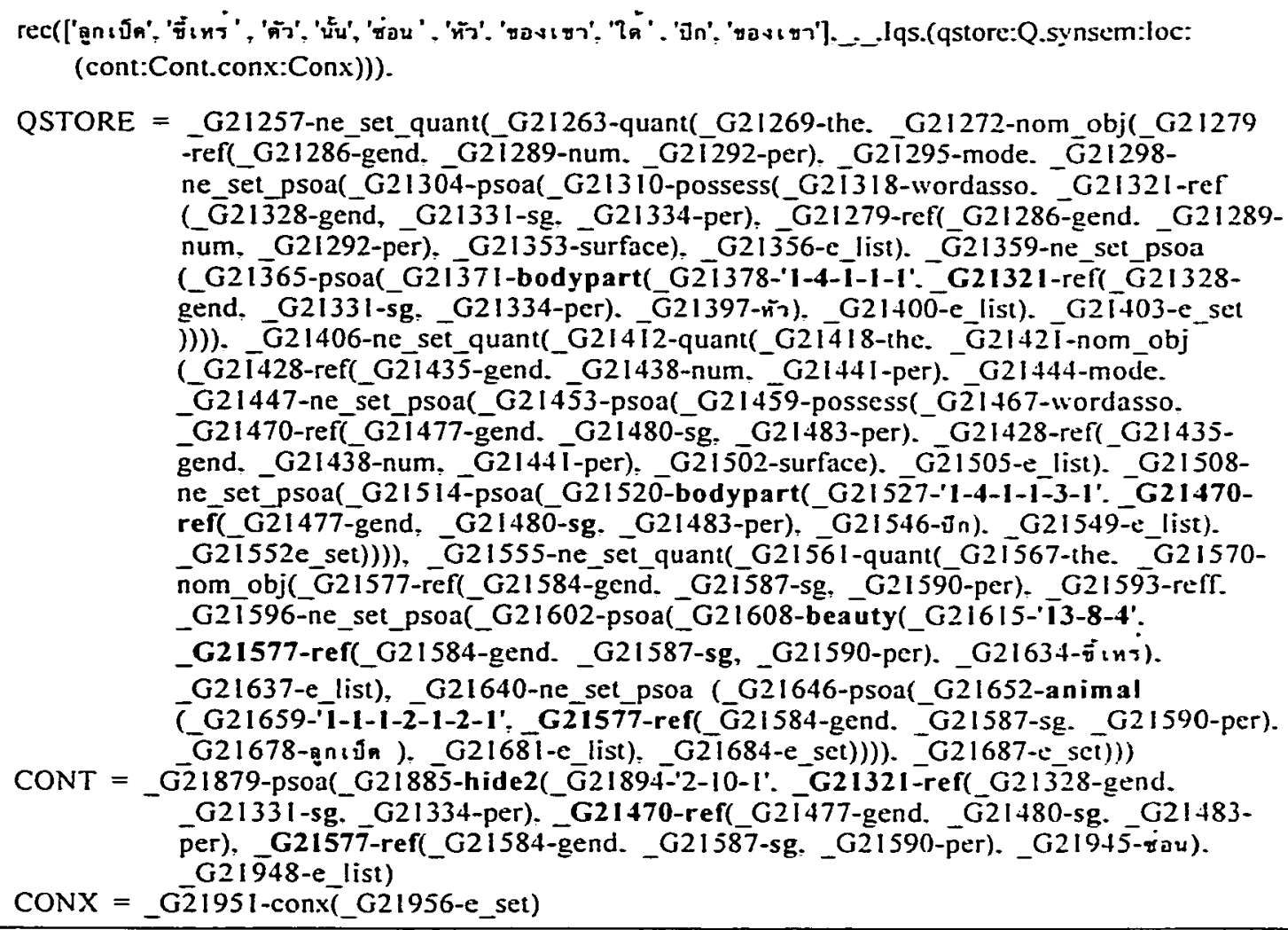

Figure 6.25: The semantic information of the TC in Example 1

and the same type of persons (or things), ref, who/that are participating in this relation (_G18882-ref, _G19053-ref and _G19160-ref in the CONT value of the SL parse; _G21321ref, G21470-ref and_G21577-ref in the CONT value of the TC parse), each ref is singular. The right of a hyphen is a feature value which is bound to the variable on the left of the hyphen.

Once the CONT values of the SL parse and that of the TL parse are recognized as the same. TCE, then cross-examines the QSTORE and the CONX values of the SL parse with those of the TC parse to determine whether each variable (index) in the CONT value is associated to the appropriate object. In Figure 6.24 and 6.25 , the first variable in the CONT value of the SL parse is _G18882-ref and that of the TC parse is _G21321-ref. Both variables are associated to a bodypart in the class of $1-4-1-1-1$ (in the QSTORE value), it is singular and

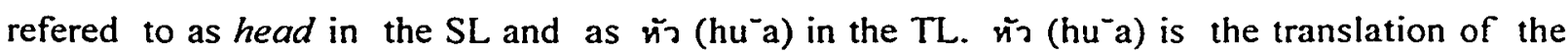




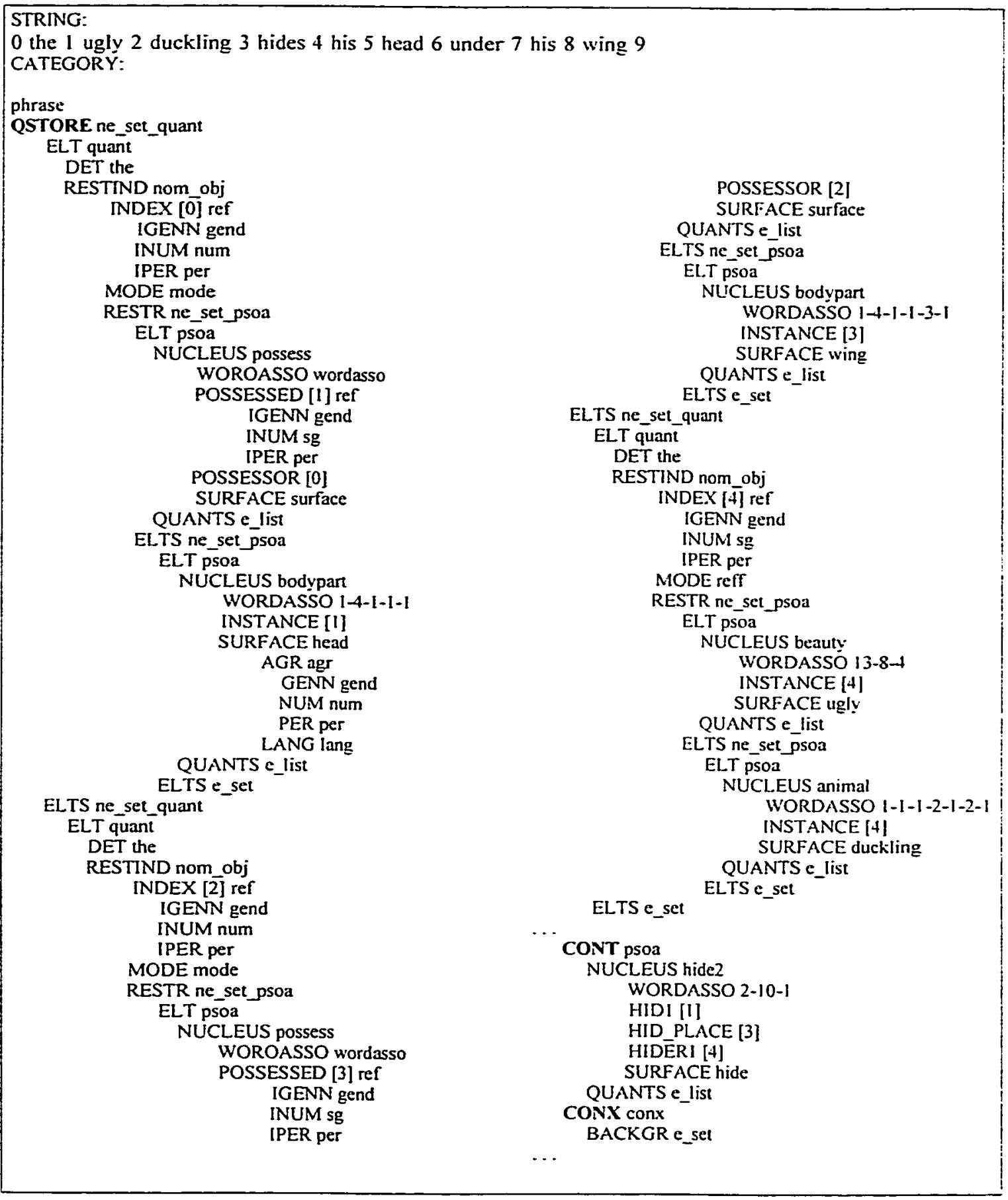

Figure 6.26: The semantic information of the parse of the SL in Example I 


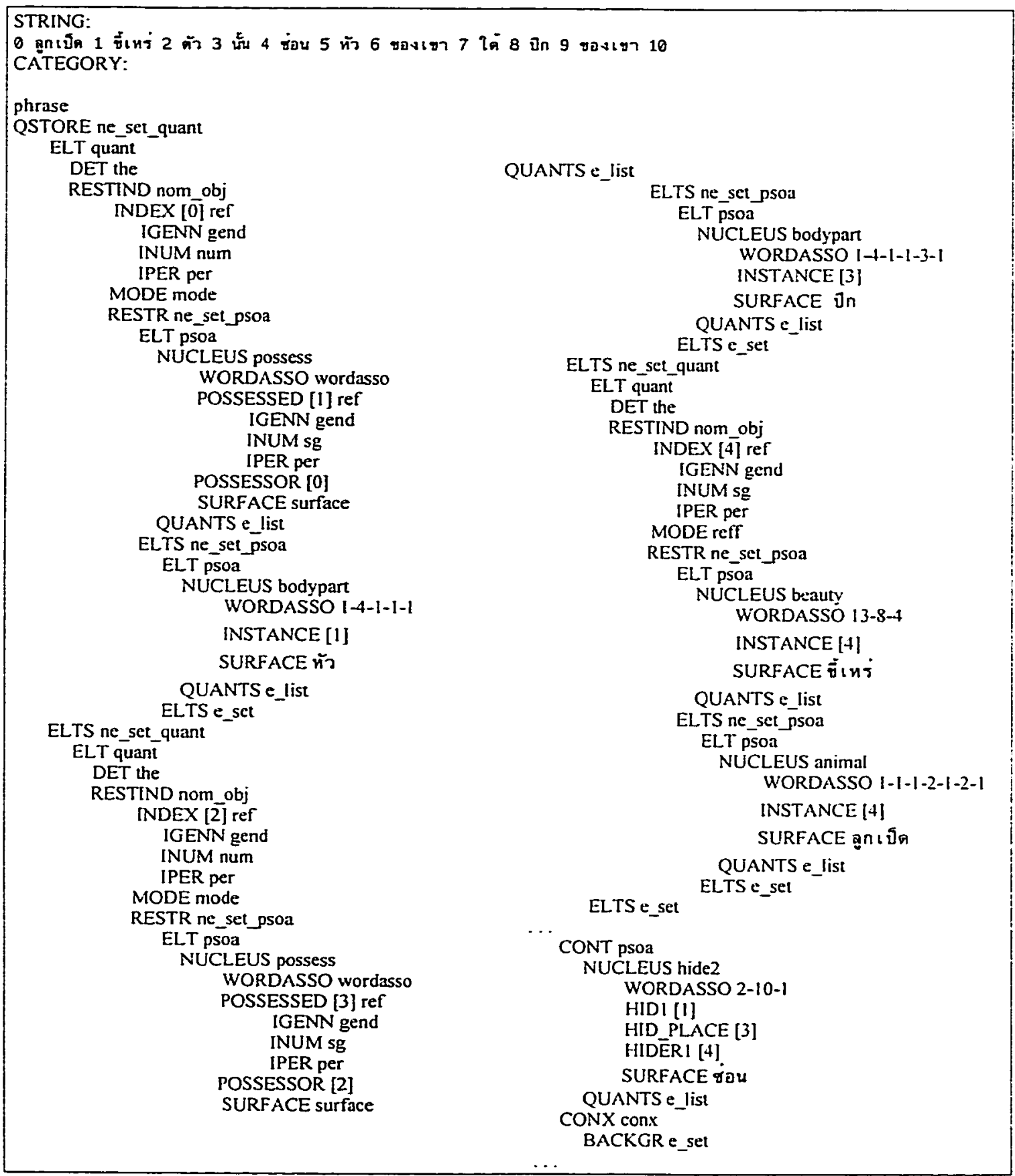

Figure 6.27: The semantic information of the parse of the TC in Example I 
word head in Thai. The second variables are _G19053-ref (of the SL CONT value) and _ G21470-ref (of the TC CONT value). These variables correspond to a bodypart in the class of 1-4-1-1-3-1, it is singular and referred to as wing in the SL and In (piig) in the TL. Again, In (piig) is a translation of wing in Thai. The last variables are _G19160-ref and _G21577ref. They are associated with an animal in the class of $1-1-1-2-1-2-1$ which is singular and referred to as duckling in the SL and ลูกเป็ด (lûugpèd) in the TL. ลูกเป็ด (lûugpèd) is the translation of the word duckling in Thai. The CONX feature in this example contains no value. According to the comparison process, TCE found no difference between the CONT, QSTORE and CONX of the SL parse and those of the TC parse. Therefore, the TC is deemed as an appropriate translation for the $\mathrm{SL}$ in the Example $\mathrm{I}$.

The CONT values of the SL and the TC parses in Example 3 (section 6.1.2.2) are not the same. The first variable of the SL CONT (G8296-ref, Figure 6.20) relates to a device in the class of 1-1-2-1-1-3-1-4 which is refered to as spring (indicated in the QSTORE value) whereas its corresponding variable in the TC CONT (G9224-ref, Figure 6.22) relates to a season in the class of 2-4-3-2 which is refered to as ฤดูใไมผผล (гy'duubajmáajphli). ฤดูใบไม่ผล (ry'duubajmáaj-phli) is one of the possible translations of the word spring. However, it is not an appropriate translation of spring in the expression of Example 3. The differences between the SL QSTORE and TC QSTORE indicate that the TC requires a repair.

The CONT values of the SL parse and the TC parse in Example 4 (Figure 6.28 and Figure 6.29) represent the same relation involved, cover2, and the same types of persons or things who/which are participating in this relation, COVERED, COVERED_PLACE and COVERERI. The SURFACE value in the CONT of the SL parse is cover and that of the TC is คลุม (khlum). The value of the feature SURFACE is a word form. คลุม (khlum) is a translation of cover. However. their WORDASSO values are different, cover belongs to the class of 2-1-19 whereas คลูม (khlum) belongs to the class of 2-1-19-2 as illustrated in Figure 6.30. Although cover and its translation คลุม (khlum) carry the same meaning, they are different in language usage. Differences in languages and cultures result in different circumstances of language usage. The word cover in John covers his ears with his hands corresponds to verifying the meaning of cover, the word and its translation are considered acceptably similar in principal features since they belong to the same superclass. 


\section{Example 4:}

SL: John covers his head with his coat.

TC: จอห์น คดุม หัว ของเซา ค่วย เสื้อคลุม ของเซา

(cəan- John) (khlum- cover) (hu־a- head) (khə־ðnkhaw- his) (dûaj- with) (sy־akhlumcoat)(kha־ mkhaw- his)

\begin{tabular}{|l|}
\hline STRING: \\
0 john l covers 2 his 3 head 4 with 5 his 6 coat 7 \\
CATEGORY: \\
phrase \\
QSTORE ne_set_quant \\
.. CONT psoa \\
NUCLEUS cover2 \\
WORDASSO 2-1-19 \\
COVERED [1] \\
COVERED_PLACE [3] \\
COVERERI [4] ref \\
IGENN masc \\
INUM sg \\
IPER per \\
SURFACE cover \\
QUANTS E_list \\
CONX conX
\end{tabular}

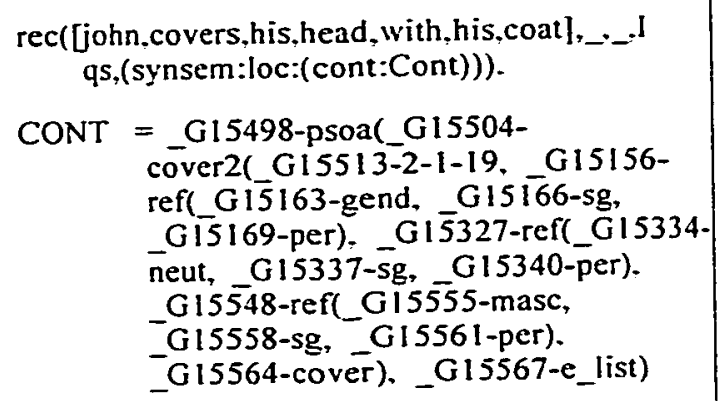

Figure 6.28: The CONT value of the SL parse of Example 4

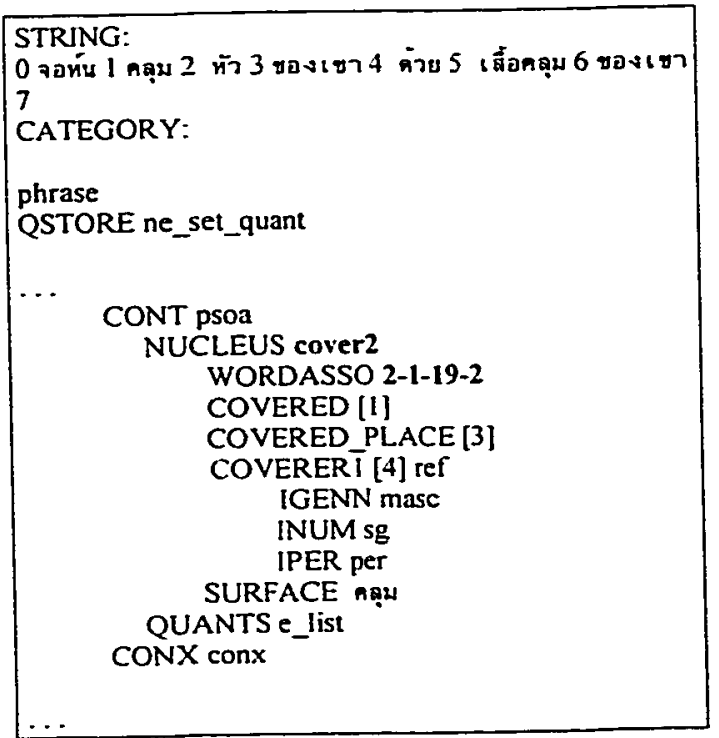

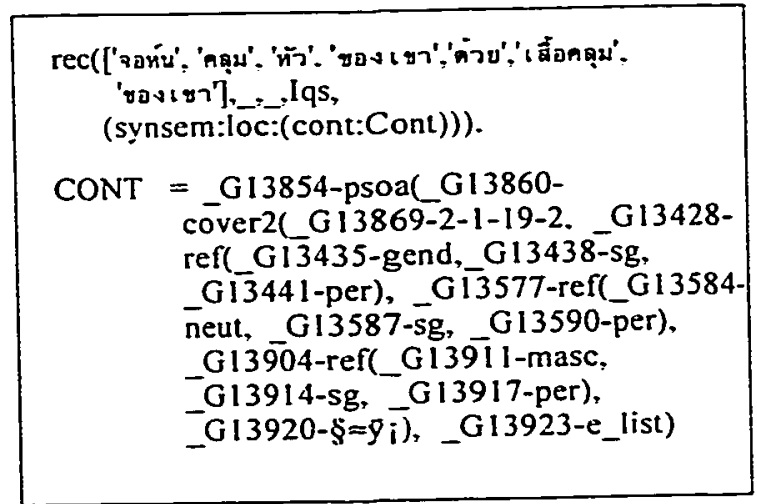

Figure 6.29: The CONT value of the TC parse of Example 4 
Table 6.3: The class of cover

\begin{tabular}{cl}
\hline WordAsso and Class description & Word \\
\hline $2-1-19$ Cover as to place something on or & cover \\
over to protect or hide. & \\
2-1-19-1 Cover as to cover eyes, ears. & ปค (pid) \\
$2-1-19-2$ Envelop & คลุม (khlum) \\
\hline
\end{tabular}




\section{Chapter 7}

\section{Repair and Iterate}

The last phase of GRMT, Repair and Iterate, performs the repair process if the translation candidate carries a different meaning from the SL. The repaired TC is then returned to the Translation Candidate Evaluation module. TCE re-analyzes the repaired TC to determine if additional repair is further required (a different meaning from the source language remains). The repair process repeats until the semantic information (CONT, QSTORE and (ONX) of the SL and the TC are acceptably similar ${ }^{1}$.

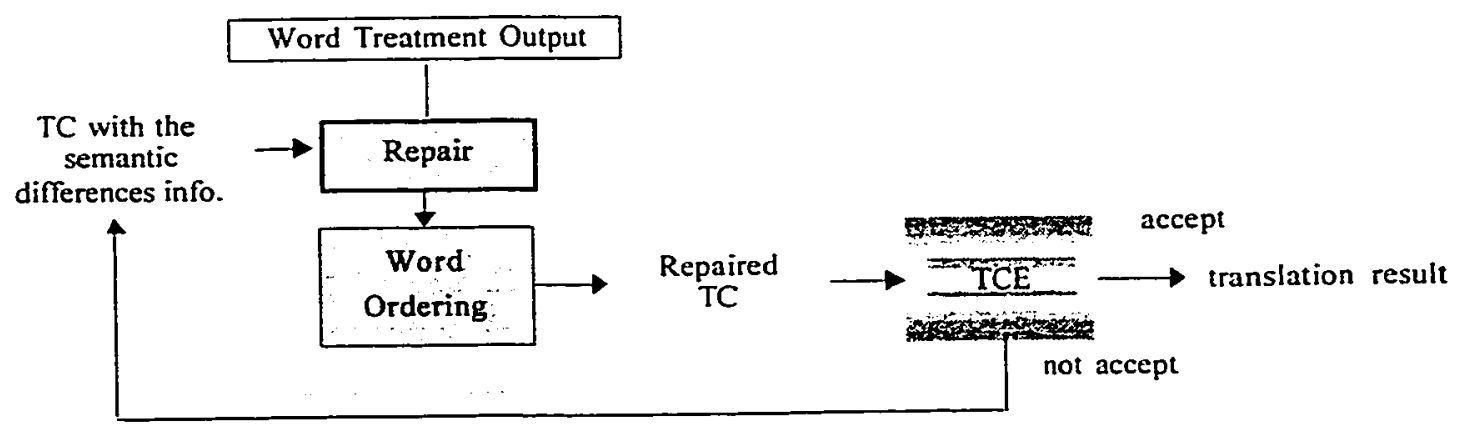

Figure 7.1: RU Architecture

RI examines the result of TCE. The TCE output is the TC with the semantic information of the SL which differs from that of the TC (Figure 7.1). With this information, RI is able to

\footnotetext{
${ }^{1}$ By acceptably similar we mean that a native TL speaker would find the TL translation represents the meaning of the SL statement to some acceptable degree (this degree may vary from language to language).
} 
detect the part of the TC which causes the mis-translation. The mis-translated part will be replaced with a more appropriate translation. RI searches the Word Treatment output (generated by ALMT, see section 5.1) for a more appropriate translation based on the information provided by TCE. The TC with the new selection is then put through the Word Ordering module (see section 5.3) to revise its syntax. Once the revision is completed, the repaired TC is returned to TCE.

The semantic information described is represented in terms of CONT, QSTORE and CONX features (see section 6.1.2.1). In the case that the CONT or the QSTORE value of the SL is different from that of the TC, the SL CONT value: SURFACE and WORDASSO features are passed to RI. The SURFACE value indicates the surface form of the word which causes the mis-translation. The WORDASSO value specifies the proper meaning of the word in question in terms of WordAsso number. Therefore, to repair the CONT or QSTORE value of the TC, RI re-selects the corresponding word in the TL for the word specified in the SURFACE value. The re-selection is done by searching the Word Treatment output for the corresponding word which has the same WordAsso number as specified in the WORDASSO value.

In the case that the CONX value of the SL differs from that of the TC, the SL CONX value: the BEARER and NAME features are passed to RI. The BEARER value specifies the index which associates with the certain name specified in the NAME value. RI repairs the TC by associating the right names to the right indices based on the information provided by TCE.

The results of analyzing the SL and the TC in Example 1, below, indicate that the TC requires a repair since it carries a different meaning from the SL (see Example 3 in section 6.1.2.2). The CONT values of the SL and the TC are the same; however, parts of their QSTORE values are different. The QSTORE values of the SL and the TL illustrated in Figure 7.2 indicates that the word spring is mis-translated (SURFACE: spring). According to the QSTORE of the SL, the proper meaning of spring in Example 1 is a device which is classified into the class of 1-1-2-1-1-3-1-4 (WORDASSO: 1-1-2-1-1-3-1-4). Therefore, RI begins the repair process by re-selecting the translation of the word spring. RI searches the Word Treatment output (Table 7.1) for the translation of spring which has WordAsso number 1-12-1-1-3-1-4 and thus, the translation สปริง (sapring) is selected. The word ฤดูใบไม่ผล (ry'duubajmáajphli) in the TC is then replaced with สปริง (sapring). The TC with the new 
selection (Figure 7.3) is put through the Word Ordering module to revise its syntax. At this step, the classifier aัน (?an- classifier) is added to complete the repaired TC.

Once the repair processes successfully, the repaired TC is analyzed by TCE. Figure 7.4 illustrates the semantic information of the SL parse and that of the repaired TC. Their CONT

Example 1:

SL: John talks about the broken spring.

TC: จอห์น พูด เกี่ยวกับ ทดุใบไม้ผลิ ที่ หัก น้น (cəon- John) (phûud- talk) (kiàw kàb- about) (ry'duubajmáajphli-spring, the season) (thîimodifying) (hàg- broken) (nán- the)
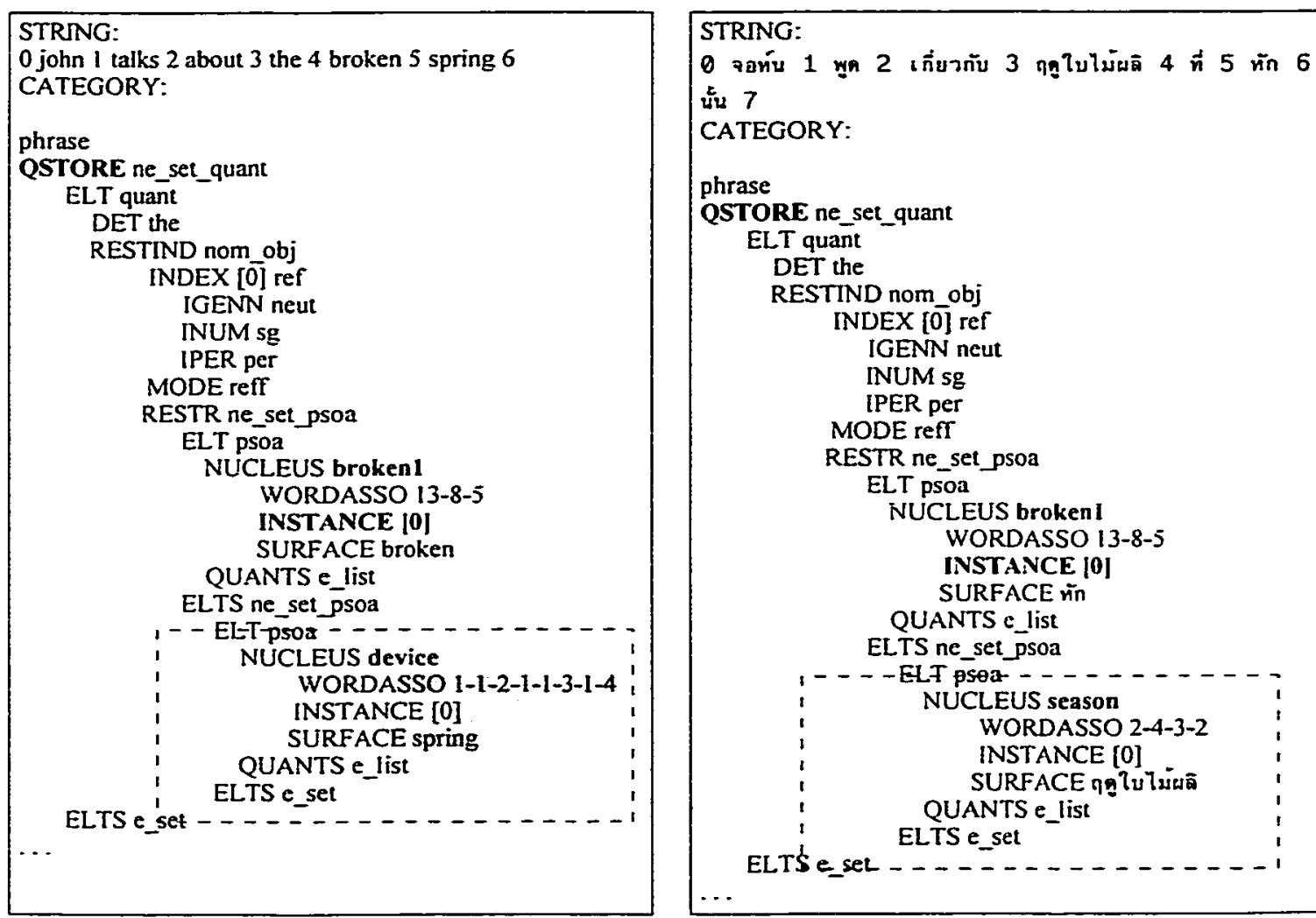

Figure 7.2 The QSTORE values of the SL and the TC parses of Example I 
Table 7.I A part of Word Treatment output of Example 1

\begin{tabular}{|c|c|c|}
\hline English & Word Treatment Output & Description \\
\hline \multirow[t]{4}{*}{ spring } & $\begin{array}{l}\text { ฤดู ในไม่ผล̃ (ry'duubajmáajphli), } \\
2-4-3-2\end{array}$ & $\begin{array}{l}\text { the season between winter and } \\
\text { summer }\end{array}$ \\
\hline & $\begin{array}{l}\text { ตปริง (sapring), } \\
1-1-2-1-1-3-1-4\end{array}$ & an elastic device \\
\hline & $\begin{array}{l}\text { กระโดต (kradòod), } \\
2-1-5-5-1\end{array}$ & $\begin{array}{l}\text { to move suddenly upward or } \\
\text { forward }\end{array}$ \\
\hline & $\begin{array}{l}\text { น้ำพุ (námphú), } \\
1-1-2-1-4-1\end{array}$ & $\begin{array}{l}\text { place where water comes up } \\
\text { naturally from the ground }\end{array}$ \\
\hline
\end{tabular}

TC: จอห์น (cəən- John) พูต (phûud- talk) เกี่ยวกับ (kiàw kàb- about) ทด่ใบไม่แลิ (ry'duubajmáajphll- spring, the season) $\frac{\dot{n}}{n}$ (thîi- modifying) หัn (hàg-broken) น้น (nán-the)

TC with the new selection: จะ. น (cวən- John) พูค (phûud- talk) เ กี่ยวกับ (kiàw kàb-about) สปริง (sapring- the device) ที่ (thîi- modifying) หัn (hàg-broken) นัน (nán- the)

Repaired TC: จอห์น (cวən-John) พูด (phûud- talk) เกี่ยวกับ (kiảw kàb-about) สปริง (sapring- the device) อับ (?an-classifier) ที่ (thîi- modifying) й (hàg-broken) นั้น (nán- the)

Figure 7.3: The repair of Example 1 
QSTORE and CONX values are the same. The repaired TC is, then, deemed as an appropriate translation for the SL in Example 1.

In the case that TCE finds no parse for a TC since it is grammatically incorrect according to TL grammar, TCE outputs the TC with the CONT and QSTORE values of the SL. RI begins the repair process by verifying the translation of the word specified in the CONT: SURFACE value of the SL. If the WordAsso number of that translation is the same as the WordAsso number specified in the CONT: WORDASSO value of the SL, then RI proceeds to verify the translation of the word specified in the QSTORE: SURFACE. However, if the WordAsso number of that translation is different from the WordAsso number specified in the CONT: WORDASSO value of the SL, then RI replaces that translation with another translation which has the same WordAsso number specified in the CONT: WORDASSO value of the SL. The TC with the new selection is then put through the Word Ordering module to revise its syntax. If the repaired TC remains syntactically incorrect, then RI verifies the words specified in the QSTORE: SURFACE value.

TCE found no parse for the TC in Example 2 (Figure 7.5) since the TC is grammatically incorrect (see Example 2 in section 6.1.1.6). RI verifies the translation of the word rent, since it is specified in the CONT: SURFACE value of the SL as illustrated in Figure 7.6. The selected translation of rent in the TC is ค่าเช่า (khâachâw) with 2-1-3-3-3-2. However, the WordAsso number specified in the CONT: WORDASSO value of the SL is 2-1-3-3-2-2. Therefore, RI searches the Word Treatment Output (Table 7.2) for another translation of rent which has the WordAsso number 2-1-3-3-2-2. RI, then replaces ค่าเช่า (khâachâw) with เช่า (châw, Figure 7.7) and revises the syntax of the TC with the new selection. The repaired TC is analyzed and compared to the SL parse. TCE now finds no difference between the SL and the repaired TC parses (Figure 7.8). 


\section{Example 2:}

SL: John rents a room from Joan.

TC: จอหน ค่าเช่า หอง หอง หนึ่ง จาก โจแอน

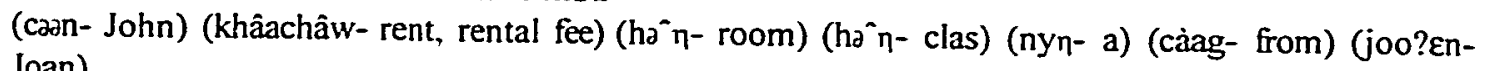
Joan)

STRING:

จ จอหนน 1 ค่าเช่า 2 ห่อง 3 ห้อง 4 หนึ่ง 5 จาก 6 โจแอน 7

No parse

Figure 7.5: The TC parse of Example 2

STRING:
0 john I rents 2 a 3 room 4 from 5 joan 6
CATEGORY:
CONT pSOa
NUCLEUS rentI
WORDASSO 2-1-3-3-2-2
LANDLORD [2] ref
IGENN fem
INUM sg
IPER per
OBJECT [0]
SURFACE rent
TENANT [1] ref
IGENN masc
INUM sg
IPER per
QUANTS E_list

Figure 7.6: CONT value of the SL parse 
Table 7.2: A part of Word Treatment output of Example 2

\begin{tabular}{|c|c|c|}
\hline English & Word Treatment Output & Description \\
\hline rent & 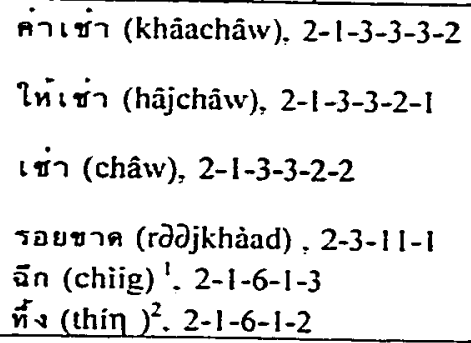 & $\begin{array}{l}\text { money paid for the use of another's } \\
\text { property } \\
\text { to give possession and use of in return } \\
\text { for rent } \\
\text { to take and hold under an agreement to } \\
\text { pay rent } \\
\text { a large tear } \\
\text { to divide by force } \\
\text { to pull violently }\end{array}$ \\
\hline
\end{tabular}

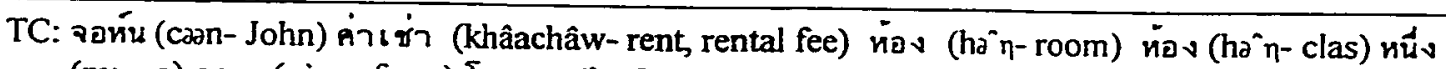
(nyๆ-a) จาก (càag- from) โจแอน (joo?ยn- Joan)

TC with the new selection: จอห์น (cวan- John) เช่า (khâachâw- rent, rental fee) ห้อง (hว ท- room)

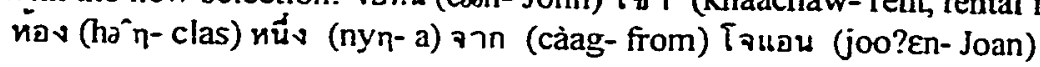

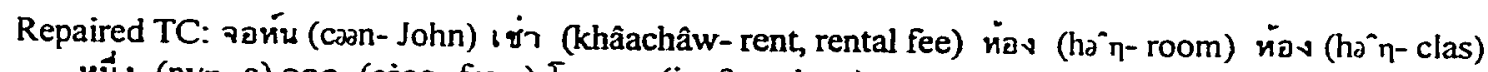
หนึ่ง (nyฤ-a) จาก (cảag-from) โจแอน (joo?ยn- Joan)

Figure 7.7: The repair of Example 2

1.2 The meanings of rent here are a past tense and a participle of rend [Longman 1992]. 

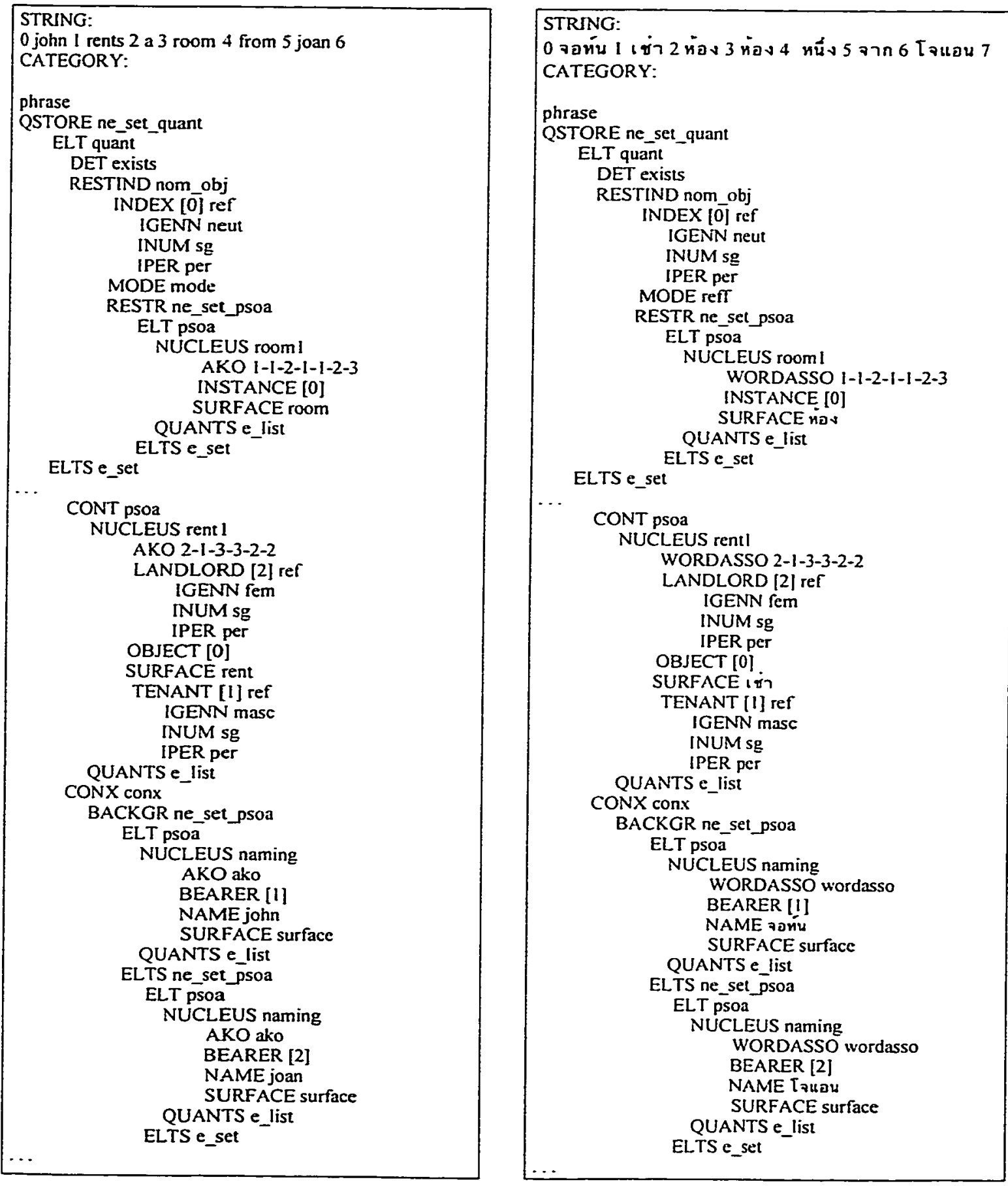

Figure 7.8: The semantic information of the SL and that of the repaired TC in Example 2 


\title{
Chapter 8
}

\section{Machine Translation Evaluation}

\author{
'There is never a single right translation, and therefore \\ never a solid ground truth against which MT output may be compared" \\ _ John White, 1999
}

Evaluation plays a crucial role in machine translation for system developers, funding agencies and technology users. The system developers (at least) want to determine whether the system performs in the ways intended. The funding agencies aim at determining whether a particular research project should be funded whereas the technology users want to determine which system best suits their needs and is cost-effective. More importantly, all system developers, funding agencies and technology users want to determine whether the output is acceptable as a translation. Information necessary to make informed judgments is required. Unfortunately, a universally accepted methodology for evaluating MT systems is not yet available, partly because there are different purposes for MT, different interests of the participants in the process, radically different theoretical approaches to MT and different languages. In addition, it is difficult to evaluate the end product of an MT system since "there is never a single right translation, and therefore never a solid ground truth against which MT output may be compared" [quoting White 1999]. Moreover, most evaluations have been done under contracts and often under confidentiality agreements. Consequently relatively little constructive criticism of the techniques employed is in the public domain [King 1990].

GRMT represents an approach to MT that is not unlike what HPSG represents with respect to grammar theory. GRMT has borrowed many ideas from the major translation 
paradigms (Direct MT, Interlingual MT, Transfer MT, Example-Based MT, KnowledgeBased MT and Shake-and-Bake MT) and included the notion of adding constraints where applicable, as found in HPSG theory. In this sense GRMT represents a new paradigm for MT systems. Just as it is difficult to evaluate past MT efforts (no generally accepted evaluation methodology), it is difficult to evaluate GRMT precisely. Nonetheless, we outline in this chapter some initial requirements for evaluation and some strategies which we hope to apply to GRMT.

\subsection{What needs to be evaluated? (Types of Evaluation)}

As in other areas of natural language processing (NLP), three types of evaluation appropriate to three different goals are recognized [Hirschman and Thompson 1996], [Hutchin 1996]:

- Adequacy Evaluation is to determine the fitness of MT systems (e.g., will the system do what is required, how well and at what cost) within a specified operational context. Adequacy evaluation is typically performed by funding agencies and by technology users.

- Diagnostic Evaluation is to identify limitations, errors and deficiencies, which may be corrected or improved by the researcher or by the developers. Diagnostic evaluation is the concern mainly of researchers and developers.

- Performance Evaluation to assess stages of system development or different technical implementations. Performance evaluation may be undertaken by either researchers or developers.

MT evaluations typically include features not present in evaluations of other NLP systems including:

- Quality of the raw translations.

- Usability of facilities for creating and updating dictionaries.

- Extendibility to new language pairs and/or new subject domains.

- Cost-benefit comparisons with human translation performance.

Quality of the raw translations: It is extremely difficult to determine what counts as a good translation whether produced by human or machine. "The relative adequacy of 
different translations of the same text can only be determined in terms of the extent to which each translation successfully fulfills the purpose for which it was intended" [quoting Nida 1976]. Therefore, intelligibility (or clarity) and fidelity (or accuracy) are the most common criteria in determining a quality of the raw translation [Hutchines and Somers 1992], [Arnold et al. 1994]. However, they remain subjective judgments.

- Intelligibility determines whether the translation consists of the correct words in the target language and whether the evaluators can understand the translation with ease. Intelligibility, therefore, can be measured by considering whether the translation is affected by grammatical errors, mistranslations and untranslated words. A common measurement is to assign scores to the translation. ALPAC's intelligibility scale is a nine-point scale [ALPAC, 1966]. The ALPAC scoring scale ranges from 1 , hopelessly unintelligible, to 9, perfectly intelligible. Another intelligibility scale is proposed by Nagao, Tsujii and Nakamura; this scoring scale ranges from 1 , the meaning of the translation is clear and needs no rewriting, to 5 , the translation cannot be understood at all [Nagao et al. 1988]. Generally, only individual sentences are evaluated. However, by isolating sentences from their contexts, such measurements are made even more subjective and uncertain than they might be [Hutchins and Somers 1992].

- Fidelity determines whether the translation preserves the meaning of the source language or whether the translation contains the same information as the original. Various tests have been proposed and implemented to provide measurements of fidelity. For example, the evaluators read the translation and judge how much more informative was the original. However, this procedure can be criticized as being excessively subjective. Another practical measurement which is feasible for measuring accuracy of translated instruction manuals is to determine whether the person who uses the translated manuals can carry out the instructions as well as the person using the original manual. An alternative measurement is to translate the translation output (generated by MT) back into the original language and then compare the result with the original text. Note that shortcomings are generally magnified by this double translation process. Also note that a translation which is faithful to the original may be difficult to understand while a translation which is easy to read may have distorted the original message [Hutchins and Somers 1992]. 
Usability of facilities for creating and updating dictionaries: The practical MT system should provide facilities for users to expand and update the dictionaries. Changes in dictionary information may result in improvements. The basic questions to determine the degree of usability are whether the system allows the users to make changes to dictionaries, whether the users can update the dictionaries with ease, and whether there is a limitation on the size of the dictionaries.

Extendibility to new language pairs and/or new subject domains: MT systems designed for one particular subject area are inherently more difficult to extend to other areas, not only because of differences in vocabulary but also because of differences of grammar. The basic question to determine the degree of expansion is whether components developed for one language pair can be applied or easily adapted for another language pair. The extendibility of the system depends highly on the modularity of its components [Hutchins and Somers 1992].

Cost-benefit comparisons with human translation performance: Cost estimates and benefits of the system must be taken into account. Costing of MT systems include the basic cost of software, the cost of installation, upgrading and maintenance, and the cost of preediting and post-editing (if any). A comparison will be made with the costs of producing the same quality of output by human translators. Benefits trade-off against costs. Possible benefits include faster production of translations, faster translation of large volumes of text, and simultaneous translation in many languages. Furthermore, the costs of maintaining dictionaries may well diminish with time since the dictionary contains large numbers of lexical entries [Hutchins and Somers 1992].

\subsection{MT Evaluation Strategies}

Some specialized evaluation strategies have been proposed and implemented. For example, scoring scales for measuring quality of the raw translations (see section 8.1), and error analysis, and the test suite. The error analysis and test suite are briefly discussed in this section. Further discussion on MT evaluation can be found in [Lehrberger and Bourbeau 1988], [King 1990], [King and Falkedal 1990], [Hutchins and Somers 1992] and [Arnold et al. 1994]. 


\subsubsection{Error Analysis}

Error analysis strategies focus on the errors the MT system makes. Error counting indicates the amount of work required to correct raw MT output to a standard considered acceptable as a translation [Hutchins and Somers 1992]. During the evaluation, all the errors that occurred in the translation are counted, for example, counting each addition or deletion of a word, or each substitution of one word by another. Different kinds of errors require different correction efforts. Therefore, the errors are classified by relatively difficulty of correction and assigned a weighting factor. For example, the weight factor for incorrect preposition selection in one system is $\mathbf{0 . 6}$ while the weight factor for incorrect number agreement (e.g.s a computers) is 0.2 (this example is taken from [Arnold 1994]). Then the quality of a translation is determined by calculating the total error score. The total error score for each individual sentence or for the whole text is the sum of all the weighted errors.

Although the error analysis strategy provides more direct information on the quality of the translation, there are problems: differences in what is considered to be an error, different levels of acceptability, and difficulties in classifying errors. The more serious problem is that error types are not independent of each other and it is then difficult to count errors accurately e.g., failure to supply any number inflection for a main verb will often mean that the subject and verb do not agree in number as required [Arnold et al. 1994]. Should this failure be counted as one error or two errors?

\subsubsection{Test Suite}

A test suite is a useful evaluation tool for NLP participants especially for developers. A test suite is a systematic collection of specially constructed linguistic expressions (e.g., sentences), perhaps with associated annotations and descriptions [Fouvry and Balkan 1996]. Figure 8.1 illustrates a fragment of English test suites (this example is taken from [Arnold, et al. 1994]). This fragment lists combinations of modal verbs (e.g., can, may) with negative not.

The test suite may include ill-formed sentences (grammatically unacceptable sentences e.g., John not run) which the parser component of the MT system should recognize as incorrect.

The test suite can be constructed as follows [Estival et al. 1994], [Balkan, Arnold and Fouvry 1995]: 
- by collecting the data (test items) from specific text types, actual texts or knowledge bases. This kind of test suite may be limited to specific problems and a specific vocabulary.

- by collecting from a list of linguistic phenomena which is abstracted from any particular application. This type of test suite is referred to as an artificial test suite. In this test suite, the range of test items and the vocabulary used is unbiased by any particular text type, corpus or knowledge base.

John runs.

John will run. modal auxiliaries

John can run.

John may run.

John should run.

John does not run. negation (with do-support)

John not run.*

John will not run.

John may not run.

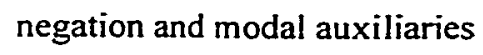

negation and modal auxiliaries

Figure 8.1: A fraction of test suites [Arnold et al. 1994]

Test suites present language phenomena in an exhaustive and systematic way starting with the simplest and increasing in complexity. Furthermore, combinations of phenomena can be generated in a controlled fashion as shown in Figure 8.1.

Test suites can be used for diagnostic evaluation or adequacy evaluation depending on their design [Estival et al. 1994]. With test suites, system developers can determine how their system will perform on a range of controlled examples. A number of test suites have been developed for evaluating MT systems [Estival et al. 1994]. For example:

- The English Eurotra "ET-UK" test suite was developed at Eurotra Essex in 1991. It consists of 955 English test sentences for evaluating the Eurotra translation system. This test suite was designed to test only a restricted number of common syntactic phenomena.

- The English-French and French-English Aerospatiale "AS-NL" test suites were constructed in 1991 to evaluate the commercial MT systems. These test suites contain 1440 English test items, and 346 French test items. 
- The French-German SYSTRAN test suite was developed at Stuttgart in 1991 for evaluating the SYSTRAN French-German translation system. This test suite contains 853 French test items.

- The IAI test suite was developed at IAI Saarbrucken in 1993. This test suite was developed for evaluating the LOGOS, German to English and French translation system. The IAI test suite contains 2481 German test items.

The AS-NL, SYSTRAN and IAI test suites were designed for both diagnostic and adequacy evaluations whereas the ET-UK test suite was designed for diagnostic and progress evaluations'. According to the Report to LRE 62-089 (D-WP1) ${ }^{2}$ [Estival et al. 1994], none of these test suites is claimed to be complete. None of these test suites actually tests the full inflectional morphology of a language systematically and none of them includes testing at a semantic level. The data of the AS-NL and ET-UK test suites are partly derived from sentences occurring in a specific corpus while the data of SYSTRAN and IAI test suites are artificially constructed. Information about the actual use of these test suites is not fully provided.

Methodology and tools are provided by Test Suites for Natural Language Processing (TSNLP) for constructing test suites [Fouvry and Balkan 1996]. The test data constructed by this method are general purpose. They are not specific to a particular domain or text type and they focus on syntactic phenomena. These test data have been validated in a testing phase where a parser, a grammar checker and a controlled language checker have been tested. However, apparently there have not yet been tested on MT systems. Therefore, the problem lies in defining an appropriate test suite for evaluating MT systems.

\subsubsection{The ARPA MT Evaluation}

The Advanced Research Projects Agency (ARPA) conducted the evaluation of three research MT systems (Candide: IBM Thomas Watson Research Laboratory, Pangloss: Carnegie Mellon University and Lingstat: Dragon Systems), six commercial MT systems

\footnotetext{
'The progress evaluation compares successive stages of development of a system over a period of time [Fouvry and Balkan 1996].

2 The Report to LRE 62-089 (D-WP1) presents the characteristics of the existing nine test suites. Four test suites were designed for evaluating MT systems (as listed above) whereas another five test suites were designed for other applications of NLP. This report was written by TSNLP [Estival et al. 1994].
} 
(Metal: Sietec, Pivot: NEC, Power Translator: Globalink, SPANAM: Pan American Health Organization, SYSTRAN: SYSTRAN, XLT: SOCATRA) and three human translations [White 1994]. To produce the human translation for this evaluation, the expert translators were prohibited from adding extra value to the text. For example, there are no parenthetical explanations of geographical locations or social customs. The ARPA MT Evaluation methodology consisted of a collection of human judgments on the quality of MT and statistical analyses of those judgments. Each translation was evaluated for adequacy, fluency and informativeness. However, the purposes of each evaluation in ARPA are different from those defined in section 8.1. In the ARPA MT evaluation:

- Adequacy determines to what extent the meaning conveyed in an expert human translation is presented in the translation under evaluation. The measurement is that the evaluators compare the translation under evaluation with human translation of the same passage and assign a score to the translation. The scoring scale ranges from 1, None of the meaning expressed in human translation is expressed in the MT translation, to 5, All meaning expressed in human translation is expressed in the MT translation.

- Fluency determines the intuitive reactions of evaluators to the well-formness and fluency in context of the translation under evaluation. The measurement is that the evaluators assign a score of 1 to 5 , where 1 represents very poor and 5 represents excellent, to the translations.

- Informativeness determines whether a translation under evaluation provides specific information which the evaluators need. Evaluators must answer a test of six questions that determine an informativeness measurement. These questions are based on the information available in the original text.

\subsection{GRMT Evaluation}

GRMT is in the research and development stage which includes design and development of an advanced prototype system, including compiling dictionaries and grammars. Evaluation is then restricted to the testing of processes without consideration of potential environments. We are unable to make detailed statistical comparison between GRMT and other MT systems. A proper and reliable statistical comparison requires very large dictionaries and corpora, the development of which is part of our future research. In addition, comparison to 
other systems permit only a black box ${ }^{3}$ approach to evaluation; we do not generally have access to their internal structures or algorithms. In contrast we want to discuss the various characteristics which we found in GRMT. The evaluation presented here, therefore, was conducted to answer the following questions:

- whether the programs written for the system perform in the ways intended.

- whether the output is acceptable as a translation.

- whether the expansions of dictionaries affect translation performance.

- whether the extendibility to new language pairs is difficult.

To determine whether the programs written for the system perform in the ways intended, we used a diagnostic trace. The diagnostic trace is a record of the stages through which a program goes to produce output. A sentence is submitted to the system for processing and the results of each stage are displayed (on screen or in print) to enable us to examine the actual operations taking place. On this basis we can discover whether the program is doing what is intended and if it is not, identify where the mistakes are occurring. We tested each component of the system (ALMT, TCE and RI) separately and together as a complete system (GRMT).

To determine whether the output is acceptable as a translation, the test is performed by running a number of sentences against the system and testing the adequacy of the dictionary information and the grammar. The outputs are then compared to two human translations. One translator is a Thai linguist (HM1) and the other translator is a Thai student (HM2) in graduate school. This evaluation concerns both intelligibility and fidelity. The evaluator render judgments by answering to the following questions:

- Is the translation is grammatically correct according to Thai grammar?

- Does the translation consist of the correct words in Thai?

- Does the translation convey the meaning presented in the human translation?

${ }^{3}$ In the black box evaluation, the evaluators have only input/output(s) pairs to work with while it is assumed that the evaluator has access to all the inner working of the system and can inspect intermediate results in the glass box evaluation [King 1990].

${ }^{4}$ These questions need to be asked and answered for all MT systems; we answer here for GRMT alone. 
The outputs are also evaluated in terms of comprehensibility. In this evaluation, the evaluators are a linguist, a grade 7 student and a grade 4 student $^{5}$. All evaluators are native Thai speakers. The measurement is conducted by reading the translation to the evaluators without providing the source text. The evaluator then determines:

- whether the translation can be understood: if the translation cannot be understood what is the cause of the misunderstanding, e.g., inappropriate word usage, inappropriate word order, or missing word.

- whether it is colloquial Thai.

ALMT was tested to generate translation candidates for 76 sentences from the bedtime story, The ugly duckling, version written by Ronne Randall (1987) based on the original story by H. C. Anderson), and 14 sentences from other sources including, newspapers and articles. The outputs of ALMT (translation candidates) are compared to the two human translations to determine their intelligibility and fidelity. The words used in the TCs of the 23th and 27th sentences (Figure 8.2) are correct. The 23th and 27th TCs are licensed by the Thai grammar and convey the same meaning as presented in the human translations. The 26th sentence carries no meaning since the word where is incorrectly translated, $\dot{\text { ทे }}$ หน (thîina $\mathrm{j}$ - where), and it results in a grammatically incorrect TC. In the 37 th sentence, หนึ่ง (ny ${ }^{\circ} \eta$ - one) is wrongly placed and the translation of the word 10 , nับ (kàb- to), is incorrect. The misplaced word and incorrect translation render the TC grammatically incorrect. A complete evaluation of all 90 sentences is illustrated in Appendix $G$. According to the evaluation results shown in Table 8.1: 23 sentences require word re-selection, 15 sentences require word re-arrangement and 47 sentences require no repair. The number of incorrectly translated words in each sentence ranges between 1-3 words. The number of misplaced words which results in a grammatically incorrect translation ranges between 1-3 words.

Figure 8.3 illustrates a fragment of the comprehensible evaluation. A complete evaluation is provided in Appendix H. 57 sentences, Table 8.2, are comprehensible (e.g., sentence 14, Figure 8.3), however, two of them do not convey the intended meaning (e.g., sentence 51, Figure 8.3). The reason the translation does not convey the intended meaning

\footnotetext{
${ }^{5}$ The grade 7 and grade 4 students were selected as evaluators because the main part of the source text is a children's bedtime story.
} 


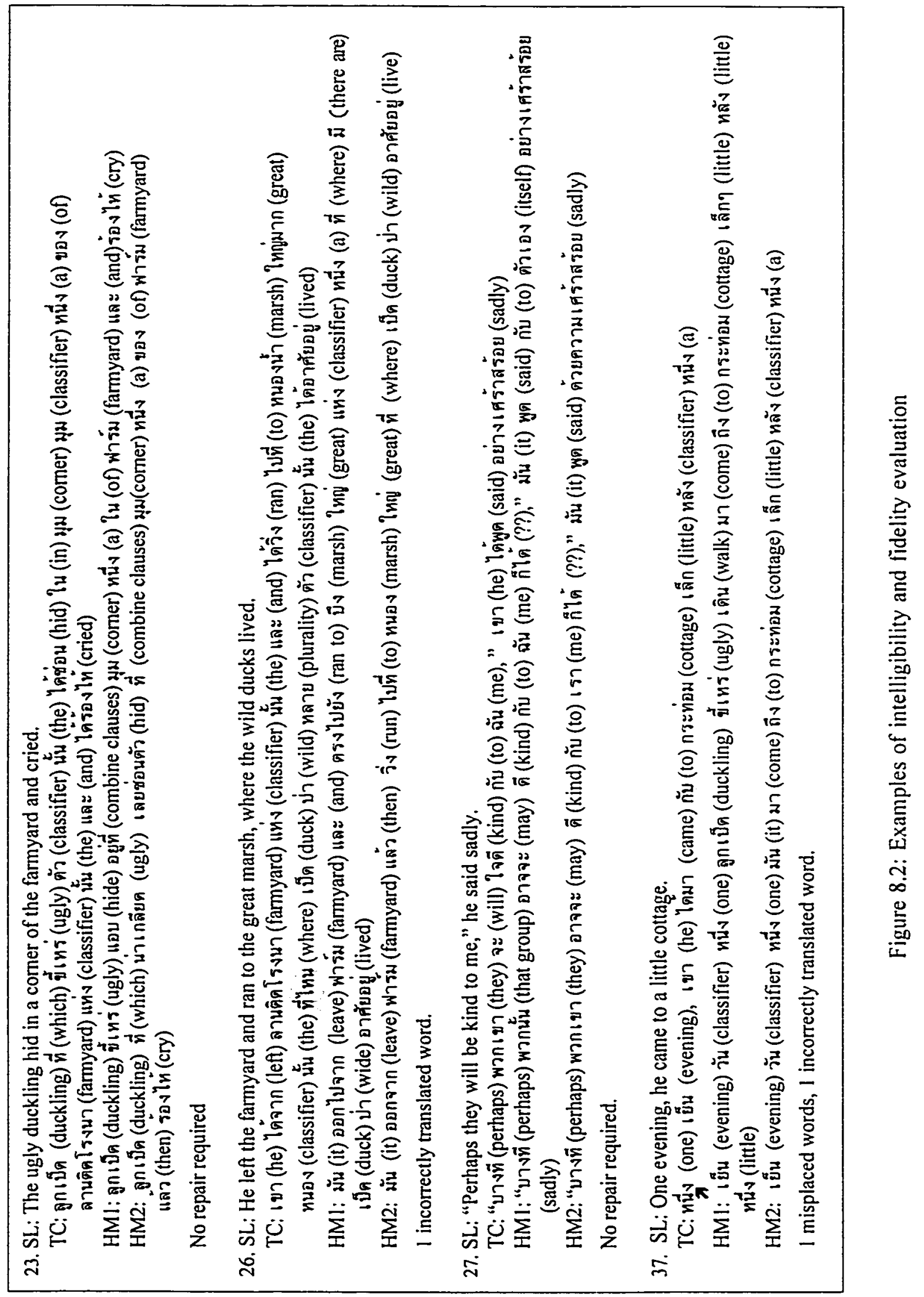


Table 8.1: The intelligibility and fidelity evaluation result of evaluating ALMT on the 90 sentences test corpus

\begin{tabular}{ll}
\hline Measurement & Number of Sentences \\
\hline grammatically correct, correct word usage and & 47 \\
convey the original meaning- require no repair & 43 \\
required repair & 2 \\
grammatically correct, correct word usage but convey different & 2 \\
meaning from the original sentence & 4 \\
1 inappropriate word usage & 15 \\
1 incorrectly translated word & 7 \\
2 incorrectly translated words & 1 \\
3 incorrectly translated words & 8 \\
1 misplaced word & 4 \\
2 misplaced words & 1 \\
3 misplaced words & 9 \\
grammatically incorrect & \\
\hline
\end{tabular}

is that some words are incorrectly translated. 33 sentences are incomprehensible. According to the evaluation results (Table 8.2), the reasons the translations are not comprehensible are:

- Some words are missing. These words need to be added to make the sentence complete and correct in terms of meaning and grammar e.g., sentence 6 (Figure 8.3).

- Some words are incorrectly translated. These words may cause grammatical incorrectness which results in a meaningless sentence e.g., sentence 57 (Figure 8.3).

- Some words are misplaced. The word is wrongly placed and it causes the sentence to be meaningless e.g., sentence 30 (Appendix $\mathrm{H}$ ).

Table 8.2: The comprehensible evaluation result

\begin{tabular}{ll}
\hline Measurement & Number of Sentences \\
\hline comprehensible & 56 \\
incomprehensible & 34 \\
not colloquial Thai & 9 \\
does not convey the intend meaning & 2 \\
\hline
\end{tabular}




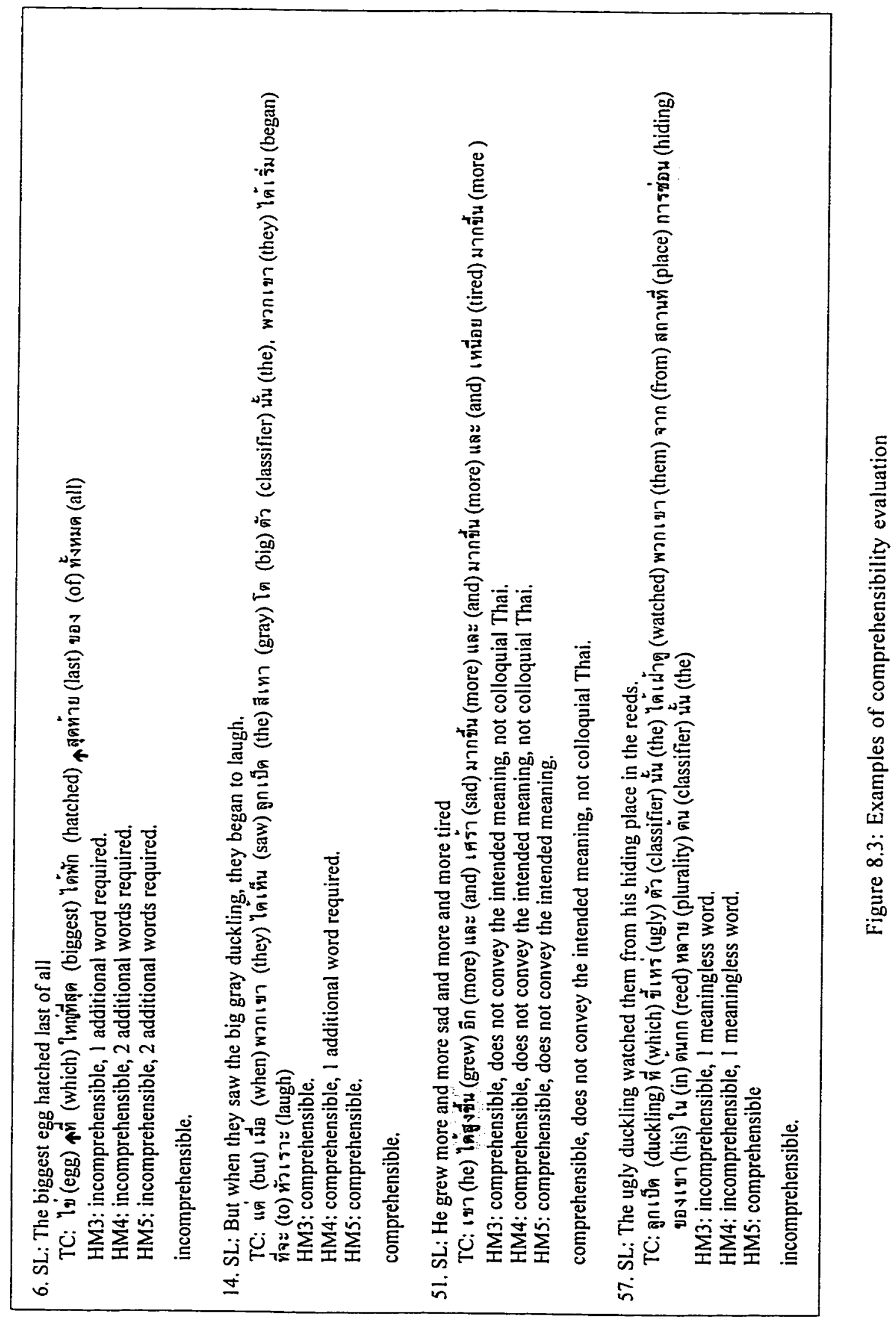




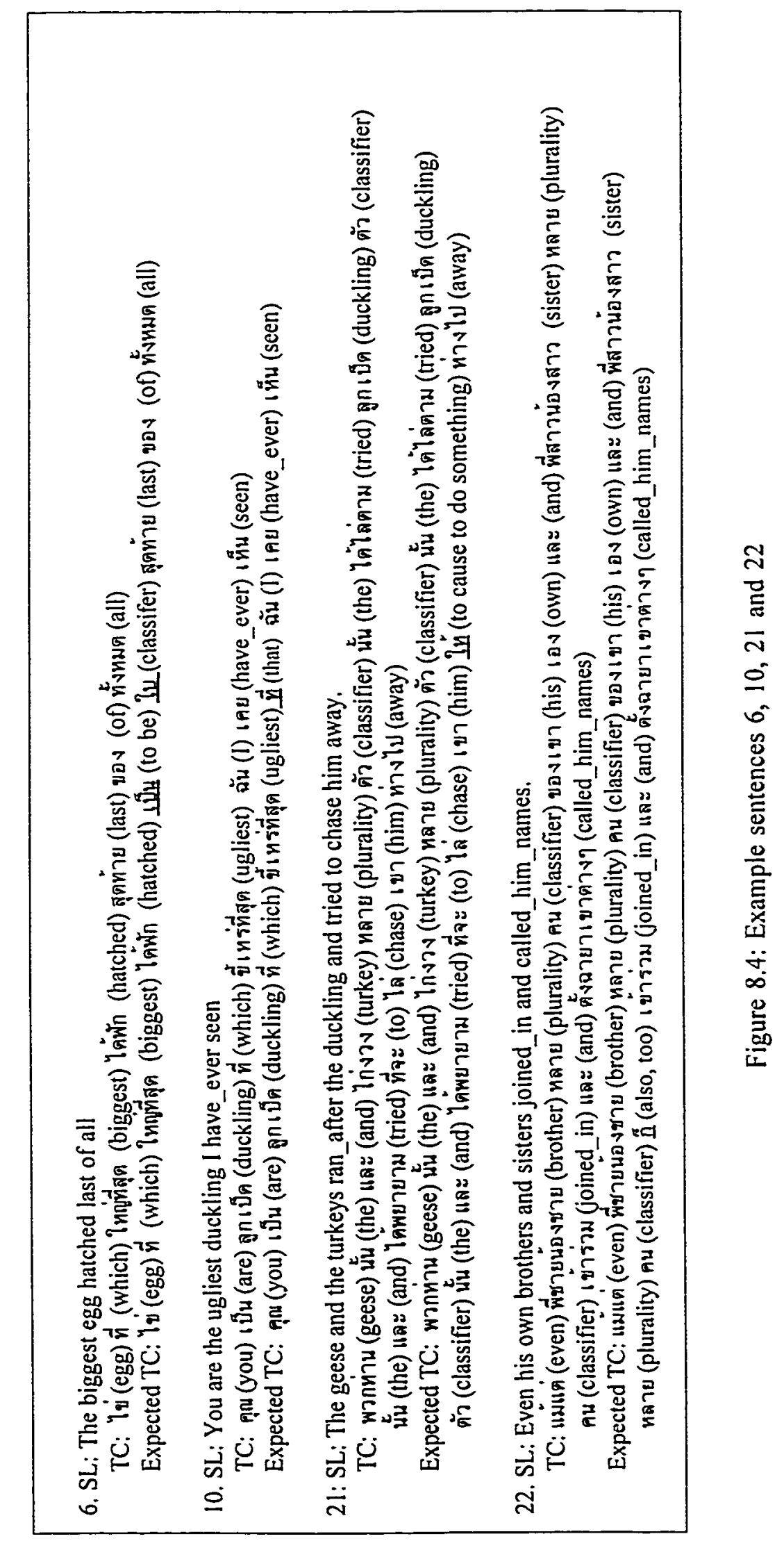


Of the 43 sentences which required repair (Table 8.1 ), 14 sentences are comprehensible and convey the meaning of the original sentences.

We are interested in evaluating the outputs of GRMT (translations) in an analogous way to the ALMT evaluation just discussed. Of the 43 sentences which required repair, 15 sentences are repairable using the current our HPSG based grammars and lexicons. 7 sentences cannot be repaired by the current RI. They are grammatically incorrect although they contain correctly translated words. To complete the TC, according to the Thai grammar, some words (e.g., classifier or linking word) need to be added while some words (e.g., plurality or classifier) need to be removed. In sentences 10,21, 22, 58 and 81 (Appendix $H$ ), the linking word $\vec{n}$ (thîi- that, which, who), $\tilde{n}$ (ka-also, too) and ให้ (hàj- to cause to do something) ${ }^{6}$ are required as shown in Figure 8.4. Sentence 6 requires เป็น (pen- to be) while the words หลาย (la-aj-plurality) and ตัว (tua-classifier) in sentence 55 need to be removed. The linking word in Thai can be classified into at least 17 categories [Punmetha 1984] e.g., $\dot{n}$ (thîi- that, which, who) is a linking word used to add an instrumental relationship as in "He

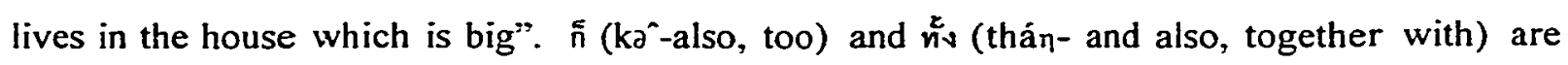
linking words using to combine two sentences which are in agreement as in "If you go then I will also go". ให้ (hàj- to cause to do something) is a linking word to indicate the purpose of the preceding action, as in "He give the book to me to make me happy". There is no explicit rule saying when and which linking word is required.

As we discussed in section 4.1, there is no plural form for nouns in Thai. A quantity of nouns can be expressed either by quantifiers or numbers and classifiers are required. However, adding the plurality หลาย (la aj) and ตัว classifier (tua) to the translation of the word bird in sentence 55 (Figure 8.5) is redundant and grammatically incorrect since flock indicates that there is more than one bird. It is unlike English in which flock requires a plural noun form.

a flock of beautiful birds

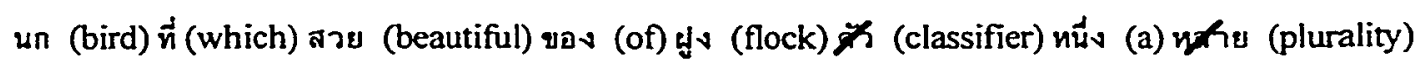

Figure 8.5: A fragment of sentence 55 .

\footnotetext{
${ }^{6}$ The conjunction ที่ (thîi- that, which, who), ถ็ (kð’-also, too) and ให้ (hàj- to cause to do something) often are not translated in English.
} 
We will be expanding the word addition (section 5.3.1) rule to cover additional linking words and to add a plurality indicator and classifier (only when necessary) as part of future research.

The remaining 21 sentences of the 90 sentence test corpus require further nontrivial development of the HPSG formalism to account for their semantic representation, for example, sentences containing the logical connections and, or, but, nor or the negation not. Due to this limitation, the sentences which contain logical connections are separated into linguistic units as illustrated in Figure 8.6 (each unit is underlined). In sentence 26, the word he (circled) was added to complete the structure of the second unit. Each linguistic unit is then repaired separately so that we can determine whether the TCE and RI phases improve the quality of the TC. Some example sentences are illustrated in Figure 8.6; the repaired TCs are grammatically correct and convey the meaning of the original sentences.

We will be expanding the lexicon and the language coverage of our HPSG parsers as part of future research and expect that outcomes of that effort to contribute to both the novel MMT paradigm GRMT espouses and to HPSG theory, e.g., the semantics of coordination.

In the first version of ALMT, we developed dictionaries containing 80 English words and 150 Thai words. The dictionaries were expanded to 348 English words and 731 Thai words in the second version of ALMT. There has been no appreciable increase in processing time when running ALMT using the larger dictionaries. This experiment lends positive evidence that a more advanced prototype will scale up reasonably.

Modification to the lexicons and grammars of the SL and TL analyzers will result in improvements. Expanding the lexicons or the coverage of language structure via HPSG formalism is relatively simple. The use of the HPSG formalism provide advantages in terms of comprehensive lexical entries. The lexicons are easy to manage. The use of ALE facilitates lexicon development and grammar writing.

Expansion in terms of adding new languages to the system is manageable since SLs and TLs are treated separately and they are related by using information provided in a SL-TL lexicon. The lexicon and grammar used in the analyzer of each language is developed separately. 


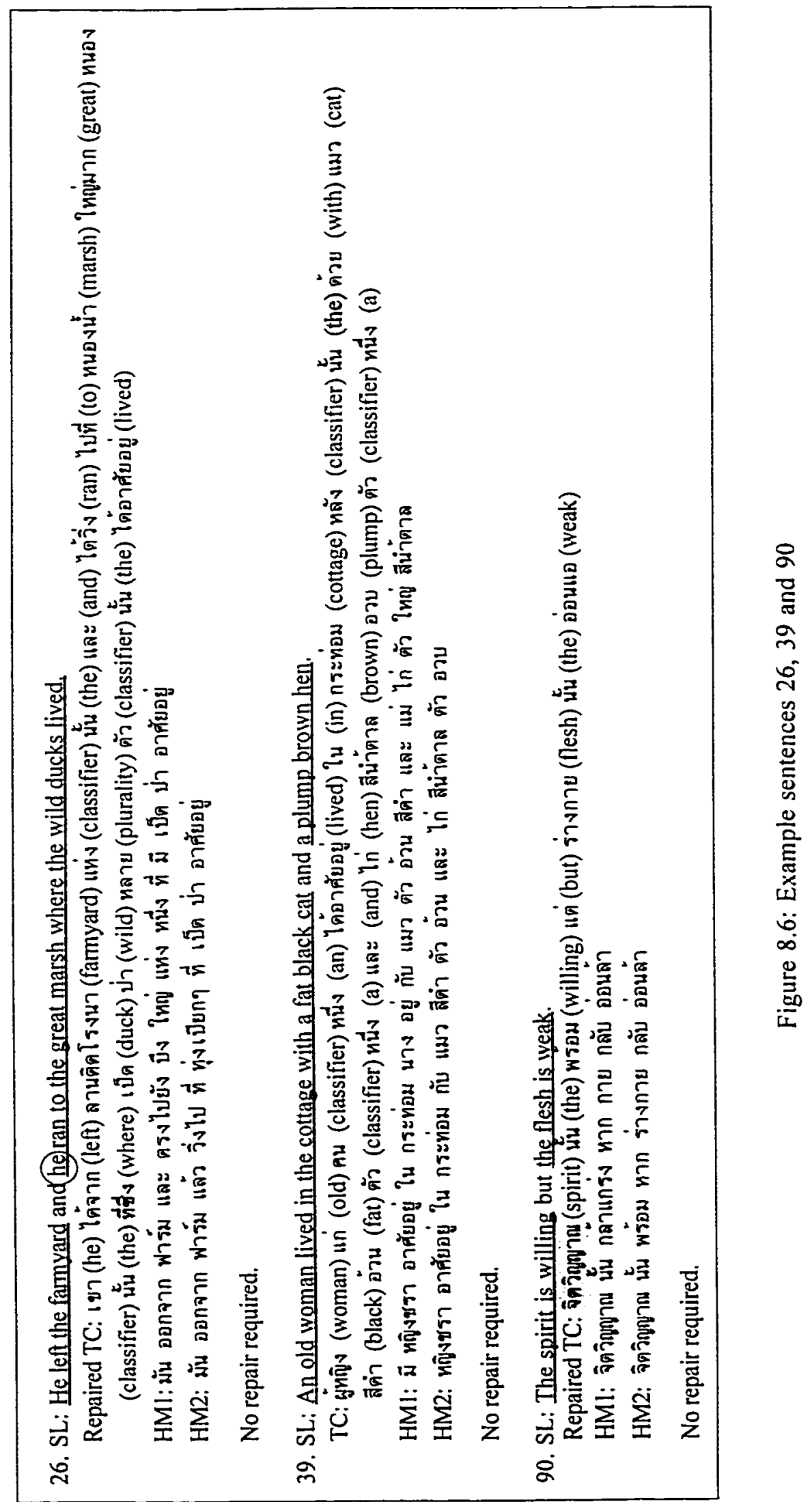




\section{Chapter 9}

\section{Discussion}

\subsection{Contributions}

The central theme of this thesis is to find new solutions that apply when developing an efficient MT and our solution is Generate and Repair Machine Translation. GRMT is a novel multi-phase architecture for an accurate machine translation system. The main concept of GRMT was introduced in chapter 3. The architecture of GRMT was designed to take advantage of, and have advantages over, the Direct, Transfer, Interlingual, Nonlinguistic and the existing hybrid approaches to MT as illustrated in Table 9.1. GRMT consists of three major components Analysis Lite MT, Translation Candidate Evaluation and Repair and Iteration. ALMT generates the translation candidate, TCE verifies an accuracy of the TC and RI repairs the TC when required.

The main features of ALMT are the use of constraints and the use of the semantic relationship between words. ALMT applies the different sets of constraints to deal with the syntax of the SL and that of the TL in separate modules. ALMT refines the scope of translation choices of each input word by applying the SL constraints. SL constraints apply to the syntax of the SL which is different from that of the TL. The selected translation words are put into grammatical order by applying the TL constraints. TL constraints apply the syntax of the TL which is different from that of the SL. The set of constraints can be applied to languages which share common significant features.

The semantic relationship between words has been developed in the form of the WordAssociation relation. The WordAsso relation is a link between WordAsso numbers. The WordAsso number represents a relation between a word and its class. We classified words according to their meanings and their usages regardless of language which makes it possible to 
Table 9.1: Advantages and disadvantages of the existing MT approaches

\begin{tabular}{|c|c|c|c|}
\hline Category & Approach & Advantages & Disadvantages \\
\hline \multirow{3}{*}{$\begin{array}{l}\text { Three Classic } \\
\text { Strategies }\end{array}$} & Direct MT & Simple approach. & Limited accuracy \\
\hline & Interlingual MT & Treat SL and TL separately. & $\begin{array}{l}\text { Difficulties in } \\
\text { developing interlingual } \\
\text { system. }\end{array}$ \\
\hline & Transfer MT & $\begin{array}{l}\text { Less complexity in analysis } \\
\text { and generation. }\end{array}$ & $\begin{array}{l}\text { Information lost } \\
\text { during the transfer } \\
\text { process. } \\
\text { Language } \\
\text { dependent. }\end{array}$ \\
\hline \multirow[t]{2}{*}{$\begin{array}{l}\text { Nonlinguistic } \\
\text { Information } \\
\text { Strategies }\end{array}$} & $\begin{array}{l}\text { Example-Based } \\
\text { MT }\end{array}$ & $\begin{array}{l}\text { Translations come with scores } \\
\text { which might be useful to a } \\
\text { post editor. }\end{array}$ & $\begin{array}{l}\text { Relies heavily on the } \\
\text { availability of a large } \\
\text { and diverse quality } \\
\text { corpus which are not } \\
\text { available for most } \\
\text { languages. }\end{array}$ \\
\hline & $\begin{array}{l}\text { Statistics-Based } \\
\text { MT }\end{array}$ & $\begin{array}{l}\text { Apply statistical techniques in } \\
\text { translation process. }\end{array}$ & \\
\hline \multirow[t]{2}{*}{$\begin{array}{l}\text { Hybrid } \\
\text { Strategies }\end{array}$} & $\begin{array}{l}\text { Knowledge-Based } \\
\text { MT }\end{array}$ & $\begin{array}{l}\text { Interpreting the SL by } \\
\text { reference to world knowledge. }\end{array}$ & 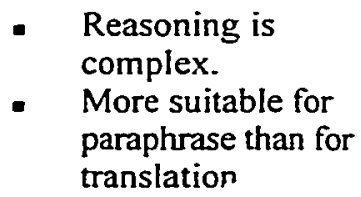 \\
\hline & $\begin{array}{l}\text { Shake-and-Bake } \\
\text { MT }\end{array}$ & $\begin{array}{l}\text { SL and TL are associated via } \\
\text { bilingual lexicon without a } \\
\text { transfer module or interlingual. }\end{array}$ & $\begin{array}{l}\text { Lack efficiency due to } \\
\text { the generation process } \\
\text { which tries all } \\
\text { possibilities. }\end{array}$ \\
\hline
\end{tabular}

to apply these to a multilingual $\mathrm{MT}$ system. This word classification plays a crucial role throughout the GRMT translation process.

The use of the WordAsso relation together with the designed (word selection) algorithm allows ALMT to select an appropriate translation for each input word efficiently. The WordAsso relation indicates a relationship between words (e.g., which word can occur with which word in the same expression) including the relationship between nouns and their classifiers. The use of classifiers in Asian languages e.g., Chinese, Japanese and Thai is similar, therefore, with some modifications it is possible to apply our classifier selection to those Asian languages.

GRMT ensures an accuracy of the translation by the TCE and RI phases. TCE analyzes the TC to verify its syntax and semantics. The semantics of the TC is extracted and compared to that of the SL to determine whether the TC conveys the meaning of the SL. 
The SL and TL grammars should be developed based on grammar theory which is an integrated theory of natural language syntax and semantics, e.g., the Head-Driven Phrase Structure Grammar. We include the WordAsso number in the semantic representation since the WordAsso number represents the word meaning and the word's usage. Differences in languages and cultures result in different circumstances of language usage; therefore, the word and its translation are considered acceptably similar in principal features if they belong to the same superclass as illustrated in chapter 6. If TCE detects any dissimilarity between the meaning of the TC and that of the SL, TCE will then provide that (dissimilarity) information to $\mathrm{RI}$.

$\mathrm{RI}$ improves the quality of the TC by replacing the mis-translated part with a more appropriate translation according to the information TCE provides.

Each step performed by GRMT is straightforward and simple to implement. GRMT is highly modular and extendible in the following respects. Each component, ALMT, TCE and RI are developed separately. Each module comprises of sub-modules for easy modification and maintainance. The SL and TL are treated separately and related via the SL-TL dictionary. The SL-TL dictionary contains simple information, a SL word form and its possible translations, with the WordAsso number, and nothing else. Other knowledge-bases e.g., the dictionary, constraints, lexicons, and grammars are developed separately, independent of languages. This would seem to be the optimal distribution of information, both from the point of building a larger, possibly multilingual MT system, and for maintaining and extending it. A further note is that GRMT translation process is not limited to a single direction translation. With a few modifications of the SL-TL dictionary, GRMT is reversible.

I hope to have demonstrated the idea of GRMT by constructing the English-Thai MT system. The English-Thai MT system translates isolated sentences (sentence by sentence). This English-Thai translation system has been developed and run under SWI-Prolog 3.2.8. The English and Thai grammars have been developed based on the Head-Driven Phrase Structure Grammar formalism [Pollard and Sag 1987; Pollard and Sag 1994] and implemented on the Attribute Logic Engine (ALE) [Carpenter and Penn 1994].

This English-Thai MT system was evaluated and it performs in the way we intended. ALMT generated acceptable translations (grammatically correct, correct word usage and convey the original meaning) for 47 out of the 90 sentence test corpus without repair. TCE and RI improved 15 sentences using the current our HPSG based grammars and lexicons. 
Twenty-one sentences which contain logical connections are first separated into linguistic units before the repair can be performed due to a current inadequacy in HPSG's semantic representation. However, each linguistic unit was then repaired successfully. Seven sentences faced with the problems of adding linking words and classifiers in Thai also require further refinements in order to repair such sentences.

\subsection{Further Research}

Several issues presented in this thesis require further research. The word addition module can be improved since it currently fails to account properly for some connecting words and some plurality indicators in Thai (see chapter 8 ). Further research is needed to determine when and which connecting word or plurality indicator is required. With the word classification provided, it is possible to select a proper linking word for each situation and to be able to identify when the plurality indicator is needed.

To develop the WordAsso relations in the future, the semantic concordance which was created at the Princeton Cognitive Science Laboratory can be used as sample set. A semantic concordance is a database combining a text and a lexicon so that words in the text are linked to the appropriate senses in the lexicon [Fellbaum 1998]. We also hope consider how statistical methods or machine learning techniques can be used to help assign the WordAsso numbers to words in an appropriate way.

The lexicon and grammar coverage is limited. When large dictionaries (SL-TL dictionary and SL dictionary) and lexicons are used, more efficient ways of indexing the entries are required. At the moment the dictionaries and the lexicons are held in Prolog's working memory, an approach that is unlikely to satisfy requirements for larger systems.

Additional research is also required to explore the semantic representation of some language structures, e.g., structures containing logical connections and negation. This additional research should be useful not only for GRMT but also for another natural language processing applications e.g., search engines and information retrieval.

I believe the results of this research will contribute to current attempts to develop accurate and reliable machine translation systems and to produce quality translations from one language to another. This accurate and reliable translation methodology should enhance the effectiveness of communication among people. 
Nevertheless, I hope to have shown that pursuing further research in this direction is a worthwhile aim, and one likely to result in commercial machine translation systems in the not too distant future. 


\section{Bibliography}

Abney, S. (1994) Parsing by Chunks, available at "http://www.sfs.nphil.uni-tuebingen.de/ abney/", as of January, 2000.

ALPAC (1966) Language and Machines: Computers in Translation and Linguistics. A report by the Automatic Language Processing Advisory Committee, Division of Behavioral Sciences, National Academy of Sciences, National Research Council, Washington, D.C.

Arnolds, D. J., et al., (1994) Machine Translation: An Introduction Guide, NCC Blackwell, London.

Balkan, L., D. Arnold and F. Fouvry (1995) Test Suites for NLP, available at "http://clwww. essex.ac.uk/group/projects/tsnlp/papers/tsnlp-csnlp95.ps.gz" as of January, 2000.

Balkan, L., D. Arnold and S. Meijer (1994) Test Suites for Natural Language Processing, available at "http://clwww.essex.ac.uk/group/projects/tsnlp/papers/tsnlp-groningen95.ps.gz" as of January, 2000.

Bar-Hillel, J., (1964) Language and Information: Selected Essays on Their Theory and Application, Addison-Wesley Publishing Company.

Bell, R., (1996) Equivalence and Fidelity: Of What, to What and to Whom? Some PseudoProblems of Translation Theory In The Knowledges of the Translator: From Literary Interpretation to Machine Classification Edited by Malcolm Coulthard and Patricia Anne Odber de Baubeta. The Edwin Mellen Press, Ltd., United Kingdom.

Beven, J. L. (1992) Lexicalist Unification-Based Machine Translation, Ph.D. Thesis, University of Edinburgh. 
Bisbey, R. and M. Kay (1972) The MND Translation System: A Study in Man-Machine Collaboration, The RAND Corporation, Santa Monica, California, March.

Boitet, C. (1990) Towards Personal MT: General Design, Dialogue Structure, Potential Role of Speech In The Proceedings of The 13th International Conference on Computational Linguistics, COLING-90, Edited by Hans Karlgren, Helsinki, Vol. 3, p. 30-35.

Brensnan, J., and Ronald M. Kaplan (1982) Introduction In Brensnan, ed.

Brew, C. (1992) Letting The Cat Out of The Bag Generation for Shake-and-Bake MT In The proceedings of the fifteenth International Conference on Computational Linguistics, COLING-92, Nantes, France, August 23-28, p. 610-616.

Brown, P., J. Cocke, S. A. Della Pietra, V. J. Della Pietra, F. Jelinek, J. D. Lafferty, R. L. Mercer and P. S. Roossin (1990) A Statistical Approach to Machine Translation In Computational Linguistics, 16(2), June, p. 79-85.

Brown, P., J. Cocke, S. Della Pietra, V. Della Pietra, F. Jelinek, R. Mercer and P. Roossin (1988) A Statistical Approach to Language Translation In Proceedings of the 12th International Conference on Computational Linguistics, COLING BUDAPEST, Vol. I, John von Neumann Society for Computing Sciences, Busapest.

Brown, P.F., A.D.P. Stephen, J.D.P Vincent, J.D. Lafferty and R.L. Mercer (1992) Analysis, Statistical Transfer, and Synthesis in Machine Translation. In Proceedings of the Fourth International Conference on Theoretical and Methodological Issues in Machine Translation of Natural Languages, Montreal, p. 83-100.

Carroll, L. (1992) Through the Looking Glass, In Alice's Adventures in Wonderland and Through the Looking Glass published by Alfred A. Knopf, Inc., New York.

Carbonell, J. G., R. E. Cullingford and A. V. Gershman (1981) Steps Toward Knowledge-Based Machine Translation. In IEEE Transaction on Pattern Analysis and Machine Intelligence, Vol. PAMI-3, NO. 4, July, p. 376- 392.

Carbonell, J. G. and M. Tomita (1987) Knowledge-based Machine Translation, The CMU Approach In Machine Translation: Theoretical and Methodological Issues Edited by $\mathrm{S}$. Nirenburg, Cambridge University Press, Cambridge. 
Carpenter, B. (1991) The Generative Power of Categorial Grammars and head-Driven Phrase Structure Grammars with Lexical Rules, In Computational Linguistics, Association for Computational Linguistics, 17(3), p. 301-313.

Carpenter, B. (1992) The Logic of Typed Feature Structures, Cambridge University Press, USA.

Carpenter, B. and G. Penn (1999). ALE: The Attribute Logic Engine User's Guide Version 3.2 Beta, available on line at "http://www.sfs.nphil.unituebingen.de/ gpenn/ale.html\# AleGrammars", as of May.

Carpenter, B. and G. Penn (1999) Compiling Typed Attribute-Value Logic Grammars.

Center for the Study of Language and Information, (1999) Head-Driven Phrase Structure Grammar (homepage), http://hpsg.stanford.edu/, Stanford University, November.

Cercone, N. (1975) Representing Natural Language in Extended Semantic Networks, Ph.D. Thesis, Department of Computer Science, The University of Alberta, Edmonton.

Cercone, N., R. Goebel, J. D. Haan and S. Schaeffer (1992) The ECO Family In Semantic Networks in Artificial Intelligence Edited by F. Lehmann, Pergamon Press, Oxford, p. 95131.

CICC, (1995a) Chinese Concept Dictionary. Technical Report 6-CICC-MT58, Machine Translation System Laboratory, Center of the International Cooperation for Computerization, Tokyo.

CICC, (1995b) Indonesian Basic Dictionary. Technical Report 6-CICC-MT53, Machine Translation System Laboratory, Center of the International Cooperation for Computerization, Tokyo.

CICC, (1995c) Indonesian Concept Dictionary. Technical Report 6-CICC-MT65, Machine Translation System Laboratory, Center of the International Cooperation for Computerization, Tokyo. 
CICC, (1995d) Indonesian Generation Rules. Technical Report 6-CICC-MT39, Machine Translation System Laboratory, Center of the International Cooperation for Computerization, Tokyo.

CICC, (1995e) Interlingual Final Edition. Technical Report 6-CICC-MT36, Machine Translation System Laboratory, Center of the International Cooperation for Computerization, Tokyo.

CICC, (1995f). Thai Analysis Rules. Technical Report 6-CICC-MT46, Machine Translation System Laboratory, Center of the International Cooperation for Computerization, Tokyo.

CICC, (1995g) Thai Basic Dictionary. Technical Report 6-CICC-MT55, Machine Translation System Laboratory, Center of the International Cooperation for Computerization, Tokyo.

CICC, (1995h) Thai Concept Classification. Technical Report 6-CICC-MT60, Machine Translation System Laboratory, Center of the International Cooperation for Computerization, Tokyo.

CICC, (1995i) Thai Generation Rules. Technical Report 6-CICC-MT50, Machine Translation System Laboratory, Center of the International Cooperation for Computerization, Tokyo.

CICC. (1995j) Thai Co-occurrence Dictionary. Technical Report 6-CICC-MT57, Machine Translation System Laboratory, Center of the International Cooperation for Computerization, Tokyo.

CICC, (1997). Technical Report on Interlingual and Concept Classification. Technical Report 6-CICC-MT3 1, Machine Translation System Laboratory, Center of the International Cooperation for Computerization, Tokyo.

Cognitive Science Laboratory, Princeton University. (1998). WordNet-A Lexical Database for English. "http://www.cogsci.princeton.edu/ wn/", February.

Collins, M. J. , (1996) A New Statistical Parser Based on Bigram Lexical Dependencies, In The Proceedings of The 34th Annual Meeting of The Association for Computational Linguistics, Santa Cruz, California, June, p. 184-191. 
Covington, M. A. (1994), Natural Language Processing for Prolog Programmers, Prentice Hall.

Cranias, L., H. Papageorgiou and S. Piperidis, (1995), A Matching Technique in ExampleBased Machine Translation The Computation and Language E-Print Archive.

Crystal, D. (1987) The Cambridge Encyclopedia of Language, Cambridge University Press, Cambridge.

Dagan, I. (1996) Bilingual Word alignment and Lexicon Construction, Tutorial In The 34 th Annual Meeting of The Association for Computational Linguistics, Santa Cruz, California, June.

Daudé, J., L. Padró and G. Rigau (1999) Mapping Multilingual Hierarchies Using Relaxation Labeling. CS.CL/9906025, "http://xxx.lanl.gov/abs/cs/9906025" as of December.

Demos, K. and M. Frauenfelder (2000) Machine Translation's Past and Future In Wired Magazine, Archive 8.05 - May 2000, "http://www.wired.com/wired/archive/8.05/" as of May.

Dorr, B. J. (1991), Parameterization of the Interlingua in Machine Translation, Computer Science Technical Report UMIACS-TR-91-119, CS-TR-2743, Institute for Advanced Computer Studies, University of Maryland, August.

Estival, D. (1994) Reversible Grammars and Their Application in Machine Translation In Reversible Grammar in Natural Language Processing, Kluwer Academic Publishers, The Netherlands, p. 293- 320.

Estival, D., A. Ballim, G. Russell and S. Warwick (1990) A Syntax and Semantics for FeatureStructure Transfer In The Proceedings of The Third International Conference on Theoretical and Methodological Issues in Machine Translation of Natural Language, Linguistics Research Center, University of Texas at Austin.

Estival, D. et al., (1994) Analysis of Existing Test Suites, Report to LRE 62-089 (D-WP1), Test Suites for Natural Language Processing (TSNLP), University of Essex, January. 
Farwell, D. and Y. Wilks (1991) ULTRA: A Multilingual Translator In Proceedings of Machine Translation Summit III, Washington and Pittsburgh: Center for Machine Translation, Carnegie Mellon University, 19-24.

Fellbaum, C. (1998) (Ed) WordNet: An Electronic Lexical Database, The MIT press, Cambridge.

Fouvry, F, and L. Balkan (1996) Test Suites for Quality Evaluation of NLP Products, available at "http://clwww_essex.ac.uk/group/projects/tsnlp/papers/index.html" as of January, 2000 .

Franklin ${ }^{\otimes}$ (1998) Language Master LM-6000b, Franklin ${ }^{\star}$ Electronic Publishers, INC. Burlington, USA (Words from Merriam-Webster).

Galloway, B. D., (1989) 3-D Semantics and the First Halkomelem Dictionary In The Proceedings of The 28th Conference on American Indian Languages, AAA Annual Meetings, 14-19, November, Washington, D. C., p. 45-58.

Galloway, B. D., (1993) A Grammar of Upriver Halkomelem, University of California Press, Berkeley.

Garvin, P. L. (1972) On Machine Translation Selected Papers, Mouton \& Co. N. V. , Publishers, The Hague.

Gazdar, G., E. Klein, G. K. Pullum and I. V. Sag (1985) Generalized Phrase Structure Grammar, Oxford: Basil Blackwell, Cambridge, Maasachusette, Harvard University Press.

Gazdar, G., and C. Mellish (1989) Natural Language Processing in Prolog, Addison-Wesley Publishing Company.

Ginzburg, J. and I. V. Sag, (1998) English Interrogative Constructures (Draft of July) In Construction : an HPSG Perspektive by I. A. Sag and A. Kathol, Language Advanced Course, 10th European Summer School in Logic, Language and Information, Saarbrücken, 17- 28 August.

Goodman, K. and S. Nirenburg (eds.) (1991) The KBMT Project: A Case Study in KnowledgeBased Machine Transiation. San Mateo, California, Morgan Kaufmann Publishers . 
Goshawke, W., I. D. K. Kelly and J. D. Wigg (1987) Computer Translation of Natural Language, SIGMA Press.

Haas, M. R. (1964) Thai-English Student's Dictionary. Stanford University Press, Stanford, California.

Haruno, M. and T. Yamazaki (1996) High-Performance Bilingual Text Alignment Using Statistical and Dictionary Information In The Proceedings of The 34th Annual Meeting of The Association for Computational Linguistics, Santa Cruz, California, June, p. 131-138.

Henisz-Dostert, B., R. R. Macdonald and M. Zarechnak (1979) Machine Translation, Mouton Publishers.

Hirschman, L.and H. S. Thompson (1996) Overview of Evaluation in Speech and Natural Language Processing In Survey of the State of the Art in Human Language Technology Edited by R. A. Cole et al., This document is available at http://cslu.cse.ogi.edu/HLTsurvey/, April, 2000.

Hutchins, J (1997) Computer-based translation systems and tools, "http://www.bcs.org.uk/siggroup/sg37.htm" as of June.

Hutchins, J (1996) Evaluation of Machine Translation and Translation Tools In Survey of the State of the Art in Human Language Technology Edited by R. A. Cole et al., This document is available at http://cslu.cse.ogi.edu/HLTsurvey/, April, 2000.

Hutchins, W. J., (1986) Machine Translation: Past, Present, Future, Ellis Horwood Limited, Chichester, UK.

Hutchins, W. J., (1988) Recent Developments in Machine Translation : A Review of the Last Five Years In New Directions in Machine Translation edited by Maxwell D., K. Schuber and T. Witkam, , Conference Proceedings, Budapest 18-19 August 1988, Foris Publications.

Hutchins, W. J. (1989a) Methods of Linguistic Analysis in Machine Translation In Progress in Machine Translation: Natural Language and Personal Computer Edited by Ian D. K. Kelly, SIGMA Press, UK, p. 3-35. 
Hutchins, W. J. (1989b) Prospects In Machine Translation In Machine Translation Summit Edited by M. Nagao, et al., Ohmsha, Ltd., Tokyo.

Hutchins, W. J. and H. L. Somers, (1992) An Introduction to Machine Translation, Academic Press Limited.

Jones, D. (1996) Analogical Natural Language Processing. UCL Press Limited, London.

Kay, M. (1989) Machines and People in Translation In Machine Translation Summit Edited by M. Nagao, et al., Ohmsha, Ltd., Tokyo.

Kay, M., J. M. Gawron and P. Norvig (1994) Verbmobil: A Translation System for Face-toFace Dialog, Lecture Notes No. 33, CSLI Publication, Stanford.

King, M. (1990) A Workshop on Evaluation: Background Paper In The Proceedings of The Third International Conference on Theoretical and Methodological Issues in Machine Translation of Natural Language, Linguistics Research Center, University of Texas at Austin, 11-13 June.

King, M. and K. Falkedal (1990) Using Test Suits in Evaluation of Machine Translation Systems In The Proceedings of The 13th International Conference on Computational Linguistics, COLING-90, Edited by Hans Karlgren, Helsinki, Vol. 2, p 21 1-216.

Kittredge, R. and J. Lehrberger (1982) Sublanguage: Studies of Language in Restricted Semantic Domains. Walter de Gruyter \& CO.

Landsbergen, J. (1987a) Isomorphic grammars and their use in the ROSETTA Translation System In Machine Translation Today: The state of the Art. Edinburgh University Press, Edinburgh.

Landsbergen, J. (1987b) Montague Grammar and Machine Translation In Linguistic Theory and Computer Applications Edited by P. Whitelock, M. M. Wood, H. L. Somers, R. Johnson and P. Bennett, Academic Press, London, p. 113- 147.

Lehrberger, J. and L. Bourbeau (1988) Machine Translation: Linguistic Characteristics of MT Systems and General Methodology of Evaluation, John Benjamins Publishing Company, Amsterdam. 
Levin, L (1990) Syntactic Theory and Grammar Design for Machine Translation In The Proceedings of The Third International Conference on Theoretical and Methodological Issues in Machine Translation of Natural Language, Linguistics Research Center, University of Texas at Austin, 11-13 June.

Locke, W. N. and A. D. Booth (1955) Machine Translation of Languages: Fourteen Essays, The Technology press of The Massachusetts Institute of Technology and John Wiley \& Sons, Inc., New York.

Longman, (1992) Longman Dictionary of Contemporary English, Clays Ltd., St. Ives plc, English.

Marchuk, Y. N. (1989) Machine Translation in the USSR In Progress in Machine Translation: Natural Language and Personal Computer Edited by Ian D. K. Kelly, SIGMA Press, UK, p37-49.

Maruyama, H. and H. Watanabe (1990) An Interactive Japanese Parser for Machine Translation In The Proceedings of The 13th International Conference on Computational Linguistics, COLING-90, Edited by Hans Karlgren, Helsinki, Vol. 3 p 257-262.

Matheson, C. (1996) HPSG Grammars in ALE, available at http://www.ltg.hcrc.ed.ac.uk/ projects/ledtools/ale-hpsg/, as of May.

Melamed, I. D. (1998) Empirical Methods for MT Lexicon Development In Machine Translation and the Information Soup, Edited by D. Farwell, L. Gerber and E. Hovy, The Proceedings of The Third Conference of the Association for Machine Translation in the Americas, AMTA'98, Langhome, PA, USA, October 28-31, p. 18- 30.

Miller, G. A. (1998) Nouns in WordNet In WordNet: An Electronic Lexical Database Edited by C. Fellbaum, The MIT press, Cambridge, p. 23-46.

Mitamura, T. Nyberg, E.H.3rd and Carbonell J.G. (1991) An Efficient Interlingua Translation System for Multi-lingual Document Production. In Proceedings of Machine Translation Summit III, Washington D.C., July.

Muraki, K. (1989) PIVOT: Two-phase Machine Translation System. In Proceedings of the Second Machine Translation Summit, Tokyo, Omsha Ltd. 
Nagao, M. (1984) A Framework of a Mechanical Translation Between Japanese and English by Analogy Principle. In Artificial and Human Intelligence Edited by Alick Elithorn and Ranan Banerji, Elsevier Science Publishers, B.V.

Nagao, M., J. Tsujii and J. Nakamura (1988) The Japanese Government Project for Machine Translation In Machine Translation System Edited by J. Slocum, Cambridge University Press, Cambridge, p. 141- 186.

Naruedomkul, K. and N. Cercone (1997) Steps Toward Accurate Machine Translation. In Proceedings of the 7th International Conference on Theoretical and Methodological Issues in Machine Translation, Santa Fe, New Mexico, USA, p. 63-75.

Naruedomkul, K., N. Cercone and B. Sirinaovakul (1999) English-Thai Translation: Initial Experiments with a Multiphase Translation system. Computational Intelligence, 15(2):128151.

Newmark, P. (1981) Approaches to Translation, Pergamon Press, Oxford.

Newmark, P. (1988) A Text Book of Translation, Prentice Hall, New York.

Newton, J. (Edited) (1992) Computers in Translation, Routledge.

Nida, E. (1976) A Framework for the Analysis and Evaluation of Theories of Translation In Translation: Application and Research, Edited by R. W. Brislin, Gardner Press, Inc., New York.

Nirenburg, S., J. Carbonell, M. Tomita and K. Goodman (1992) Machine Translation: A Knowledge-Based Approach, Morgan Kaufmann Publishers.

Nirenburg, S., V. Raskin and A. Tucker (1986) On Knowledge-Based Machine Translation In The Proceedings of 11 th International Conference on Computational linguistics (COLING'86), Bonn, August, 627-638.

Pan American Health Organization (1999) Machine Translation at the Pan American Health Organization SPANAM® and ENGSPAN®, http://www.paho.org/english/ags/mt-home.htm, December. 
Pendergraft, E. D. (1968) Translating Languages In Automated Language Processing, Edited by $\mathrm{H}$. Borko, John Wiley and Sons, Inc. New York.

Penn, G. (1993) hpsg.pl available at "http://www.sfs.nphil.uni-tuebingen.de/ gpenn/ale.html \#AleGrammars" as of January 1996.

Pollard, C. and Sag, I. A. (1987) Information-Based Syntax and Semantics, Lecture Notes No. 13, Stanford, Calif: CSLI Publication.

Pollard, C. and I.A. Sag (1994) Head-Driven Phrase Structure Grammar, Center for the Study of language and Information, Stanford, The university of Chicago Press, Chicago \& London.

Popowich, F. (1996) A Chart Generator for Shake and Bake Machine Translation In The Proceedings of the Ilth Canadian Conference on artificial intelligence, AI'96, May 22-24.

Poznanski, V., J. L. Beaven and P. Whitelock (1995) An Efficient Generation Algorithm for lexicalist MT In Proceedings of the 33rd Annual Meeting of the Association for Computational Linguistics, Boston, MA.

Punmetha, N. (1984) Thai Grammar, 2nd Edition, Rungraungsan Publishers, Bangkok, Thailand. (นววรรณ พันธุเมธา (2527) ไวยากรณ์ไทย. รุ่งเริองสาส์นการพิมพ์. กรุงเทพ. ประเทศไทย)

Randall, R. (1987) The ugly duckling, Ladybird, Loughborough, England.

Rosetta, M. T.(1994) Compositional Translation, Kluwer Academic Publishers.

Russell, S.J. and P. Norvig (1995) Artificial Intelligence: A Modern Approach, Prentice Hall, New Jersey.

Sag, I. A. and T. Wasow. 1999 Syntactic Theory: A Formal Introduction, CSLI Lecture Notes Number 92, Center for the Study of language and Information, Stanford, California.

Sager, N. (1986) Sublanguage: Linguistic Phenomenon, Computational Tool In Analyzing Language in Restricted Domains: Sublanguage Description and Processing Edited by R. Grishman and R. Kittredge. Lawrence Erlbaum Associates Publishers, London. 
Sato, S. and M. Nagao (1990) Toward Memory-based Translation In The Proceedings of The 13th International Conference on Computational Linguistics, COLING-90, Edited by Hans Karlgren, Helsinki, Vol. 3, p. 247- 252.

Schubert, L. K., R. G. Goebel and N. Cercone (1979) The Structure and Organization of a Semantic Net for Comprehension and inference. In Associative Networks: Representation and Use of Knowledge by Computers. Edited by N. V. Findler. Academic Press, New York, p. $121-175$.

Shieber, S. M. (1986) An Introduction to Unification-Based Approachs to Grammar, CSLI Lecture Notes Number 4, Center for the Study of Language and Information CSLI, Leland Stanford Junior University.

Slocum, J. (1988) Machine Translation System, Cambridge University Press, Cambridge.

Somers, H. L. (1990) Current Research in Machine Translation In The Proceedings of The Third International Conference on Theoretical and Methodological Issues in Machine Translation of Natural Language, Linguistics Research Center, University of Texas at Austin.

Sumita, Iida and Kohyama (1990) Translating with Examples: A New Approach to Machine Translation In The Proceedings of The third International Conference on Theoretical and Methodological Issues in machine Translation of Natural language, University of Texas at Austin, 11-13 June.

Systran (1999) Translation software, available at http://www.systransoft.com/, as of December.

The Thai Royal Institute (1995) Classifiers, Kurusapa Ladpao Publishers, Bangkok, Thailand. (ราชบัณทิตยสถาน (1995) ลักษณะนาม ฉบับราชบัณทิตยสถาน, โรงพิมพ์คุรุสภา ลาดพร่าว, กรุงเทพ, ประเทศไทย)

Tomita, M. (1985) Feasibility Study of Personal/Interactive Machine Translation Systems. CMU-CS-85-140. Department of Computer Science, Carnegie-Mellon University.

Trujillo, A. and S. Berry (1996) Connectivity in bag Generation In Proceedings of The 16 th International Conference in Computational Linguistics, COLING'96, Copenhagen, Denmark, p. 101-106. 
Turcato, D. (1998) Automatically Creating Bilingual Lexicons for Machine Translation from Bilingual Text, In The Proceedings of The 36th Annual Meeting of the Association for Computational Linguistics and 17th International Conference on Computational Linguistics COLING-ACL'98, Volume II, Montreal, Quebec, Canada, August 10-14, p. 1299- 1305.

Uchida, H. (1989) ATLAS-II: A Machine Translation System Using Conceptual Structure As An Interlingua. In Proceedings of the Second Machine Translation Summit, Tokyo, Omsha Ltd.

Weaver, W., (1955) Translation In Machine Translation of Languages: Fourteen Essays Edited by W. N. Locke and A. D. Booth, The Technology press of The Massachusetts Institute of Technology and John Wiley \& Sons, Inc., New York.

Weaver, W., (1989) The Process of Translation In The Craft of Translation Edited by J. Biguenet and R. Schulte, The University of Chicago Press, Chicago, p. 117-124.

White, J. S. (1999) MT Evaluation, A Tutorial Description In Machine Translation and the Information Soup

White, J. S., T. A. O'Connell, F. E. O'Mara (1994) Advanced Research Projects Agency Machine Translation Program: 3Q94 Evaluation, The Final Report for the 3Q94 ARPA MT Evaluation, PRC Inc.

Whitelock, P. (1992) Shake-and-Bake Translation In The proceedings of the fifteenth International Conference on Computational Linguistics, COLING-92, Nantes, France, August 23-28, p. 784-79I.

Whitelock, P. and K. Kilby (1995) Linguistic and Computational Techniques in Machine Translation System Design, 2nd Edition, UCL Press Limited, London.

Wielemaker, J. (1999) SWI-Prolog available at http://www.swi.psy.uva.nl/projects/SWIProlog/, August.

Wilks, Y. (1972) An Artificial Intelligence Approach to Machine Translation, Report CS264, Computer Science Department, Stanford University. 
Woszczyna, M. et al., (1995) Recent Advances in JANUS: A Speech Translation System, available at http://www.is.cs.cmu.edu/ monika/papers/html/euro93.janus/, available as of August.

Yngve, V. H. (1955) Syntax and the Problem of Multiple Meaning In Machine Translation of Languages: Fourteen Essays Edited by W. N. Locke and A. D. Booth, The Technology press of The Massachusetts Institute of Technology and John Wiley \& Sons, Inc., New York.

Zajac, R. (1988) Interactive Translation: A New Approach In The Proceedings of The 12th International Conference on Computational Linguistics COLING BUDAPEST, Vol. II, $22-$ 27 August, Budapest, p. 785-790. 


\section{Appendix A}

\section{WordAssociation Hierarchy}

This appendix illustrates the WordAssociation hierarchy, discussed in section 4.2.1. Class and its WordAsso number are shown in the first column. Examples of each are shown in the second column.

\section{A.1 The IS-A Classes}

The semantic relation between classes and their superclasses is represented by is- $a$.

\begin{tabular}{|c|c|}
\hline WordAsso Number and Class & Examples \\
\hline 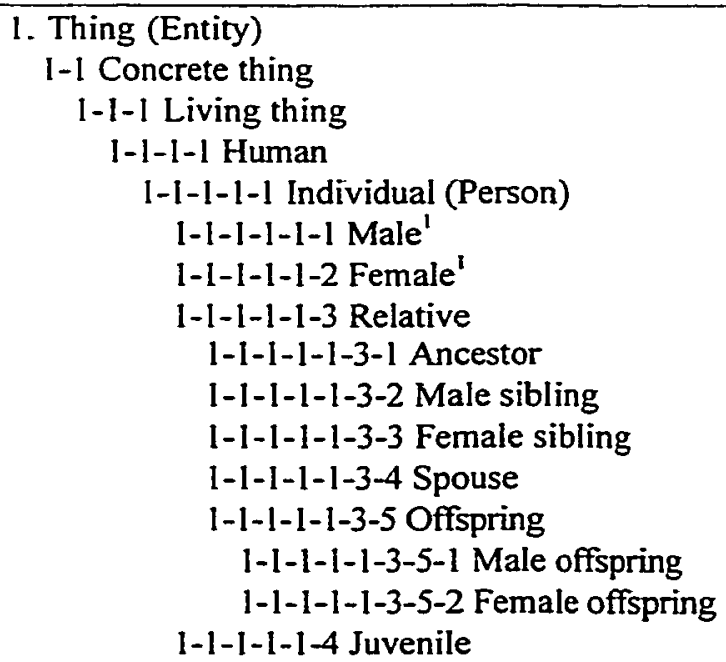 & 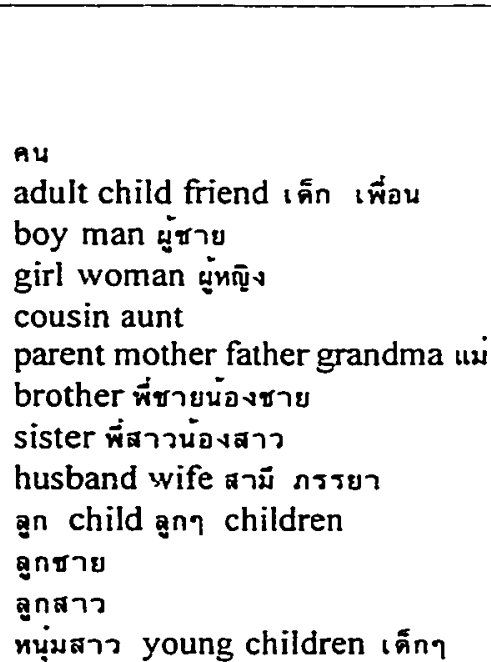 \\
\hline
\end{tabular}

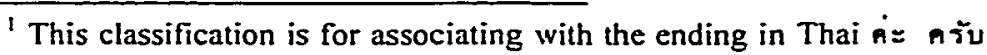




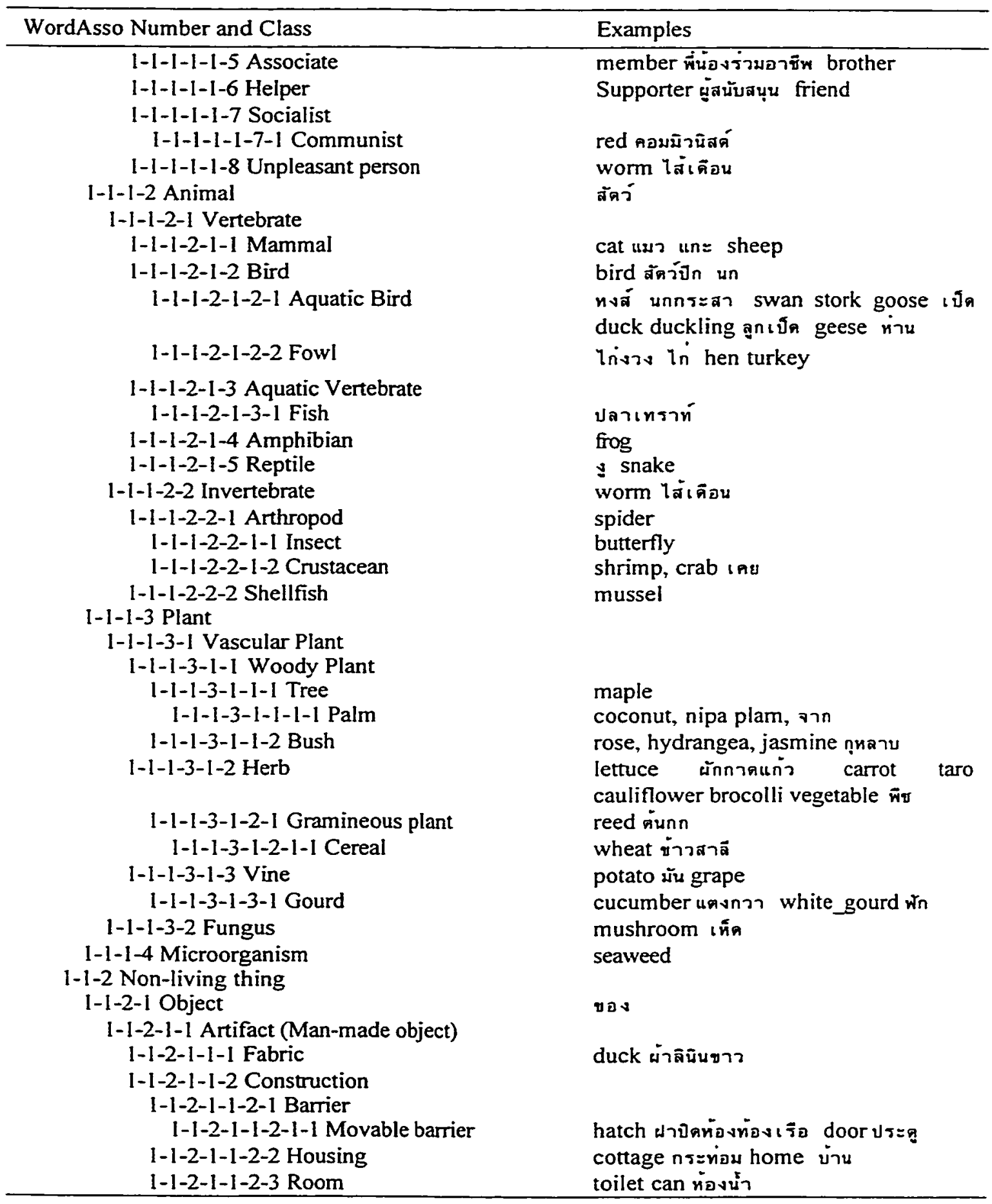




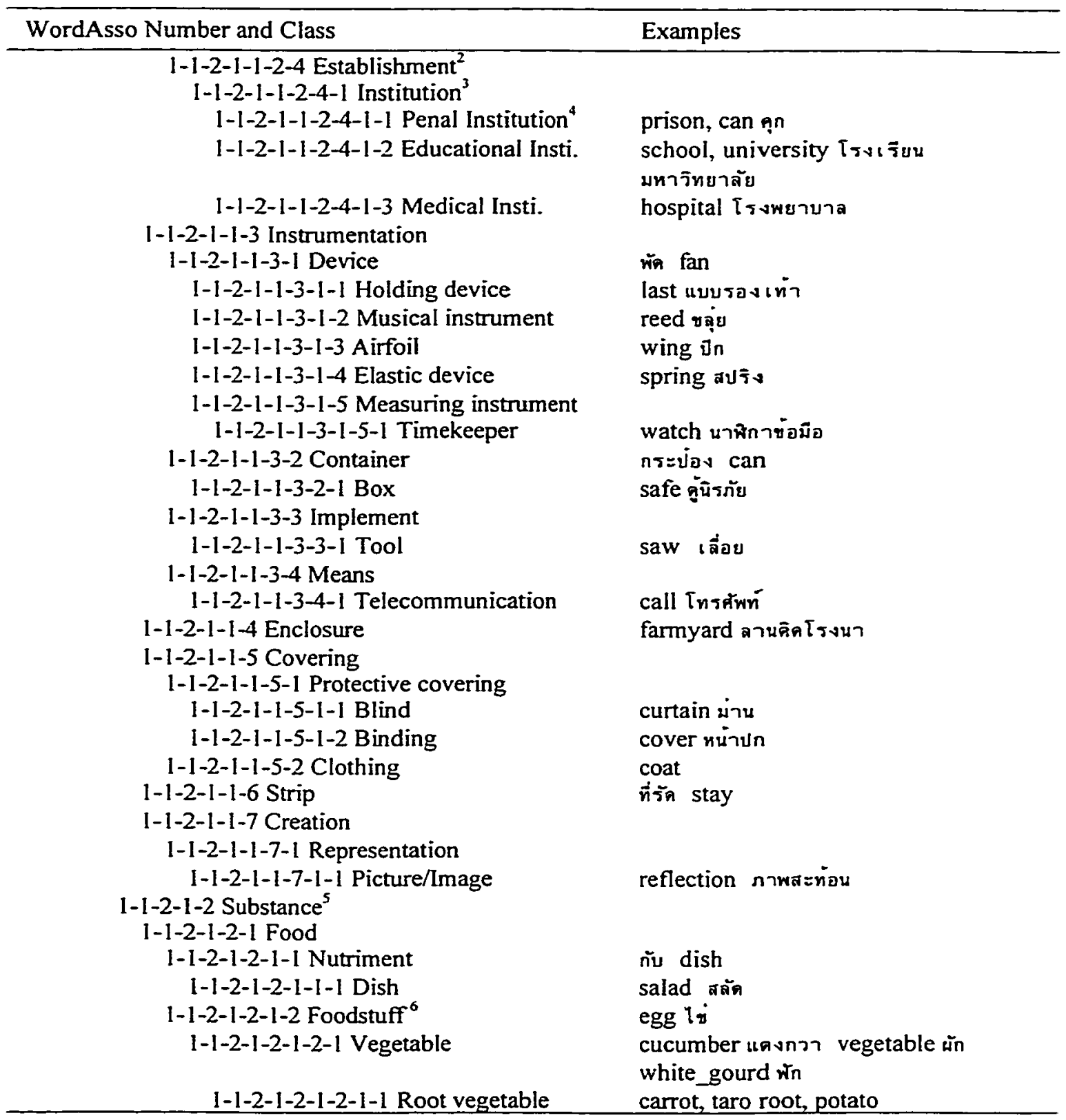

${ }^{2}$ Establishment is a public or private structure (business or government or educational) including buildings and equipment for business or residence.

3 Institution is a building or complex of buildings where an organization for the promotion of some cause is situated.

${ }^{4} \mathrm{Penal}$ Institution is an institution where persons are confined for punishment and to protect the public.

${ }^{s}$ Substance is that which has mass and occupies space.

${ }^{6}$ A substance that can be used or prepared for use as food. 


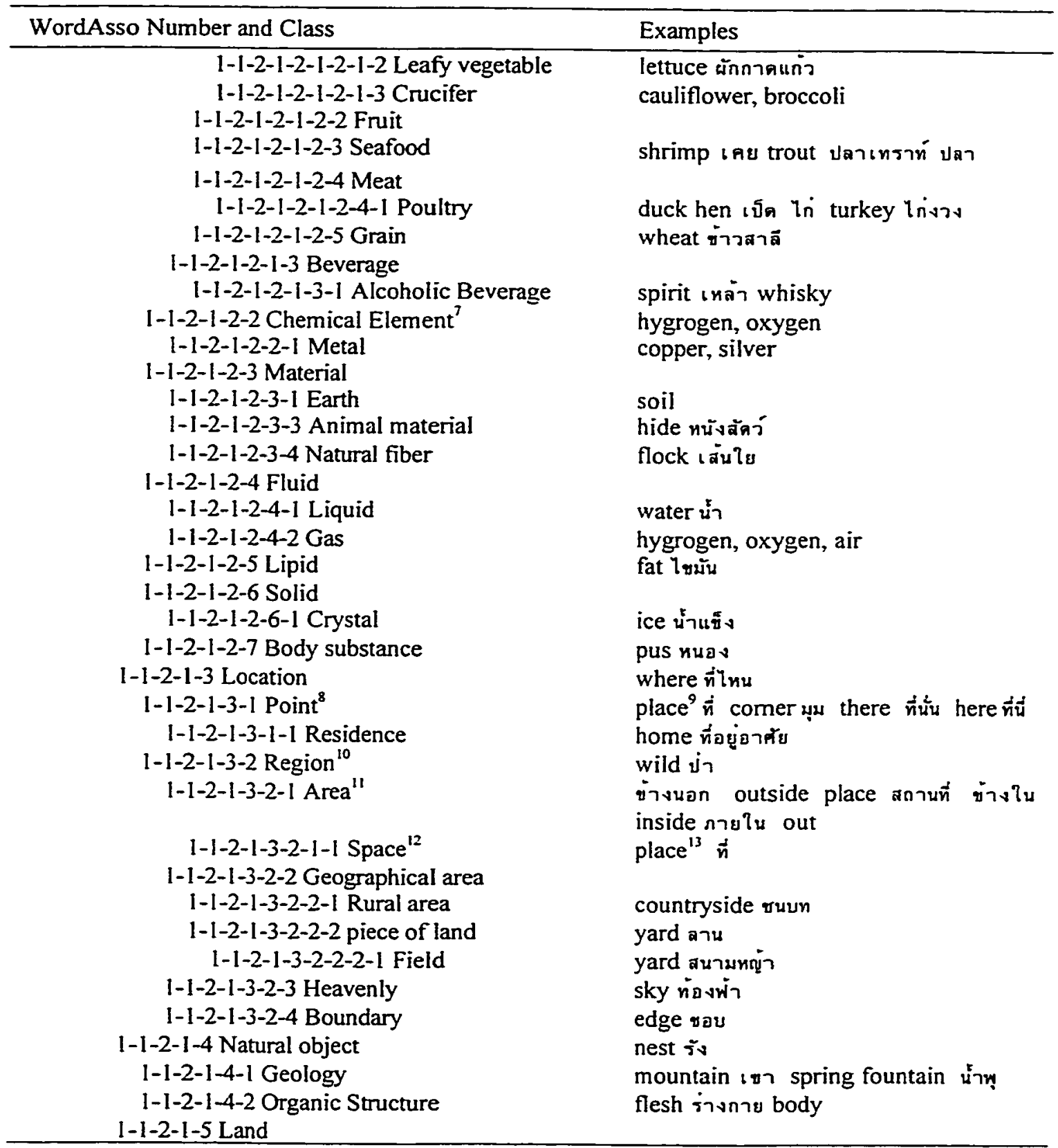

\footnotetext{
${ }^{7}$ Element is any of more than a hundred simple substances that consist of atoms of only one kind and that, alone or in combination, make up all substances.

${ }^{8}$ Point is the precise location of something.

9 Place is a point located with respect to surface features of some region; this place is nice.

${ }^{10}$ Region is a large indefinite location on the surface of the earth.

"Area is a particular geographical region of indefinite boundary.

${ }_{12}$ Space is an area reserved for some particular purpose.

${ }^{13}$ Place is a space reserved for sitting (as in a theater or on a train or airplane).
} 


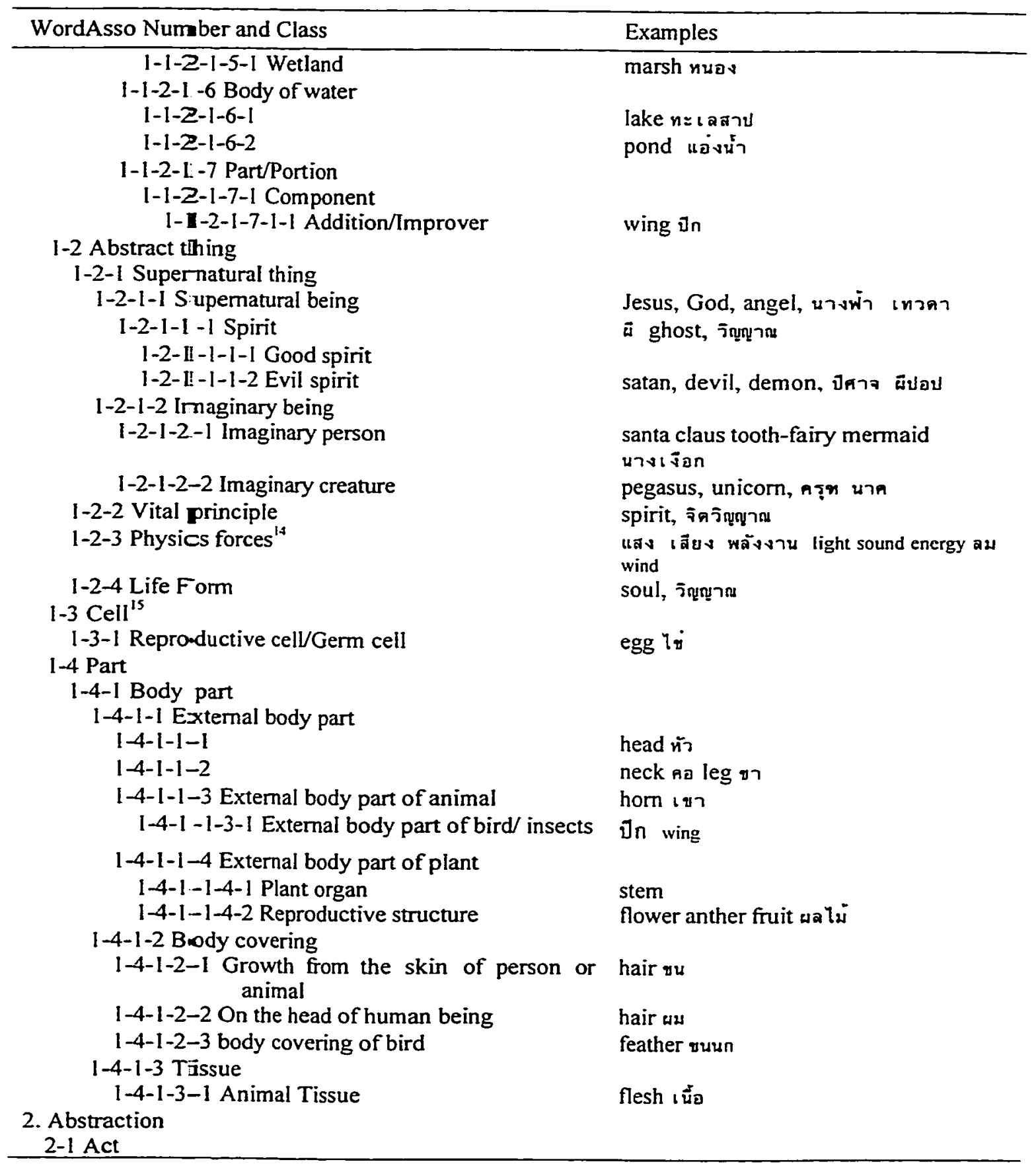

\footnotetext{
${ }^{14}$ Physics is the science concerned with th estudy of matter and natural forces, such as light, heat, movement, etc.

${ }^{15}$ Cell is the basic structural and functional unit of all organisms; A tiny mass of protoplasm that contains a nucleus, is enclosed by a membrane, and forms the fundamental unit of living matter.
} 


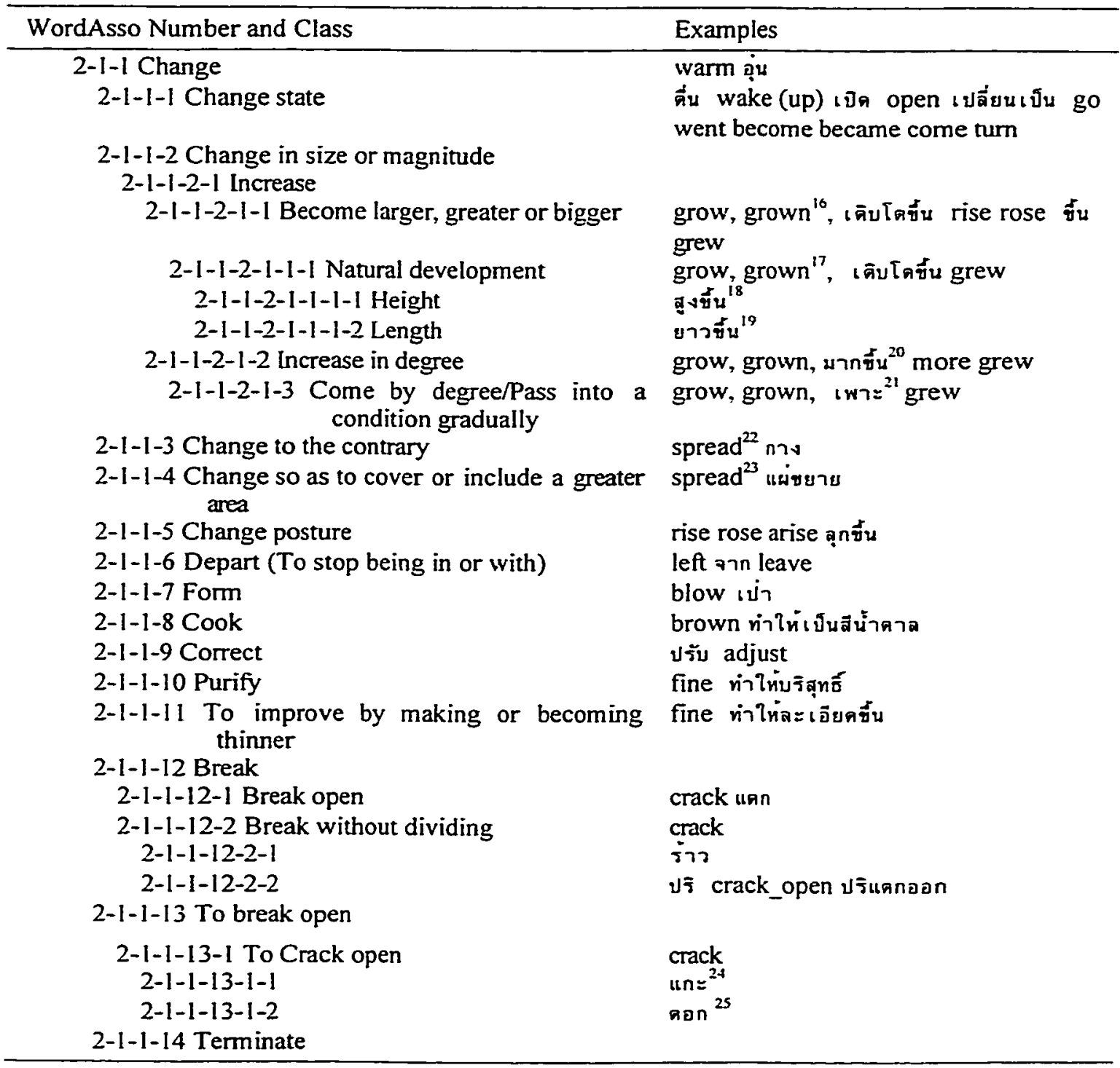

${ }^{16}$ Grow is to increase in amount, size e.g., The company has grown rapidly in the last five years.

17 Grow is to increase in size by natural development e.g., Grass grows after rain.

${ }^{18}$ Grow is to increase in size by natural development e.g., He's grown six inches.

19 Grow is to increase in size by natural development e.g., She doesn't like her hair short, so she's letting it grow.

${ }^{20}$ Grow is to increase in degree e.g. A growing number of people are taking part-time jobs.

${ }^{21}$ Grow is to come by degree or to pass into a condition gradually, e.g., He grew more and more sad.

22 Spread is to cause to open, stretch out, e.g., Spread the map out. directions.

${ }^{23}$ Spread is to stretch out so as to cover or include a greater area, e.g., The city has spread out rapidly in all

${ }^{24}$ แn=, to break open (break off with the fingers and thumb), e.g., To crack nuts.

is ตอ , to break open, e.g., I cracked two eggs. 


\begin{tabular}{|c|c|}
\hline WordAsso Number and Class & Examples \\
\hline \multicolumn{2}{|l|}{ 2-1-1-14-I Interrupt } \\
\hline \multicolumn{2}{|l|}{$2-1-1-15$ Improve } \\
\hline 2-1-1-15-1 Educate & school สอน \\
\hline $2-1-1-15-2$ Refine & school อบรม \\
\hline \multicolumn{2}{|l|}{$2-1-1-16 \mathrm{Be}$ born 6} \\
\hline $2-1-1-16-1$ & be born เก๊ด \\
\hline $2-1-1-16-2$ & hatch $^{27}$ ฟก \\
\hline $2-1-1-17$ Cause to be/cause to do something & make $^{2 s}$ ทำให \\
\hline \multicolumn{2}{|l|}{$2-1-1-18$ change integrity } \\
\hline 2-1-1-18-1 Break up & melt หลอม \\
\hline 2-1-1-18-2 Liquify & melt ละลาย \\
\hline 2-1-2 Come to pass & happen, occur, be $e^{29}$ เกิดขึ้น on \\
\hline \multicolumn{2}{|l|}{ 2-1-3 Interact } \\
\hline 2-1-3-1 Communicate & ask ถาม talk คุย \\
\hline $2-1-3-1-1$ Utter & 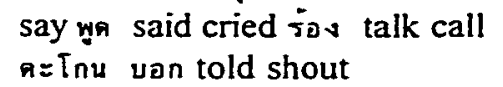 \\
\hline 2-1-3-1-2 Express emotion/feeling & cry ร่องไห้ cried laugh หัวเราะ \\
\hline 2-1-3-1-3 Ask/Order & call เรียก \\
\hline 2-1-3-1-3-1 Request & ask ขอร์อง \\
\hline $\begin{array}{l}\text { 2-1-3-1-3-2 Order } \\
2-1-3-1-4 \text { Demand }\end{array}$ & ask ด่องการ want $^{30}$ \\
\hline \multicolumn{2}{|l|}{$2-1-3-1-5$ Inform } \\
\hline $2-1-3-1-5-1$ Teach & lecture talk บรรยาย \\
\hline $2-1-3-1-5-2$ Let something be known & told บอก \\
\hline $2-1-3-1-5-3$ Narrate/Give a detailed account of & told เล่า \\
\hline 2-1-3-1-6 Telecommunicate & call โทรศัพท์ \\
\hline 2-1-3-1-7 Declare & call ประกาศ \\
\hline $\begin{array}{l}2-1-3-2 \text { Treat/Interact in the certain way } \\
2-1-3-2-1 \text { Mock }\end{array}$ & $\begin{array}{l}\text { make fun of เยาะเย่ laughed at } \\
\text { หัวเราะเยาะ }\end{array}$ \\
\hline \multicolumn{2}{|l|}{ 2-1-3-3 Transfer } \\
\hline 2-1-3-3-1 Give & give ให้ \\
\hline \multicolumn{2}{|l|}{ 2-1-3-3-2 Exchange } \\
\hline $2-1-3-3-2-1$ & let ให่เช่า rent \\
\hline $2-1-3-3-2-2$ & give $^{31}$ pay จำย rent เช่า \\
\hline \multicolumn{2}{|l|}{ 2-1-3-3-3 Payment } \\
\hline 2-1-3-3-3-1 Penalty & fine ค่าปรับ \\
\hline 2-1-3-3-3-2 Regular payment & ค่าเช่า rent \\
\hline $2-1-3-4$ Charge & \\
\hline 2-1-3-4-1 Impose & fine ปรับ \\
\hline
\end{tabular}

\footnotetext{
${ }^{26} \mathrm{Be}$ born is to come into existance through birth.

27 Hatch is (of an egg) to break, letting the young bird out.

${ }^{28}$ Make is to put into a certain state, position., e.g., Eating the unripe apples made him ill.

29 Be e.g., Ex: I lost my wallet, this was during the visit to my parents' house.

${ }^{30} \mathrm{~W}$ ant is to wish or demand the presence of e.g.. I want you here at noon.

31 Give, e.g., I can't believe you gave $\$ 3000$ for that broken-down old car.
} 


\begin{tabular}{|c|c|}
\hline WordAsso Number and Class & Examples \\
\hline $2-1-3-5$ Collect in one place & gather จับกลุ่ม \\
\hline $2-1-4$ Support & \\
\hline 2-1-4-1 Take care & mother เลี้ยงดู รดน์ำ water \\
\hline 2-1-5 Move & \\
\hline $2-1-5-1$ Move so as to change position & $\begin{array}{l}\text { walk เดิน went ไป go wander } \\
\text { เดินไป่ดินมา wing บิน fly เดินแถว } \\
\text { march tum เลี้ยว flew }\end{array}$ \\
\hline $2-1-5-2$ Move so as of a body part & duck กัม ทัน turn \\
\hline 2-1-5-2-1 Move round a central or fixed point & turn หมุı ${ }^{32}$ \\
\hline $\begin{array}{l}\text { 2-1-5-2-2 Move so that a different side faces } \\
\text { upwards or outwards }\end{array}$ & turn พล்ก \\
\hline $2-1-5-3$ Move to change a residence, affiliation & move ย่าย \\
\hline 2-1-5-4 Move thing & ขน carry \\
\hline 2-1-5-4-1 Move thing with force & poke ทิ่ม duck จับกดลง \\
\hline $\begin{array}{l}\text { 2-1-5-4-2 Move thing from one place to another } \\
\text { /Transport/carry }\end{array}$ & \\
\hline 2-I-5-4-2-1 Move a moving thing & พา $^{33}$ take bring took \\
\hline 2-1-5-4-2-2 Move a non-moving thing & take $^{34}$ เอา took \\
\hline 2-1-5-5 Move forward slowly, as if by inches & edge เขบิบ \\
\hline $2-1-5-5-1$ Move forward as if by jumping & spring $ก ร=โ ด ด$ \\
\hline 2-1-5-6 Move toward something & come มา come_over_to ตรงมาที่ \\
\hline 2-1-5-7 Move upward & ข้น rise ซี้นสู่ rose_into \\
\hline 2-1-5-8 Move downward & \\
\hline 2-1-5-8-1 Submerge & dive คำ \\
\hline $2-1-5-9$ Move very fast & jิ $\operatorname{ran} \ldots$ \\
\hline $2-1-5-10$ Follow & ran after ไล่ตาม ดาม \\
\hline $2-1-5-1$ I Put in the certain place & place วาง \\
\hline 2-1-5-12 Drift & blow ปลิว \\
\hline $2-1-5-13$ Go across or through & through ผ่าน \\
\hline $2-1-5-14$ Cause to move in a circular movement & wind หมุน \\
\hline $\begin{array}{l}\text { 2-1-5-15 Move to (cause to) have influence or effect } \\
\text { over a wider area }\end{array}$ & spread กระจาย \\
\hline 2-1-5-15-1 Diseases & แพร่ \\
\hline 2-1-5-15-2 Fire & ลาม \\
\hline $2-1-5-16$ Stir & คน \\
\hline 2-1-6 Displace & chase ไล่ ดำ transplant \\
\hline 2-1-6-1 Separate & \\
\hline $2-1-6-1-1$ Cut & saw เลื่อย \\
\hline 2-1-6-1-2 Pull violently & rent ที้ง rend \\
\hline $2-1-6-1-3$ Tear & rent ān rend \\
\hline 2-1-7 Prod & egg กระตุ่น \\
\hline 2-1-8 Make/Create & make $^{35}$ ทำ \\
\hline
\end{tabular}

\footnotetext{
${ }^{32}$ Turn is to move around an axis or a center, e.g., The wheels are tuming.

${ }^{33}$ Take, e.g., We usually take the children to school in the car.

${ }^{34}$ Take, e.g., Don't forget to take your bag when you go.

${ }^{35}$ Make is to produce something, e.g., She made a cake.
} 


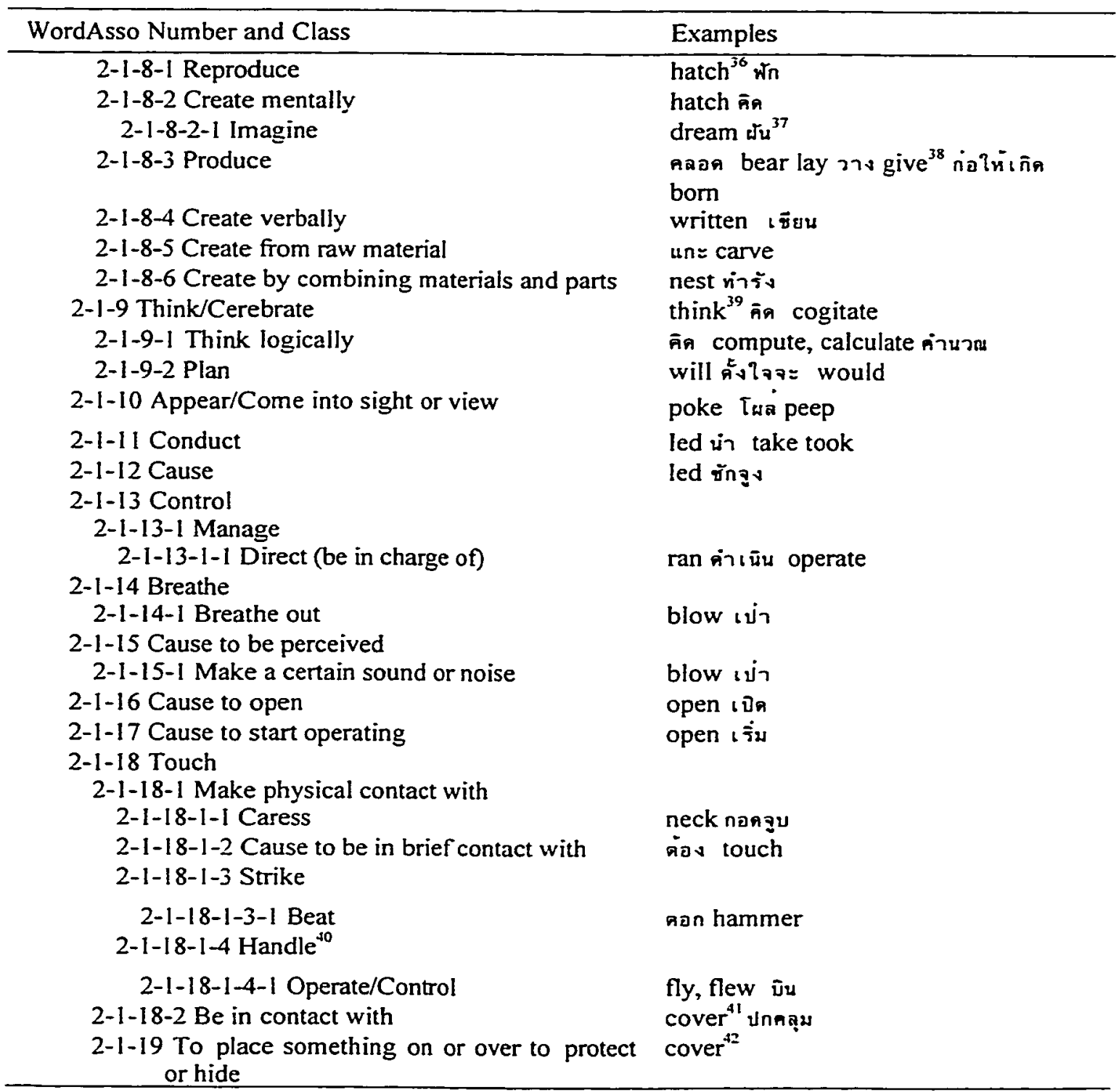

\footnotetext{
${ }^{36}$ Hatch is to (sit) on eggs.

${ }_{38}^{37}$ Dream is to imagine something, e.g., I never said that!You must have been dreaming; have a daydream.

${ }^{38}$ Give, e.g., I hope my son didn't give you any trouble.

39 Think is to use the power of reason: make judgments or careful considerations; use the mind to form ideas and opinion, e.g., She thought long and hard before coming to the decision.

to Handle is to touch. lift or hold with hands.

${ }^{41}$ Cover is to be or lie on or over the surface of something; spread over something e.g., The furniture was covered with dust.

${ }^{42}$ Cover is to place something upon or over something in order to protect or hide it, e.g., The noise was so loud that she covered her ears with her hands.
} 


\begin{tabular}{|c|c|}
\hline WordAsso Number and Class & Examples \\
\hline $2-1-19-1$ Cover as to cover eyes, ears & จดด \\
\hline 2-1-19-2 Envelop & คลุม ${ }^{94}$ \\
\hline $\begin{array}{l}2-1-20 \text { To provide with a covering or caused to be } \\
\text { covered }\end{array}$ & spread ทา \\
\hline $2-1-21$ Close & close ปด \\
\hline $2-1-22$ Inactive & rest w̄n \\
\hline 2-1-23 Attempt & tried try พยายาม \\
\hline 2-1-24 Consume & have has had \\
\hline 2-1-24-1 Take in liquids & drink ติ่ม \\
\hline 2-1-24-2 Take in solid food & eat $\bar{n} น$ \\
\hline $2-1-24-3$ Inhale/exhale smoke from cigarettes & smoke สูบ \\
\hline $2-1-25$ Watch & watch เผ่าด \\
\hline 2-2 Activity & use การใชั \\
\hline 2-2-1 Human activity & \\
\hline 2-2-1-1 Movement & chase การตามล่า \\
\hline 2-2-1-1-1 Stoke/A single complete movement & poke การกระทุ่ง \\
\hline $2-2-1-1-2$ Walking & march การสวนสนาม \\
\hline $2-2-1-1-3$ Group action & \\
\hline 2-2-1-1-3-1 Group procession & march การเดินขบวน \\
\hline 2-2-1-1-3-2 Business & fishing การประมง \\
\hline 2-2-1-1-4 Play & let การเสริฟ์ลูกระเน็ต \\
\hline $2-2-1-2$ Stay & stay การพักอยู่ \\
\hline 2-2-1-3 Recreation & \\
\hline $\begin{array}{l}2-2-1-3-1 \text { Sport } \\
2-2-1-4 \text { Work }\end{array}$ & fishing ตกปลา \\
\hline 2-2-1-4-1 Investigation & research งานวิจัย \\
\hline 2-2-1-5 Keeping something secret & hiding การช่อน \\
\hline 2-2-2 Sensory activity & \\
\hline 2-2-2-1 Looking & look การมอง การแอบมอง peep \\
\hline 2-2-3 Action & \\
\hline 2-2-3-1 Arrival/Reaching & coming การมาถึง \\
\hline 2-2-3-2 Departure & leave การลาจาก \\
\hline 2-2-3-3 Rescue & release การปล่อย \\
\hline 2-3 Attribute & $\begin{array}{l}\text { name ชื่อ age, appearance ability, trait, } \\
\text { kind, sort ชนิด ประเภn }\end{array}$ \\
\hline 2-3-1 Property of living thing & $\begin{array}{l}\text { sex, kindness, weight, healthy, } \\
\text { aliveness }\end{array}$ \\
\hline $\begin{array}{l}2-3-1-1 \text { Property of Human } \\
2-3-1-2 \text { Property of Animal }\end{array}$ & $\begin{array}{l}\text { occupation, position, title } \\
\text { function }\end{array}$ \\
\hline 2-3-2 Property of non-living thing & shape \\
\hline $2-3-2-1$ of food/thing & greasy \\
\hline 2-3-3 Property of temperature & degree \\
\hline 2-3-4 Property of emotion & happiness \\
\hline
\end{tabular}

\footnotetext{
${ }^{43}$ Dn e.g.. covered her ears.. covered her eyes.

44 mags e.g., covered the body.
} 


\begin{tabular}{|c|c|}
\hline WordAsso Number and Class & Examples \\
\hline $2-3-5$ Property of vision (Visual property) & $\begin{array}{l}\text { dark มีด light, lightness, brightness, } \\
\text { ความสว่าง สี color }\end{array}$ \\
\hline \multicolumn{2}{|l|}{$\begin{array}{l}\text { 2-3-6 Property of movement } \\
\text { 2-3-6-1 Come forth }\end{array}$} \\
\hline 2-3-6-1 Come forth & out ${ }^{45}$ ออกมา \\
\hline 2-3-6-2 Go forth & out $^{46}$ aอnไป off \\
\hline 2-3-6-3 Away from the open air/outside & in 47 เข่าไป \\
\hline $2-3-6-4$ To or toward the inside & in $^{48}$ เข้ามา \\
\hline 2-3-7 Property of quality & importance ความสำคัญ \\
\hline \multicolumn{2}{|l|}{ 2-3-8 Away from a surface or edge } \\
\hline $2-3-8-1$ away from a surface or edge & out ออกจาก \\
\hline $\begin{array}{l}\text { 2-3-9 Property of space } \\
\text { 2-3-10 The inner part of a solid object or the faces } \\
\text { away from the open air } \\
\text { 2-3-11 Form/Shape }\end{array}$ & $\begin{array}{l}\text { distance position } \\
\text { ด่านใน }^{49} \text { inside outside ค่านนอก }\end{array}$ \\
\hline 2-3-11-1 Amorphous shape & รอยร่าว crack rent รอยขาด \\
\hline $2-3-12$ Time & timing \\
\hline \multicolumn{2}{|l|}{ 2-4 Measure/Quantity } \\
\hline 2-4-1 Number & one, 1 , หนึ่ง five ห่า \\
\hline \multicolumn{2}{|l|}{ 2-4-2 Classifier } \\
\hline \multicolumn{2}{|l|}{$\begin{array}{l}2-4-2-1 \text { Classifier of object } \\
2-4-2-1-1 \text { Classifier of living thing }\end{array}$} \\
\hline $2-4-2-1-1$ Classifier of living thing & \\
\hline $2-4-2-1-1-1$ Classifier of person & คน \\
\hline $2-4-2-1-1-2$ Classifier of animal & ตัว \\
\hline 2-4-2-1-1-3 Classifier of plant & ตัน \\
\hline \multicolumn{2}{|l|}{$2-4-2-1-2$ Classifier of non-living thing } \\
\hline 2-4-2-I-2-I Classifier of tool & อัน \\
\hline $2-4-2-1-2-2$ Classifier of room & หอง \\
\hline $2-4-2-1-2-3$ Classifier of external body part & ขา หัว มือ \\
\hline $2-4-2-1-2-4$ Classifier of wing & In \\
\hline $2-4-2-1-2-5$ Classifier of root vegie, crucifer & ทัว \\
\hline $2-4-2-1-2-6$ Classifier of place & $\dot{\bar{n}}$ \\
\hline $2-4-2-1-2-7$ Classifier of marsh & แอ่ง \\
\hline $2-4-2-1-2-8$ Classifier of place, lake & แห่ง \\
\hline $2-4-2-1-2-9$ Classifier of marsh & หนอง \\
\hline $2-4-2-1-2-10$ Classifier of housing & หลัง \\
\hline $2-4-2-1-2-11$ Classifier of door & ประดู \\
\hline $2-4-2-2$ Classifier for pairs of anything & i \\
\hline 2-4-2-2 Classifier of collection & ชนิด ประเภท \\
\hline
\end{tabular}

\footnotetext{
is Out is away from the inside e.g., "Open the bag and take the money out", "Blood poured out from the wound ${ }^{r}$.

${ }^{46}$ Out is away from the inside e.g.. "She opened the cage and let the bird out".

${ }^{47}$ In is away from the outside e.g." "Open the box and put the money in".

${ }^{48}$ In is to or toward the inside e.g." "There was a loud explosion and the walls fell in".

49 Inside. e.g.. He reached into his inside jacket pocket.
} 


\begin{tabular}{|c|c|}
\hline WordAsso Number and Class & Examples \\
\hline 2-4-2-2-1 Classifier of human & กลุ่ม \\
\hline 2-4-2-2-2 Classifier of animal & d \\
\hline $2-4-2-3$ Classifier of time & day วัน hour ขั่วโมง \\
\hline $2-4-2-4$ Classifier of measurement & yard หลา \\
\hline 2-4-2-5 Classifier of frequency & ที ครั้ง \\
\hline 2-4-2-6 Classifier of action & \\
\hline \multicolumn{2}{|l|}{ 2-4-3 Time } \\
\hline \multicolumn{2}{|l|}{ 2-4-3-I Time period } \\
\hline $2-4-3-1-1$ & $\begin{array}{l}\text { สุดสัปดาห์ weekend ตอนเช้า แต่เช่า } \\
\text { เช่า morning กลางวัน เวลาเย็น } \\
\text { กลางตีน evening ในตอนน้น then }\end{array}$ \\
\hline $2-4-3-1-2$ & decade ทศวรรу hour month day วัน \\
\hline 2-4-3-2 Season & winter ๆดูหนาว ทดูใบไม่แลี spring \\
\hline 2-4-3-3 Calendar month & march เดือนมีนาคม \\
\hline 2-4-3-4 Time off & leave การลาหยุด \\
\hline 2-4-4 Clock time & midnight, noon, 2:00 am. เที่ยงคิน \\
\hline 2-4-5 Indefinite quantity & $\begin{array}{l}\text { very มากๆ นอย little great มาก many } \\
\text { มากทุ่สุ most handsome มากมาย more }\end{array}$ \\
\hline $\begin{array}{l}\text { 2-4-5-1 Indefinite number more than } 2 \text { or } 3 \text { but } \\
\text { not many (normally followed by cIf.) }\end{array}$ & หลาย ส่วนใหญู most several \\
\hline 2-4-6 Definite quantity & all ทั้งหมด \\
\hline $\begin{array}{l}2-4-6-1 \text { The complete amount of something } \\
\text { including all its component elements or parts. }\end{array}$ & ตลอด ${ }^{50}$ all, whole \\
\hline 2-4-7 Degree of truth & จรังา \\
\hline $2-4-8$ To such a (great) degree & So อยำงนั้น \\
\hline 2-4-9 Linear unit & yard หลา \\
\hline $\begin{array}{l}\text { 2-5 Psychological feature (a feature of the mental life of } \\
\text { a living organism) } \\
2-5-1 \text { Cognition }\end{array}$ & ความรู้สีก feeling \\
\hline $2-5-1-1$ Intention & will ความด้งใจ spirit \\
\hline 2-5-1-2 Imaginary & dream ความะน \\
\hline 2-5-1-3 Representational process & symbol สัญญลลกษณ์ \\
\hline 2-5-1-4 Problem solving & research การวิจ \\
\hline 2-5-1-5 Ability & $\operatorname{mind}^{51}$ สติปญญา \\
\hline 2-5-1-6 Content & matter เ รื่อง \\
\hline \multicolumn{2}{|l|}{ 2-5-1-6-1 Concept } \\
\hline 2-5-1-6-1-1 Category & make ยิ่ทอ \\
\hline \multicolumn{2}{|l|}{ 2-5-1-7 Learning } \\
\hline 2-5-1-7-1 Education & school การศึกษา \\
\hline \multicolumn{2}{|l|}{ 2-5-2 Motivation } \\
\hline 2-5-3-1 Desire & want ความด้องการ \\
\hline 2-5-3-2 Emotion & anger กวามโกระ \\
\hline
\end{tabular}

\footnotetext{
so All, e.g., We walked all the way.

st Mind is the ability to think and reason: intellect. e.g.. He has a very sharp mind.
} 


\begin{tabular}{|c|c|}
\hline WordAsso Number and Class & Examples \\
\hline 2-5-4 Remember & think ${ }^{52}$ นีก recall \\
\hline 2-5-5 Confidence & sure แน่ใจ \\
\hline 2-5-6 Mind & ใจ $\operatorname{mind}^{53}$ \\
\hline $2-5-6-1$ & spirit \\
\hline $2-5-6-2$ & spirit \\
\hline 2-6 Perceive (to become aware of through the senses) & 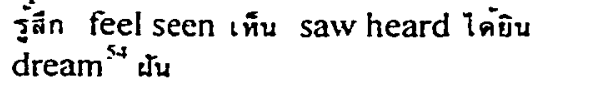 \\
\hline 2-6-1 Look & look มอง แอบมอง peep \\
\hline 2-6-1-1 Look attentively & $\begin{array}{l}\text { looked_around มองไปรอบๆ } \\
\text { watch เผ่าด }\end{array}$ \\
\hline $2-6-2$ Feel & \\
\hline 2-6-2-1 Unsatisfy & anger โnรo \\
\hline 2-6-2-2 Satisfy & pleased พอใจ happy $\$ 5$ \\
\hline 2-6-2-3 Pleased & pleased ยินดี \\
\hline 2-6-2-4 Like & like ชอบ love รัก \\
\hline 2-6-2-5 Separated & lonely อำงว่าง เหงา \\
\hline $\begin{array}{l}\text { 2-6-2-6 Dislike } \\
\text { 2-6-2-7 Reject/Disapprove }\end{array}$ & $\begin{array}{l}\text { hate } \\
\text { mind รังเกียจ }\end{array}$ \\
\hline 2-6-2-8 Desire & want ต้องการ กระหาย hungry \\
\hline 2-7 Continue to exist & last persist ยาวนาน \\
\hline 2-8 Remain in good condition & last คงทน \\
\hline $2-9$ Judge $^{57}$ & \\
\hline 2-9-1 Think & think ${ }^{\text {s8 }}$ คิด believe, consider \\
\hline 2-9-2 Expect $^{59}$ & think นีกว่า must คงจะ เชื่อว่า believe \\
\hline 2-9-3 Test/Prove ${ }^{60}$ & test prove tried nตaอง try \\
\hline $2-9-4$ Accept $^{61}$ & เชื่อ believe \\
\hline $2-10$ Keep & \\
\hline $\begin{array}{l}2-10-1 \text { To put or keep out of sight } \\
2-10-2 \text { To keep from being known }\end{array}$ & hid ซ่อน hidden hide hiding \\
\hline $\begin{array}{l}\text { 2-10-2 To keep from being known } \\
\text { 2-1 I Confine/Deprive of freedom }\end{array}$ & $\begin{array}{l}\text { hide hid hidden จดบัง hiding } \\
\text { corner จนมม }\end{array}$ \\
\hline 2-12 Decide/Come to decision about something & decide ตัดลินใจ ตกลงใจ \\
\hline 2-13 Leave & left จากไป leave \\
\hline 2-13-1 Escape & run away, หนีจากไป \\
\hline 2-14 Leave behind & left $\overline{\hat{n}}$, leave \\
\hline 2-15 Social relation & \\
\hline
\end{tabular}

\footnotetext{
52 Think is to recall knowledge from memory, e.g., I can't think what her last name was.

${ }^{53}$ Mind is a person's (way of) thinking or feeling; thoughts, e.g., She looks very worried, I wonder what is on her mind.

${ }_{54}$ Dream, experience while sleeping, e.g., What did you dream about?

${ }^{55}$ Happy, feeling that something is right or good, satisfied, e.g.. The government won't be very happy about the latest unemployment statistics.

$\$ 6$ Desire is to feel or have a desire for: want strongly e.g. I want to go home now.

57 Judge is to form an opinion of or pass judgement on.

58 Think is to believe, consider; have an opinion e.g., $I$ think he is very smart.

${ }^{59}$ Expect is to regard something as probable or likely, e.g.. 1 didn't think to find her in the kitchen.

${ }^{60}$ Test/Prove is to put to the test or give experiment.

${ }^{61}$ Accept is to consider or hold as true. accept as true, e.g. I believed his report.
} 


\begin{tabular}{|c|c|}
\hline WordAsso Number and Class & Examples \\
\hline \multicolumn{2}{|l|}{ 2-15-1 Communication } \\
\hline 2-15-1-1 Written material & will พินัยกรรม \\
\hline $\begin{array}{l}\text { 2-15-1-2 Content } \\
\text { 2-15-1-2-1 Significant }\end{array}$ & point, there, ครงน้น \\
\hline \multicolumn{2}{|l|}{ 2-15-1-3 Language } \\
\hline 2-15-1-3-1 Natural language & Egyptian ภาษาอียิปต์ \\
\hline 2-15-1-4 Signal & symbol เคริ่องหมาย \\
\hline $2-15-1-4-1$ Visual signal & traffic lights, สัญญญานไฟจราจร \\
\hline $\begin{array}{l}\text { 2-15-1-4-2 Written symbol } \\
\text { 2-15-1-5 Visual communication }\end{array}$ & font \\
\hline 2-15-1-5-1 Facial gesture & laugh การหัวเราะ การยิ้ม smile \\
\hline \multicolumn{2}{|l|}{ 2-15-1-6 Auditory communication } \\
\hline 2-16 To discover by chance or experience & find หาให้พ \\
\hline 2-17 Encounter & meet wy \\
\hline 2-18 Search $^{62}$ & มองหา look for \\
\hline 2-19 Examine E3 $^{2}$ & ดู look \\
\hline 2-20 Blow & blow พัด \\
\hline \multicolumn{2}{|l|}{ 2-21 Relation } \\
\hline 2-21-1 Part & rest ส่วนที่เหลือ \\
\hline 2-21-2 Isolated & alone, all by yourself โดยลำพัง \\
\hline 2-21-3 Spatial relation & room ที่ว่าง \\
\hline 2-22 Stop & stop หยุด stopped \\
\hline 2-23 Not stopping/Continuously & $\mathrm{on}^{65}$ ต่อเนื่อง ไม่หยุด $\mathrm{all}^{66}$ คลอด \\
\hline \multicolumn{2}{|l|}{ 2-24 Remove } \\
\hline $2-24-1$ & throw off, shake off สลัด \\
\hline $2-24-2$ & spirit \\
\hline $\begin{array}{l}\text { 2-25 Treat/Provide treatment for } \\
2-25-1 \text { Operate }\end{array}$ & \\
\hline $2-25-1-1$ Sterilize & ตอน castrate \\
\hline 2-26 Cause to grow or develop & grow grown grew \\
\hline 2-26-1 Plant/Crops & ปลูก \\
\hline 2-26-2 Hair/Beard & $7 i^{2}$ \\
\hline 2-27 Let go/Set free & release ปล่อย \\
\hline $2-27-1$ To press so as to allow something to move & release ปลด ${ }^{67}$ \\
\hline 2-28 Utilize & use ใชี \\
\hline $\begin{array}{l}\text { 2-29 Be familiar or acquainted with a person or an } \\
\text { object, place }\end{array}$ & know รูจัก \\
\hline 2-30 Know how to do or perform something & know \\
\hline
\end{tabular}

\footnotetext{
${ }^{62}$ Search is to try to find, try to locate or discover, e.g., looking for a lost book/ a new job.

${ }^{63}$ Examine is to observe carefully or inspect; to use the eyes in order to find something. e.g.. You could see it if you'd only look.

${ }^{64}$ Blow is to be blowing or storming e.g., "The wind blew from the west".

${ }^{65} \mathrm{On}$, e.g., We worked on (and on) all night.

${ }^{66}$ All, e.g., He worked hard all last year.

${ }^{67}$ Release a button. a handle. etc. that can be pressed tp allow part of machine to move.
} 


\begin{tabular}{|c|c|}
\hline WordAsso Number and Class & Examples \\
\hline $\begin{array}{l}\text { 2-31 To have knowledge of something; have } \\
\text { infomation in the mind } \\
\text { 2-32 Study }\end{array}$ & know \\
\hline $2-32-1$ Investigate & research วิจัย \\
\hline \multicolumn{2}{|l|}{ 2-33 Designate } \\
\hline 2-33-1 Label & call เรียกว่า ด้งข่อ name \\
\hline 2-34 Do/Perform ${ }^{68}$ & do ทำ make $\mathrm{e}^{69}$ \\
\hline 2-35 Wait & wait_for so \\
\hline $2-36$ Begin & begin, start. เริม began \\
\hline 2-37 Arrive/reach a destination & come มาถึง \\
\hline 2-38 Pay attention to & mind สนใจ \\
\hline \multicolumn{2}{|l|}{ 2-39 Let/allow } \\
\hline 2-39-I Give permission & let อนุญาติ \\
\hline $\begin{array}{l}\text { 2-39-2 Make it possible through lack of action for } \\
\text { something to happen }\end{array}$ & let ปล่อยให้ \\
\hline 2-40 Join/Get together & joined_in เข้ารวม \\
\hline 2-41 have ownership/possession of & own เป็นเจำของ \\
\hline 3 Phenomenon ${ }^{70}$ & luck โชค fortune \\
\hline \multicolumn{2}{|l|}{ 3-1 Natural Phenomenon } \\
\hline 3-1-1 Physical phenomenon & lightning, reflection การสะท่อน \\
\hline $\begin{array}{l}\text { 3-1-2 Geological phenomenon } \\
\text { 3-2 Chemical phenomenon }\end{array}$ & $\begin{array}{l}\text { flood } \\
\text { fire }\end{array}$ \\
\hline 4 Event $^{71}$ & fire, ไฟไหม่, accident \\
\hline \multicolumn{2}{|l|}{$\begin{array}{l}\text { 4-1 Nature event } \\
4-1-1 \text { Sound }\end{array}$} \\
\hline 4-1-1-1 Human made sound & call เสียงต $=โ n น$ \\
\hline 4-1-1-2 Animal made sound & $\begin{array}{l}\text { quack แควก ทำเสียงฟื้อย่างแมว purr } \\
\text { peep ปิบ }\end{array}$ \\
\hline 4-1-2 Movement & spread การแพรกระจาย \\
\hline \multicolumn{2}{|l|}{5 State $^{72}$} \\
\hline 5-1 Relationship & motherhood พี่ชายน้องชาย พี่สาวน้องสาว \\
\hline 5-2 Alive/living & เป็น live มีชีวิด \\
\hline 5-3 Survive & live ดำรงชีวิต \\
\hline \multicolumn{2}{|l|}{ 5-4 Physiological state } \\
\hline 5-4-1 IIIness & cold ไข้ทวัต \\
\hline 5-4-2 State of body and mind & tired เหนื่อย กระหาย hungry thirsty ทิว \\
\hline $\begin{array}{l}\text { 5-5 Reputation } \\
\text { 5-6 Atmosphere }\end{array}$ & $\begin{array}{l}\text { name ชื่อเสียง } \\
\text { spirit }^{73} \text { บรรยากาศ }\end{array}$ \\
\hline
\end{tabular}

${ }^{68}$ Perform is to act or perform an action.

${ }^{69}$ Make is to perform an action, e.g., to make a decision.

70 Phenomenon is any state or process known through the senses rather than by intuition or reasoning.

${ }_{72}$ Event is something that happens at a given place and time.

${ }^{72}$ State is the way something is with respect to its main attributes: "the current state of knowledge", "in a weak financial state".

${ }^{73}$ Spirit is the general atmosphere of a place or situation, e.g., He came to the party. but didn ${ }^{2} t$ really enter into the spirit of it. 


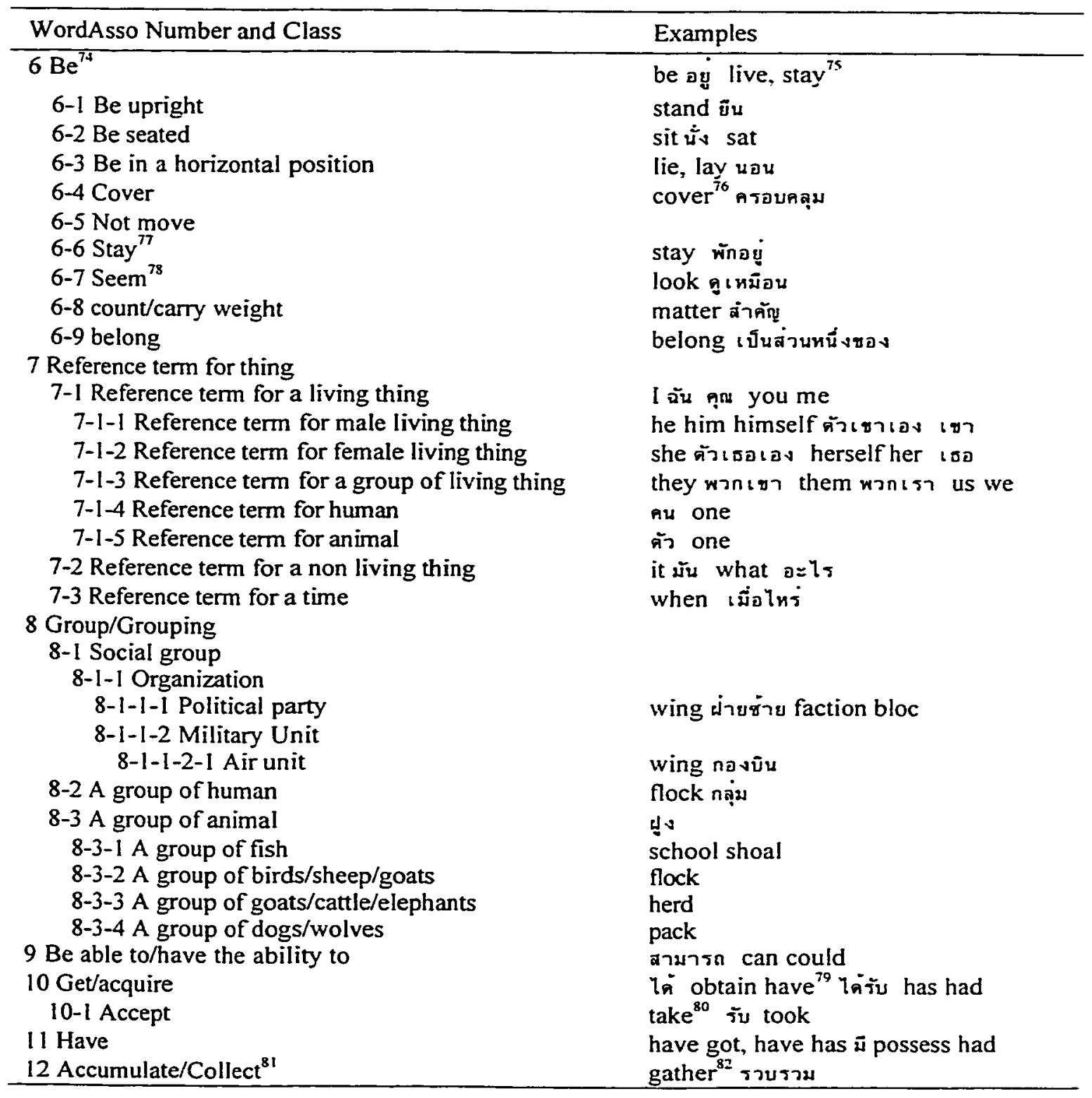

\footnotetext{
${ }_{75}^{74} \mathrm{Be}$ is to occupy a certain position or area, be somewhere, e.g., The boy is in the house.

${ }^{75}$ Stay is to stop and remain rather than go on or leave, e.g., Can you stay for dinner?

${ }_{77}$ Cover is to fill; extend over, e.g., The city covers 25 square miles.

${ }^{77}$ Stay is to live in a place for a while as a visitor or guest e.g.. My mother is staying with us this week.

${ }_{78}$ To seem by expression or appearance, e.g. You look tired.

79 Have is to receive or obtain, e.g., We must have your answer by Friday.

${ }^{80}$ Take is to accept, e.g., Do you take traveller's check?

${ }^{81}$ Collect, e.g.. collect evidence.

${ }^{82}$ Gather, e.g., He travels about the world gathering facts about little-known diseases.
} 


\begin{tabular}{|c|c|}
\hline WordAsso Number and Class & Examples \\
\hline \multicolumn{2}{|l|}{13 Attribute value } \\
\hline 13-I Name & Johns, Mary, ตำ แดง จอห์น รอนนี่ \\
\hline & John, Ronne Randall โจนส์ \\
\hline 13-2 Sex & male, female ชาย หญูง \\
\hline 13-3 Title $\ldots$ & prof, $\mathrm{mr}, \mathrm{mrs}$, miss, dr. นาง คุณ \\
\hline \multicolumn{2}{|l|}{ 13-5 Occupation/function } \\
\hline 13-5-1 Human's occupation & $\begin{array}{l}\text { faculty, student, nurse, doctor, nun, } \\
\text { quack ยาม นางชี sister หมอเถื่อน } \\
\text { priest watch นักเริยน }\end{array}$ \\
\hline 13-5-2 Animal's function & $\begin{array}{l}\text { working dog, watching dog, hunting } \\
\text { dog, toy dog, guard dog, quide dog, } \\
\text { carriage dog }\end{array}$ \\
\hline \multicolumn{2}{|l|}{ 13-6 Kind/Sort } \\
\hline 13-6-1 Person (of color) & $\begin{array}{l}\text { Asian, European, Negro, black คนคำ } \\
\text { white คนขาว Egyptian คนอียิปด์ ไทย } \\
\text { Thai }\end{array}$ \\
\hline 13-6-2 Animal (kind /pedigree) & $\begin{array}{l}\text { dalmatian, toy poodle, doberman, } \\
\text { alsatian, siamese cat, persian cat, } \\
\text { butterfish }\end{array}$ \\
\hline $\begin{array}{l}\text { 13-6-3 Plant (genus) } \\
\text { 13-6-4 Equipment } \\
\text { 13-6-5 Number }\end{array}$ & $\begin{array}{l}\text { mountain rose, tea rose, china rose, } \\
\text { Mac, PC, Unix } \\
\text { even }\end{array}$ \\
\hline 1;-7 Age & $10,20,30$ \\
\hline 13-7-1 Age of living thing & young, old แก่ \\
\hline 13-7-1-1 Age of plant & young อ่อน \\
\hline 13-7-1-1-1 Age of plant part & green อ่อน \\
\hline 13-7-1-1-1-1 Age of fruit & green ติบ \\
\hline \multicolumn{2}{|l|}{ 13-7-1-2 Age of human } \\
\hline 13-7-1-2-1 Age of male & หนุ่ม \\
\hline 13-7-1-2-2 Age of female & สาว \\
\hline 13-7-2 Age of non-living thing & เท่า old new ใหม่ \\
\hline \multicolumn{2}{|l|}{ 13-8 Appearance } \\
\hline 13-8-1 Size & little เล็์ \\
\hline 13-8-1-1 Size of a living thing & biggest โศที่สุด big โด \\
\hline 13-8-1-2 Size of a non-living thing & biggest ใหญุที่สุด big ใหญ่ ใหญ่มาก great \\
\hline \multicolumn{2}{|r|}{ fat อ่วน อวบ plump } \\
\hline 13-8-3 Length & short สัน long ยาว \\
\hline 13-8-4 Beauty & $\begin{array}{l}\text { ugly ugliest beautiful สวย สวยงาม } \\
\text { handsome รูปงาม }\end{array}$ \\
\hline 13-8-4-1 Beauty of a living thing & ขี้เหร่ ขี้เหรที่สุด \\
\hline 13-8-4-2 Beauty of a non-living thing & นำเกลียด น่าเกลียดที่สุด \\
\hline 13-8-5 Texture & fine บาง \\
\hline 13-8-5-1 Covered in fresh grass and leaves & green $^{83}$ เขียวชอุ่ม \\
\hline
\end{tabular}

${ }^{83}$ Green, e.g., The countryside is very green. 


\begin{tabular}{|c|c|}
\hline WordAsso Number and Class & Examples \\
\hline $\begin{array}{l}\text { 13-8-5-2-1 } \\
13-8-5-3 \text { Evenness }\end{array}$ & 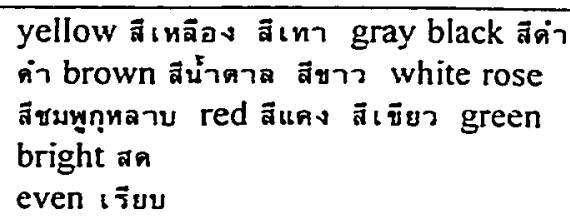 \\
\hline \multicolumn{2}{|l|}{ 13-8-9 Height } \\
\hline $13-8-9-1$ & high \\
\hline $13-8-9-2$ & tall \\
\hline 13-9 Trait & animal ${ }^{8-4}$ อย่างสัตว \\
\hline 13-9-1 Wildness (A state of nature) & wild ป่า \\
\hline 13-9-2 Behavior & violent, wild อย่างบาคลัง \\
\hline 13-9-3 Inexperience & green $^{85}$ อ่อนหัด \\
\hline \multirow[t]{2}{*}{ 13-10 Quality } & 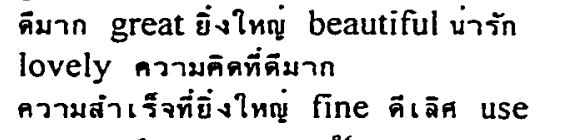 \\
\hline & ปร $=$ โยชน์ สดใส bright $^{86}$ \\
\hline 13-10-1 Kindness ${ }^{87}$ & kind ใจดี \\
\hline 13-10-2 Humaneness ${ }^{88}$ & kind กรุณา \\
\hline 13-10-3 Ability & เป็น able weak ${ }^{89}$ อ่อนแอ \\
\hline $13-10-4$ movement and form & graceful อ่อนช้อย \\
\hline 13-10-5 Importance & important สำคัญ \\
\hline $13-10-6$ & bright $^{90}$ จลาด clever \\
\hline $13-10-7$ & fine งดงาม \\
\hline 13-11 Healthy & fine สบายดี \\
\hline \multicolumn{2}{|l|}{ 13-12 Degree } \\
\hline 13-12-1 of temperature/weather & warm อุ่น cold หนาว fine ปลอดโปร่ง \\
\hline \multirow{3}{*}{$13-12-3$ of emotionality } & $\begin{array}{l}\text { แจ่ใส sunny gleaming เปนประกาย } \\
\text { สว่าง bright }\end{array}$ \\
\hline & warm อบอุ่น มัน"1 sadly \\
\hline & $\begin{array}{l}\text { อย่างเศรา่าสร่อย cold เยือกเย็น เบื่อ } \\
\text { tired อย่างภาคภูม proudly }\end{array}$ \\
\hline 13-12-3-1 Happiness & happy เป็นสุข เศรา sad \\
\hline $13-12-4$ of certainty & certainly อยางแน่นอน แน่นอน sure \\
\hline $13-12-5$ of truth & true จริง \\
\hline 13-13 Duration & long นาน ส้น little (while) \\
\hline $\begin{array}{l}\text { 13-14 Timing } \\
13-14-1 \text { before the usual/ arranged or expected time }\end{array}$ & early เร็วกว่าที่กำหนด \\
\hline
\end{tabular}

\footnotetext{
${ }^{84}$ Animal c.g., animal desires.

${ }^{85}$ Green is a young and inexperienced and therefore easily deceived and ready to believe anything.

${ }^{86}$ Bright is showing hope or signs of future success, e.g., You have a bright future ahead of you.

${ }^{87}$ Kindness is tendency to be kind and forgiving.

${ }^{88}$ Humaneness is the quality of compassion or consideration for others (people or animals).

${ }^{89}$ Weak is lacking power.

${ }^{90}$ Bright is clever, e.g., She's very bright.

${ }^{91}$ มัน is to feel a strong urge, to be having great pleasure.
} 


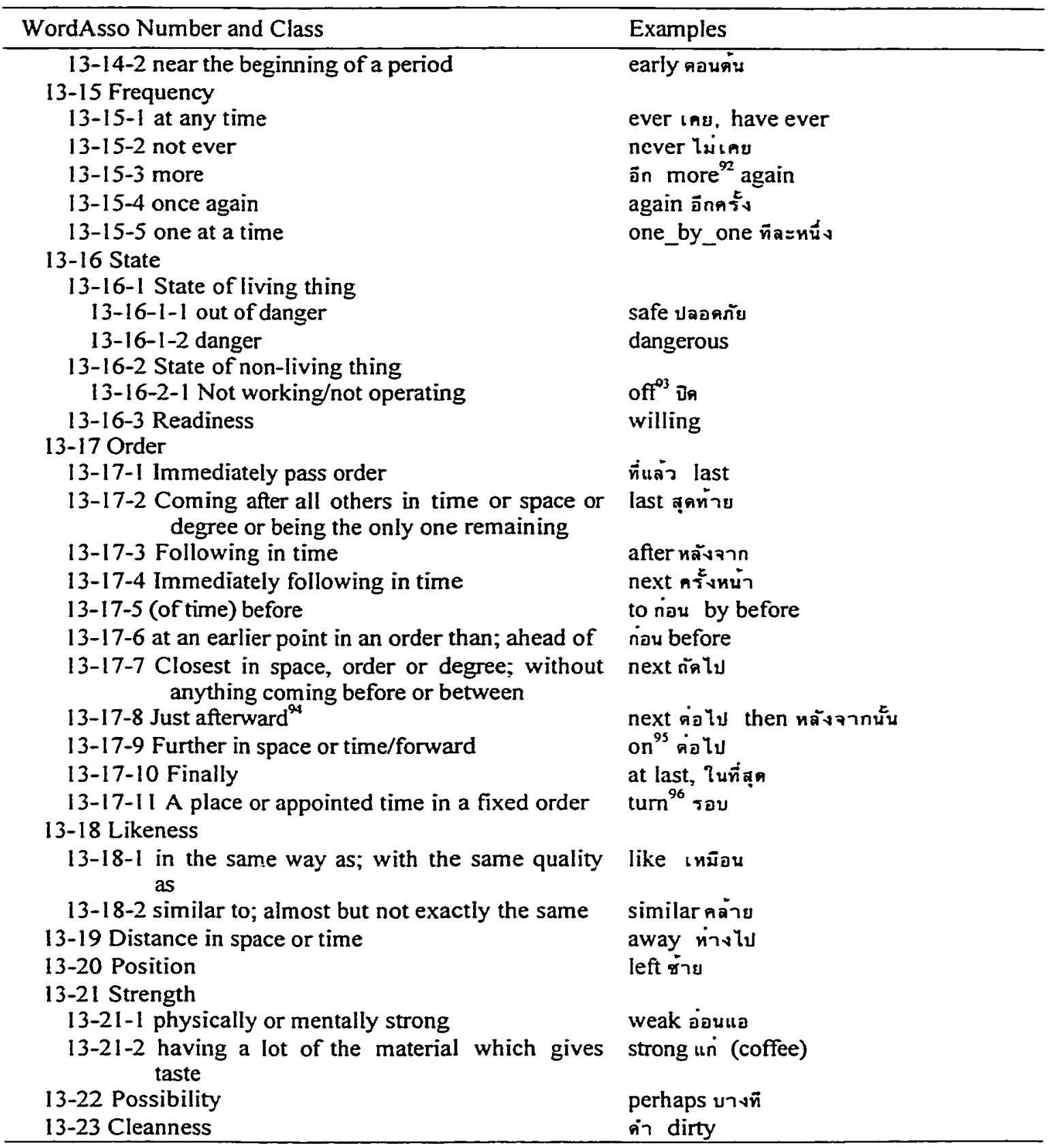

\footnotetext{
92 more; again, e.g., I'll repeat th equestion once more.

93 off ; not working; not operating; (of a machine or electrical apparatus), e.g., The TV is off.

94 Just afterward, e.g., First. you heat that fat; next, you add the onions.

${ }^{95}$ On, e.g. If you walk on you'll come to the church; It's time to move on.

96 Tum, e.g., You've missed your turn so you'll have to wait: It's my turn to drive next.
} 


\begin{tabular}{|c|c|}
\hline WordAsso Number and Class & Examples \\
\hline $\begin{array}{l}\text { 13-24 Property of location } \\
\text { 13-25 Shape } \\
\text { 13-26 Of or relating to } \\
\text { 13-27 in or into a state of being disconnected or } \\
\text { removed } \\
\text { 13-28 Equality } \\
\text { 13-29 Correctness } \\
\text { 13-30 } \\
\text { 13-31 Aliveness }\end{array}$ & $\begin{array}{l}\text { lonely }{ }^{97} \text { โดด เดี่ยว } \\
\text { bend turn ทางโค่ง } \\
\text { algebraic ทางพืชคณีต } \\
\text { off }^{98} \text { ออก } \\
\text { even เสมอกัน } \\
\text { right ถูก correct } \\
\text { willing } \\
\text { dead }\end{array}$ \\
\hline
\end{tabular}

${ }^{97}$ Lonely is a (of a building or other object) with no others of the same type near, e.g., a lonely house in the ivood.

98 off, e.g., How do you get this lid off? 


\section{A. 2 Other Classes}

Words which are used to link phrases with clauses or connect clauses together or provide the basis for a descriptive phrase e.g., prepositions, conjunctions, definite determiner are classified as well in a separate classification.

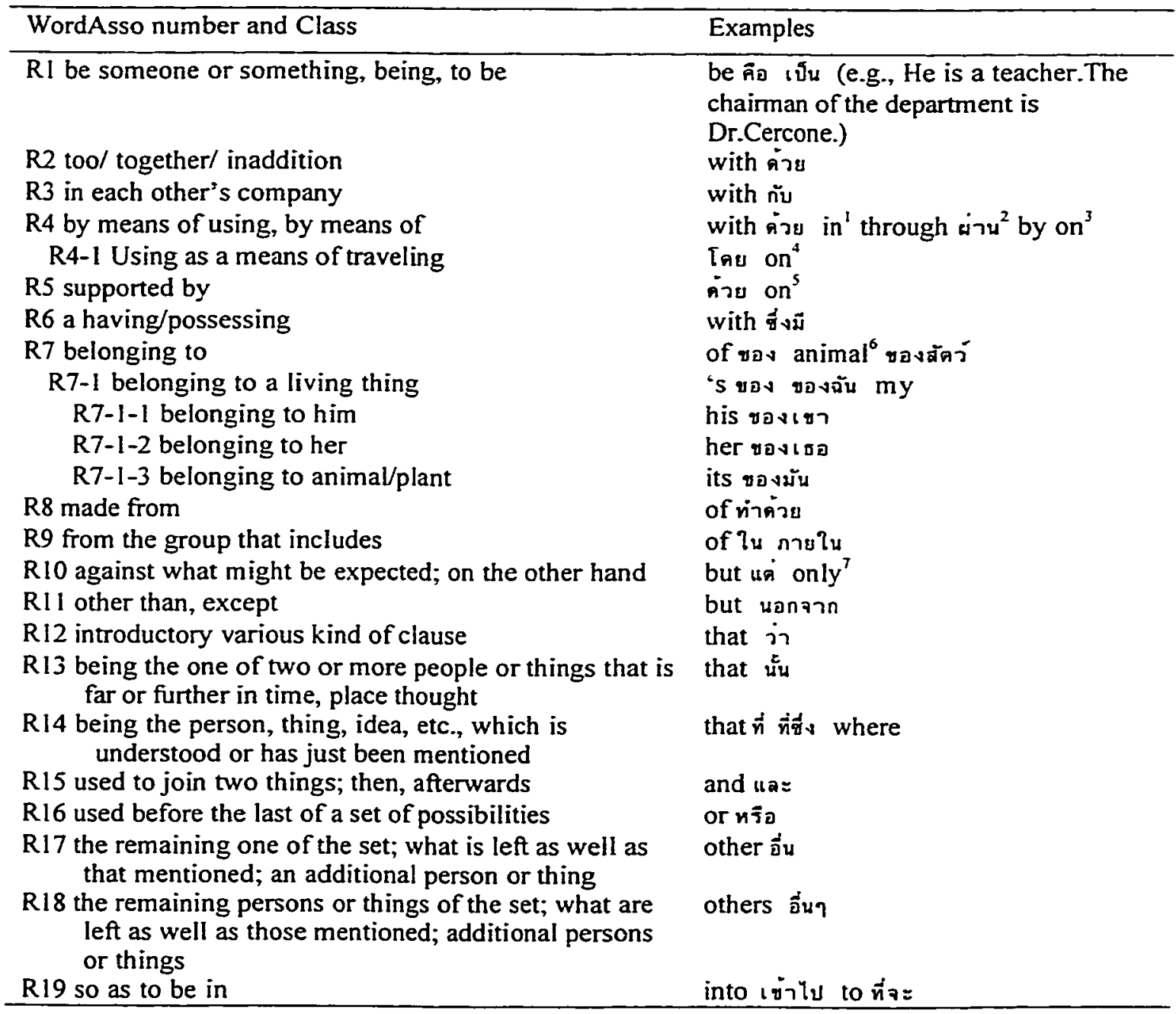

In. e.g., Write it in pencil.

2 Through, e.g.. I got this job through an employment agency.

${ }^{3}$ On, e.g., A car runs on petrol.

4 On, e.g., on foot, on a ship.

${ }^{5} \mathrm{On}, \mathrm{e}$.g., He went round the world on the money his aunt gave him.

${ }^{6}$ Animal e.g., cooking with animal fats.

7 Only: except that, but; e.g., She wants to go, only she hasn't got enough money. 


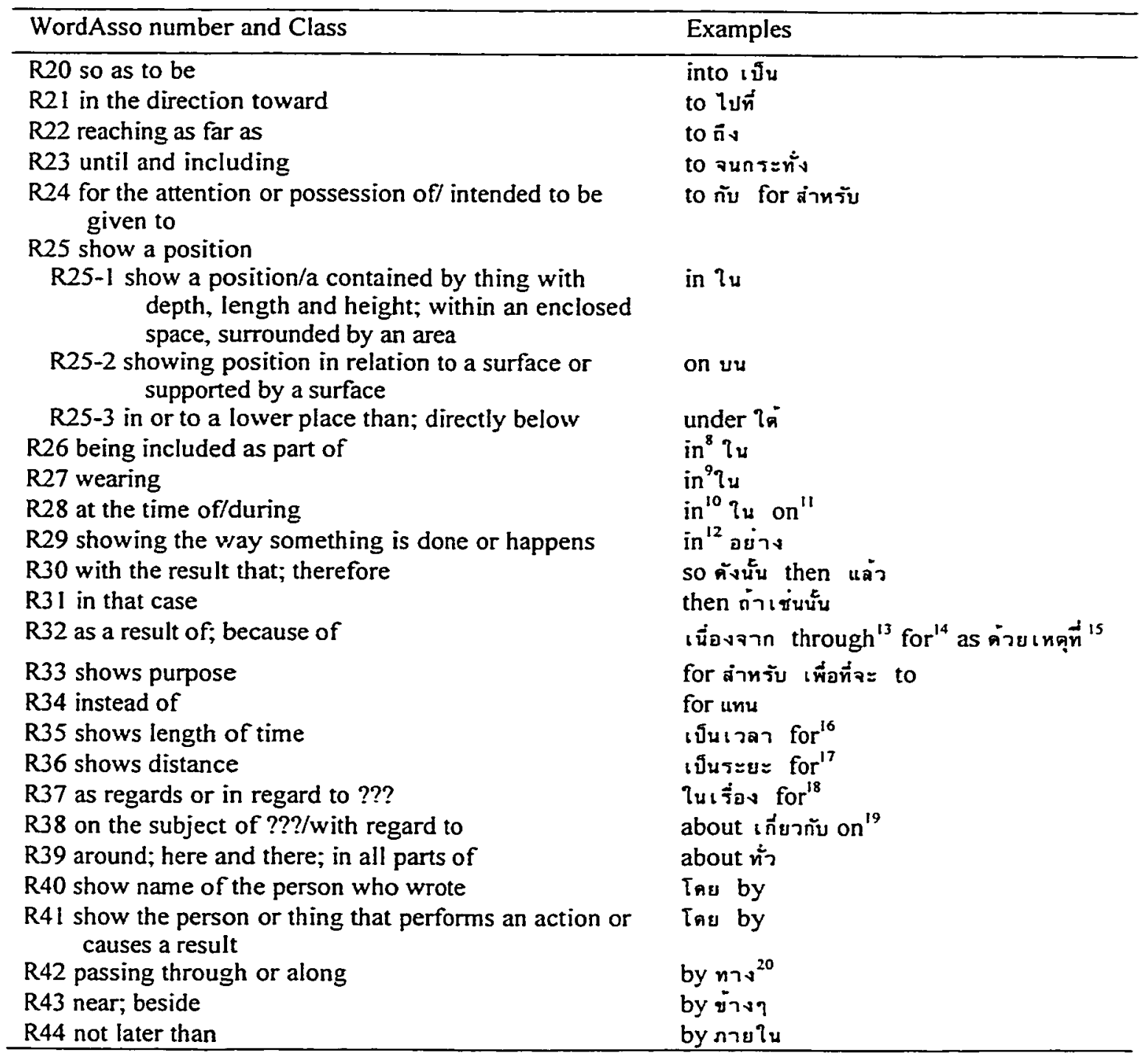

\footnotetext{
${ }^{8}$ In, e.g., Can you see the mistake in this sentence?

${ }^{9}$ In, e.g., A man in uniform.

${ }^{10}$ In, e.g., In spring, in January.

"On, e.g., on the morning of July.

12 In, e.g., Speaking in anger.

${ }^{13}$ Through, e.g., The war was lost through bad organization.

${ }^{14}$ For, e.g.. He was rewarded for his bravery.

is ค่วยเหตุที e.g.. As she has no car, she cannot get there easily.

${ }^{16}$ For, e.g., She didn't answer for several minutes.

${ }^{17}$ For, e.g., They ran fast for a mile or two.

${ }^{18}$ For, e.g.. France is famous for its wines.

${ }^{19}$ On, e.g. a book on India.

${ }^{20}$ nาง e.g., They came in by the back door., It's quicker if you go by the main road.
} 


\begin{tabular}{|c|c|}
\hline WordAsso number and Class & Examples \\
\hline R45 in accordance with/according to & by ตาม ${ }^{21}$ under ภายใต้ว2 \\
\hline $\begin{array}{l}\text { R46 used to show the size of units or groups that follow } \\
\text { each other }\end{array}$ & by $\bar{n} a=$ \\
\hline R47 show a point in space & $\mathrm{at}^{23} \vec{n}$ \\
\hline $\begin{array}{l}\text { R48 at the time that } \\
\text { R48-I show an exact point in time }\end{array}$ & $\begin{array}{l}\text { when }^{2 a} \text { เมื่อ as ขณ }=\vec{n}^{25} \\
\mathrm{at}^{20} \text { ตอน }\end{array}$ \\
\hline $\begin{array}{l}\text { R49 show an intended aim or object towards which a } \\
\text { thing or action is directed }\end{array}$ & $\mathrm{at}^{27}$ ไปที่ \\
\hline $\begin{array}{l}\text { R50 show the subject or activity in which a judgment } \\
\text { about someone's ability is made }\end{array}$ & $a t^{28} ? u$ \\
\hline R5I earlier than the time when & ก่อนที่ before ${ }^{29}$ \\
\hline R52 in or into a state of & under ภายใต้ว0 \\
\hline $\begin{array}{l}\text { R53 considering that } \\
\text { R54 on condition that; supposing that } \\
\text { R55 although } \\
\text { R56 exclusive of anyone or anything else } \\
\text { R57 nothing more than } \\
\text { R58 every single one of two or more things or people } \\
\text { considered separately. }\end{array}$ & 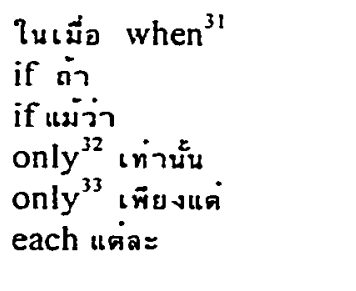 \\
\hline $\begin{array}{l}\text { R59 used in comparison } \\
\text { R60 in the way or manner that }\end{array}$ & $\begin{array}{l}\text { as } \text { เท่า }^{34} \\
\text { as ดังที่ }\end{array}$ \\
\hline $\begin{array}{l}\text { R61 from one place to another } \\
\text { R62 on all sides; surrounding a centre } \\
\text { R63 somewhere near; in the area }\end{array}$ & $\begin{array}{l}\text { around ไปทั้ว } \\
\text { around รอบๆ } \\
\text { around แถวนี้ }\end{array}$ \\
\hline $\begin{array}{l}\text { R64 away from inside } \\
\text { R65 starting at }\end{array}$ & ออกจาก out_of ${ }^{39}$ \\
\hline $\begin{array}{l}\text { R65-I starting at (the stated place, position, or } \\
\text { condition) }\end{array}$ & from จาn \\
\hline
\end{tabular}

\footnotetext{
21 ตาม e.g., to play by the rules.

22 Under: according to. e.g., Under the terms of the agreement, you have to pay weakly rent.

23 At. e.g., at my house.

${ }^{24}$ When; at the time that: e.g., Things were differentwhen I was a child.

${ }^{25}$ ขn= $\vec{n}$, while, when, e.g., He saw her as he was getting off the bus.

${ }^{26}$ At, e.g., at 10:00 pm; I often work at night.

27 At, e.g., Aim at the target.

$28 \mathrm{At}$, e.g., He's clever at arranging things.

${ }^{29}$ Before, e.g., It will be some time we know the full results.

${ }^{30}$ Under, e.g., At last we brought the fire under control.

${ }^{31}$ When; considering that, e.g., why do you want a new job when you've got such a good one already?

${ }^{32}$ Only, e.g. I will have this car and this car only.

${ }^{33}$ Only, e.g. I was only asking.

${ }^{34}$ As, e.g., He's not as old as me.

35 As, e.g., Do as I say; He does as his father said. (Another person gives an order).

36 ไปท์ 2 e.g. I travelled around for a few years.

37 sauๆ e.g., The children gathers around to hear the story.

38 แถวนี e.g.. Is there anyone around?

39 out_of, e.g.. We are moving out of our flat.
} 


\begin{tabular}{cl}
\hline WordAsso number and Class & Examples \\
\hline R65-2 starting at (the stated time) & from ด้ ตัแต่ \\
R66 which is more than might me expected & even แม่แต่ \\
R67 belonging to oneself and to no one self & own เอง \\
R68 & to ให้ \\
\hline
\end{tabular}




\section{Appendix B}

\section{SL Dictionary}

This appendix illustrates a fragment of the English dictionary, discussed in sections 3.3 and 5.1.3, in Prolog representation style as illustrated in (1). Each entry contains the English entry and all its possible syntactic categories.

(1) entry_e (English, [cat 1, cat2,...]).

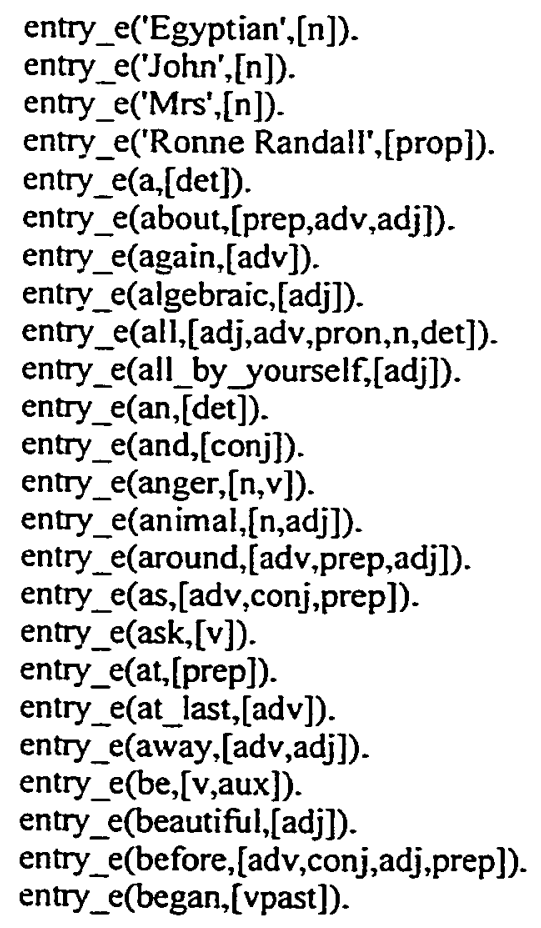




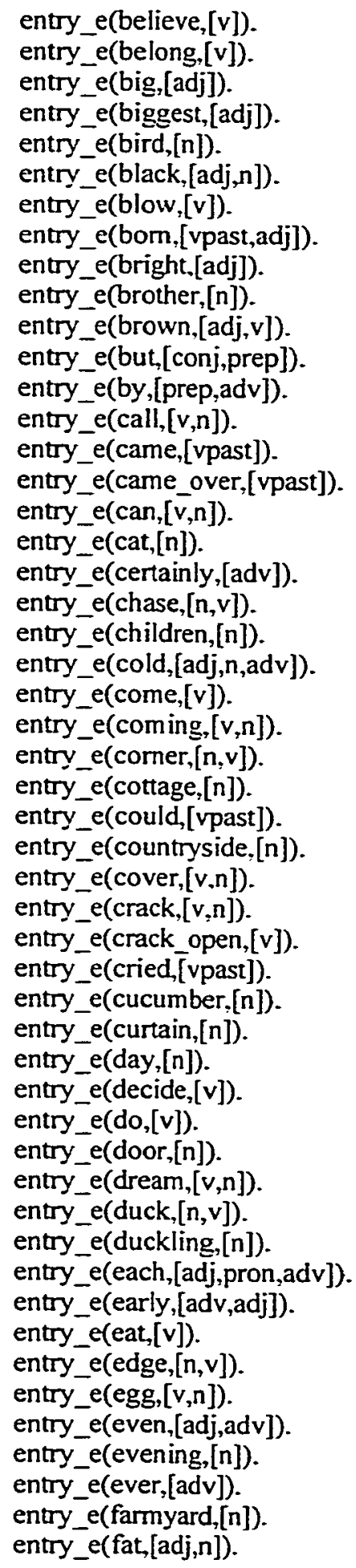


entry_e(feather,[n]).

entry_e(feeling.[n,v]).

entry_e(find, [v]).

entry_e(fine,[n,v,adj,adv]).

entry_e(fish.[n]).

entry_e(fishing, $[n, v])$.

entry_e(five,[n]).

entry_e(flesh,[n]).

entry_e(flew,[vpast]).

entry_e(flock.[n,v]).

entry_e(for.[prep,conj]).

entry_e(friend, $[n])$.

entry_e(from.[prep]).

entry_e(gather, [v]).

entry_e(geese,[n,plur]).

entry_e(give, [v]).

entry_e(happy,[adj]).

entry_e(has,[v]).

entry_e(hatch, $[n, v])$.

entry_e(have,[v]).

entry_e(have_ever,[v]).

entry_e(he,[pron]).

entry_e(head,[n]).

entry_e(heard,[vpast]).

entry_e(hen,[n]).

entry_e(her,[pron]).

entry_e(here,[adv]).

entry_e(herself,[pron]).

entry_e(hid,[vpast]).

entry_e(hide,[v]).

entry_e(hidden,[adj,vpast]).

entry_e(hiding,[v]).

entry_e(him.[pron]).

entry_e(himself,[pron]).

entry_e(his,[pron]).

entry_e(home, [n]).

entry_e(into,[prep]).

entry_e(it,[pron]).

entry_e(its,[pron]).

entry_e(kind,[n,adj]).

entry_e(knew,[vpast]).

entry_e(know,[v]).

entry_e(lake,[n]).

entry_e(last.[v,adj,adv]).

entry_e(led,[vpast]).

entry_e(left,[adj,vpast]).

entry_e(leg,[n]).

entry_e(let.[n,v]).

entry_e(lettuce,[n]).

entry_e(like,[v,adj,prep]).

entry_e(little.[adj,adv]).

entry_e(live,[v,adj]). 
entry_e(lonely,[adj]).

entry_e(long.[adj,adv]).

entry_e $(l o o k,[v, n])$.

entry_e(look_around,[v]).

entry_e(lovely, [adj]).

entry_e(make, $[v, n])$.

entry_e(make_fun_of,[v]).

entry_e(many, [adj]).

entry_e(march, $[v, n])$.

entry_e(marsh,[n]).

entry_e(matter, $[n, v])$.

entry_e(me,[pron]).

entry_e(melt. $[v])$.

entry_e(mind, $[n, v])$.

entry_e(peep, $[v, n])$.

entry_e(ran,[vpast]).

entry_e(ran_after,[vpast]).

entry_e(reed, $[n])$.

entry_e(reflection, $[\mathrm{n}])$.

entry_e(release, $[v, n])$.

entry_e(rend,[v]).

entry_e(rent,[v,vpast]).

entry_e(research, $[n, v])$.

entry_e(rest, $[n, v])$.

entry_e(room,[n]).

entry_e(rose,[n,vpast,adj]).

entry_e(run_away,[v]).

entry_e(sad,[adj]).

entry_e(sadly, [adv]).

entry_e(safe,[adj,n]).

entry_e(said,[vpast]).

entry_e(salad,[n]).

entry_e(sat,[vpast]).

entry_e(saw,[n,v,vpast]).

entry_e(school, $[n, v])$.

entry_e(seen,[vpast]).

entry_e(several,[adj]).

entry_e(she,[pron]).

entry_e(should,[aux]).

entry_e(shout, $[v, n])$.

entry_e(so,[adv, conj]).

entry_e(spirit,[n,v]).

entry_e(spread, $[v, n])$.

entry_e(spring, $[v, n]$ ).

entry_e(stay,[n,v]).

entry_e(stopped,[vpast]).

entry_e(stork,[n]).

entry_e(student,[n]).

entry_e(sunny,[adj]).

entry_e(sure,[adj,adv]).

entry_e(swan,[n]).

entry_e(symbol,[n]). 


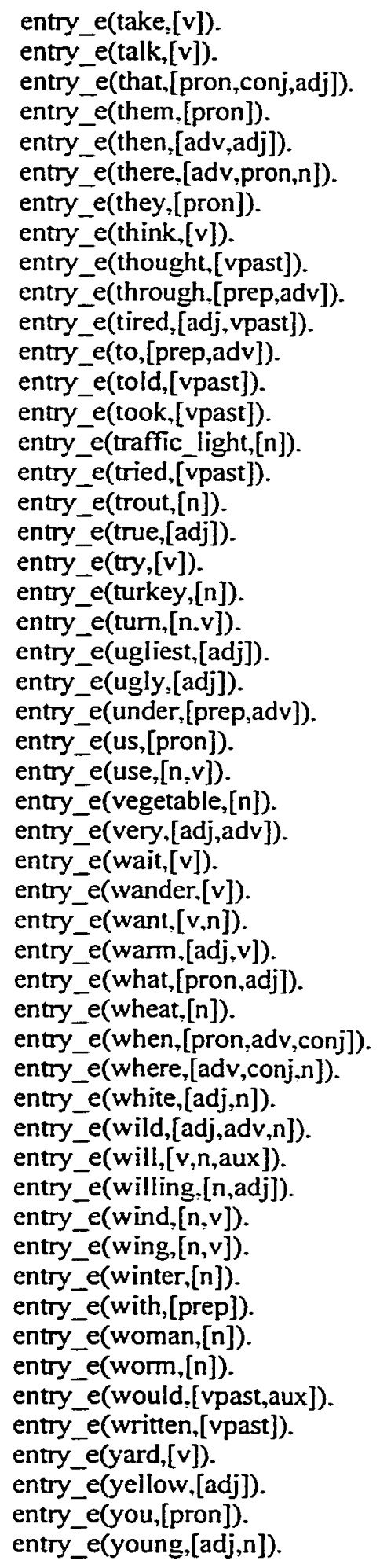




\section{Appendix C}

\section{SL-TL Dictionary}

This appendix illustrates a fragment of the English-Thai dictionary, discussed in sections 3.3 and 5.1.3, in Prolog representation style as illustrated in (1). Each entry contains the English entry and all its possible corresponding words in Thai. Each Thai word is related to its WordAssociation number.

(1) entry (English, [wordasso ('Thail', [wordassol, wordasso2,..]), wordasso ('Thai2', [wordassoa, wordassob,...]),... ]).

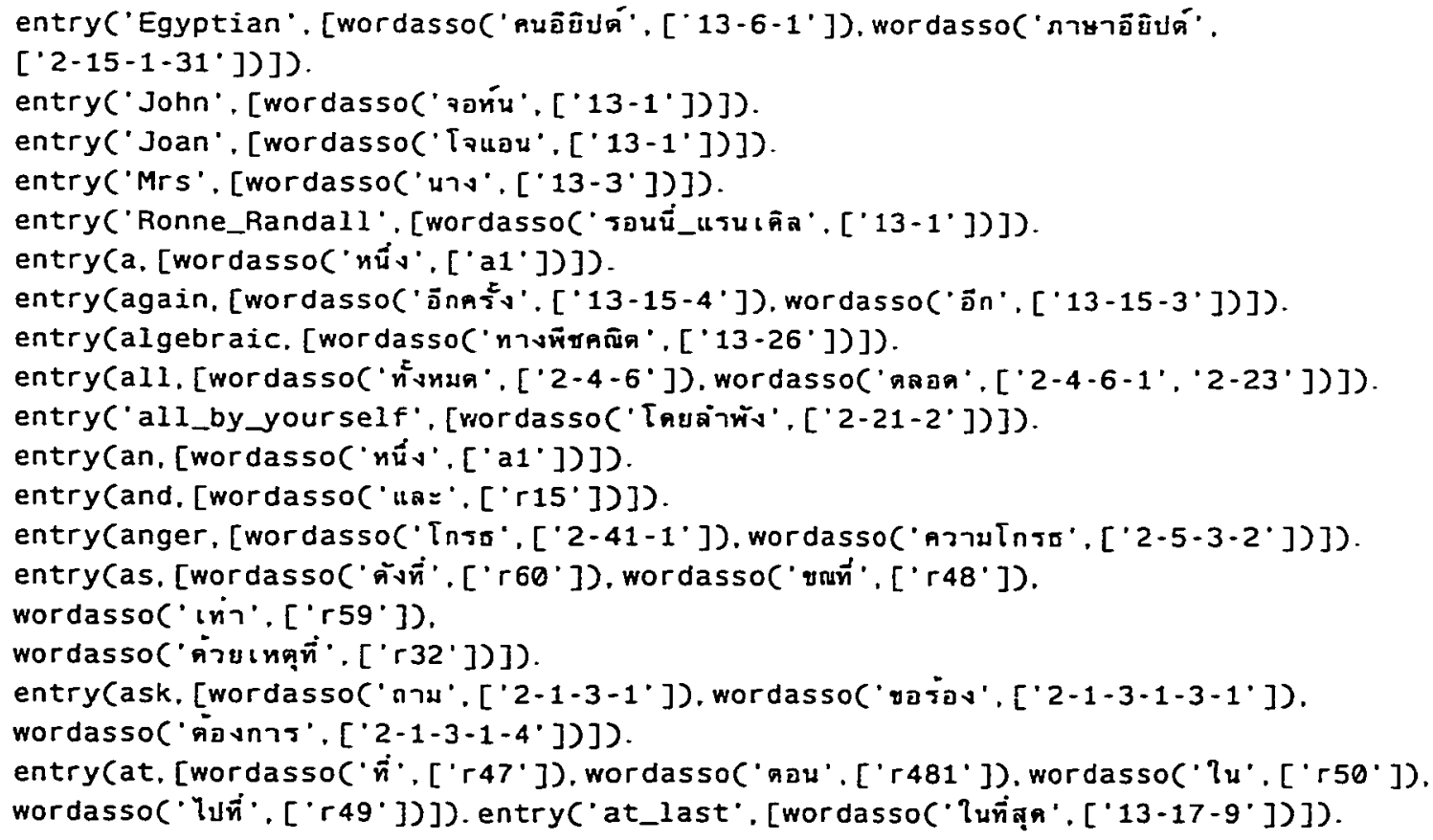




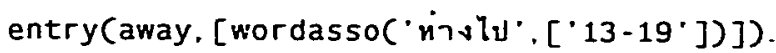

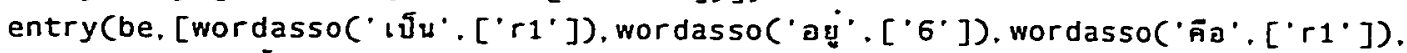

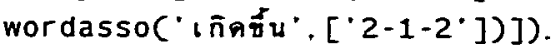

entry (beautiful, [wordasso( ${ }^{\prime}$ สาย ${ }^{\prime},\left[{ }^{\prime} 13-8-4^{\prime}\right]$ ), wordasso( ${ }^{\prime}$ ส วยงาม,$\left[{ }^{\prime} 13-8-4^{\prime}\right]$ ),

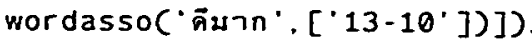

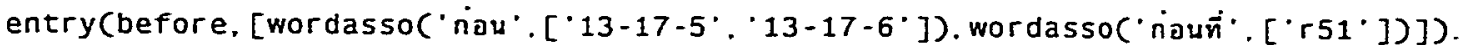

entry (began. [wordasso( ${ }^{\circ}$ เริ่ม', $\left.\left.\left[{ }^{\prime} 2-36^{\prime}\right]\right)\right]$ ).

entry (believe. [wordasso(' เขื่อ'. ['2-9-1', '2-9-4']), wordasso('เชื่อว่า', ['2-9-2'])]).

entry (belong_with. [wordasso('เป็นส่วนหนึ่งของ', $\left[{ }^{\prime} 6-9^{\prime}\right]$ ) ]).

entry (big. [wordasso ( ' ใหญ่' [ ['13-8-1-2']), wordasso (' [ด'. ['13-8-1-1'])]).

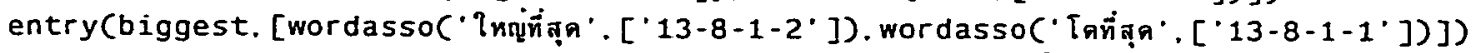

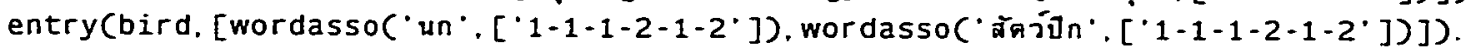
entry(born. [wordasso( เ เกิด',['2-1-1-16-1'])]).

entry(bright. [wordasso( 'สว่าง', ['13-12-2']), wordasso('สดใส'. ['13-10']),

wordasso('สด '. ['13-8-5-2-1']), wordasso('จลาด '. ['13-10-6'])]).

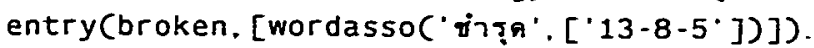

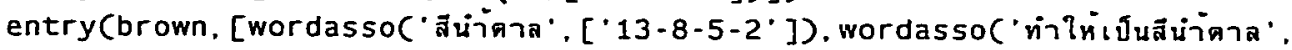

$\left.\left.\left[\cdot 2-1-1-8^{\prime}\right]\right)\right]$.

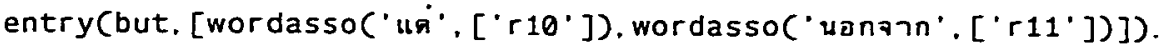

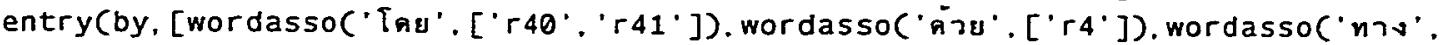
$[$ ['r42'].

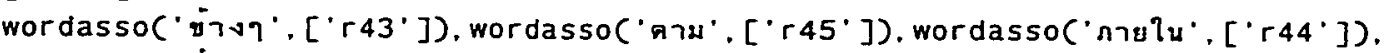

wordasso( 'rau $\left.^{\prime} .\left[{ }^{\prime} 13-17-5^{\prime}\right]\right)$. wordasso('

entry(call, [wordasso( ' เ รยก '. ['2-1-3-1-3']), wordasso(' ประกาศ', ['2-1-3-1-7']). wordasso( ต $=$ โกน', ['2-1-3-1-1']).

wordasso(' โทรศัพท์' $\left[{ }^{\prime} 2-1-3-1-6^{\prime},{ }^{\prime} 1-1-2-1-1-3-4-1^{\prime}\right]$ ), wordasso('เสียงดะโกน'.

[.4-1-1-1.]).

wordasso( เรยยว่า $\cdot[\cdot 2-33-1 \cdot])])$.

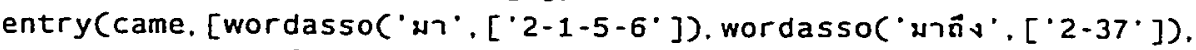

wordasso('กลายเป็น', ['2-1-1-1'])]).

entry (came_over_to, [wordasso('ตรงมาที่'. ['2-1-5-6. $]$ )])

wordasso('ท่องน้ำ' [ ['1-1-2-1-1-2-3'])]).

entry(cat. [wordasso(' แมว '. ['1-1-1-2-1-1'])]).

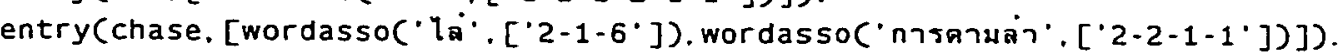

entry(children. [wordasso('เด็กๆ ', ['1-1-1-1-1-4']), wordasso('aูกๆ' ,

$[1-1-1-1-1-3-5 \cdot])])$.

entry(come, [wordasso('มา', ['2-1-5-6']), wordasso('มาถิง $\left.\cdot\left[{ }^{\prime} 2-37^{\prime}\right]\right)$,

wordasso('naายเป็น', ['2-1-1-1'])]).

entry(corner. [wordasso(' มุม', ['1-1-2-1-3-1']), wordasso( ' จนมุม' $\left[{ }^{\prime} 2-11^{\prime}\right]$ )]).

entry (cottage. [wordasso( $n$ s:n่อม'. $\left.\left.\left[11-1-2-1-1-2-2^{\prime}\right]\right)\right]$ ).

entry (could, [wordasso('

entry (countryside. [wordasso(' ชนun', ['1-1-2-1-3-2-2-1'])]).

entry (cover. [wordasso ('คลุม' [ ['2-1-19-2']), wordasso( 'จด ' ['2-1-19-1']).

wordasso('ปnnąa'. ['2-1-18-2']).

wordasso( ครอบคลุม', ['6-4']), wordasso( หน้ำปก',$\left.\left.\left[{ }^{\prime} 1-1-2-1-1-5-1-2 \cdot\right]\right)\right]$ ).

entry (crack, [wordasso(' แตก' $\left[{ }^{\prime} 2-1-1-12-1^{\prime}\right]$ ), wordasso(' ตอก '. ['2-1-1-13-1-2']).

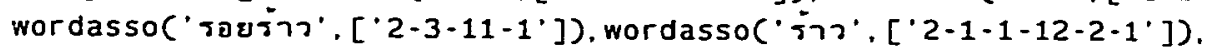




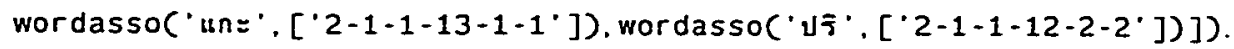

entry ('crack_open' , [wordasso ('ปริแตnออก'. ['2-1-1-12-2-2'])]).

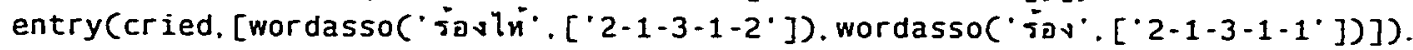

entry (cucumber. [wordasso (' แดงกวา' , ['1-1-1-3-1-3-1', '1-1-2-1-2-1-2-1']) ]).

entry(day, [wordasso( 'วัน', ['2-4-2-3', '2-4-3-1-2']), wordasso(' กลางวัน',

$\left.\left.\left[\cdot 2-4-3-1-1^{\prime}\right]\right)\right]$.

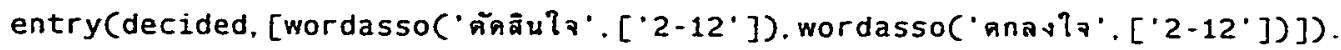

entry(did, [wordasso(' viา $^{\prime},\left[{ }^{\left.\prime 2-34^{\prime}\right]}\right]$ )]).

entry(do, [wordasso(' viา $\left.\left.^{\prime} \cdot\left[{ }^{\prime} 2-34^{\prime}\right]\right)\right]$ ).

entry (does. [wordasso(' niา $^{\prime}\left[{ }^{\prime} 2-34^{\prime}\right]$ )] $)$.

entry(door. [wordasso('ประด. ' ['1-1-2-1-1-2-1-1'])])

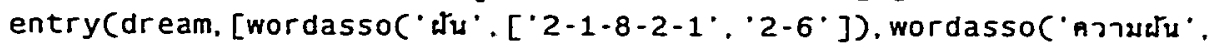

$[\cdot 2-5-1-2 \cdot])]$.

entry (duck. [wordasso (' เป็ด', ['1-1-1-2-1-2-1', '1-1-2-1-2-1-2-4-1']).

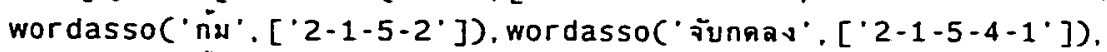

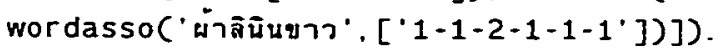

entry (duckling. [wordasso(' ลูกเป็ด' $\left.\left.\left[{ }^{\prime} 1-1-1-2-1-2-1^{\prime}\right]\right)\right]$ ).

entry (each. [wordasso ('แต่a:,$\left.\left.\left[{ }^{\prime} r 58^{\prime}\right]\right)\right]$ ).

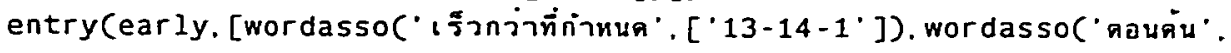

$[\cdot 13-14-2 \cdot])]$ ).

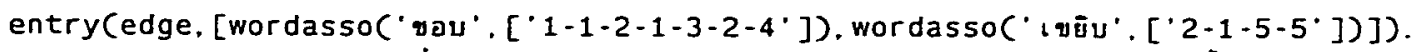

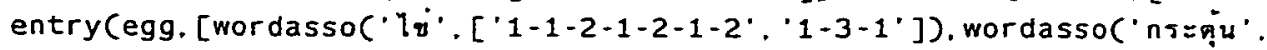

$[\cdot 2-1-7 \cdot])]$ ).

entry(evening. [wordasso('เวลาเย็น', ['2-4-3-1-1'])]).

entry (ever. [wordasso ('เคย' . ['13-15-1'])]).

entry (farmyard. [wordasso(' ลานติดโรงนา' $\left[{ }^{\prime} 1-1-2-1-1-4^{\prime}\right]$ )] ).

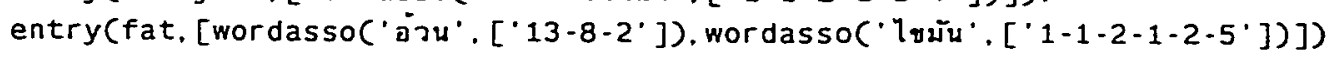

entry (feather. [wordasso ('ขนนก' $\left.\left.\left[{ }^{\prime} 1-4-1-2-3^{\prime}\right]\right)\right]$ ).

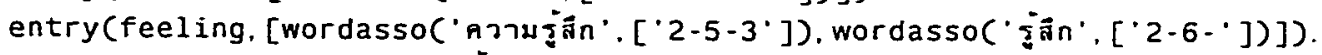

entry (find. [wordasso( 'หาให้พบ', ['2-16'])]).

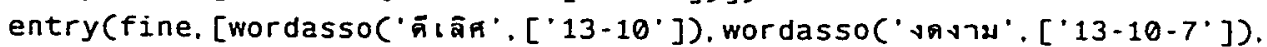

wordasso ('ปลอดโปร่ง', ['13-12-1']), wordasso ('สบายด ', ['13-11']).

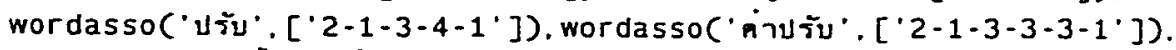

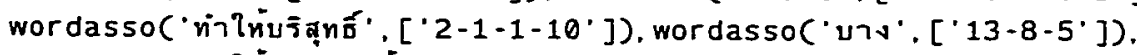

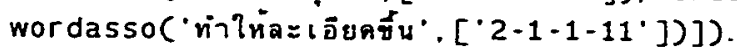

entry(fish. [wordasso( 'ปลา' $[$ ['1-1-1-2-1-3-1', 1-1-2-1-2-1-2-3'])])

entry(fishing. [wordasso('ตกปลา', ['2-2-1-3-1']), wordasso(' การปร=มง'.

$[\cdot 2-2-1-1-3-2 \cdot])]$ ).

entry(five. [wordasso('n' $\left.\left.\cdot\left[{ }^{\prime 2-4-1} \cdot\right]\right)\right]$ ).

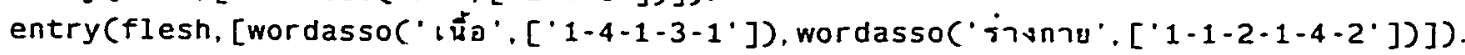

entry (flew, [wordasso( 'บิu', ['2-1-18-1-4-1',2-1-5-1']) $]$ ).

entry(flock. [wordasso(' 'ง '. ['8-3-2']), wordasso('ną่ม'. ['8-2']).

wordasso('เส่นใย'. ['1-1-2-1-2-3-4'])]).

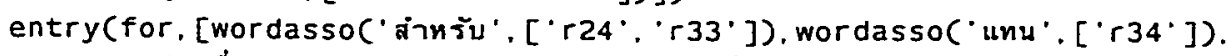

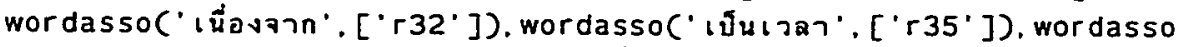

('เป็ระยะ '. ['r36']), wordasso( 'ในเรื่อง', ['r37'])]). 


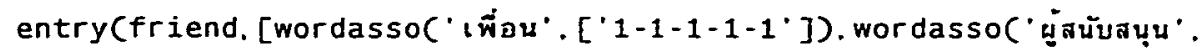

$\left.\left.\left.\left[\cdot 1-1-1-1-1-6^{\prime}\right]\right)\right]\right)$.

entry (from. [wordasso(' จาก'. ['r65-1']), wordasso( ด้ ตังแต่ '. ['r65-2'])]).

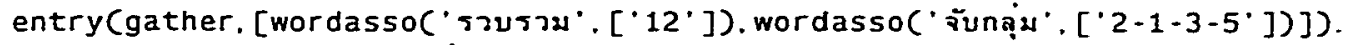

entry (geese, [wordasso( ' $^{\prime}$ (w),$\left.\left.\left[1-1-1-2-1-2 \cdot 1^{\prime}\right]\right)\right]$ ).

entry (gleaming, [wordasso (' เป็นร ร=กาย'. ['13-12-2'])])

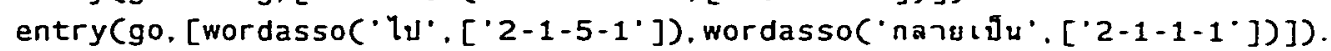

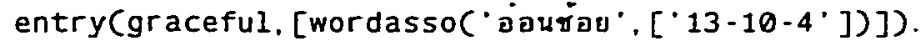

entry (gray. [wordasso('ลีเn)'. ['13-8-5-2']) $]$ ).

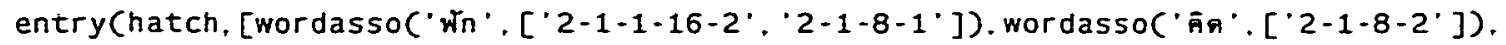

wordasso (' เาปดห่องท่องเ รือ', ['1-1-2-1-1-2-1-1']) $]$ ).

entry(he. [wordasso('เขา' $\left.\left.\left[{ }^{\prime} 7-1-1 \cdot\right]\right)\right]$ ).

entry (head. [wordasso( 'หัว', ['1-4-1-1-1'])]).

entry(heard. [wordasso( (ด้อิน', ['2-6'])]).

entry (hen, [wordasso ( $4 n^{\prime},\left[{ }^{\prime} 1-1-1-2-1-2-2^{\prime}, 1-1-2-1-2-1-2-4-1^{\prime}\right]$ ) ]).

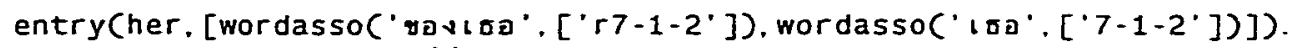

entry (here, [wordasso( ' nै $\left.\left.^{\prime} \cdot,\left[{ }^{\prime} 1-1-2-1-3-1 \cdot\right]\right)\right]$ ).

entry(herself, [wordasso('ตัวเธอเอง', $\left[{ }^{\prime} 7-1-2^{\prime}\right]$ )] $)$.

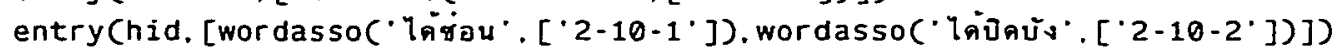

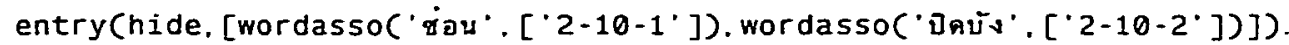

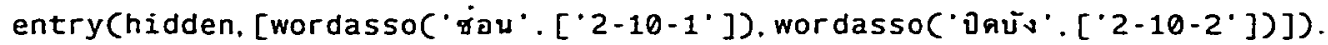

entry (him. [wordasso('เขา', ['7-1-1'])]).

entry(himself. [wordasso(

entry (his, [wordasso('ของเขา'. ['r7-1-1'])]).

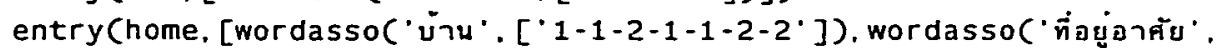

$\left.\left.\left.\left[\cdot 1-1-2-1-3-1-1^{\prime}\right]\right)\right]\right)$.

entry (hungry, [wordasso( ${ }^{\prime}$ หิว,$\left.\left[{ }^{\prime} 5-4-2^{\prime}\right]\right)$, wordasso( ${ }^{\prime}$ กระหาย,$\left.\left.\left[{ }^{\prime} 2-6-2-8^{\prime},{ }^{\prime} 5-4-2^{\prime}\right]\right)\right]$ )

entry (i. [wordasso(' ฉัน'. [ $7-1 \cdot])]$ ).

entry (ice, [wordasso ( 'น้ำแช์ง', ['1-1-2-1-2-6-1'])]).

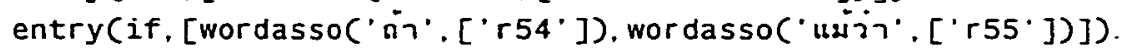

entry (in. [wordasso (' ?น', ['r25-1', 'r26', 'r27', 'r28']), wordasso('เข้ามา',

$\left.\left[\cdot 2-3-6-4^{\prime}\right]\right)$.

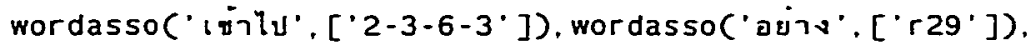

wordasso(

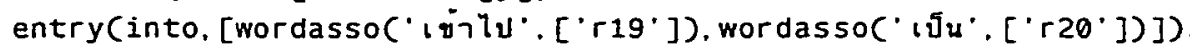

entry (it. [wordasso(' มัน,$\left.\left.\left[{ }^{\prime} 7-2^{\prime}\right]\right)\right]$ ).

entry (its, [wordasso('ของมัน', ['r7-1-3']) $]$ ).

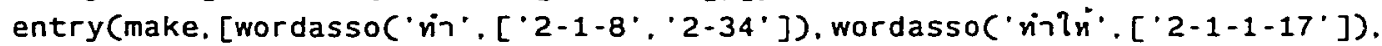

wordasso('ย่ท่อ'. ['2-5-1-6-1-1']) ]).

entry ('make_fun_of', [wordasso(' เยาะเย่ย'. $\left.\left.\left[{ }^{\prime} 2-1-3-2-1^{\prime}\right]\right)\right]$ )

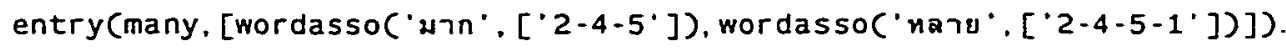

entry (neck, [wordasso( คอ $\left.^{\prime},\left[{ }^{\prime} 1-4-1-1-2^{\prime}\right]\right)$, wordasso(' nอดจุบ'. ['2-1-18-1-1'])]).

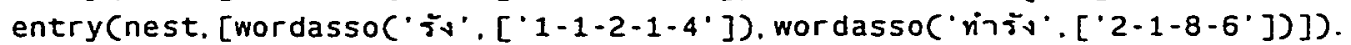

entry (never. [wordasso(' ไม่ เคย '. ['13-15-2'])]).

entry (new, [wordasso( 'ใหม่', ['13-7-2'])]).

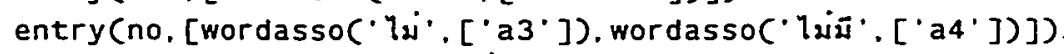

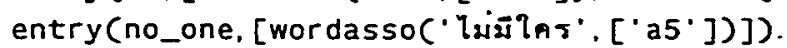




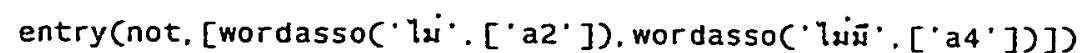

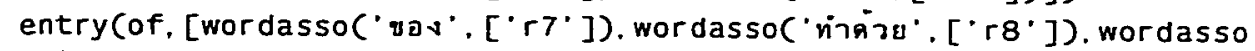

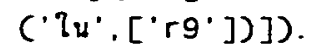

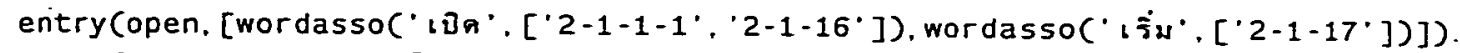

entry(or. [wordasso( ' $^{\prime}$ รa'. $\left.\left.\left[{ }^{\prime} r 16^{\prime}\right]\right)\right]$ ).

entry(other. [wordasso( ' $\left.\left.^{\circ}{ }^{\prime},\left[{ }^{\prime} r 17^{\prime}\right]\right)\right]$ ).

entry (others. [wordasso('อิ่นๆ ', $\left.\left.\left[{ }^{\prime} r 18^{\circ}\right]\right)\right]$ ).

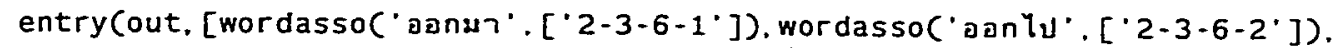

wordasso('ออกจาก '. $\left[2-3-8-1^{\prime}\right]$ ), wordasso(' ข้างนan'. ['1-1-2-1-3-2-1']) $]$ ).

entry(out_of, [wordasso('aอกจาn'. ['r64'])]).

entry (plump. [wordasso('a) '. [ [ 13-8-2'])]).

entry (pond. [wordasso ('แอ่งน่ำ'. ['1-1-2-1-6-2'])]).

entry (proudly. [wordasso ('อย่างภาคภูมิ' $\left.\left.\left[{ }^{\prime} 13-12-3^{\prime}\right]\right)\right]$ ).

entry (purr. [wordasso ('เพอร์'. [ $\left[{ }^{\prime} 4-1-1-2^{\prime}\right]$ )] ).

entry (quack. [wordasso('แควก'. $\left[{ }^{\prime} 4-1-1-2^{\prime}\right]$ ). wordasso(' หมอเถี่อน'. ['13-5-1'])]).

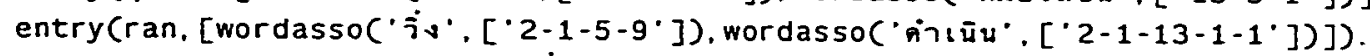

entry(ran_after. [wordasso(' ไล่ตาม '. ['2-1-5-10'])]).

entry(red, [wordasso(') สีแคง' [ ['13-8-5-2']), wordasso ('คอมมิวนิสต์',

$\left.\left.\left[{ }^{\prime} 1-1-1-1-1-7-1^{\prime}\right]\right)\right]$ ).

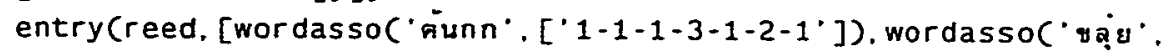

$\left.\left.\left[{ }^{\prime} 1-1-2-1-1-3-1-s^{\prime}\right]\right)\right]$ ).

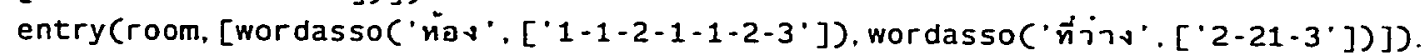

entry (salad, [wordasso( ' สล้ด' . ['1-1-2-1-2-1-1-1'])]).

entry (sat, [wordasso( 'นั้ง' $\left.\left.\left[{ }^{\prime} 6-2^{\prime}\right]\right)\right]$ ).

entry (seen. [wordasso( เ $^{\prime}$ เ $\left.\left.^{\prime},\left[{ }^{\prime} 2-6^{\circ}\right]\right)\right]$ ).

entry (several, [wordasso( หลาย', $\left.\left.\left[2-4-5-1^{\prime}\right]\right)\right]$ ).

entry (she. [wordasso('เסอ'. ['7-1-2'])]).

entry (should. [wordasso( $\cos s^{\prime},\left[{ }^{\prime} a 12^{\prime}\right]$ ) $]$ ).

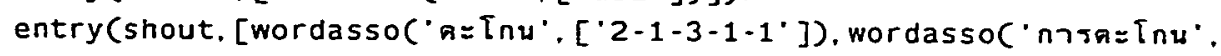

$[\cdot 2-15-1-6-1 \cdot])])$.

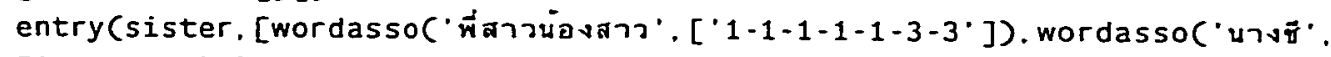

$[13-5-1, j)]$ ).

entry(sky, [wordasso( 'ทองพา',$\left.\left.\left[1-1-2-1-3-2-3^{\prime}\right]\right)\right]$ ).

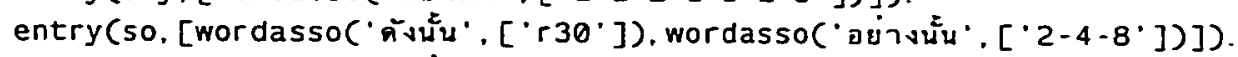

entry (weak. [wordasso (' อ่อนแอ' $\left[{ }^{\prime} 13-21-1^{\prime},{ }^{\prime} 13-10-3^{\prime}\right]$ ) $]$ ).

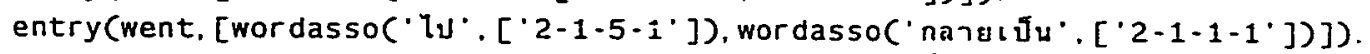

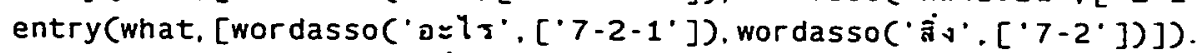

entry (wheat, [wordasso (' ช่าวสาลี', ['1-1-1-3-1-2-1-1'])]).

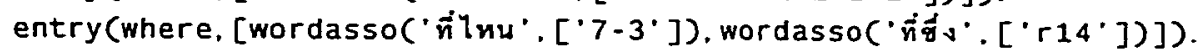

entry(white. [wordasso('สีขาว ', ['13-8-5-2']), wordasso(' กนขาว ', ['13-6-1'])]).

entry (yellow, [wordasso (' สีเหลือง ', ['13-8-5-2'])]).

entry (you, [wordasso( ${ }^{\prime} \mathrm{M}^{\prime},\left[{ }^{\prime} 7-1^{\prime}\right]$ ) $]$ ). 


\section{Appendix D}

\section{Types, Their Features and Their Value Types}

This appendix illustrates some types defined in our grammars as discussed in section 6.1.1.2. Their features and their value types are also provided.

\begin{tabular}{|c|c|c|}
\hline Type & Features/Type of value & $\begin{array}{l}\text { Immediate } \\
\text { Supertype }\end{array}$ \\
\hline sign & {$\left[\begin{array}{ll}\text { SYNSEM } & \text { synsem } \\
\text { QSTORE } & \text { set_quant }\end{array}\right]$} & entity \\
\hline $\begin{array}{l}\text { phrase } \\
\text { word } \\
\text { synsem }\end{array}$ & $\left.\begin{array}{ll}\cdots & \\
\cdots & \\
\text { LOC } & \text { loc } \\
\text { NONLOCAL } & \text { nonlocal }\end{array}\right]$ & $\begin{array}{l}\text { sign } \\
\text { sign } \\
\text { mod_synsem }\end{array}$ \\
\hline $\begin{array}{l}\text { pre_mod_synsem } \\
\text { post_mod_synsem } \\
\text { loc }\end{array}$ & {$\left[\begin{array}{ll}\text { CAT } & \text { cat } \\
\text { CONT } & \text { cont } \\
\text { CONX } & \text { conx }\end{array}\right]$} & $\begin{array}{l}\text { synsem } \\
\text { synsem } \\
\text { entity }\end{array}$ \\
\hline $\begin{array}{l}\operatorname{con} x \\
\text { cat }\end{array}$ & 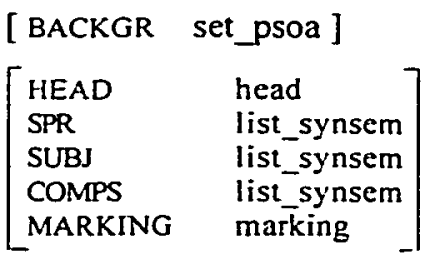 & $\begin{array}{l}\text { entity } \\
\text { entity }\end{array}$ \\
\hline $\begin{array}{l}\text { cont } \\
\text { nom_obj }\end{array}$ & $\left.\begin{array}{l}\text { mode } \\
\text { ind } \\
\text { set_psoa }\end{array}\right]$ & $\begin{array}{l}\text { entity } \\
\text { cont }\end{array}$ \\
\hline
\end{tabular}




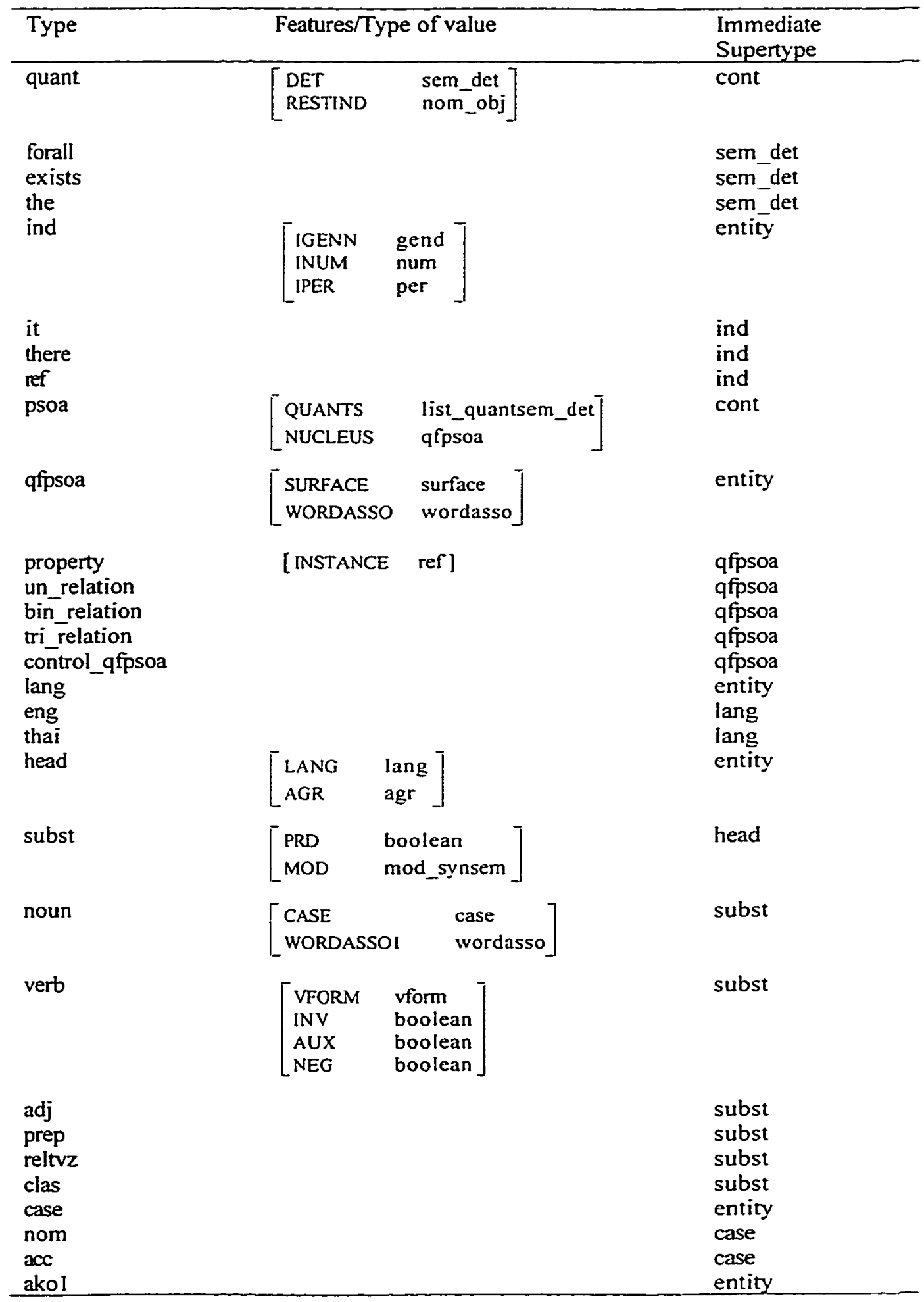




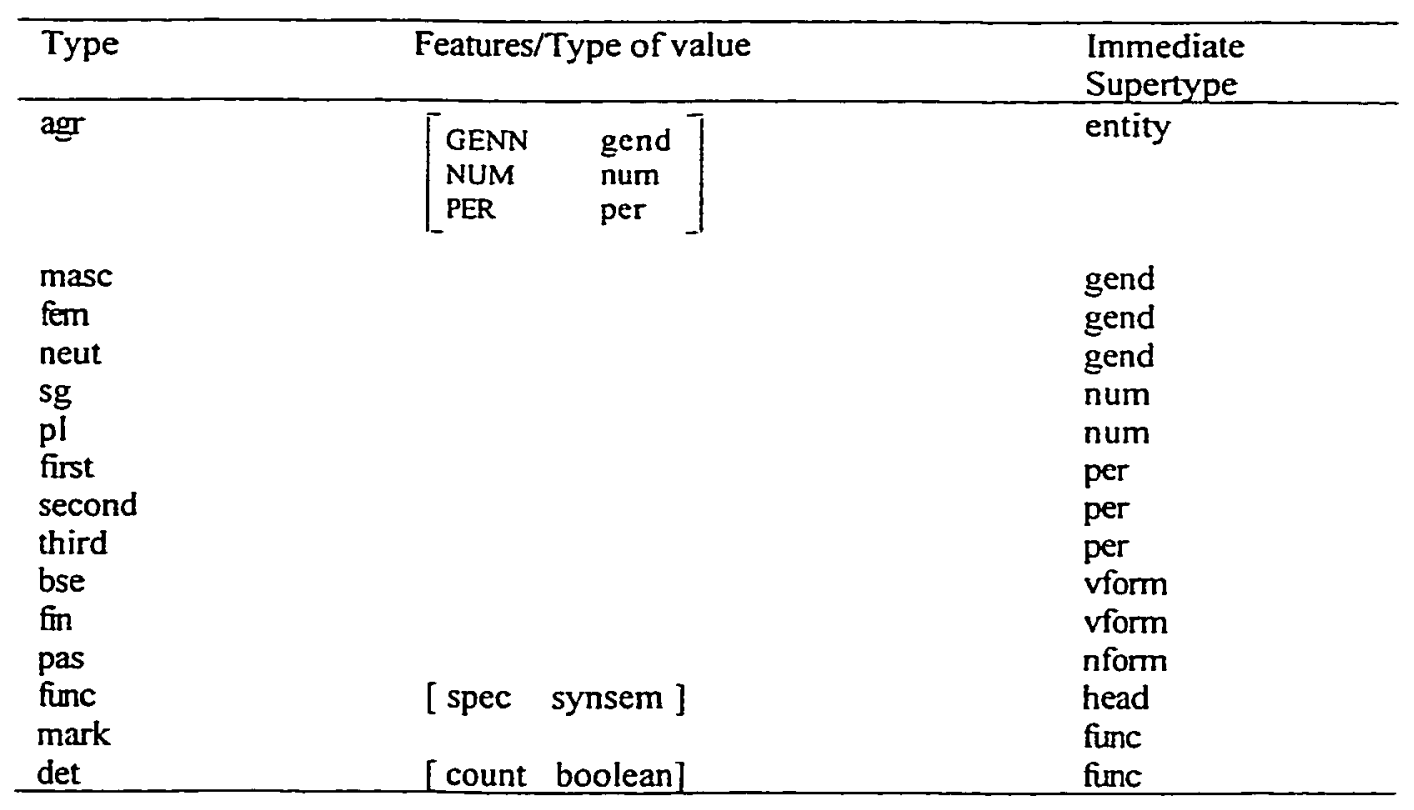




\section{Appendix E}

\section{Lexical Rules}

This appendix contains the lexical rules discussed in section 6.1.1.3. Our lexical rule is adapted from the lexical rule which was provided by Gerald Penn [Penn 1993] and Colin Matheson [Matheson 1996]. Lexical rules 1-6 are used for deriving the third singular verb, simple past verb, present participle verb, passive verb and plural noun for English lexical entries. Lexical rule 6 is used to form the simple past verb for Thai.

I. The 3 rd-singular verb lexical rule

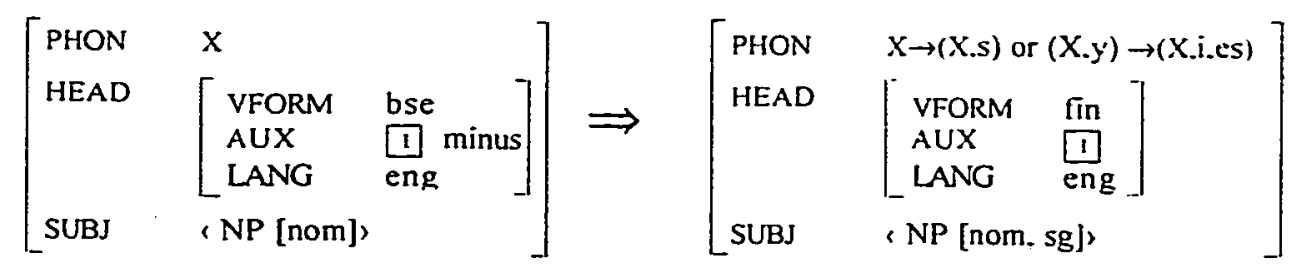

2. The simple-past verb lexical rule

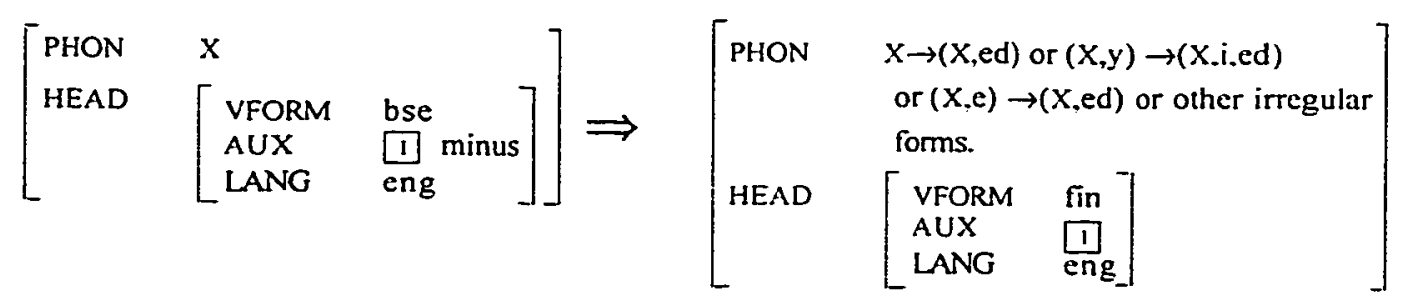


3. The present-participle lexical rule

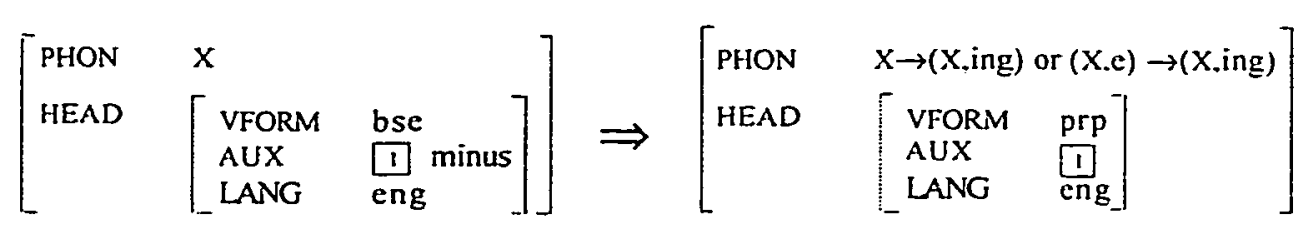

4. The passive lexical rule

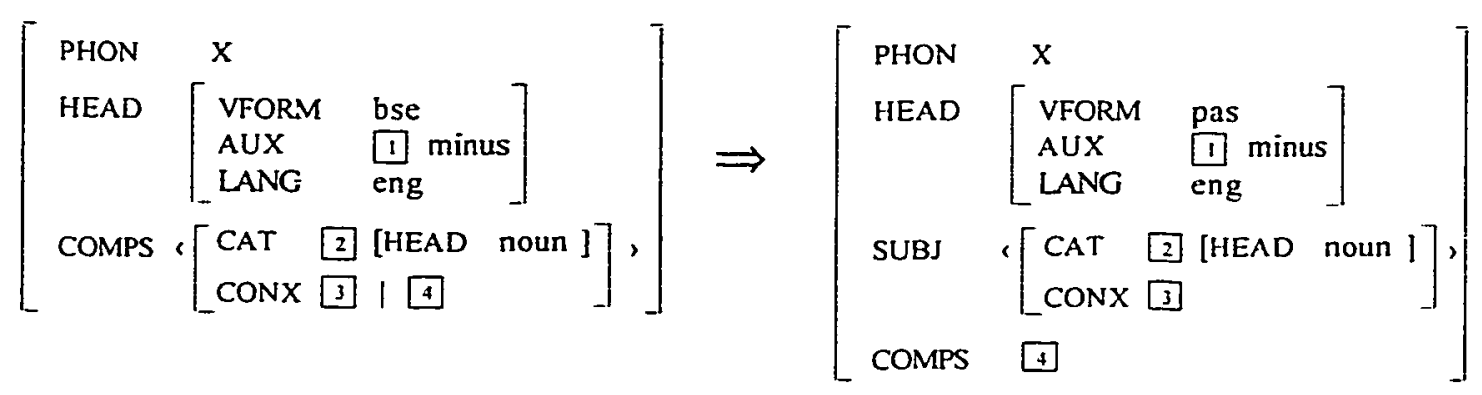

5. The plural noun formation

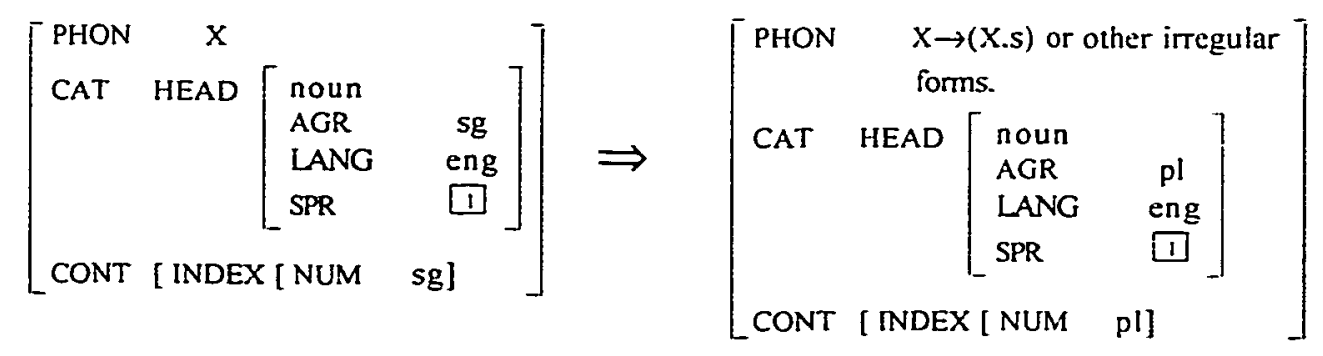

6. The Thai simple_past lexical rule

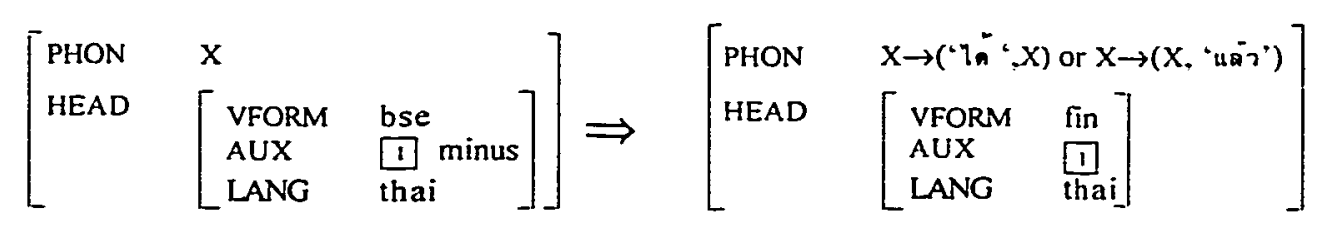


It is noted that the Thai verb does not have an inflection resulting from verb agreement (see section 4.1). The words แล่ว ( $\left.\mid \varepsilon^{\prime} \varepsilon w\right)$ and ได้ (dâj) are added to the verb to indicate past tense. แล่ว ( $\left.l \varepsilon^{\prime} \varepsilon w\right)$ appears immediately after the verb whereas ได้ (dâi) immediately precedes the verb. 


\section{Appendix F}

\section{SL and TL Grammars}

This appendix contains the English and Thai grammars discussed in section 6.1.1.6. Our grammar is a modification to the grammars which were provided by Gerald Penn [Penn 1993] and Colin Matheson [Matheson 1996].

\section{F.1 English Grammar}

1. Subject_Head Rule

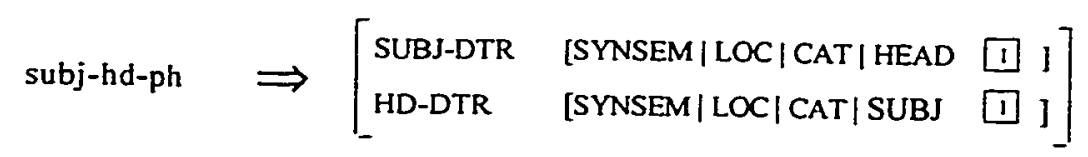

2. Head_Complement rule

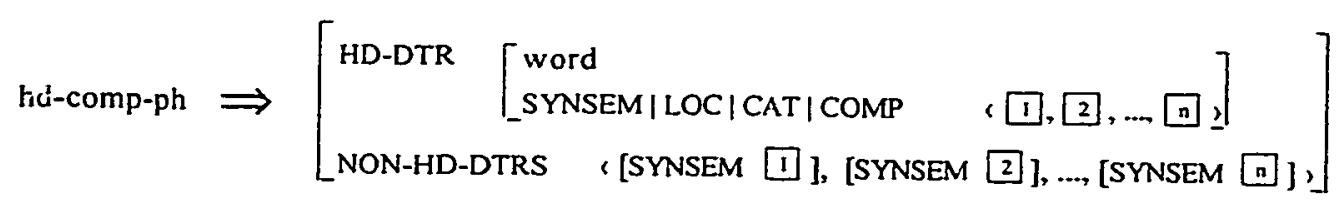




\section{Coordination rule}

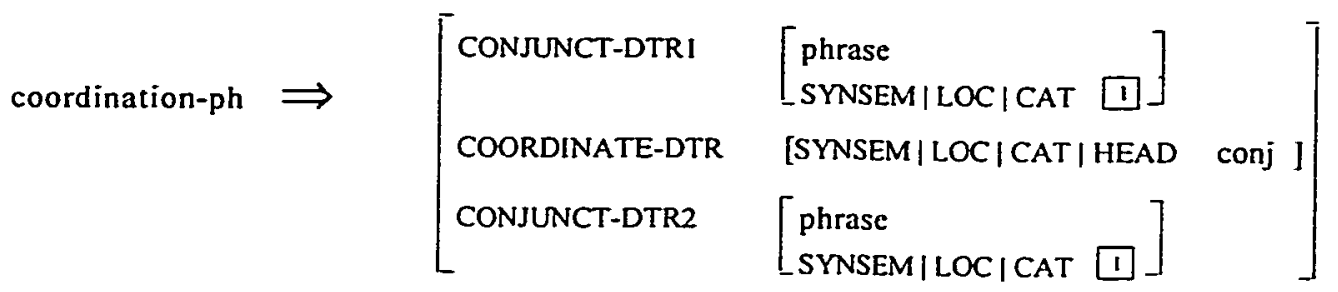

4. Head_Subject_Complement Rule

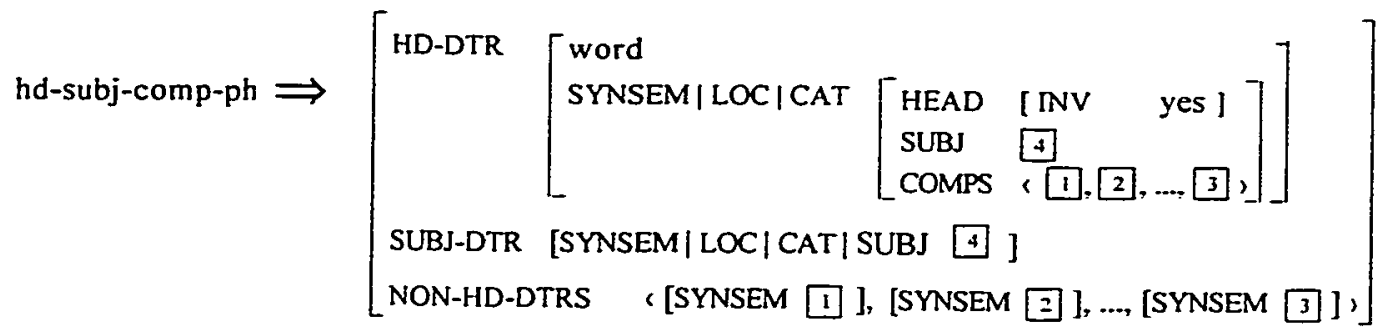

5. Specifier_head_Rule

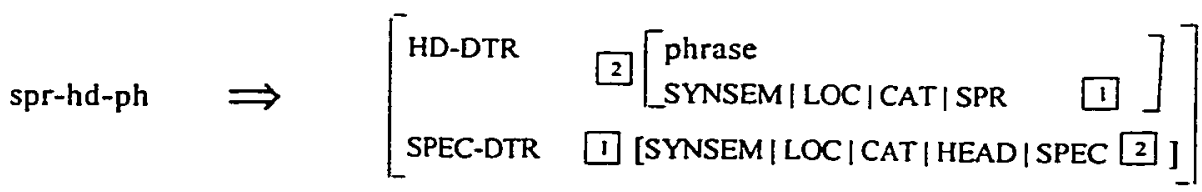

6. Adjunct_head and Head_adjunct rules

$$
\begin{aligned}
& \operatorname{adjunct-hd-ph} \Rightarrow\left[\begin{array}{cc}
\text { ADJUNCT-DTR } & \text { [SYNSEM } \mid \text { LOC } \mid \text { CAT } \mid \text { HEAD } \mid \text { MOD } 2, \\
\text { HD.DTR } & 2 \text { ( phrase ] }
\end{array}\right] \\
& \text { hd- adjunct-ph } \Rightarrow\left[\begin{array}{lll}
\text { HD-DTR } & 2] \text { [ phrase ] } \\
\text { ADJUNCT-DTR } & \text { [SYNSEM / LOC ICAT | HEAD IMOD } & 2], \\
& & \text { post_mod_synsem ] }
\end{array}\right]
\end{aligned}
$$




\section{F.2 Thai Grammar}

\section{Subject Head Rule}

$$
\text { subj-hd-ph } \Rightarrow\left[\begin{array}{lll}
\text { SUBJ-DTR } & \text { [SYNSEM | LOC I CAT I HEAD } & 01 \\
\text { HD-DTR } & \text { [SYNSEM I LOC } \mid \text { CAT } \mid \text { SUBJ } & 0]
\end{array}\right]
$$

2. Head_Complement rule

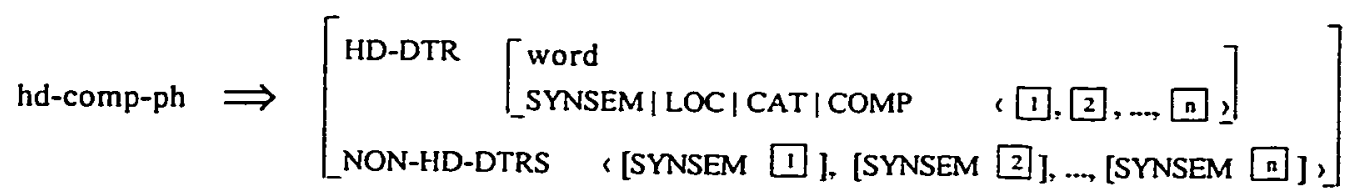

3. Coordination rule

$$
\text { coordination-ph } \Rightarrow\left[\begin{array}{ll}
\text { CONJLNCT-DTRI } & {\left[\begin{array}{l}
\text { phrase } \\
\text { SYNSEM/LOCICAT } \square
\end{array}\right]} \\
\text { COORDINATE-DTR } & {[\text { SYNSEM|LOCICAT|HEAD conj ] }} \\
\text { CONJUNCT-DTR2 } & {\left[\begin{array}{l}
\text { phrase } \\
\text { SYNSEM|LOCICAT } \square
\end{array}\right]}
\end{array}\right]
$$

4. Head_specifier Rule

$$
\text { hd-spr-ph } \Rightarrow \quad\left[\begin{array}{ll}
\text { HD-DTR } & \square\left[\begin{array}{ll}
\text { phrase } & \\
\text { SYNSEM | LOC } \mid \text { CAT } \mid \text { SPR } & 0
\end{array}\right] \\
\text { SPEC-DTR } & \square\left[\text { SYNSEM | LOC } \mid \text { CAT } \mid \text { HEAD } \mid \text { SPEC }\left[\begin{array}{l}
2]
\end{array}\right]\right.
\end{array}\right.
$$


5. Adjunct_head and Head_adjunct rules

$$
\begin{aligned}
& \operatorname{adjunct-hd-ph} \Rightarrow\left[\begin{array}{cc}
\text { ADJUNCT-DTR } & {[\text { SYNSEM } \mid \text { LOC } \mid \text { CAT } \mid \text { HEAD } \mid \text { MOD } 2,} \\
\text { HD-DTR } & 2] \text { pre_mod_synsem ] }
\end{array}\right] \\
& \text { hd- adjunct-ph } \Rightarrow\left[\begin{array}{ll}
\text { HD-DTR } & 2] \text { [ phrase ] } \\
\text { ADJUNCT-DTR } & \text { [SYNSEM | LOCICAT | HEAD IMOD } 2 . \\
&
\end{array}\right.
\end{aligned}
$$




\section{Appendix G}

\section{Intelligibility and Fidelity Evaluation}

This appendix contains the evaluation of ALMT with respect to intelligibility and fidelity as outlined in Chapter 8.

\section{Source Text:}

Sentence 1- 76: The ugly duckling version written by Ronne Randall (1987).

Sentence 77-90: Newspapers and Articles.

\section{Translators:}

HM1: Thai Linguist

HM2: Thai Student (Graduate School)

\section{Legends:}

Inappropriate word usage: This word does not distort the meaning of the expression but it is inappropriate.

Incorrectly translated word: This word is incorrectly translated. It causes the sentence to be meaningless or the sentence conveys a different meaning from the original.

א Misplaced word: The word is wrongly placed and it affects the meaning of the sentence. It should be moved in the direction of the arrow.

त Misplaced word: The word is wrongly placed and it affects the meaning of the sentence. It should be moved in the direction of the arrow. 


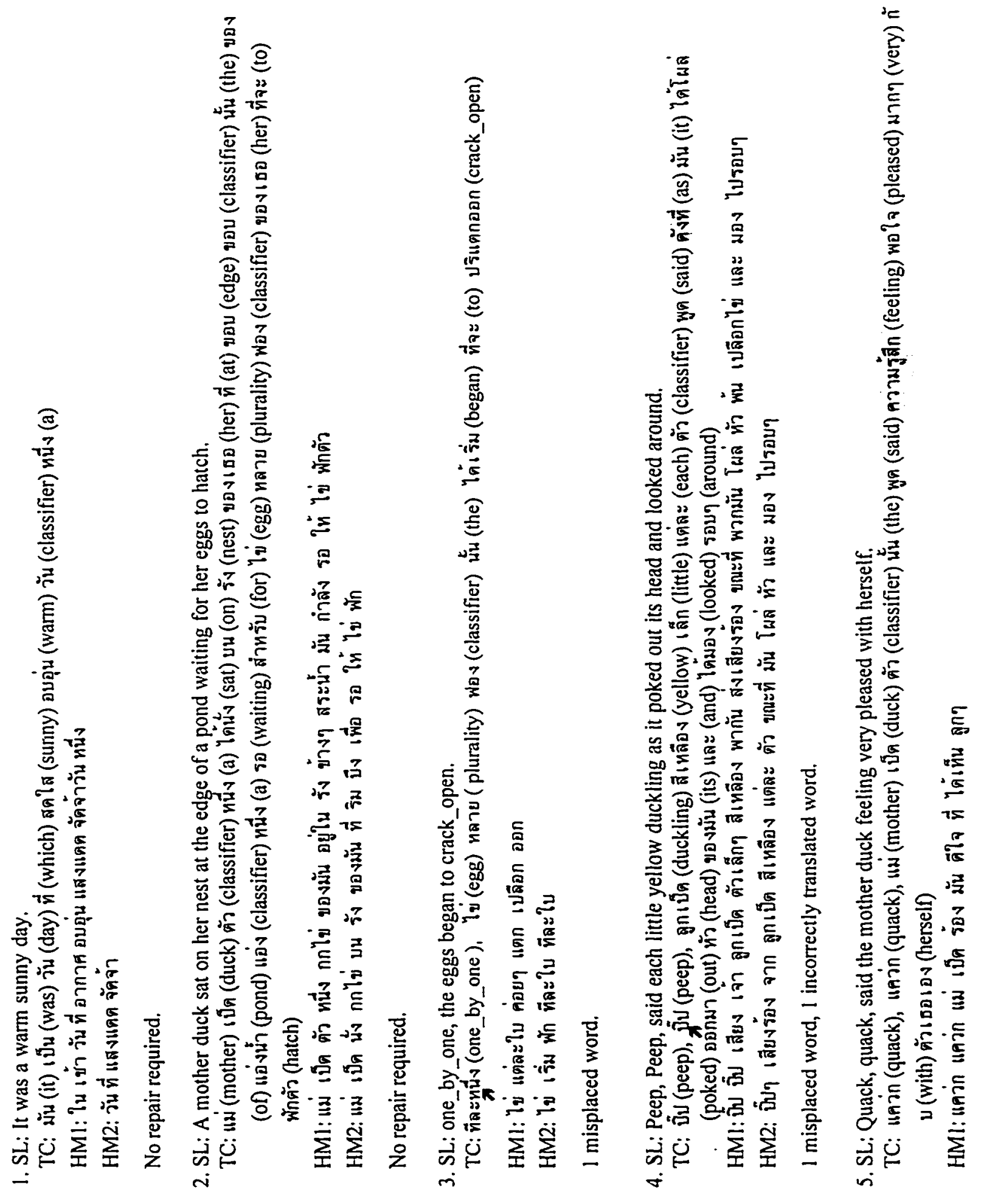




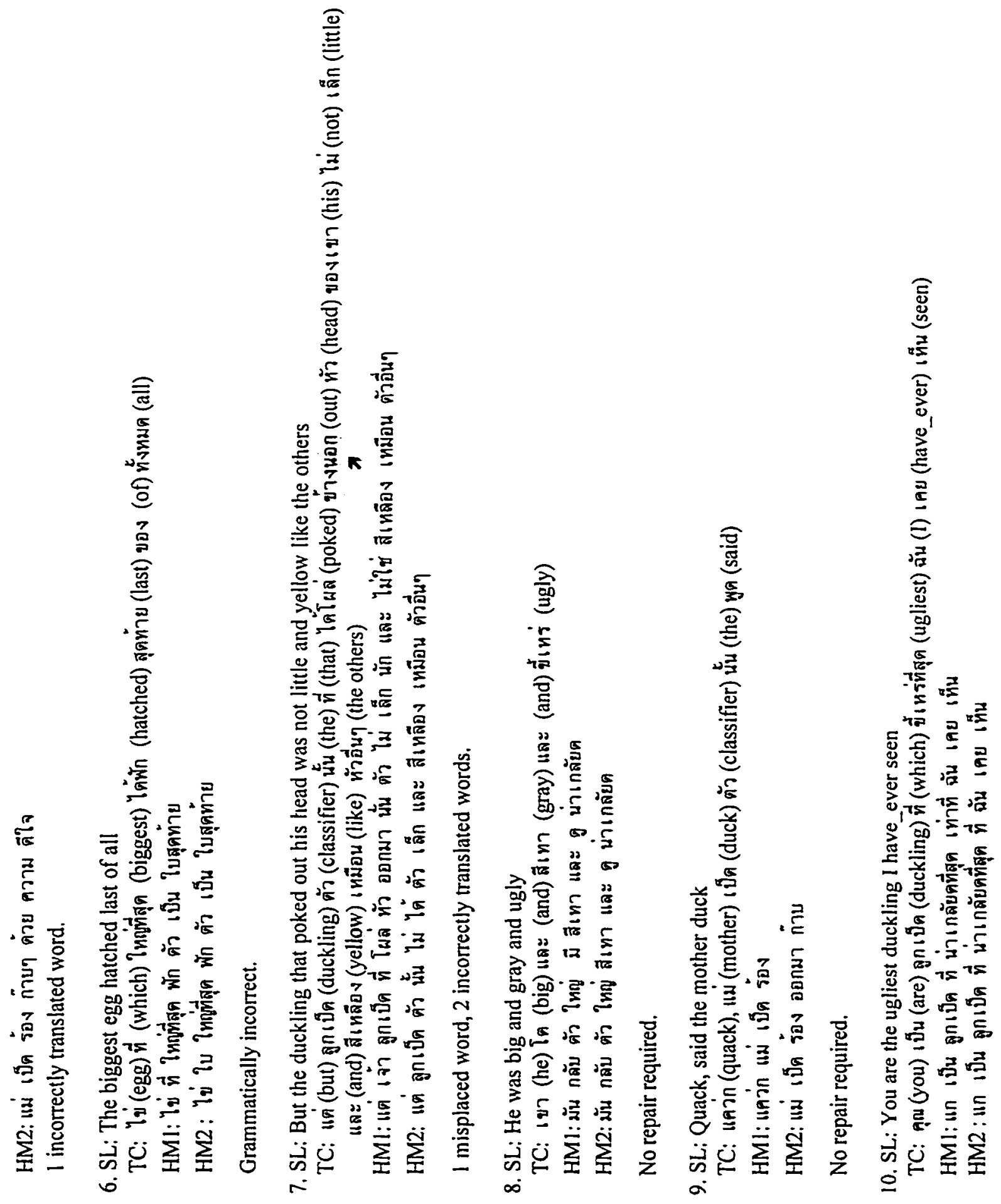




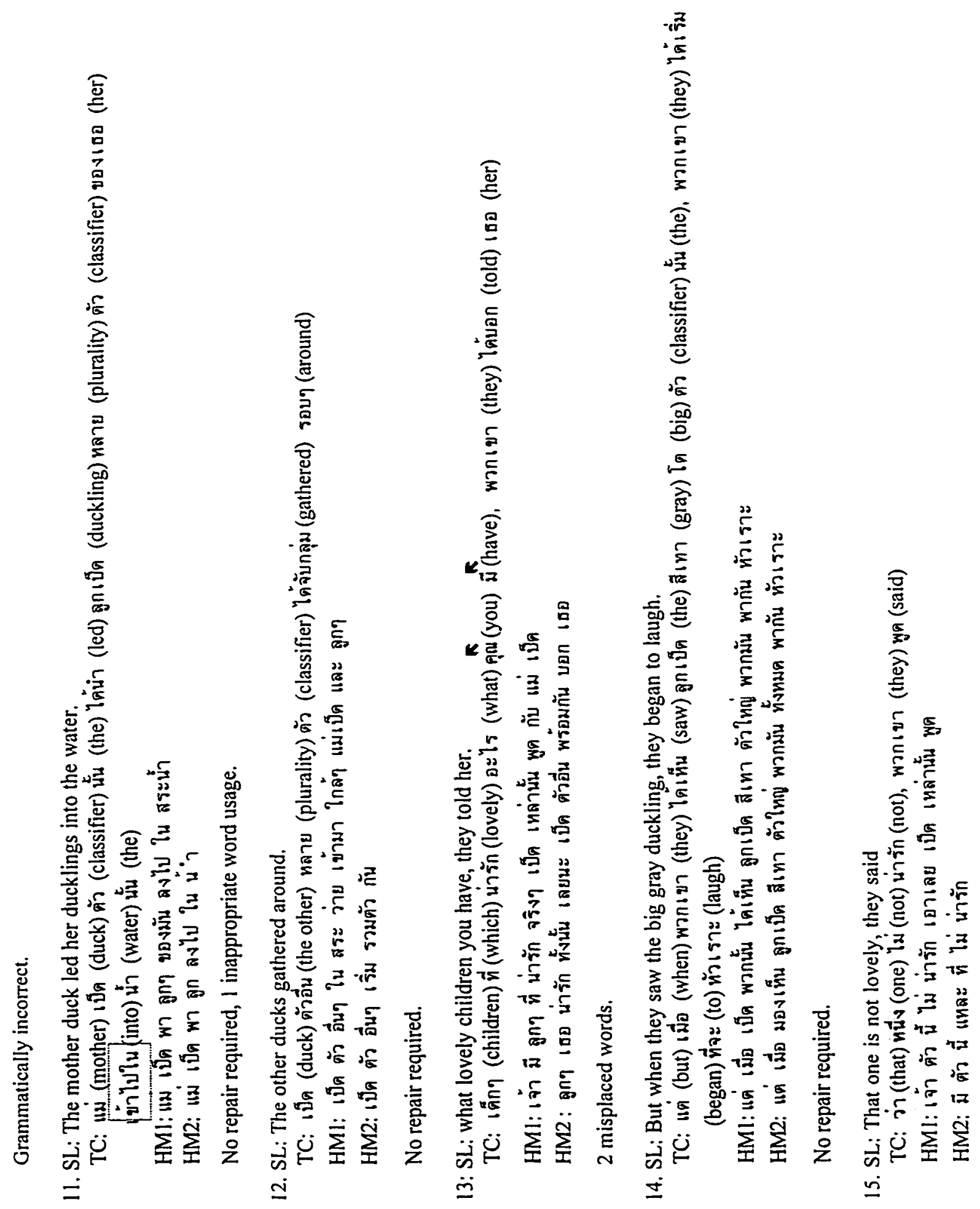




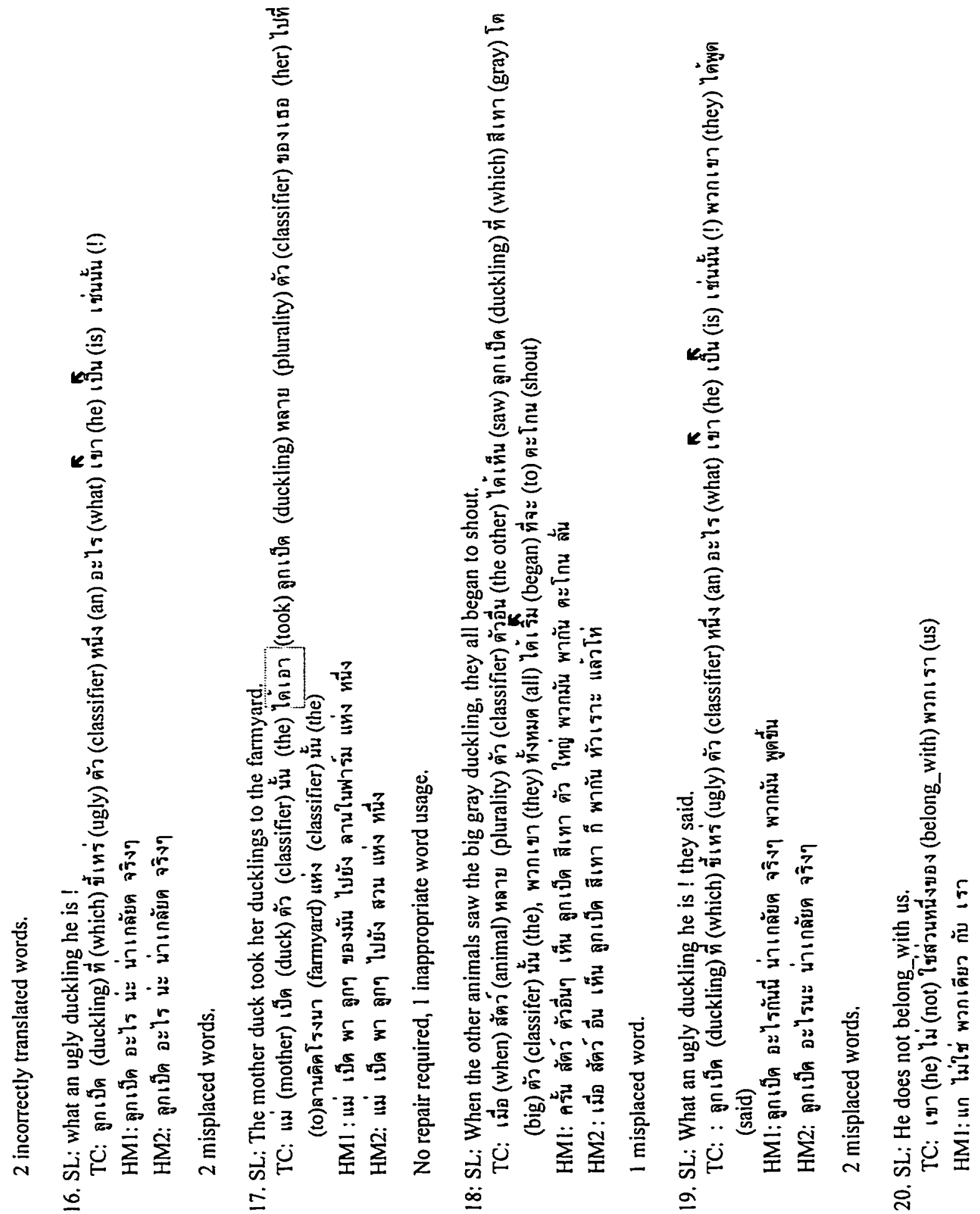




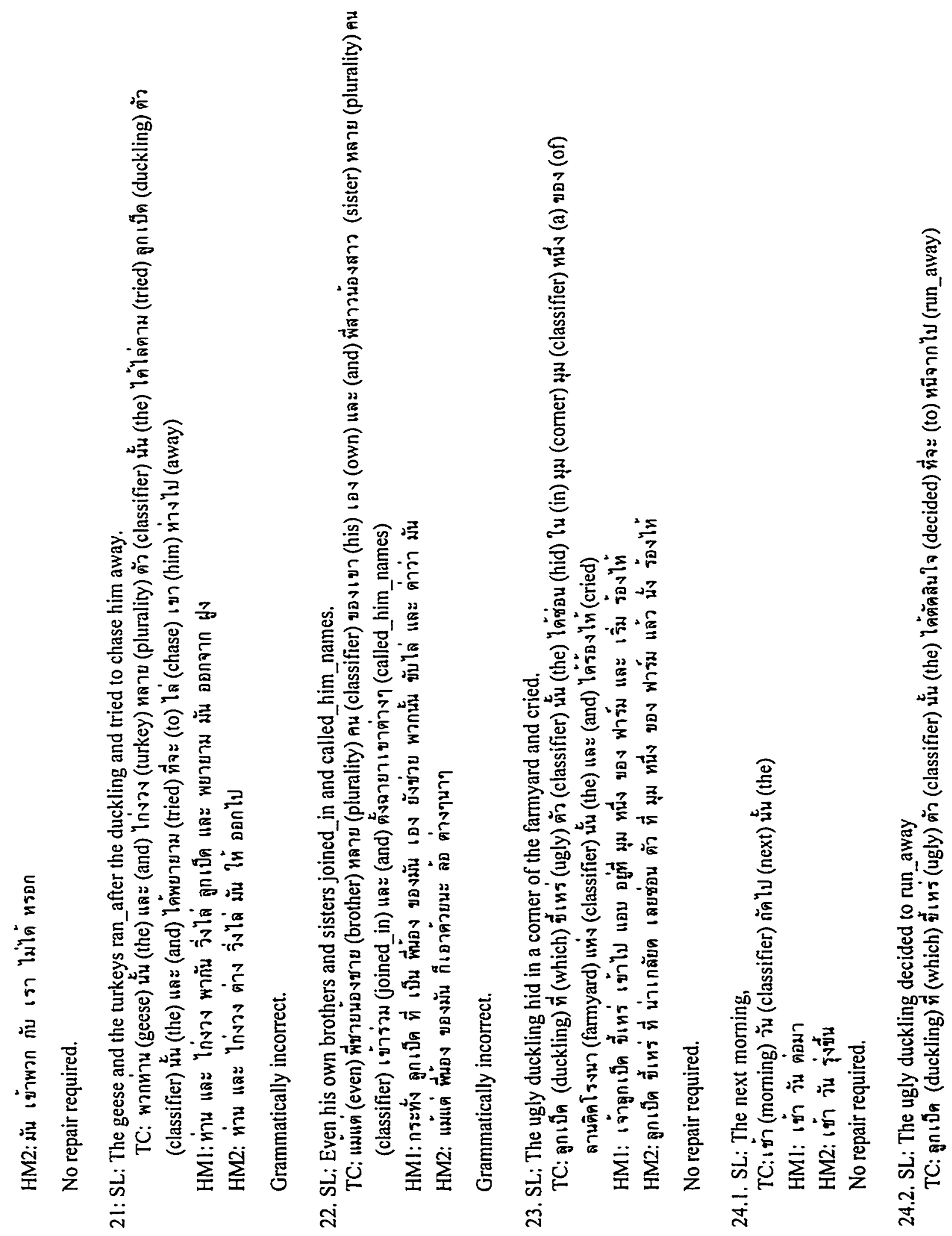




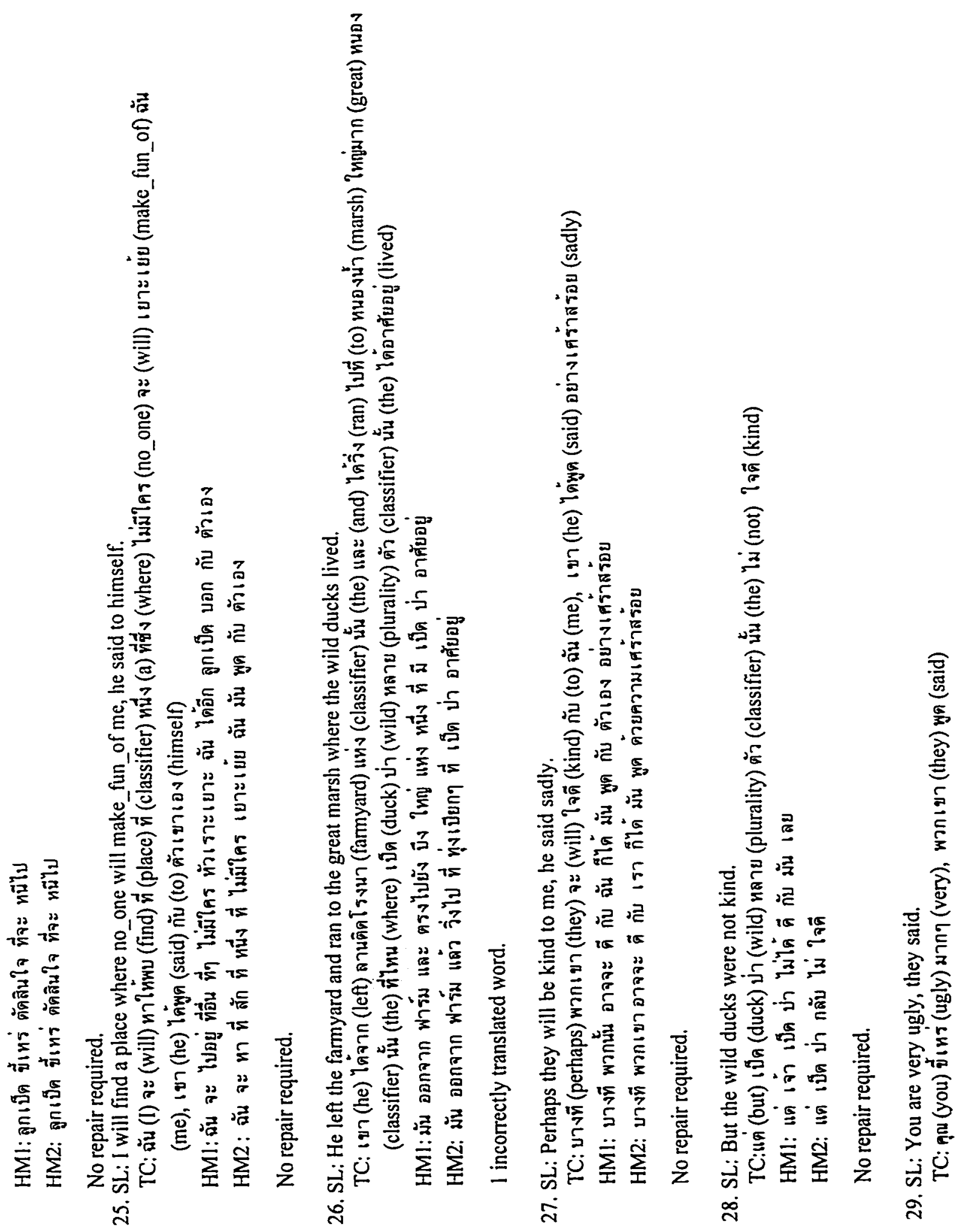




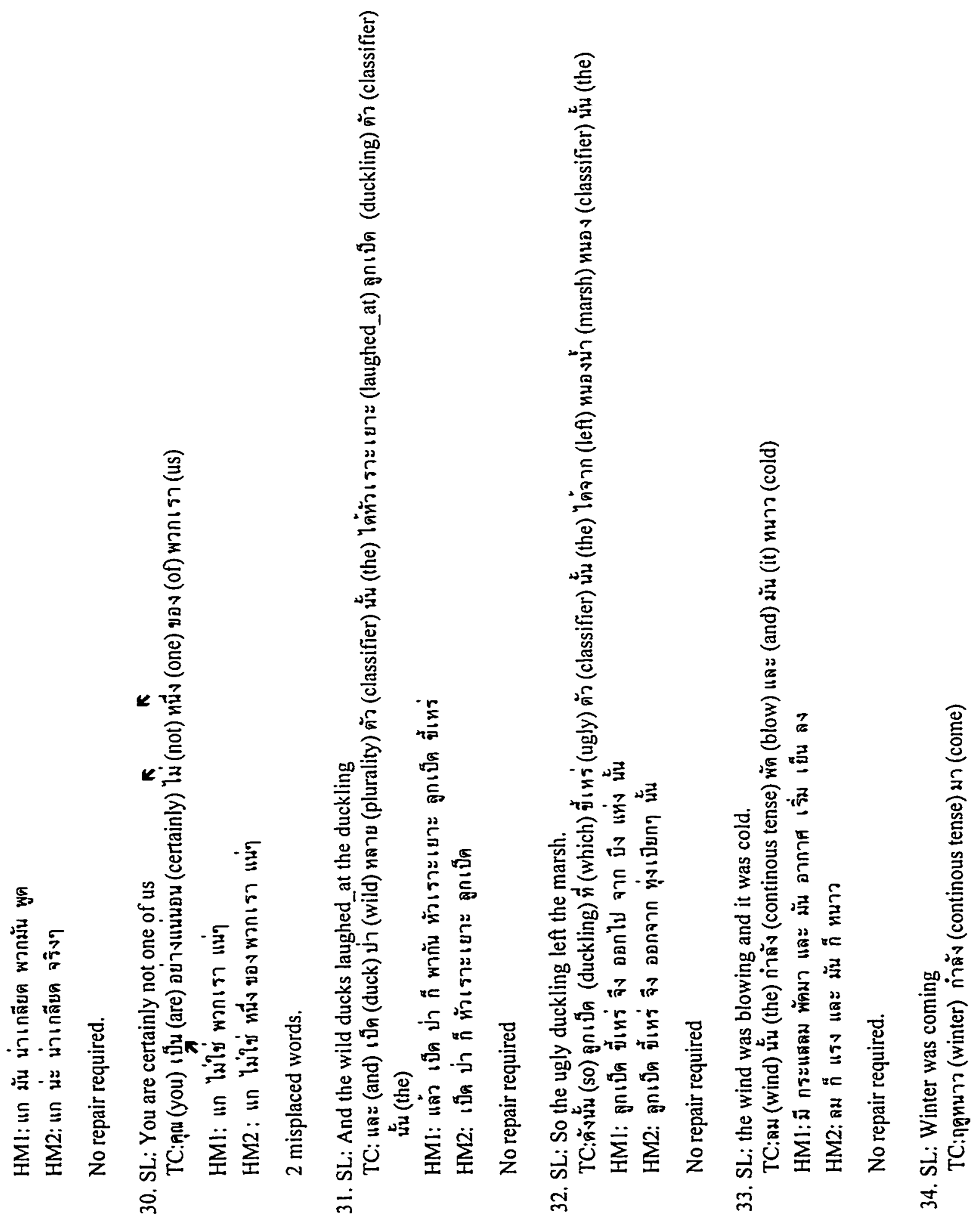




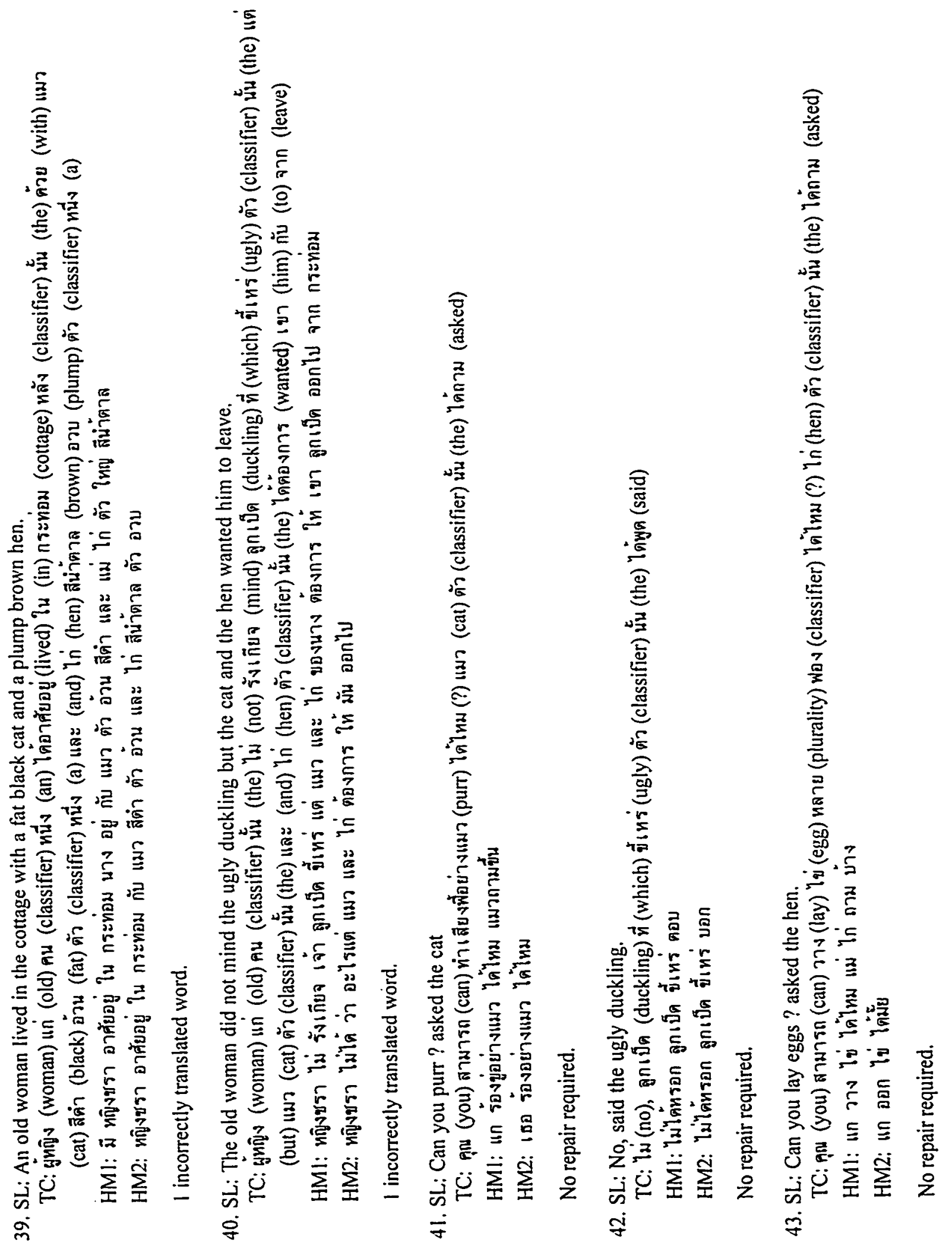




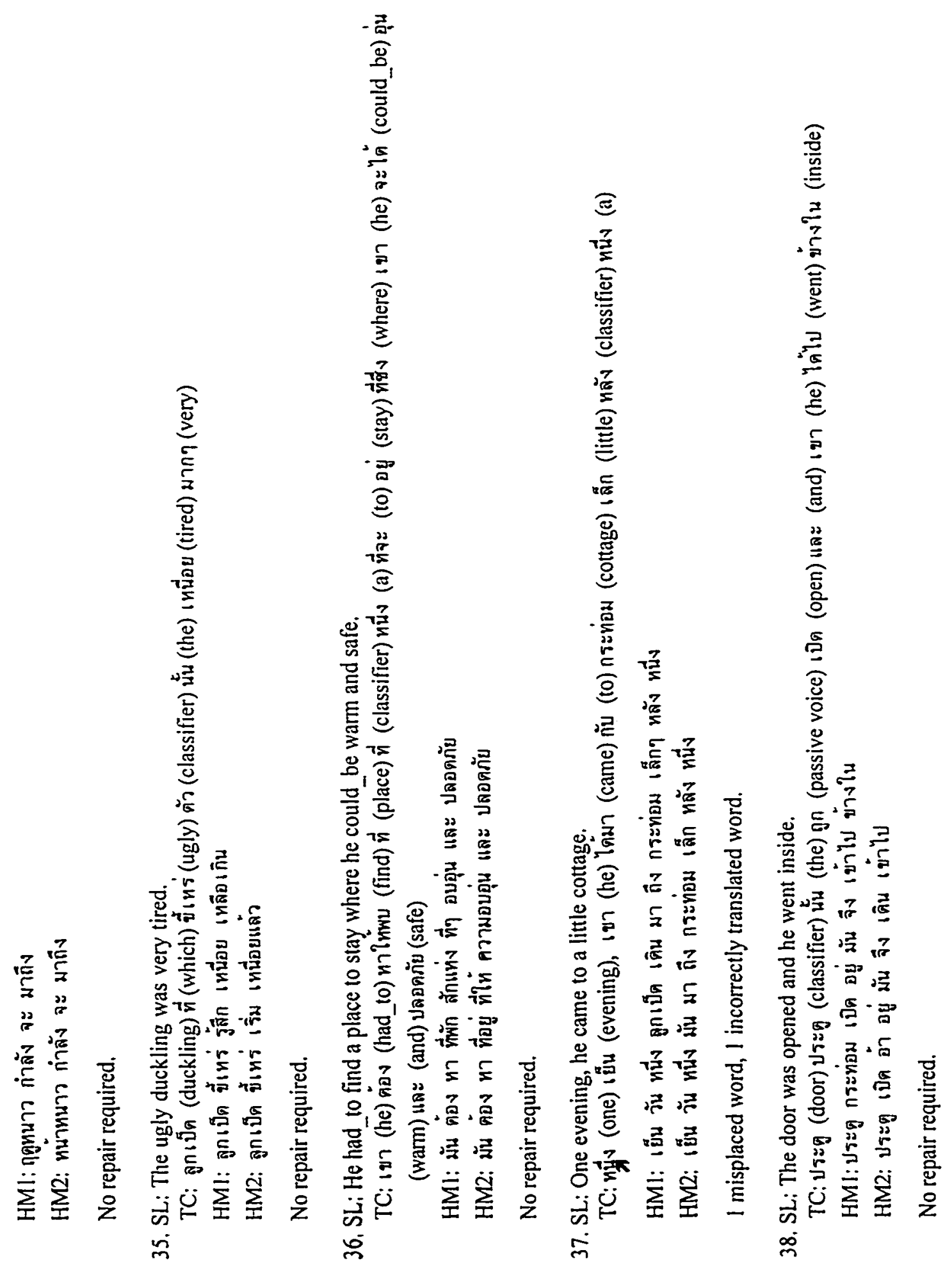




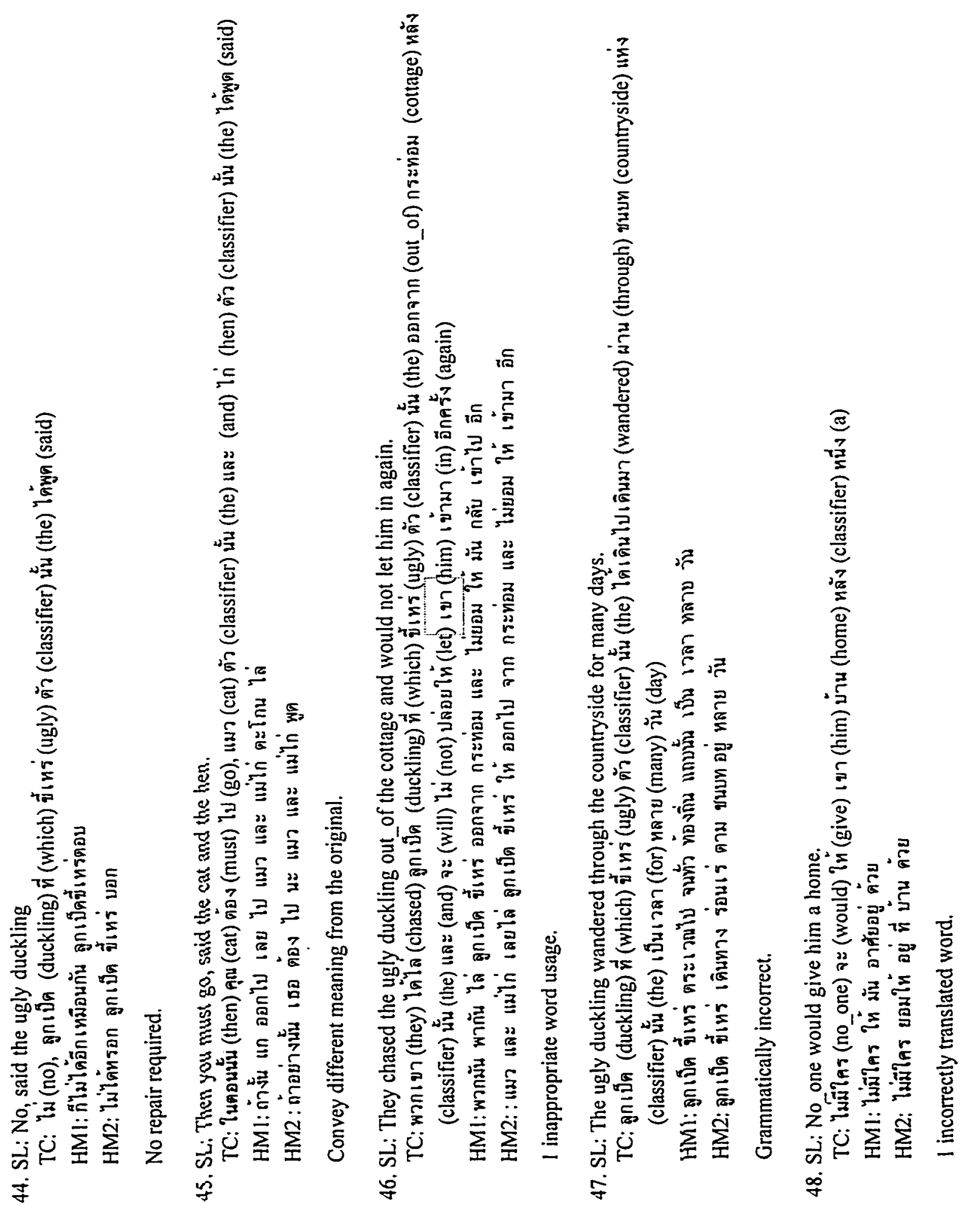




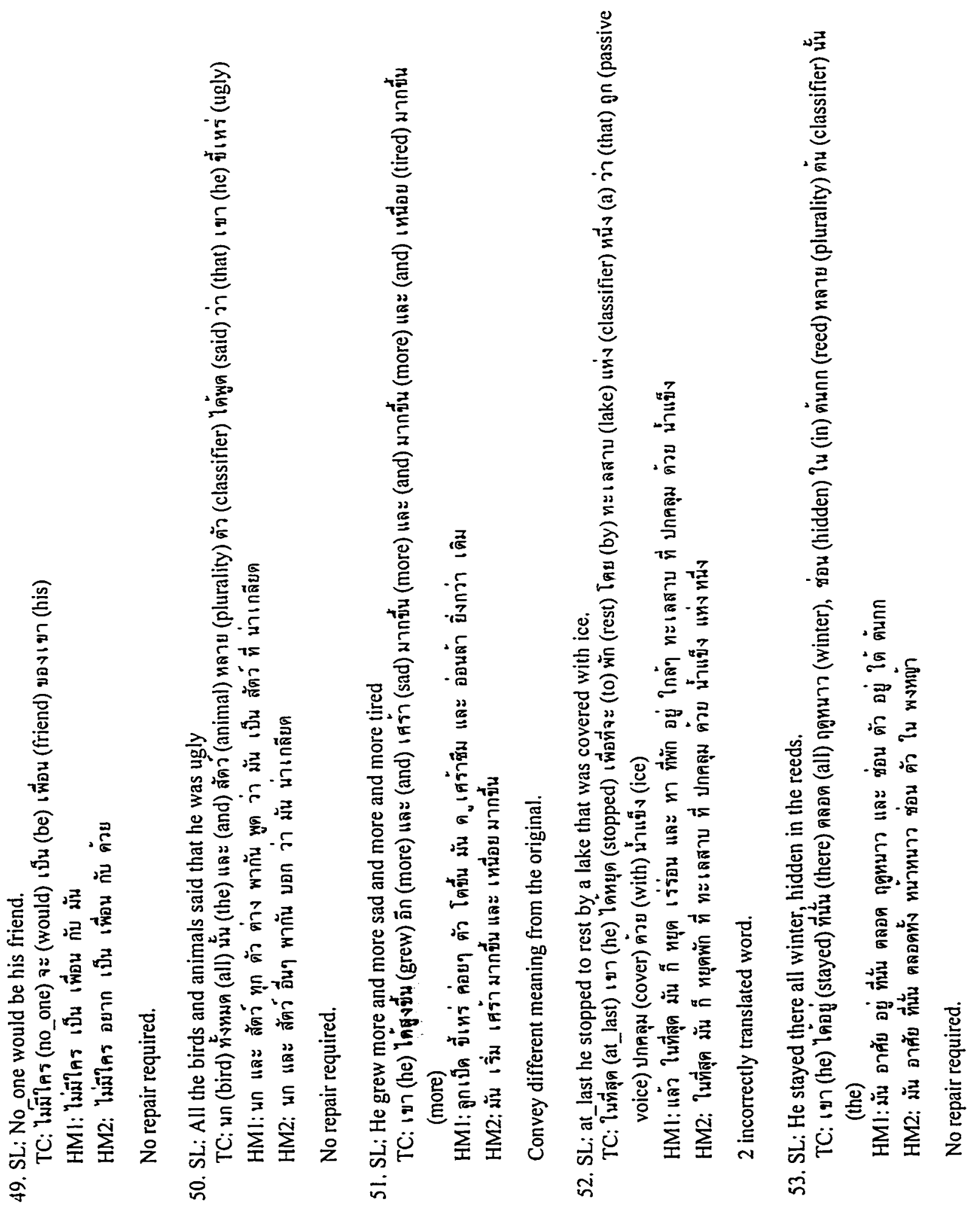




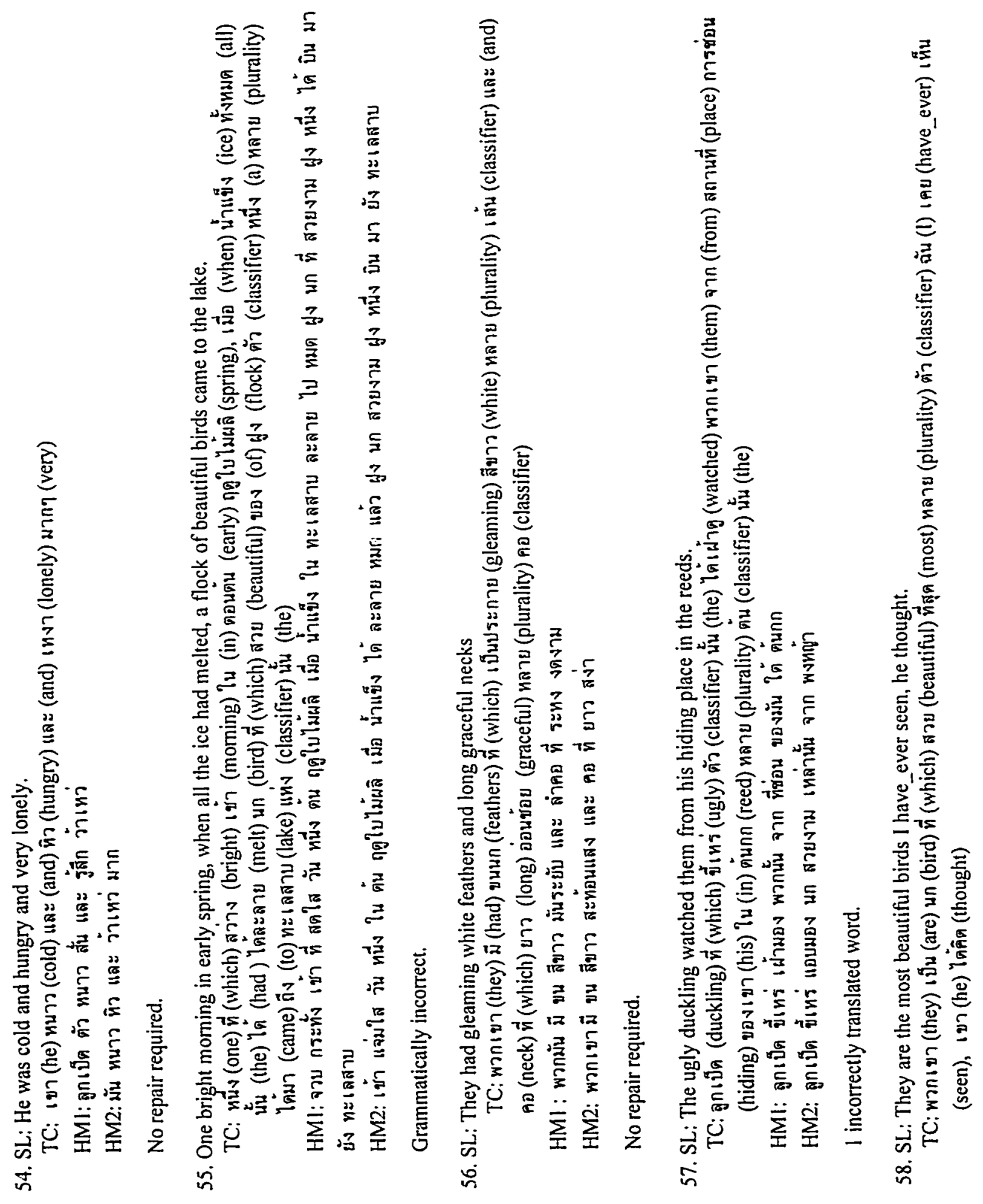




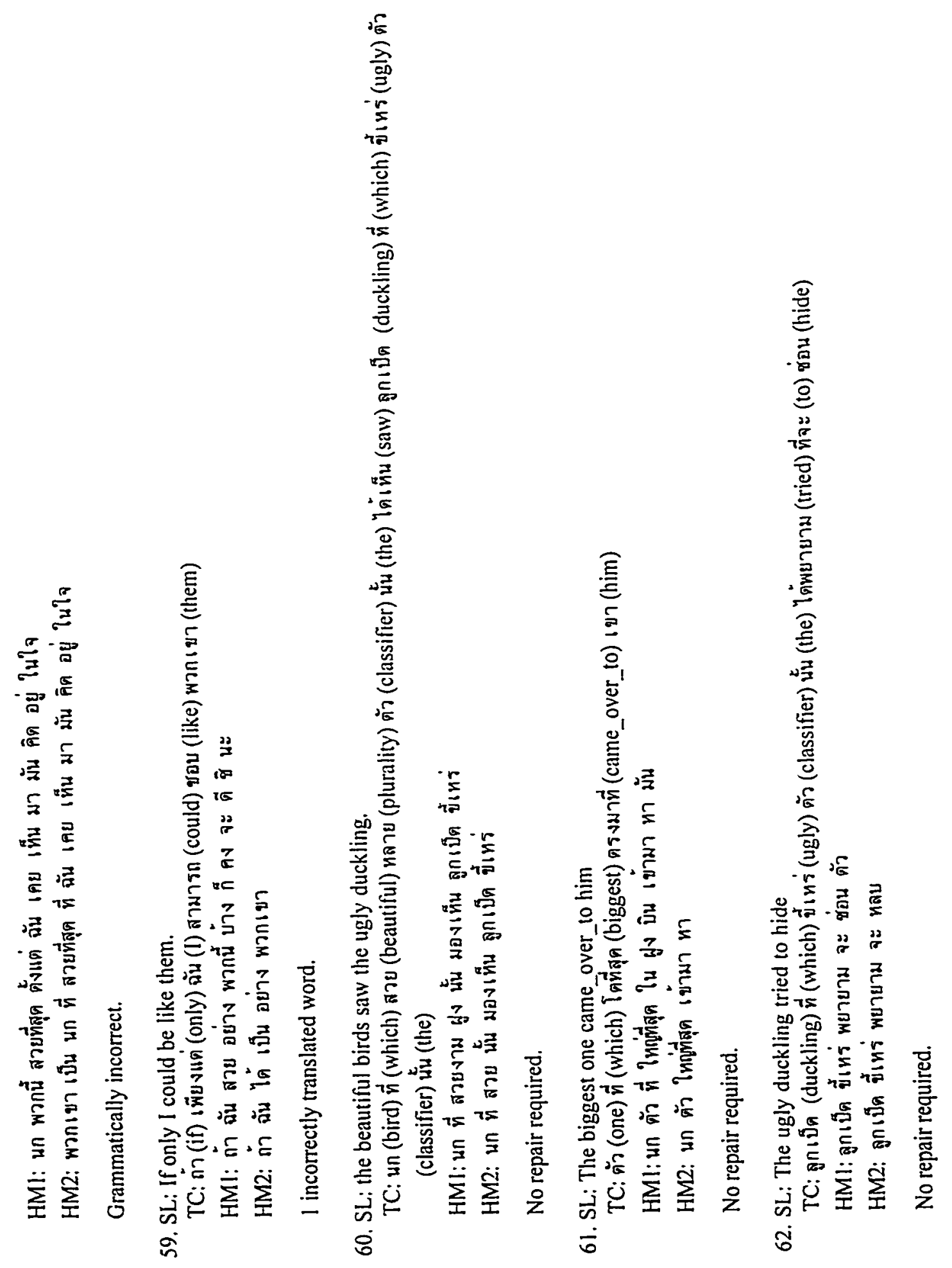



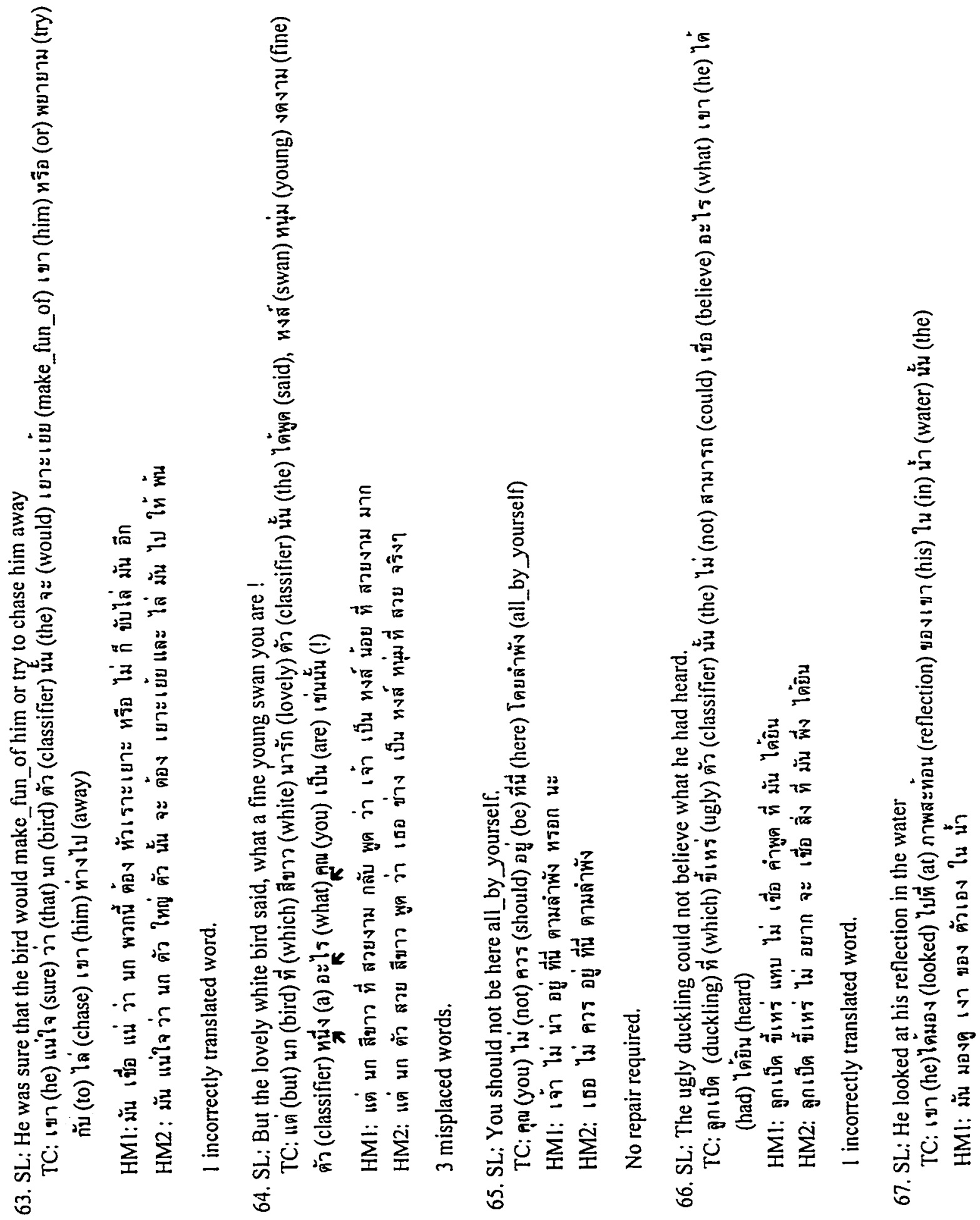


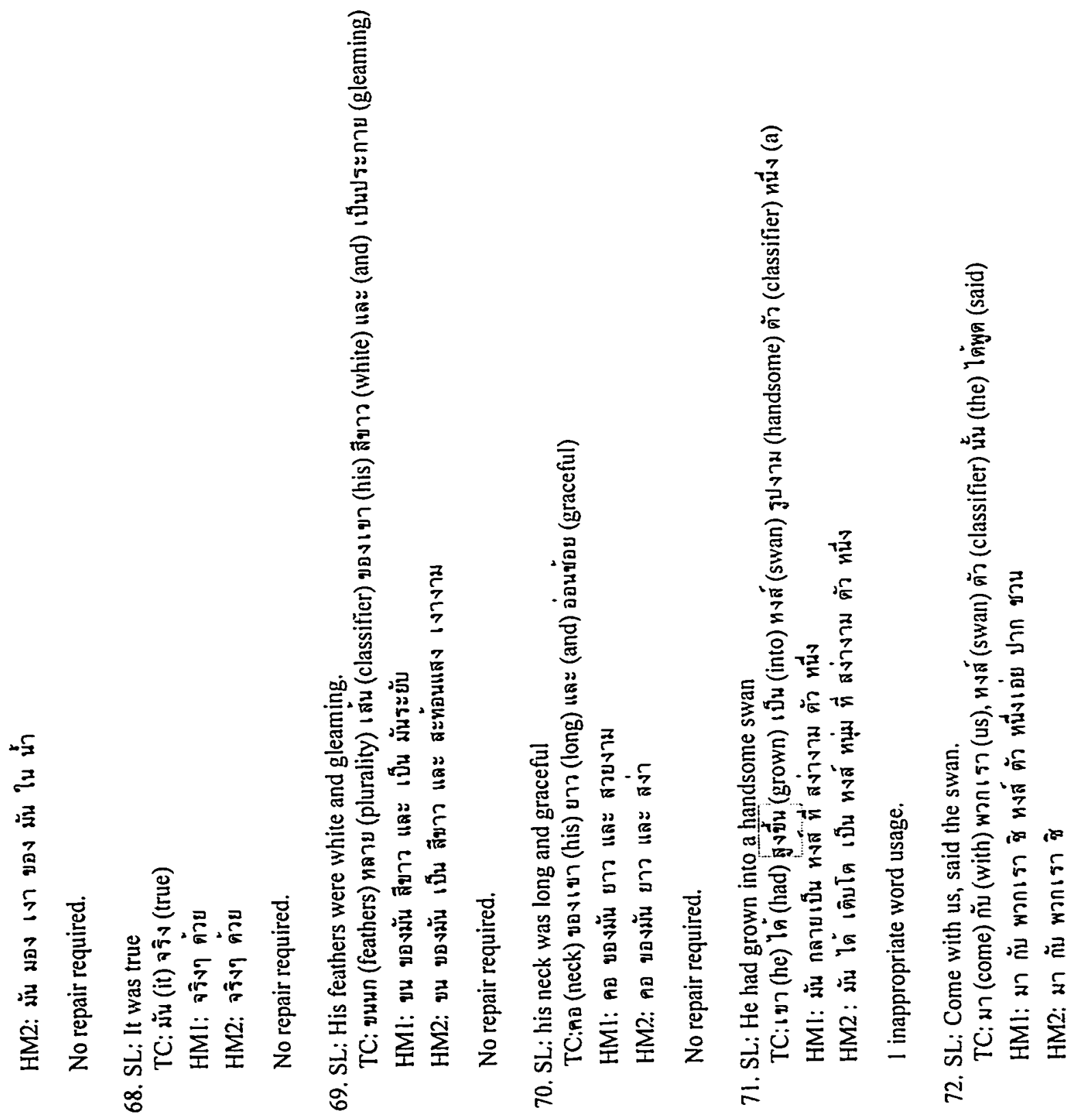




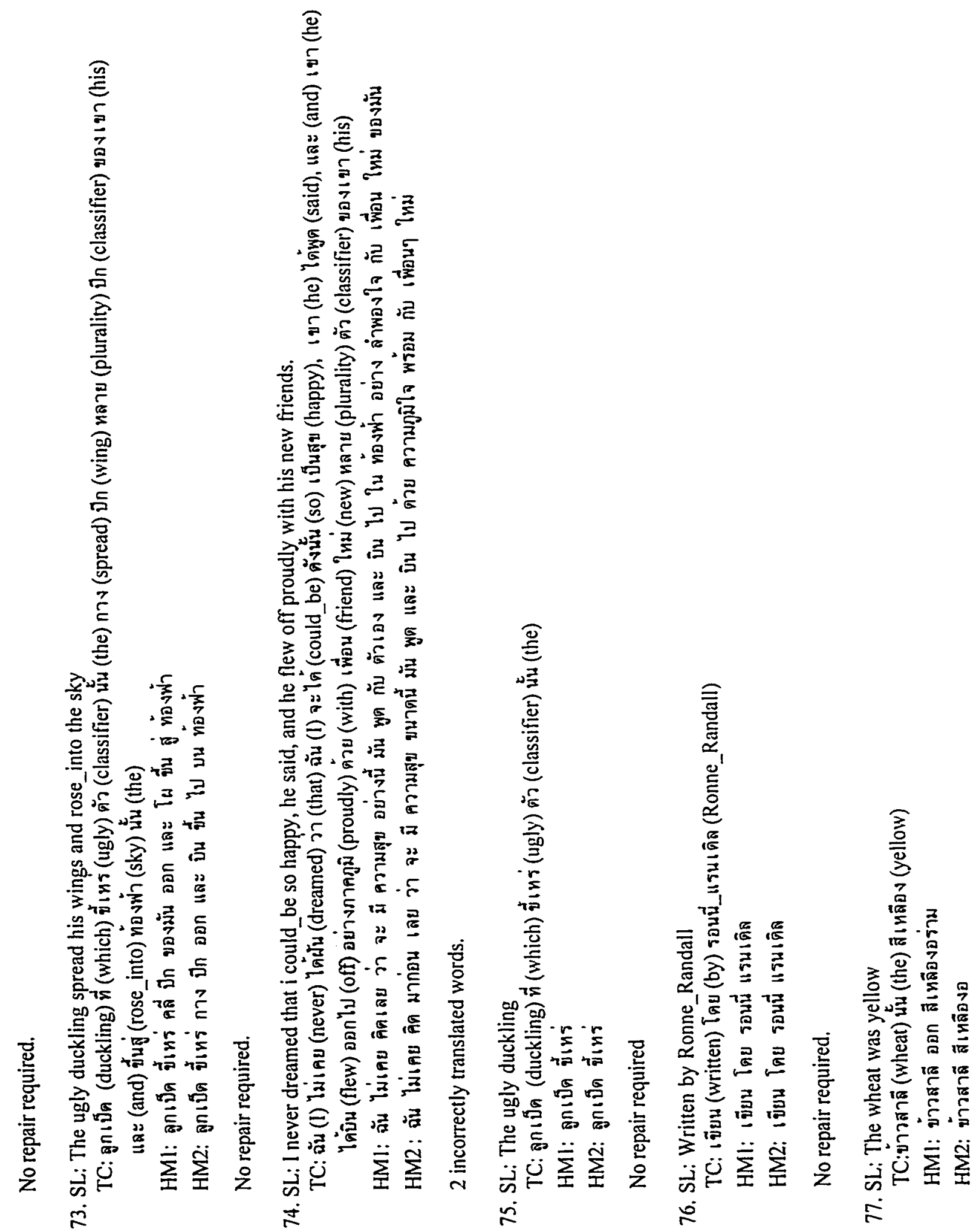




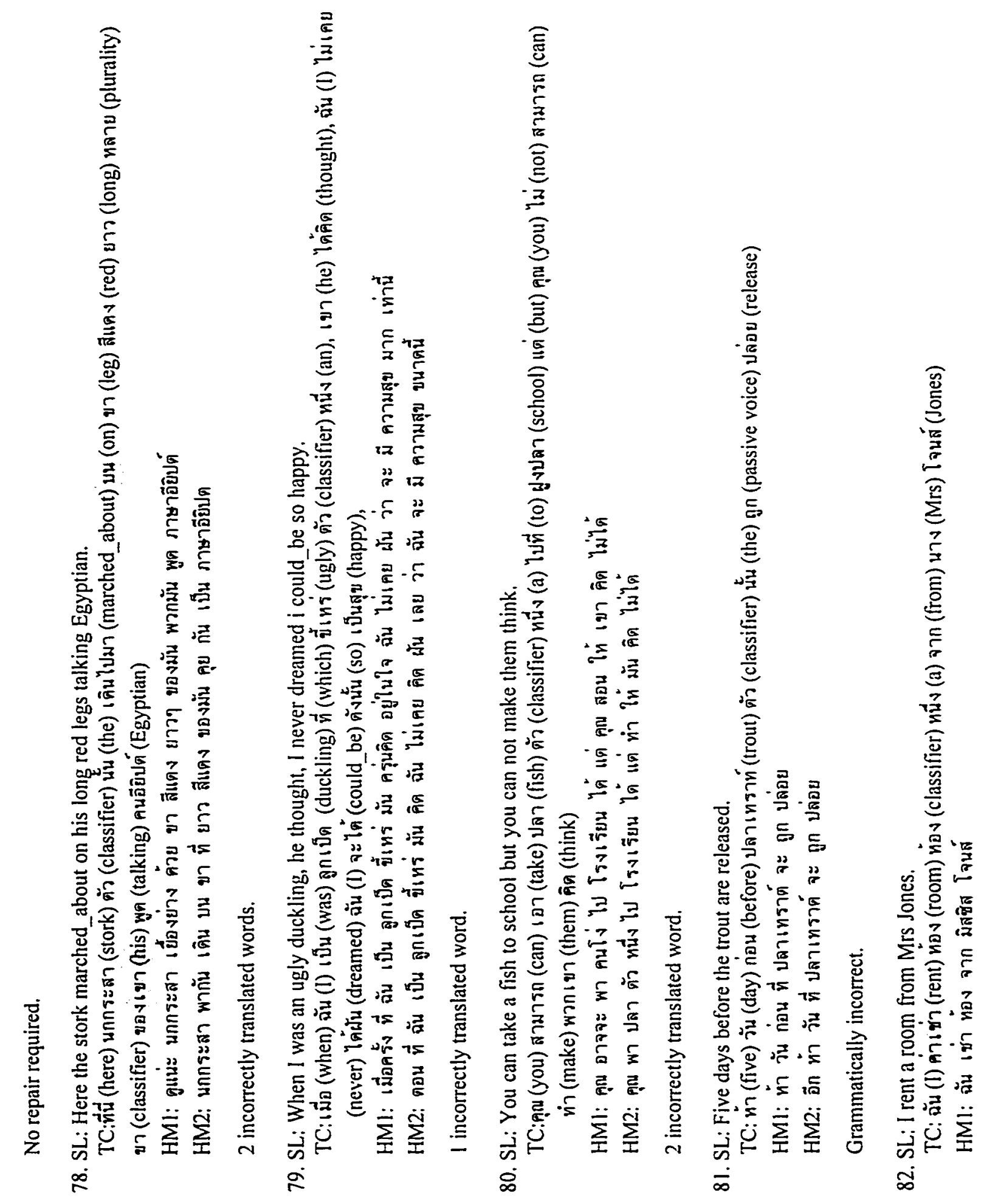




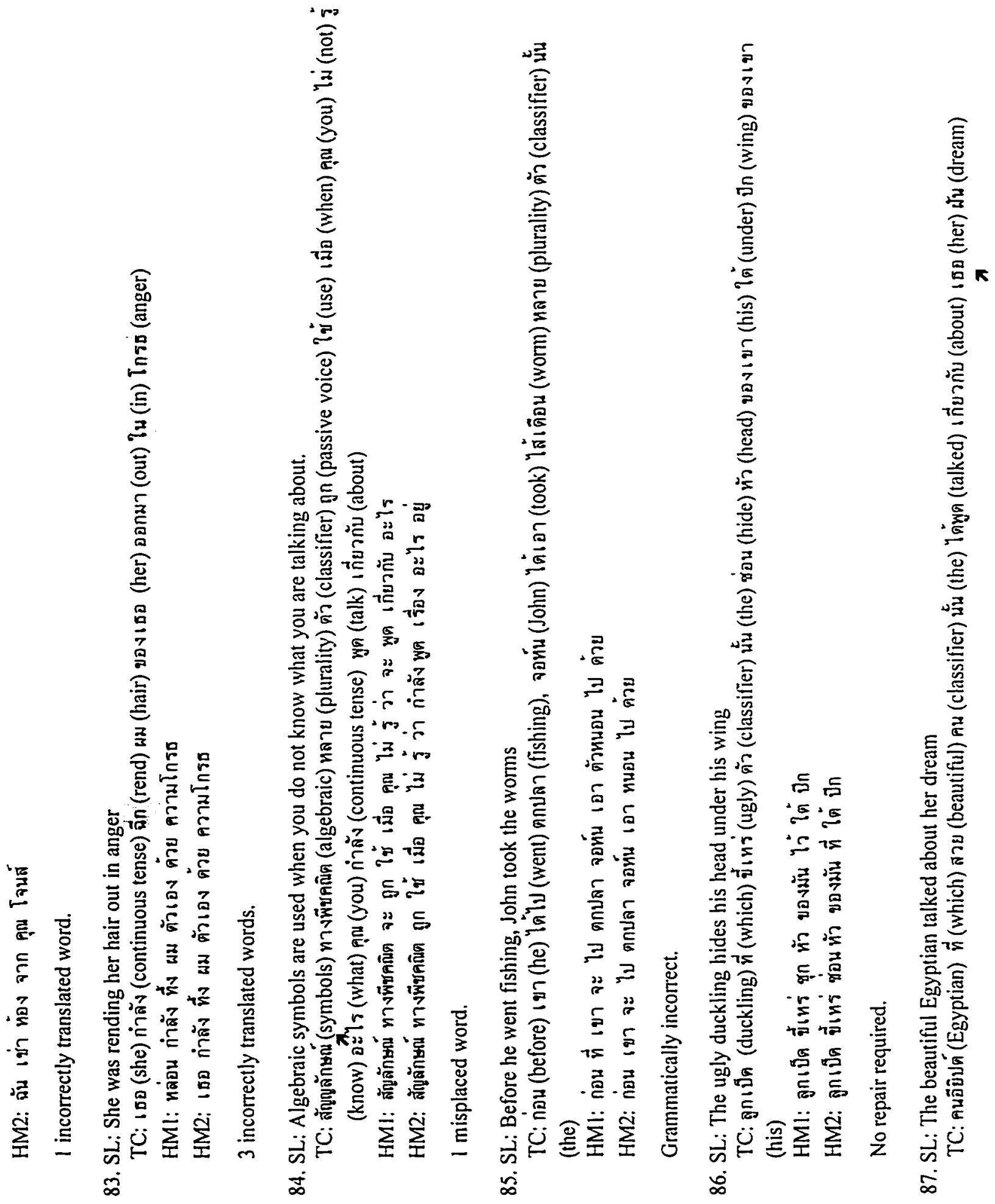




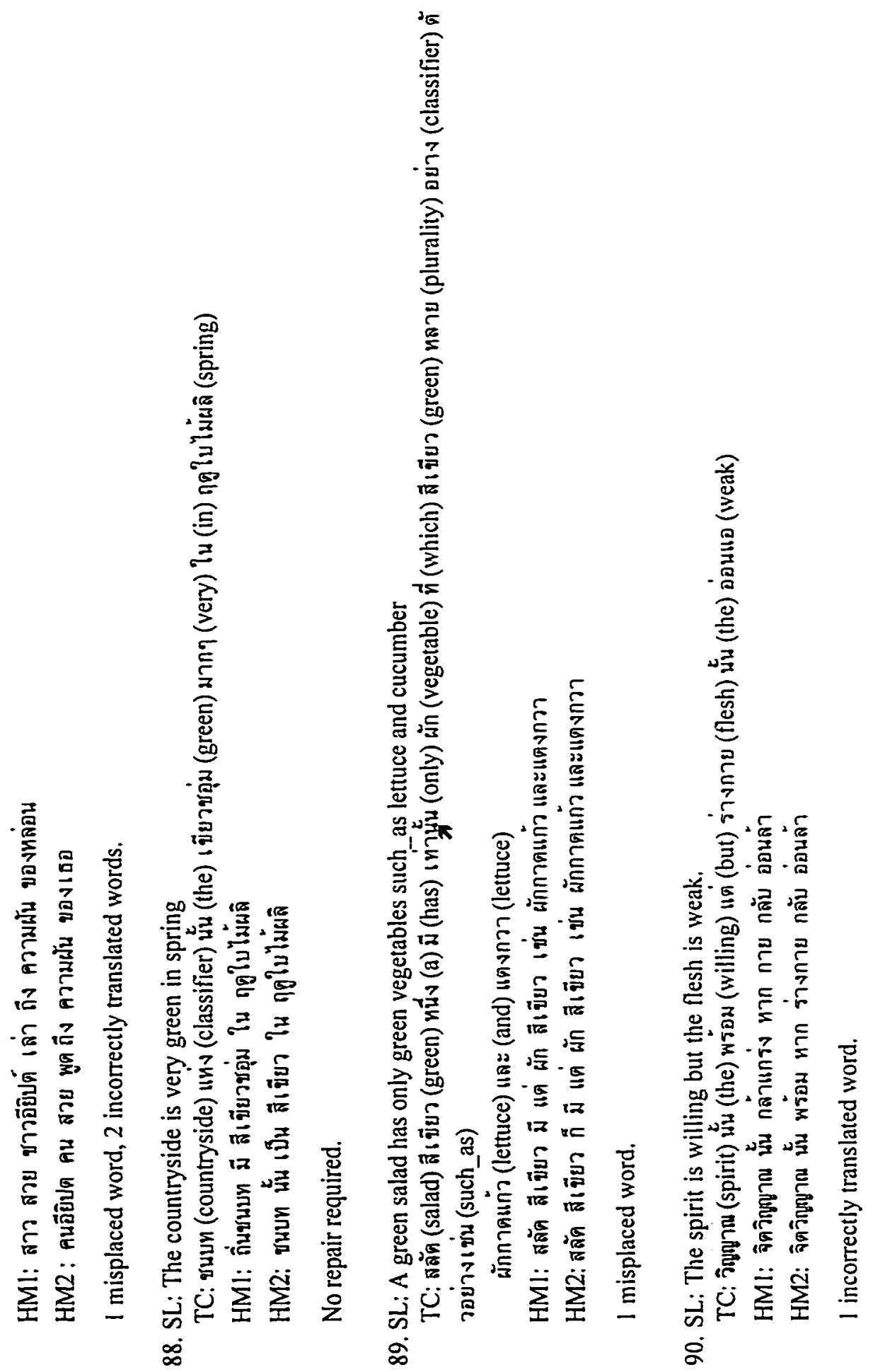




\section{Appendix H}

\section{Comprehensibility Evaluation}

This appendix contains the evaluation of ALMT with respect to comprehensibility as outlined in Chapter 8.

\section{Source Text:}

Sentence 1- 76: The ugly duckling version written by Ronne Randall (1987).

Sentence 77- 90: Newspapers and Articles.

\section{Evaluators:}

HM3: Thai Linguist

HM4: Thai Student (Grade 7, Age 12)

HM5: Thai Student (Grade 4, Age 9)

\section{Legends:}

$\uparrow$ Additional word required: The word, when installed, will make the sentence complete and correct in terms of meaning and grammar.

Inappropriate word usage: This word does not distort the meaning of the expression but it is inappropriate.

Meaningless word: This word renders the sentence meaningless.

Unnecessary word: This word is not needed nor used in spoken language.

r Misplaced word: The word is wrongly placed and it affects the meaning of the sentence.

It should be moved in the direction of the arrow. 
Misplaced word: The word is wrongly placed and it affects the meaning of the sentence.

It should be moved in the direction of the arrow. 


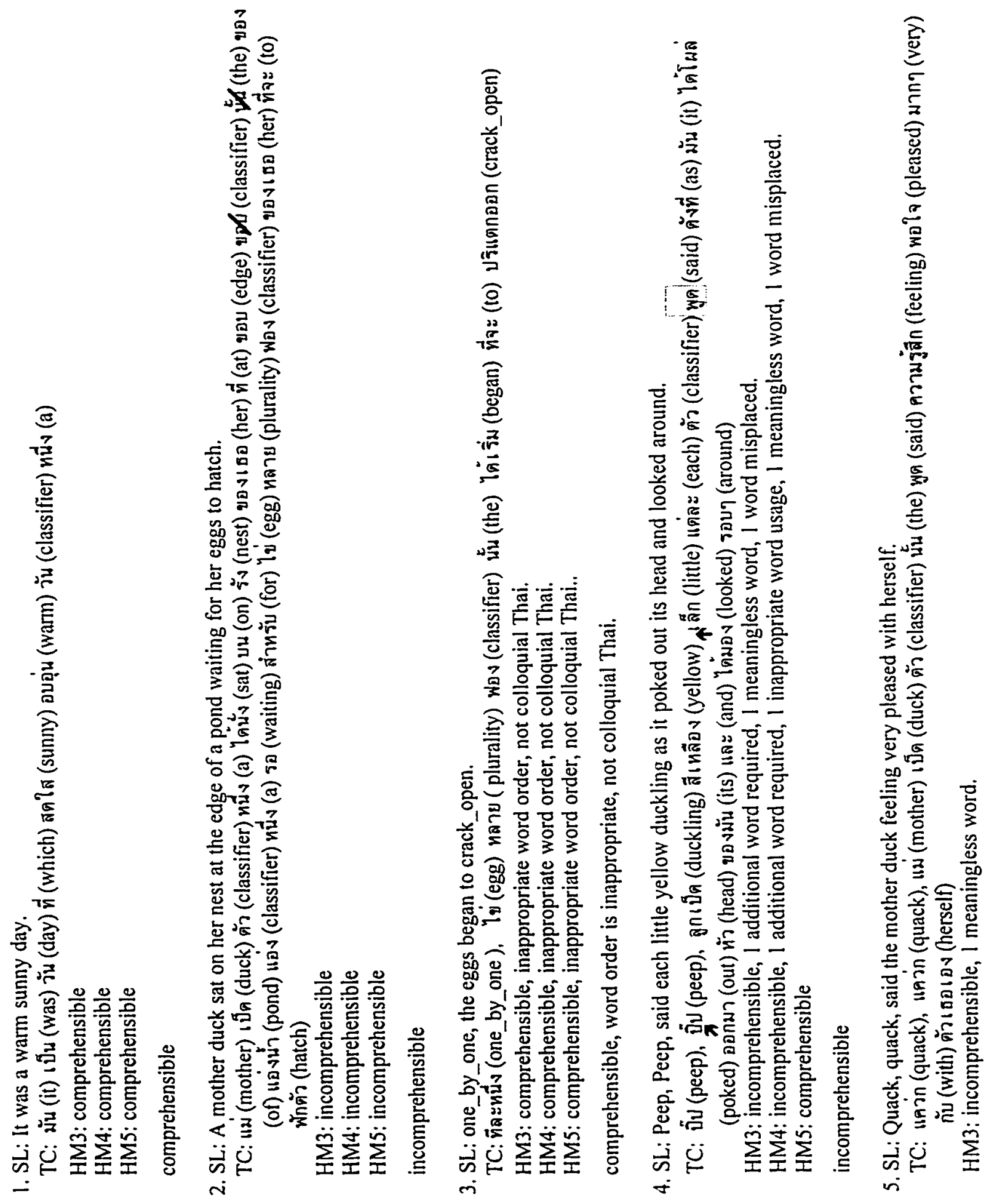




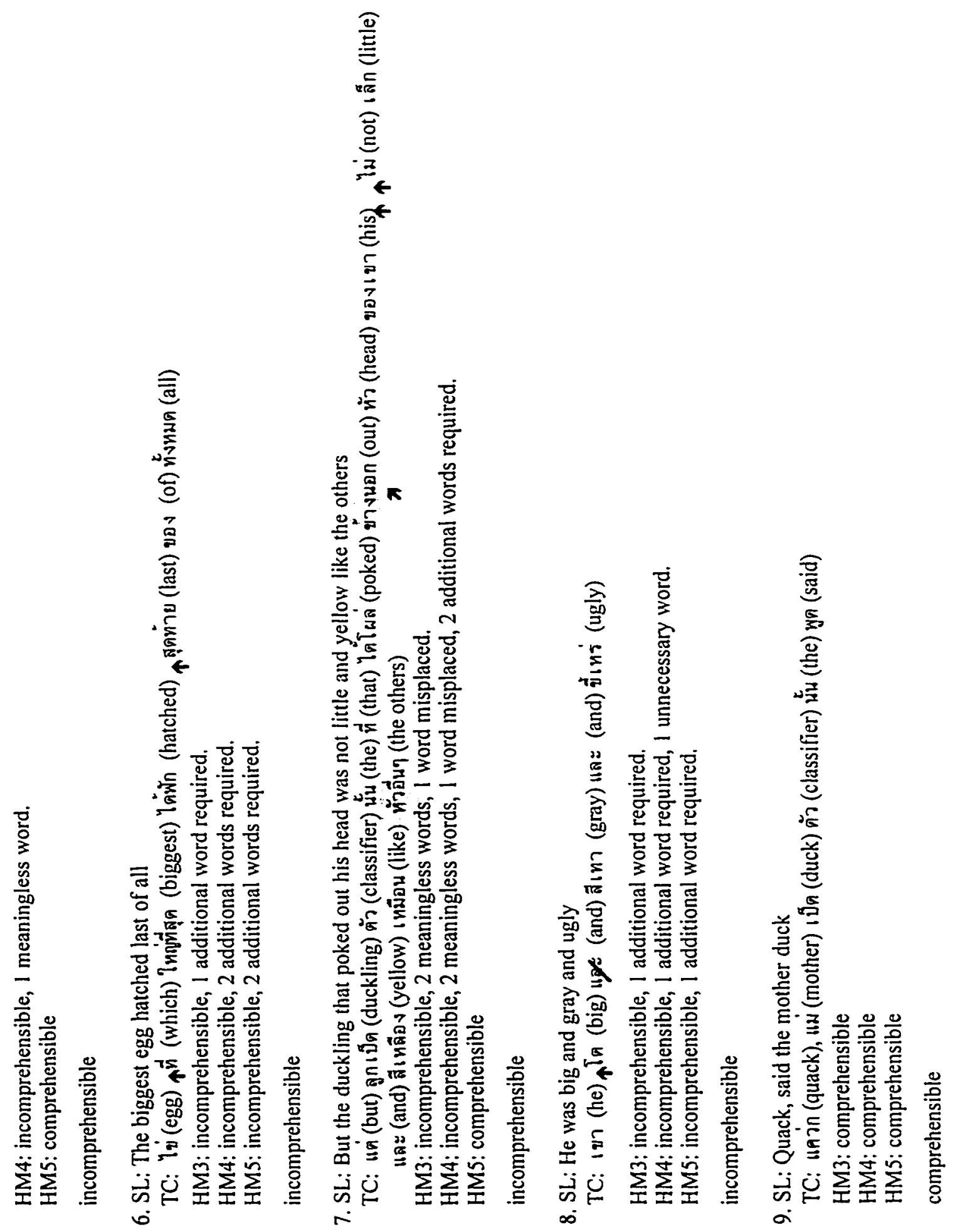




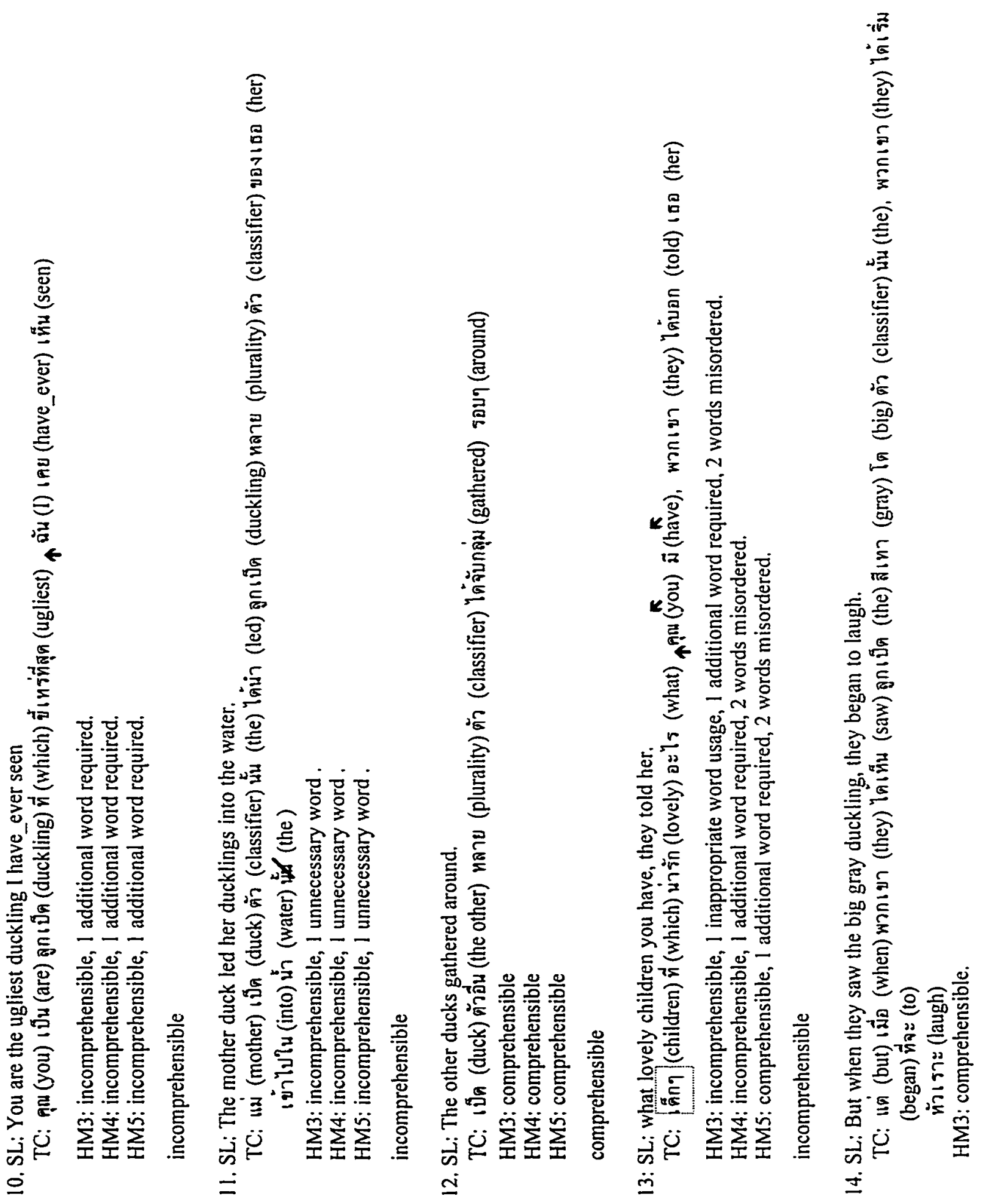




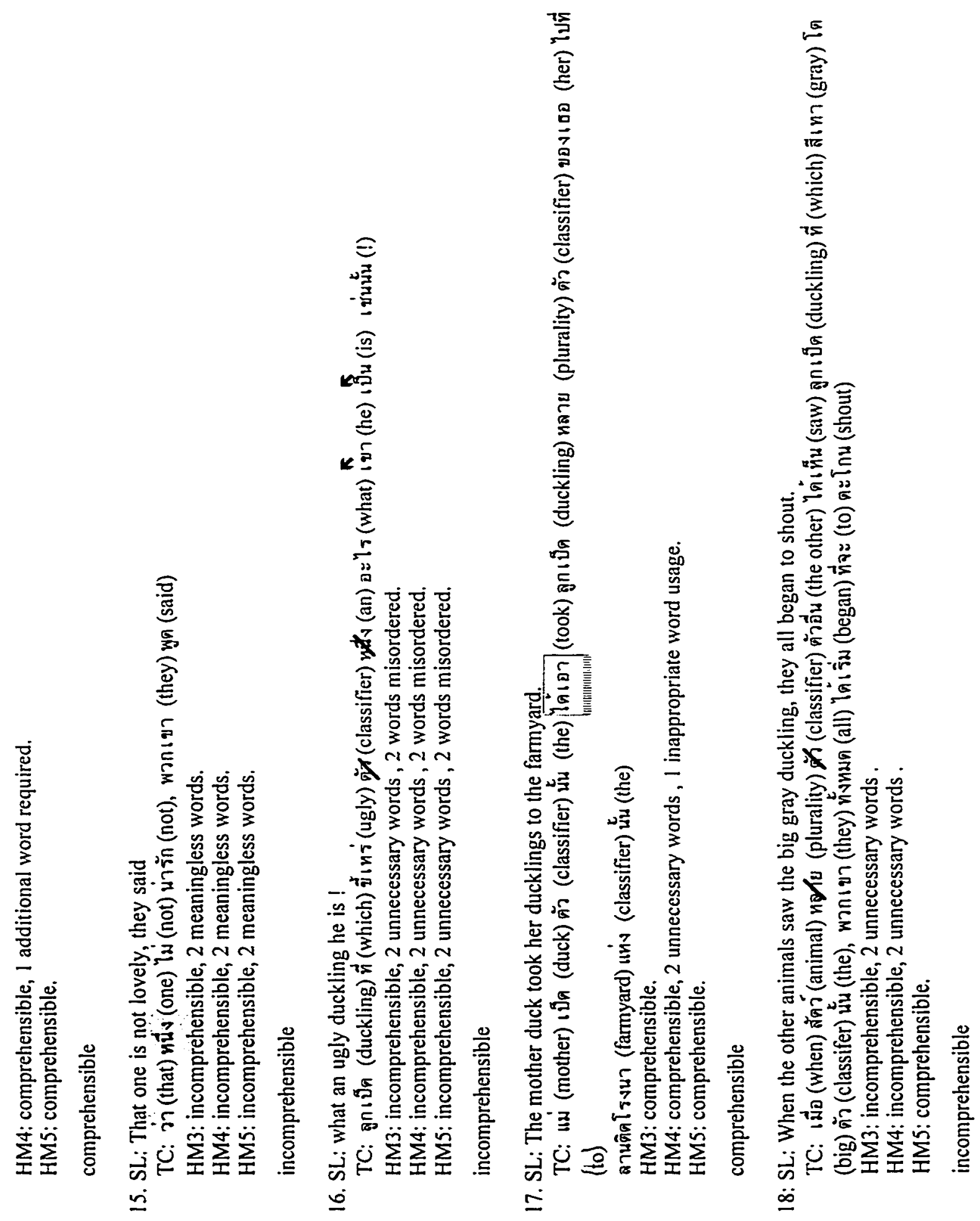




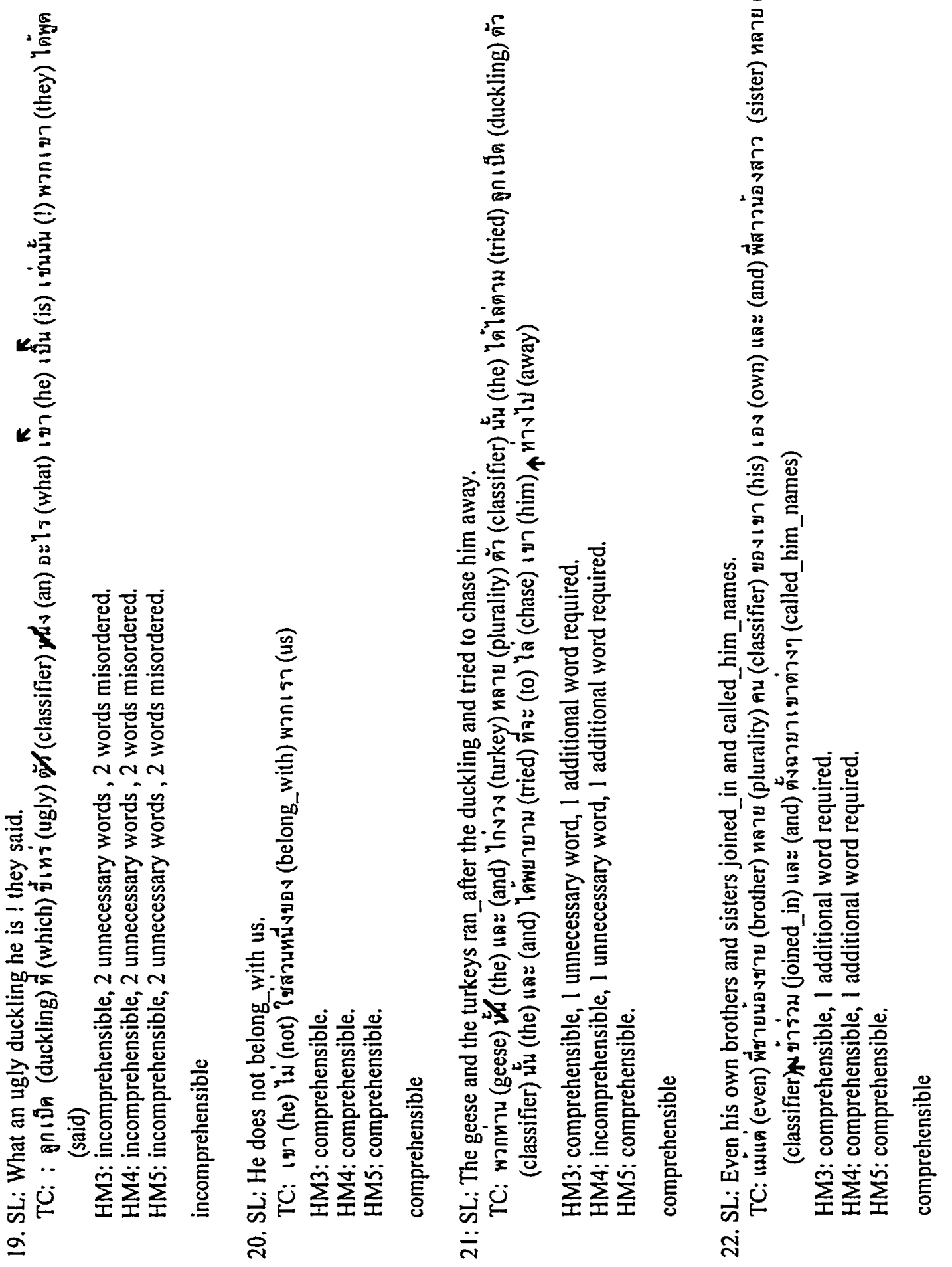



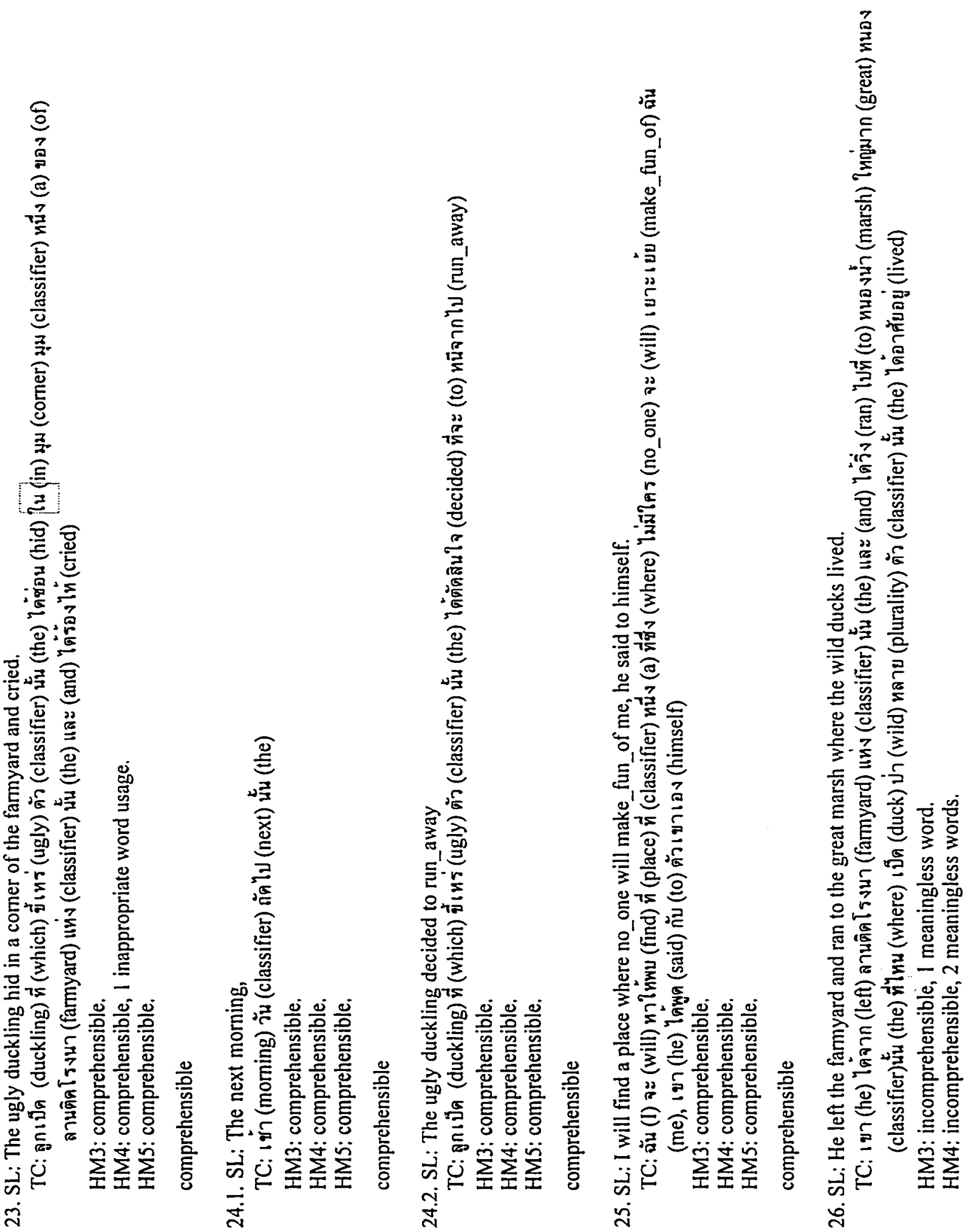


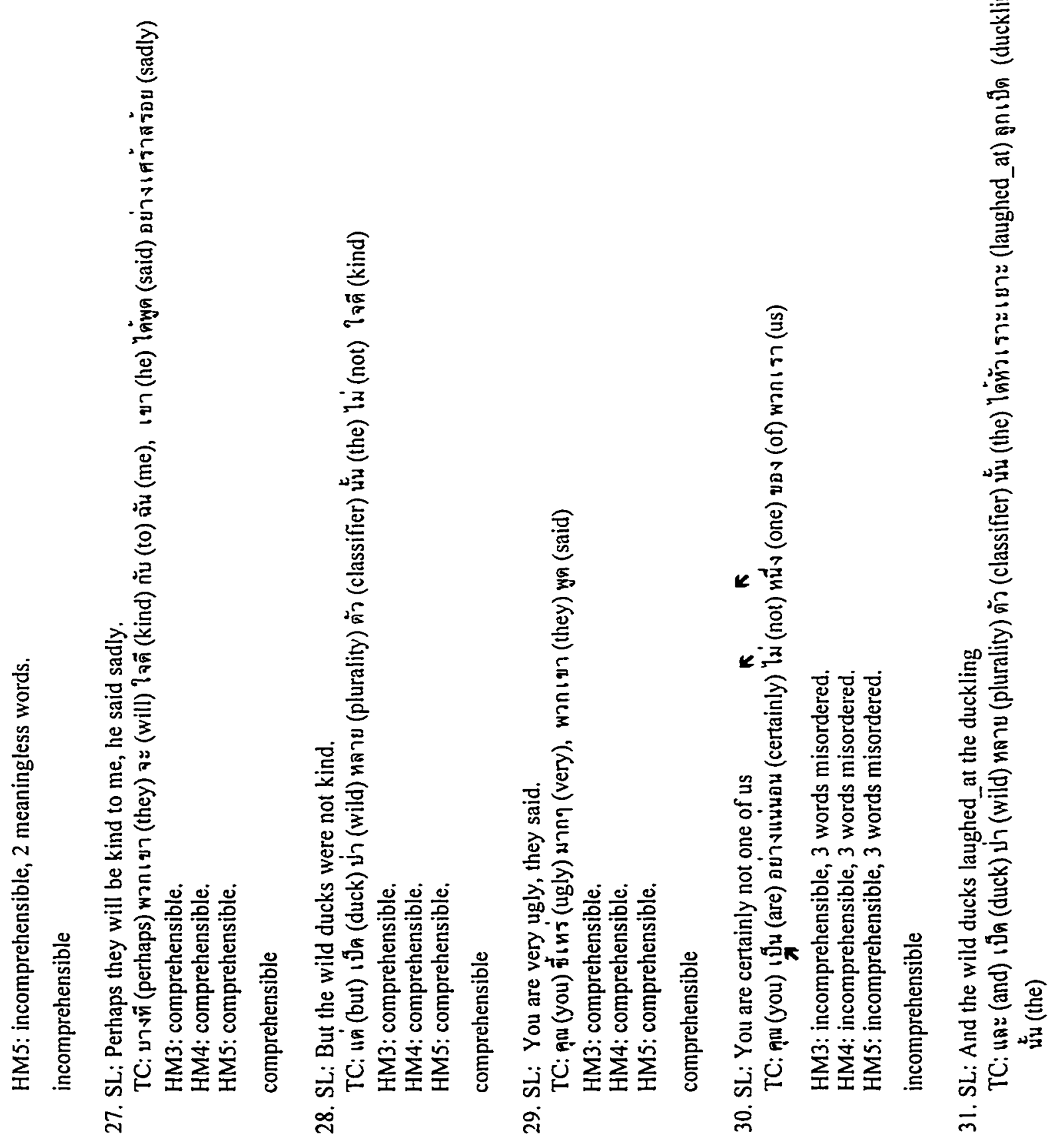




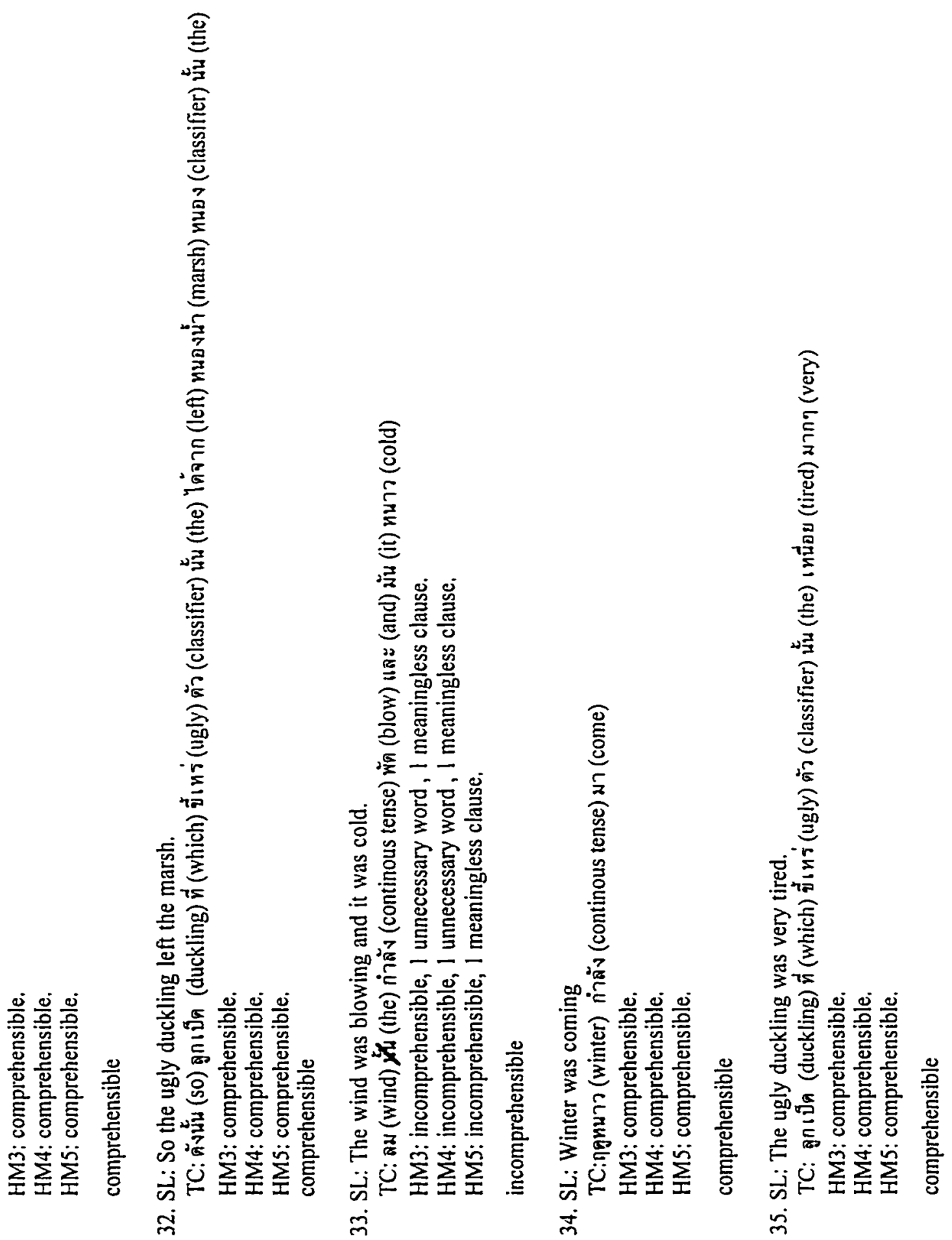



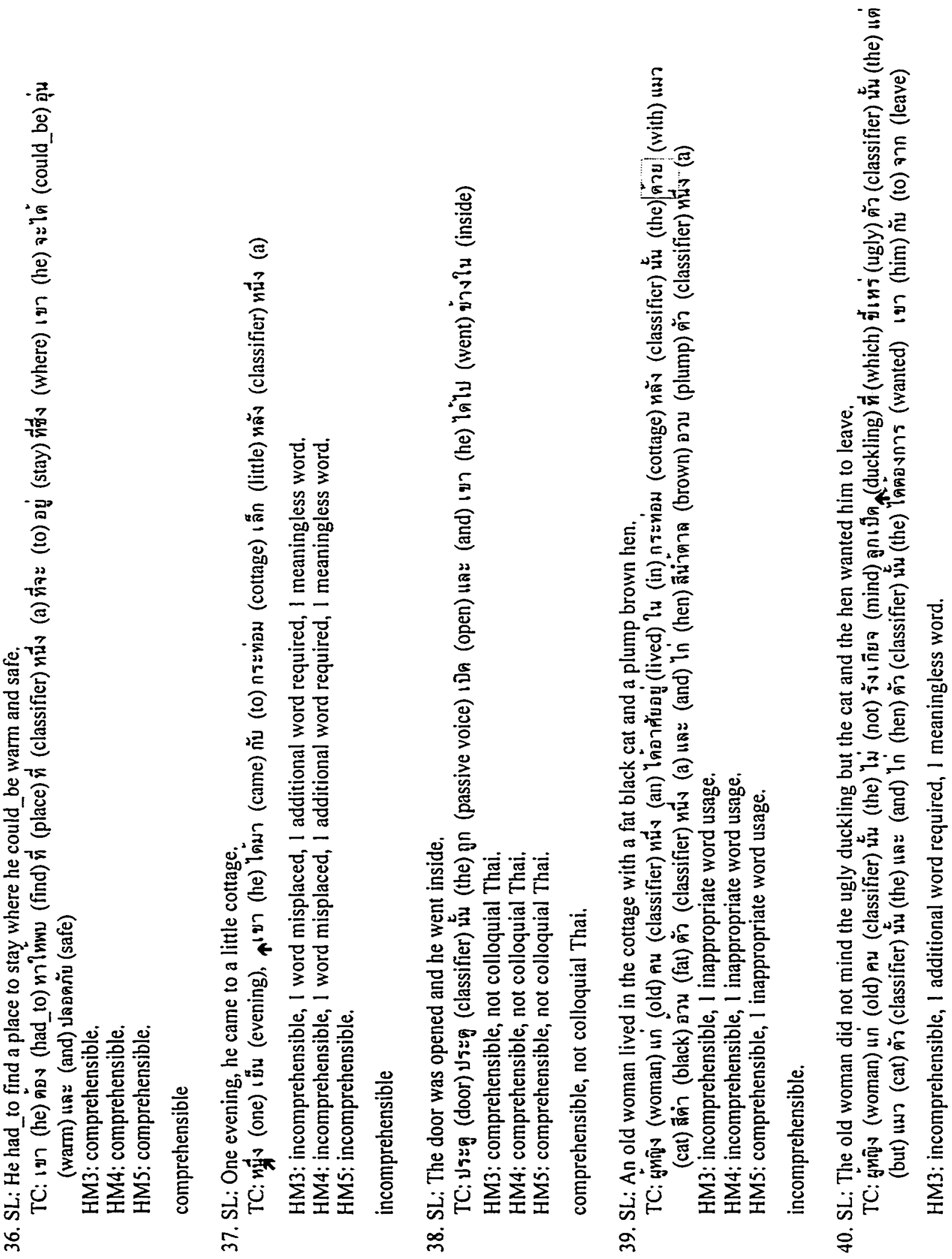


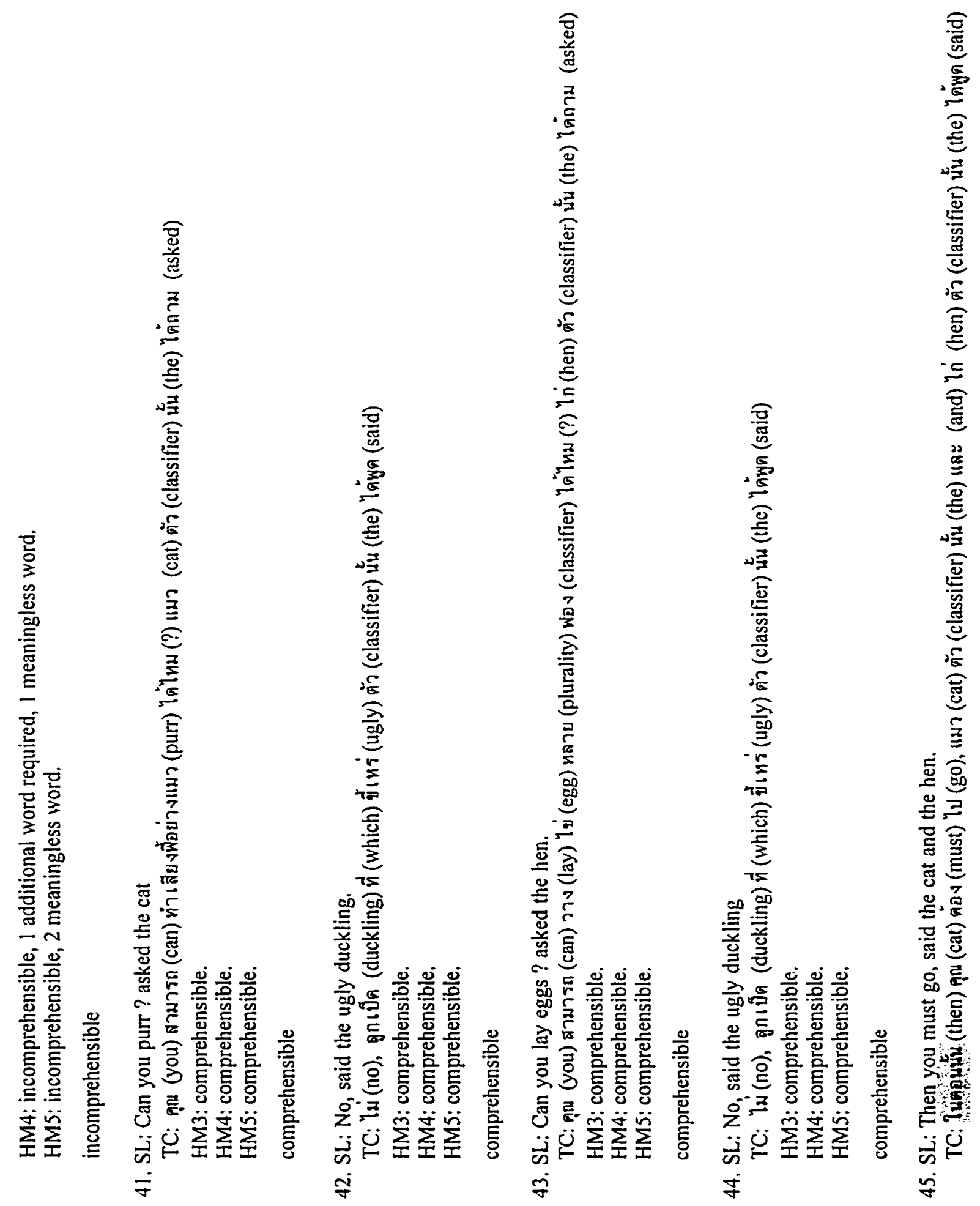




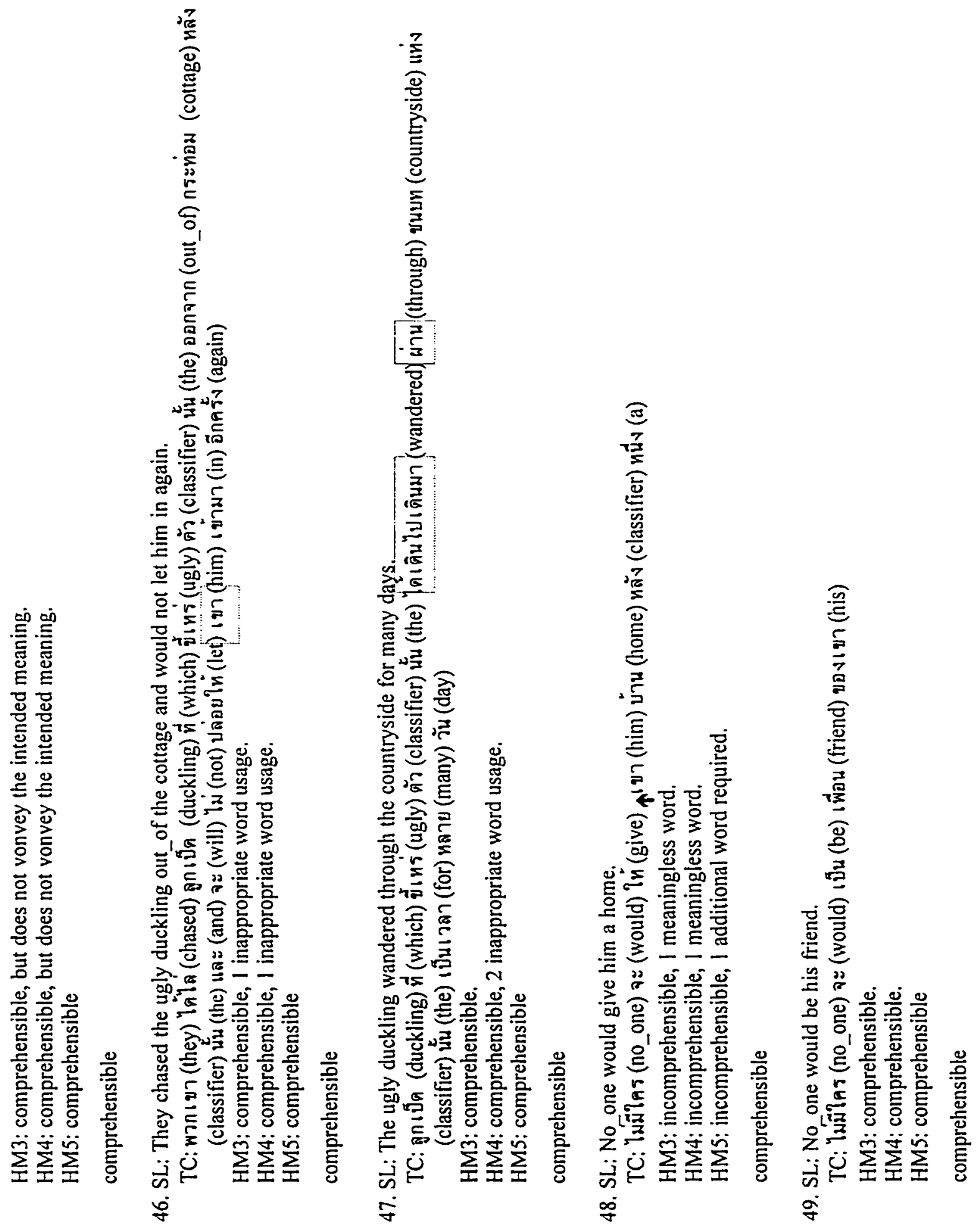



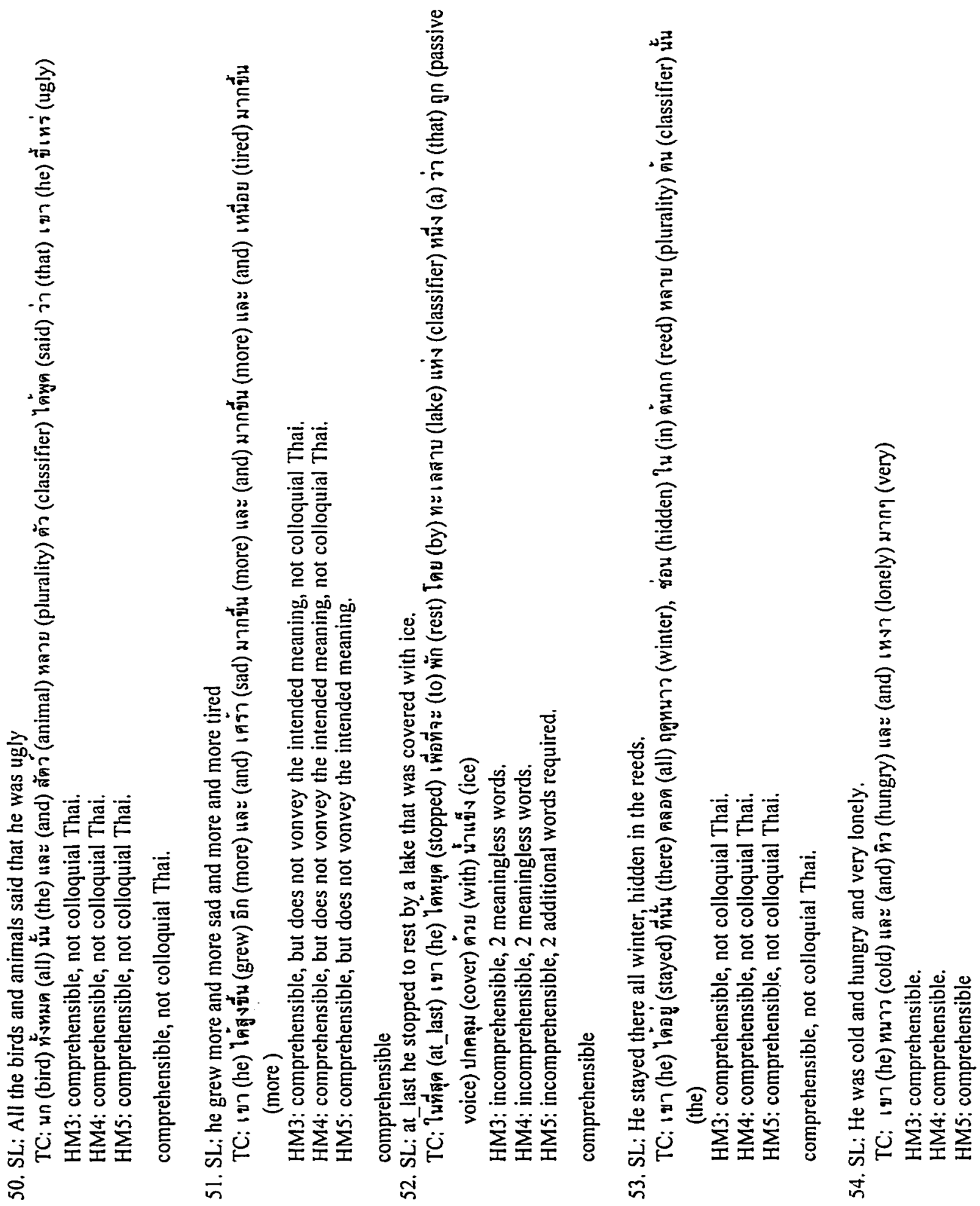


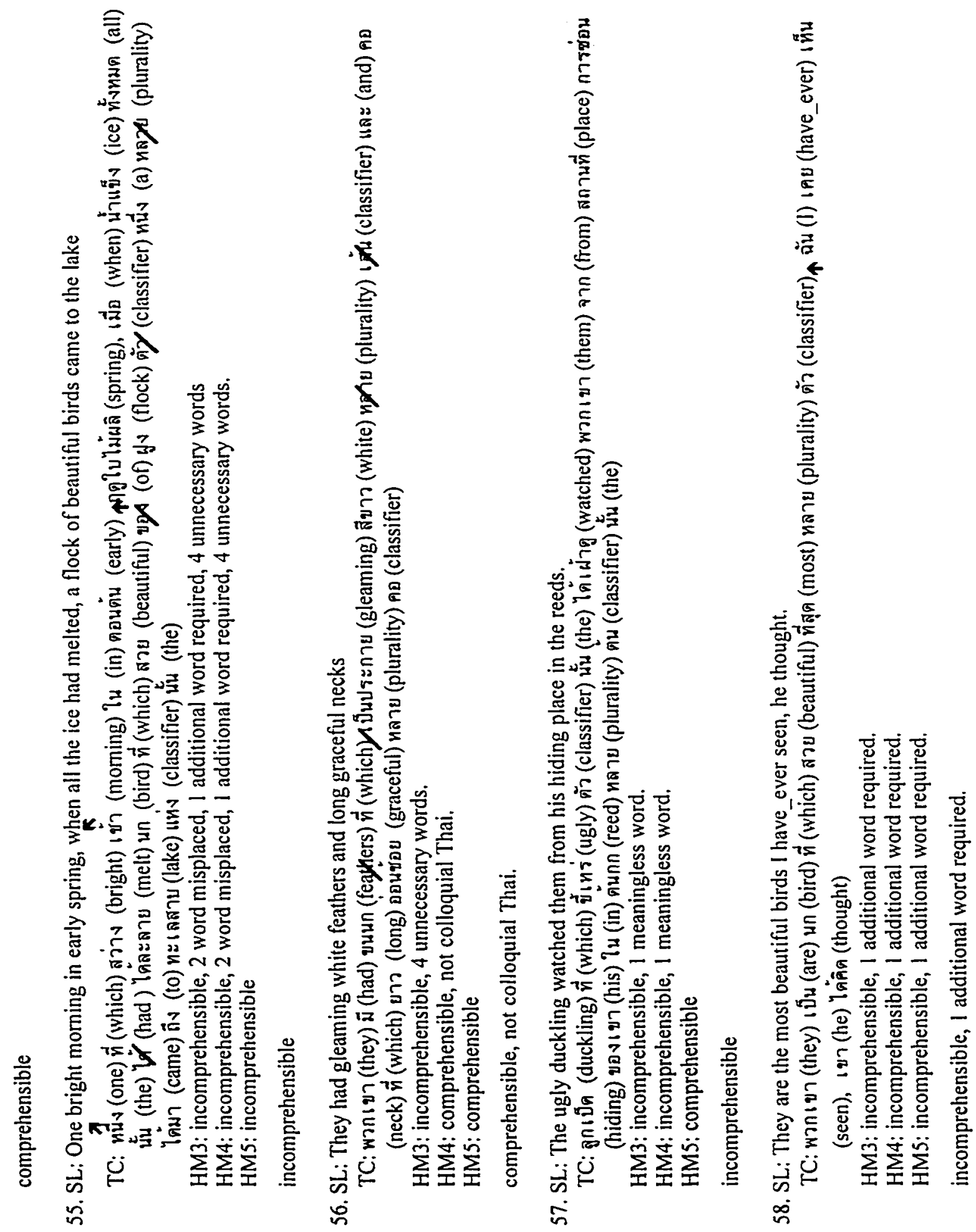




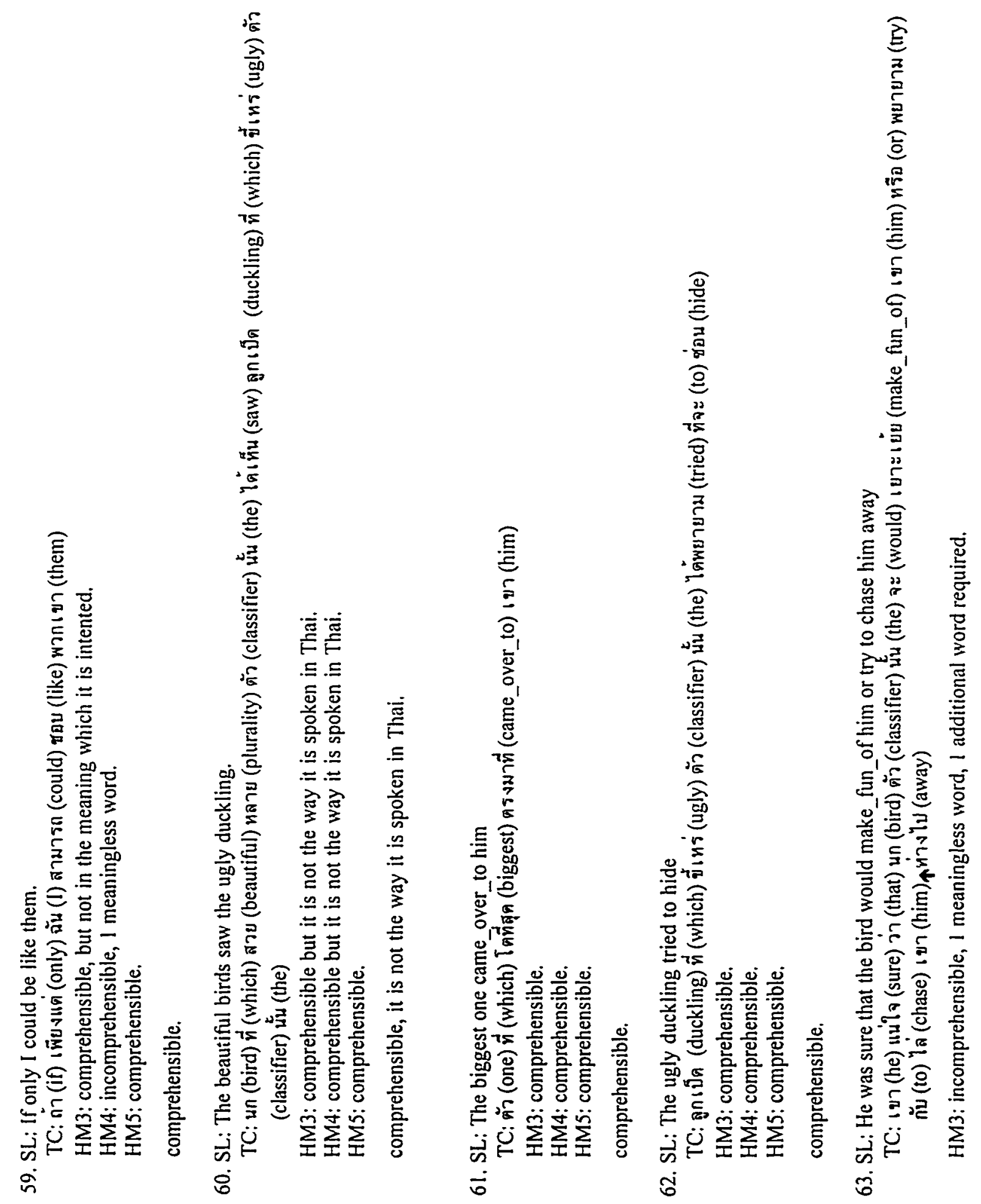




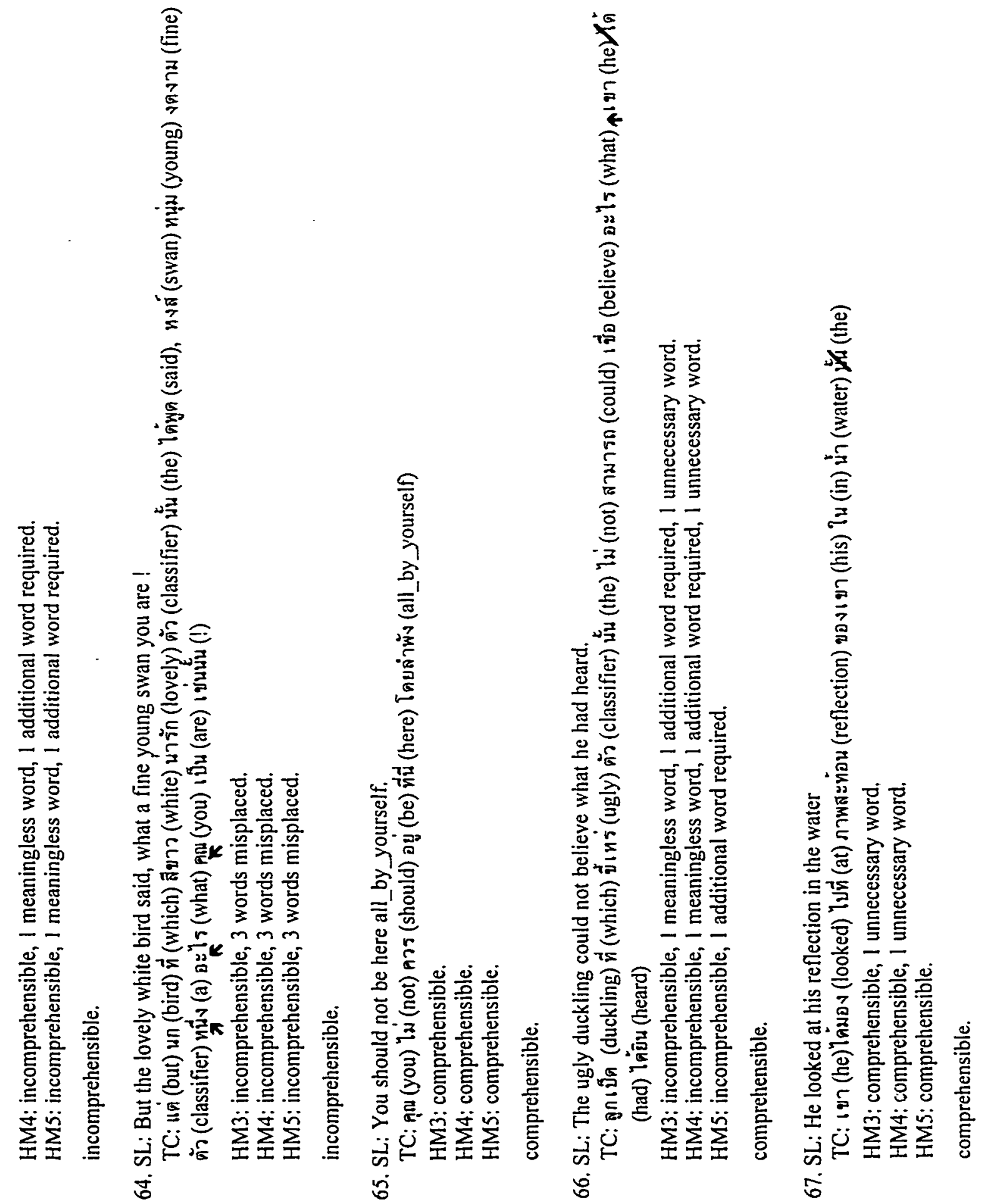




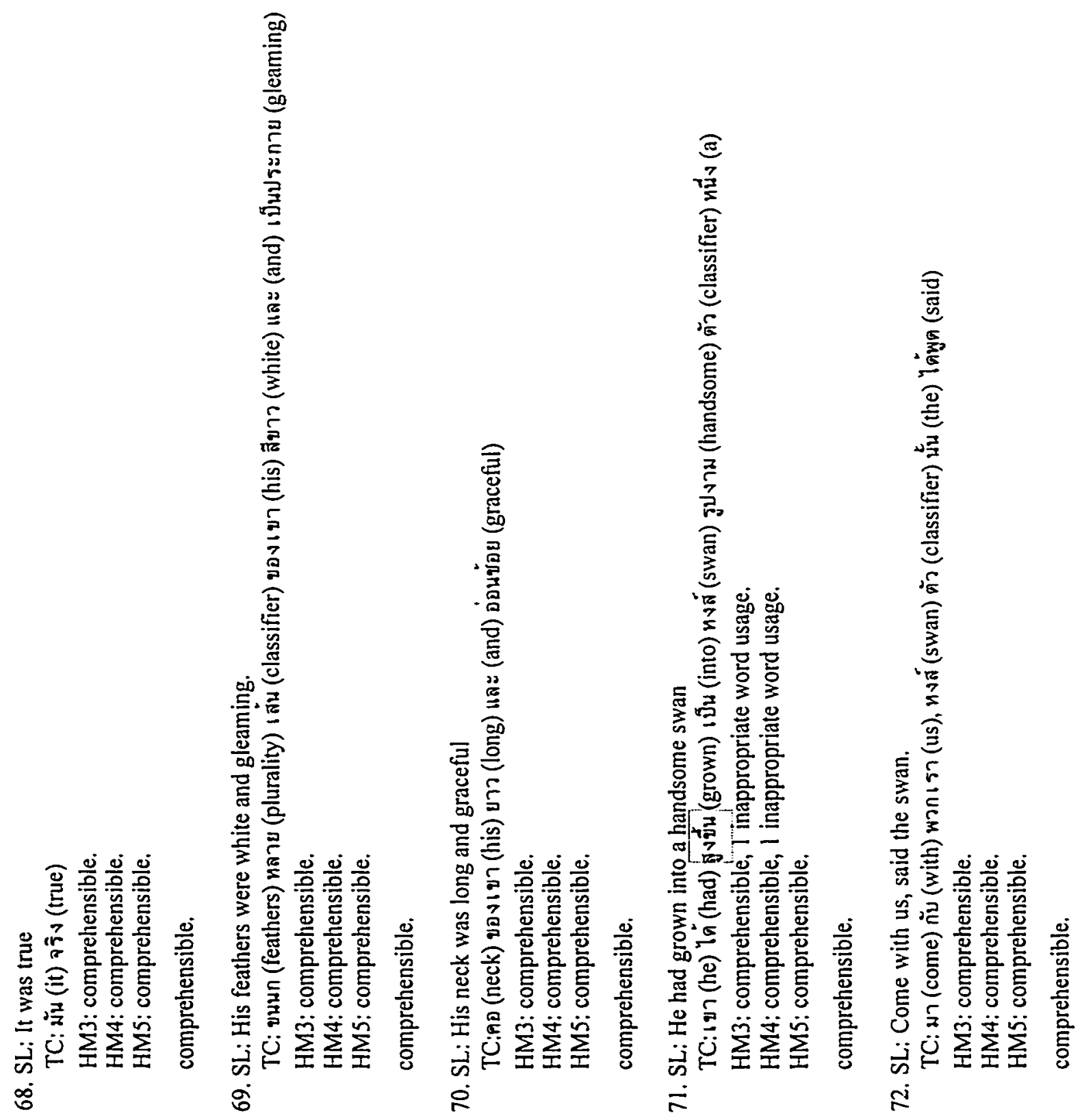




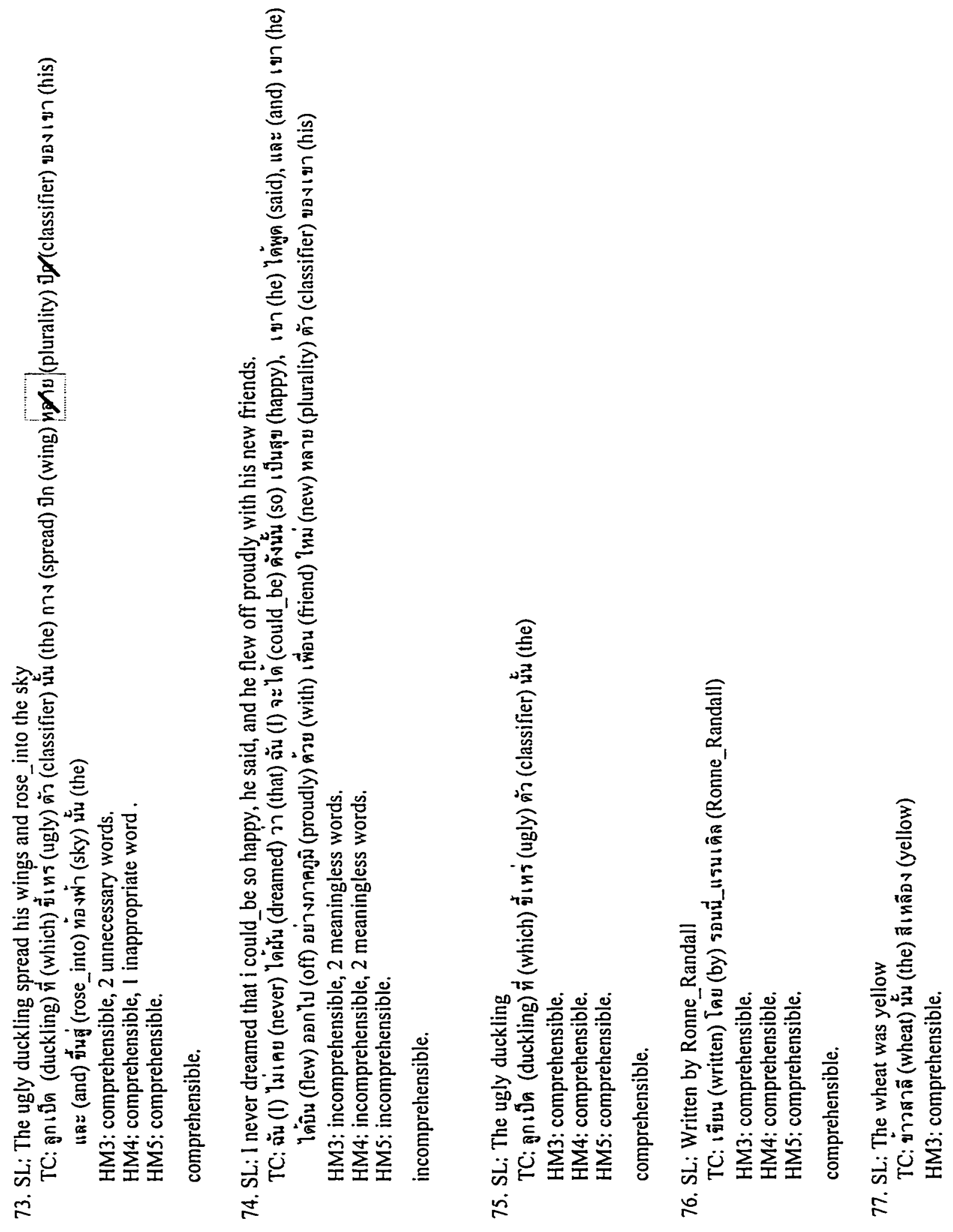




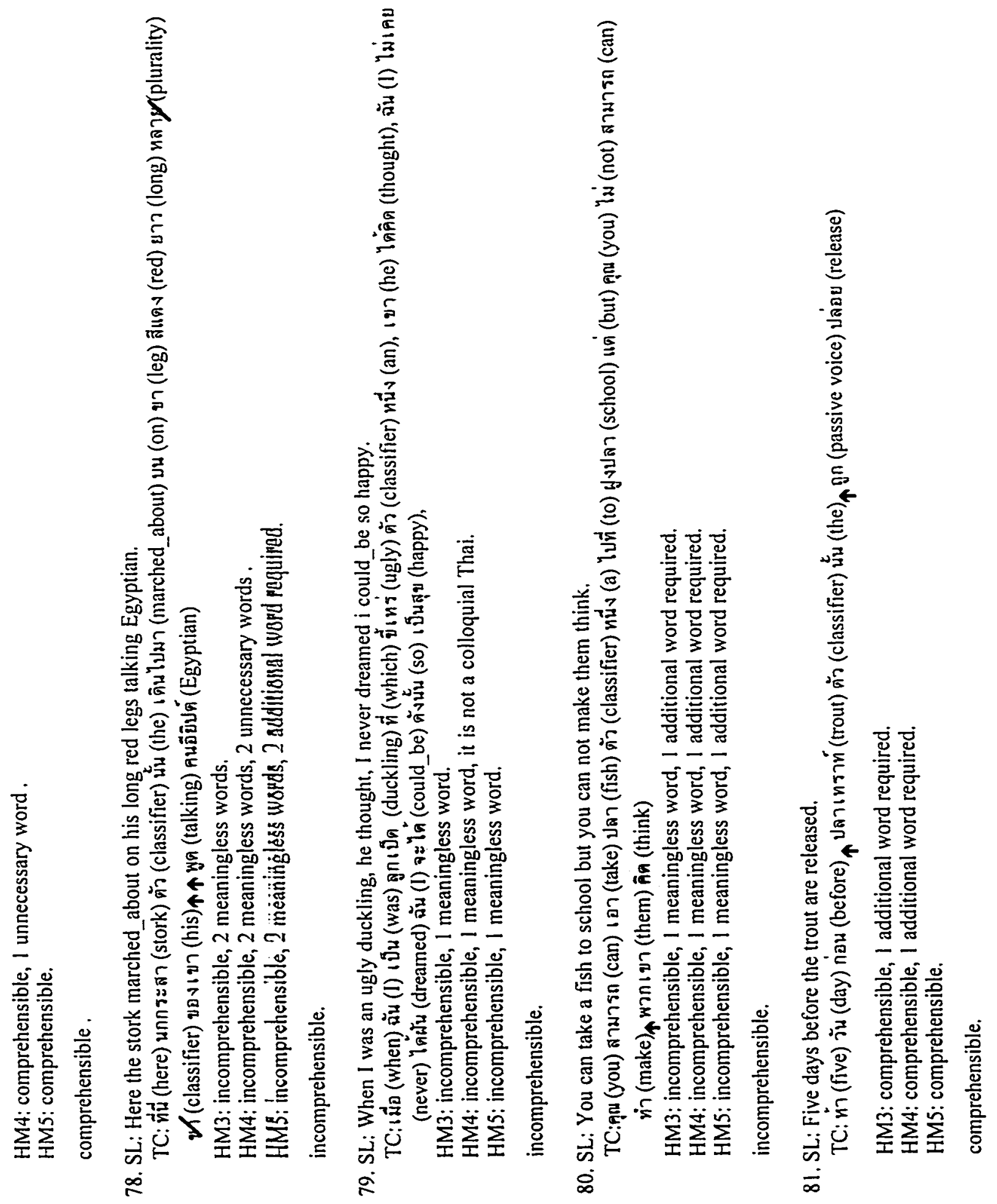




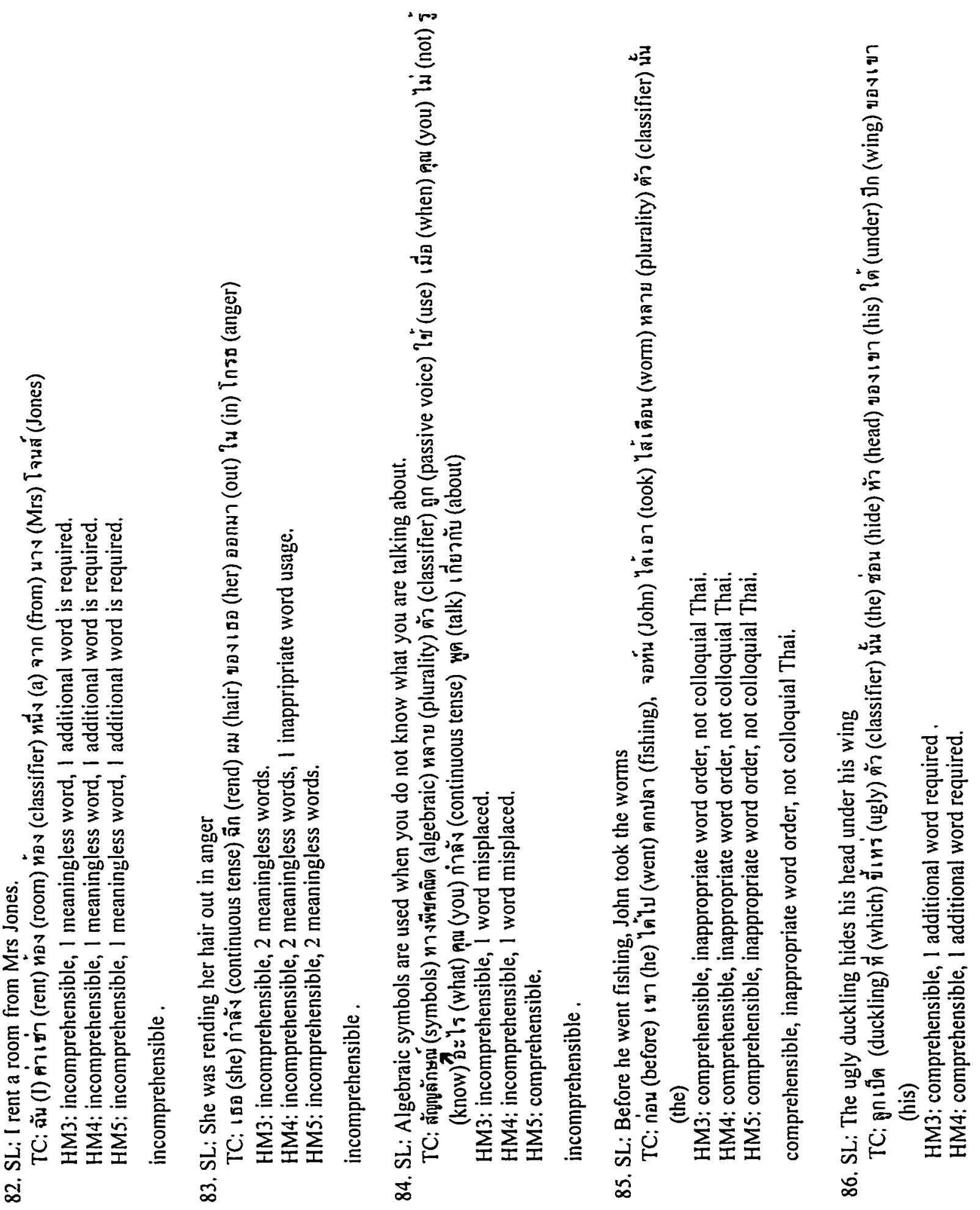




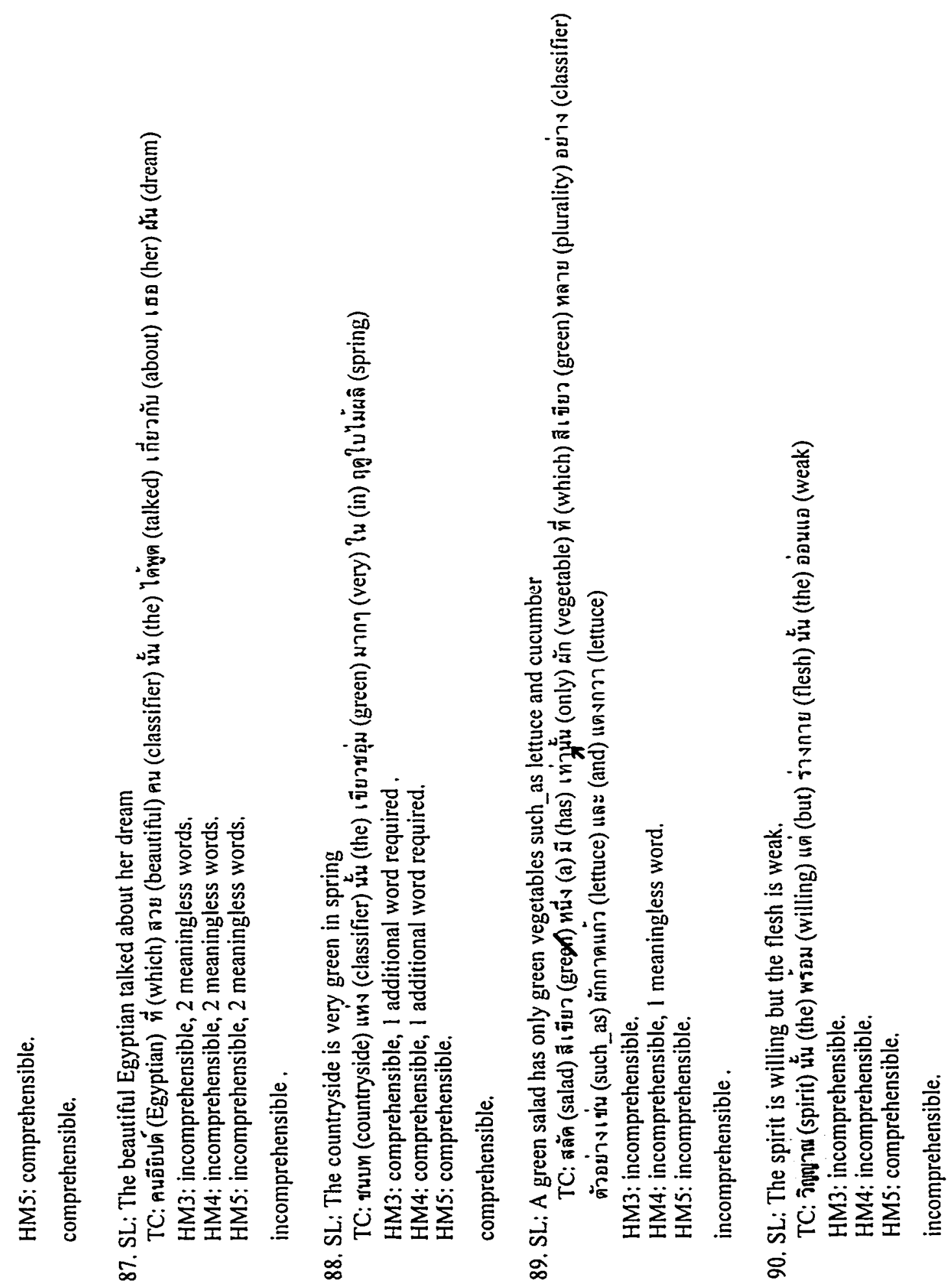

